\title{
Part of The Whānau: The Emergence of Takatāpui Identity He Whāriki Takatāpui
}

Elizabeth Kerekere

A thesis submitted in fulfilment of the requirements

for the degree of Doctor of Philosophy

Te Kawa a Māui School of Māori Studies

Victoria University of Wellington

April 2017 


\section{KARANGA}

Karanga mai e ngā tūpuna takatāpui

Anei tāu mokopuna

E karanga atu nei i raro i te mana o Tūranganui a Kiwa

Ko Ngāti Oneone rātou ko Te Aitanga a Māhaki

ko Whānau a Kai, ko Rongowhakaata, ko Ngāi Tāmanuhiri

Ahakoa ngā piki me ngā heke, ahakoa e rehurehu mai rā ō āhua

E kore koutou e warewaretia

He Whāriki Takatāpui tēnei mō koutou, hei whakamānawa i ngā taonga tuku iho

E kore tēnei mahi e mutu, mā Te Roopū Tīwhanawhana te kaupapa e kawe

Hei para i te huarahi mō ngā reanaga e whanake ake, e whanake ake

Call to me, our takatāpui ancestors

Here I stand, your descendant

I call to you under the mana of Türanganui a Kiwa

Ngāti Oneone, Te Aitanga a Māhaki

Whānau a Kai, Rongowhakaata and Ngāi Tāmanuhiri

Although the journey has been difficult and your form sometimes indistinct

You were never forgotten

This Whāriki Takatāpui is dedicated to you, to honour the treasures you have passed down Although it may never end, Tīwhanawhana Trust will carry this work To clear a pathway for coming generations who will ever move onwards 


\section{ABSTRACT}

Since the early 1980s, Māori who are whakawāhine, tangata ira tāne, lesbian, gay, bisexual, trans, intersex or queer have increasingly adopted the identity of 'takatāpui' - a traditional Māori term meaning 'intimate companion of the same sex.' As the first study on takatāpui identity and well-being, this is fashioned as a Whäriki Takatāpui; a woven mat which lays the foundation for future research and advocacy. Kaupapa Māori research provides the tools for this task while Kaupapa Māori theory ensures the harvest of Māori narratives is underpinned by te reo, tikanga and mātauranga - Māori language, culture and knowledges. The preparation of weaving materials is represented by Mana Wāhine; which considers whakapapa (genealogy), intersectional colonial oppression with an artistic approach to analysing whakataukī (historical metaphor). Mana Motuhake represents the design of the Whāriki; the colours and patterns emanating from the subjective experiences of six leaders who have embraced a takatāpui identity. Te Whare Tapa Whā represents weaving together takatāpui health and well-being in response to the issues and discrimination they face. Oral history interviews were held with takatāpui participants who reflected a diversity of iwi, geographical location, gender identities and sexualities and, at the time of interview, ranged from 17 to 68 years of age. In order to gain insight into the perception of whānau with takatāpui members, semi structured interviews were also held with two kuia (female elders) and 12 whānau members of the takatāpui rangatahi (young people) interviewed. In total 27 participants were interviewed in three stages over four years. Their responses were recorded, transcribed then analysed based on the elements of the Whäriki Takatāpui framework. Despite colonial efforts to remove historical trace, this study reveals new evidence of takatāpui behaviour within traditional Māori narratives. It finds that takatāpui identity is predicated on Māori identity with a spiritual connection to takatāpui tūpuna (ancestors) that is crucial in addressing the discrimination they may face within their whānau and culture. It identifies the range of issues that impact on takatāpui health and well-being while highlighting the creative and strengthbased manner in which takatāpui build resilience and connection through identity. 


\section{CONTENTS}

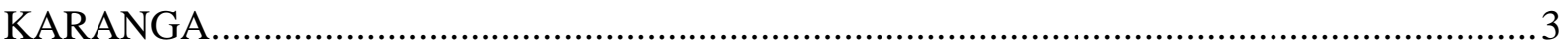

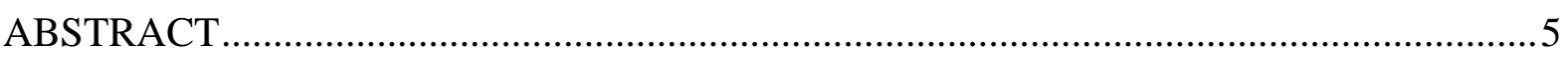

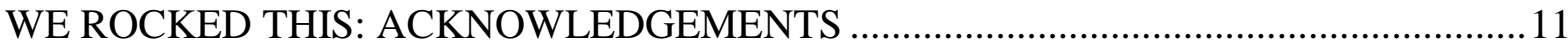

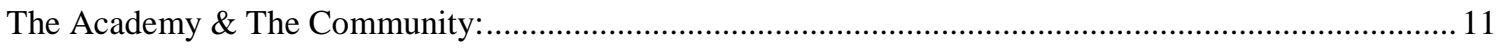

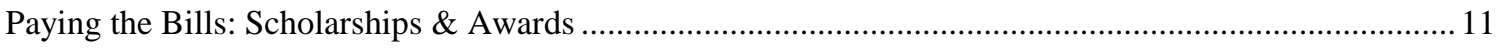

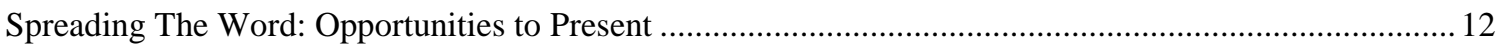

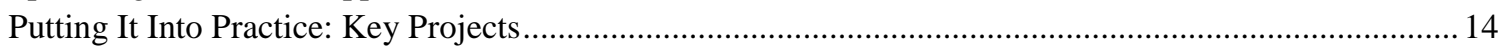

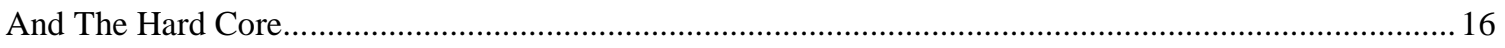

CHAPTER 1: MAHIA TE MAHI: THE WHY, THE WHO \& THE WHAT ........................ 17

The Why: Putting Takatāpui on the Map.......................................................................... 17

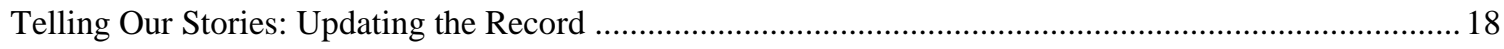

Building Our Communities: Putting Research into Practice ..................................................................... 20

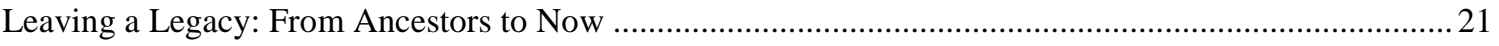

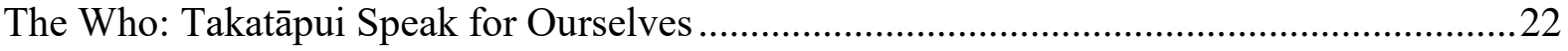

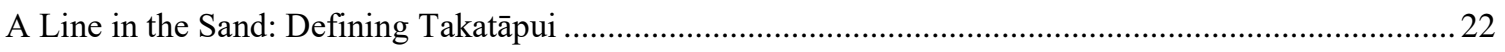

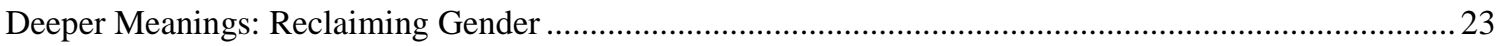

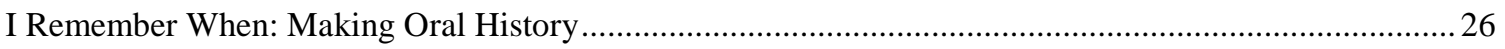

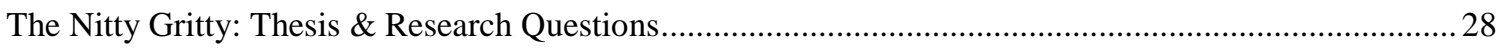

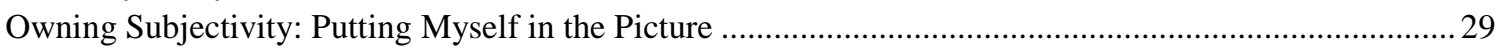

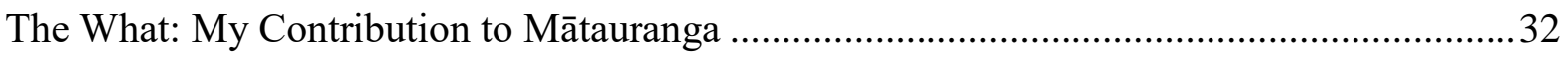

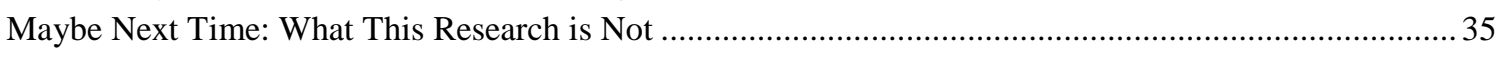

Kaupapa Māori Research: Gathering The Tools ............................................................... 40

Kaupapa Māori Theory: Harvesting Language \& Culture ............................................... 41

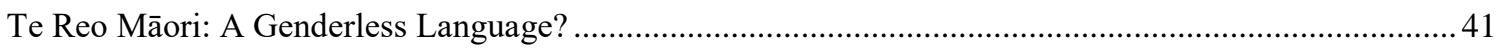

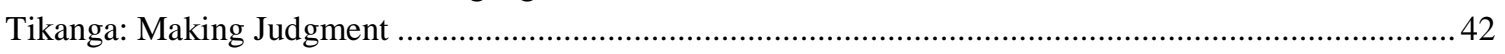

Mana Wāhine: Preparing to Fight Back...................................................................... 43

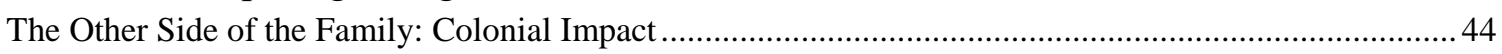

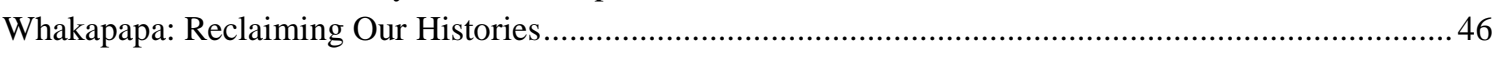

Mana Motuhake: Designing Identity in a Colonised Land ............................................. 47

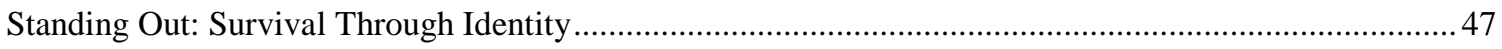

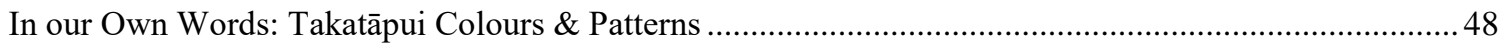

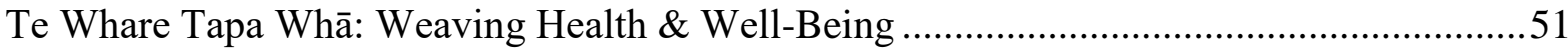

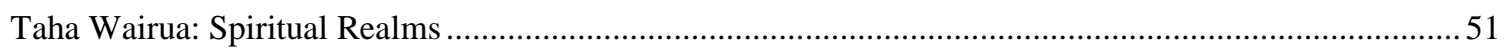

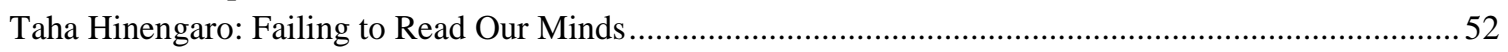

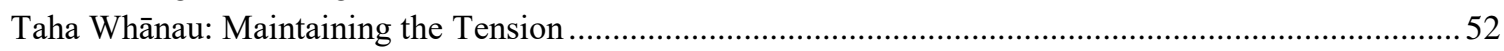

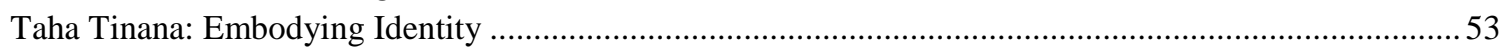

Whakamutunga: Tying Up Loose Ends ......................................................................53

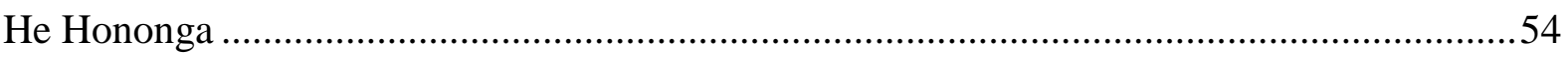

CHAPTER 3: WHAKAPAPA: LEARNING FROM THE PAST …....................................57

Covering Up \& Toning Down: The Other Side of the Family ...........................................5 
Trusting Whakapapa: Takatāpui Existence

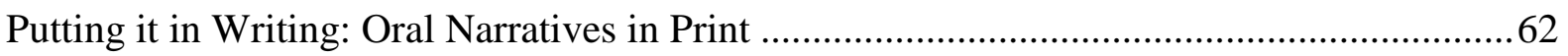

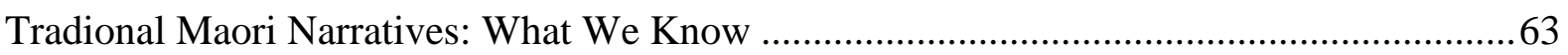

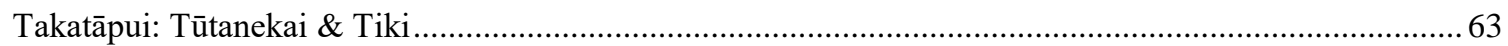

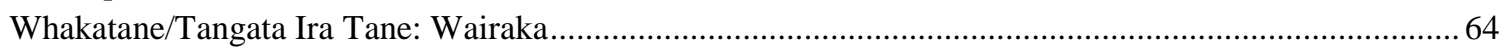

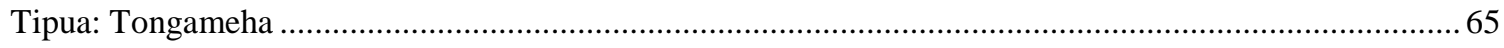

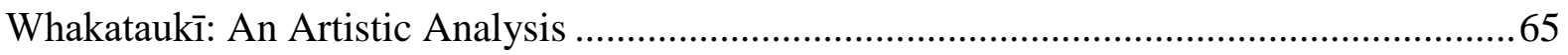

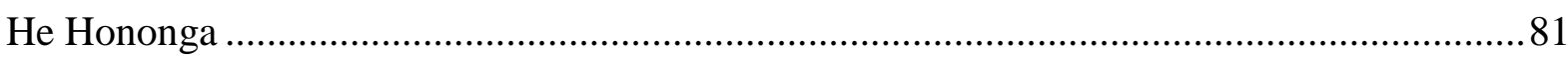

CHAPTER 4: SURVIVING CHILDHOOD: GROWING UP DIFFERENT ....................... 83

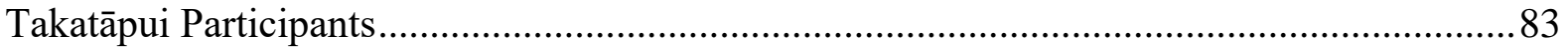

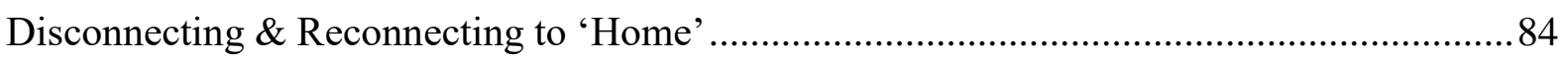

From the Mouths of Babes: First Awareness ..................................................................... 92

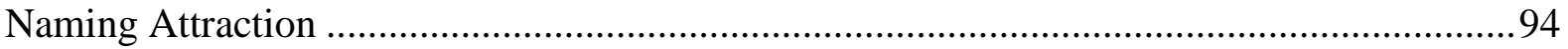

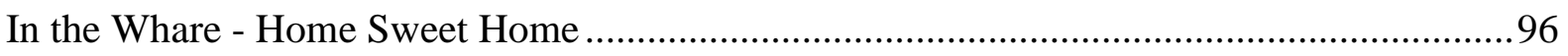

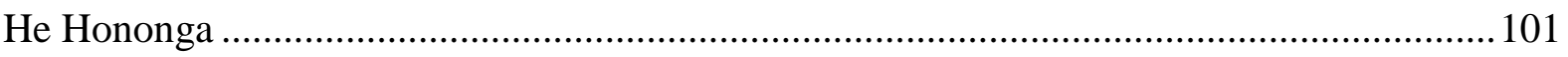

CHAPTER 5: SCHOOL, WORK \& CLAIMING IDENTITIES ....................................... 105

Making It or Faking It: Negotiating the Classroom........................................................ 105

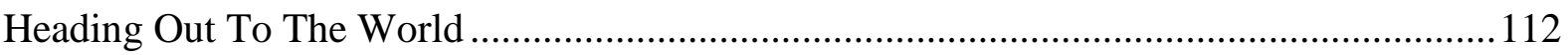

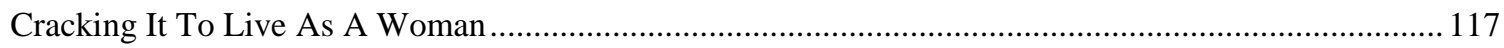

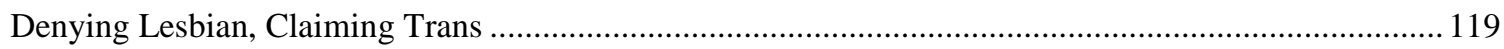

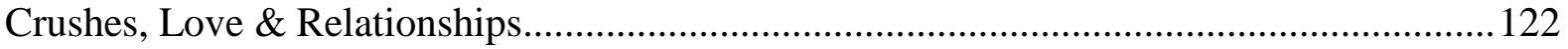

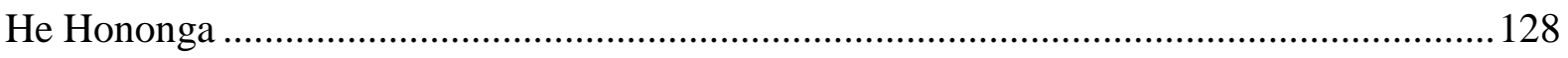

CHAPTER 6: UN/CONDITIONAL LOVE: YOU CAN'T PICK YOUR WHĀNAU ........131

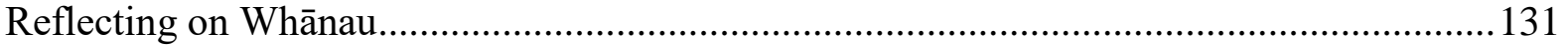

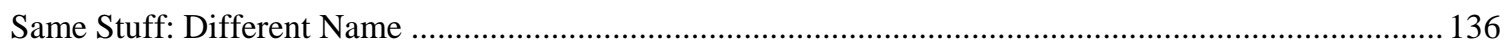

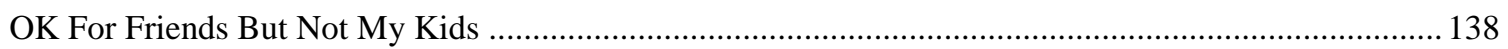

The Mother of Kapa Haka in Men's Clothes: Tūini Ngāwai..............................................139

Expecting The Worst, Hoping For the Best: Whānau ...................................................... 142

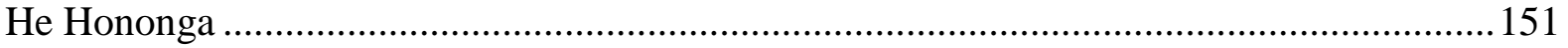

CHAPTER 7: HONOA TE PITO MATE KI TE PITO ORA: RECLAIMING TAKATĀPUI

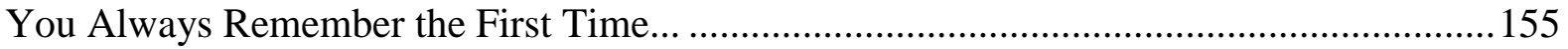

Breathing Life into Definition: Takatāpui Meanings......................................................... 160

Taking Takatāpui to the World: Tīwhanawhana Trust ......................................................... 162

The Good, the Bad \& the Ugly: 2004

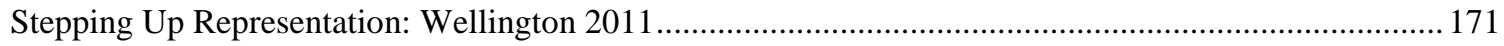




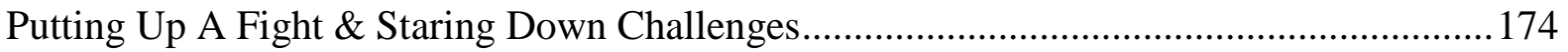

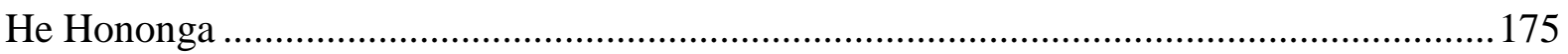

CHAPTER 8: WHAKAMUTUNGA: HE WHĀRIKI TAKATĀPUI ................................ 177

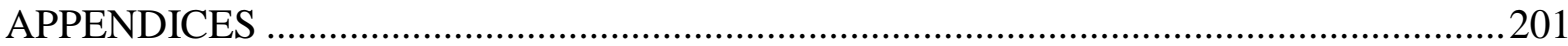

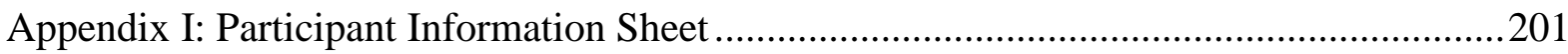

Appendix II: Consent to Participation in Research............................................................203

Appendix III: Oral History Recording Agreement Form .................................................205

Appendix IV: Takatāpui Interview Guidelines - Life Story (2012-2013) ............................207

Appendix V: Takatāpui Interview Guidelines - Suicide Prevention (2015) ........................209

Appendix VI: Whānau Interview Guidelines (2013) .........................................................211

Appendix VII: Rangatahi \& Whānau Interview Guidelines (2016) ....................................213

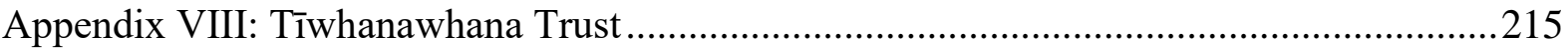




\section{WE ROCKED THIS: ACKNOWLEDGEMENTS}

I completed this $\mathrm{PhD}$ extramurally from Gisborne with regular trips to Te Kawa a Māui, School of Māori Studies, Victoria University in Wellington and three months in the United States of America. Many people supported me to do this work for our communities - ngā mihi aroha ki a koutou!

\section{The Academy \& The Community:}

My long-suffering supervisors: now Deputy Vice-Chancellor Māori Rawinia Higgins and Dr Ocean Mercier who saw me through to the dramatic end.

The whānau at Te Kawa a Māui and MAI ki Pōneke.

Our Tīwhanawhana Trust Board members: Kevin Haunui, Heta Timu, Peri Te Wao, and Kassie Hartendorp; our stunning whānau; and the many organisations we work with. A special shout out to Duncan Matthews, Toni Duder and Morgan Butler at RainbowYOUTH for sharing your offices and whiteboards with me.

The participants for your generosity and strength:

- Takatāpui: Jennifer Edwards, Kevin Haunui, Peri Te Wao, Hinemoana Baker, Ahi Wi Hongi, Morgan Cooke, Kassie Hartendorp, Morgan Butler, Mere-Ana Nicholson, Emilie Rākete, Ariki Brightwell, Nathaniel Gordon-Stables, Cameron Kapua-Morrell

- Whānau: Tewhanaupani Milner Maitai, Heni Poutu, Kellie Butler, Ellen Tupaea, Nina Turanga, Robert Rākete, Matahi and Raipoia Brightwell, Angelique Gordon-Stables. Frank Kapua, Natasha Morrell, Nan Kapua, Monique Kapua-Morrell, Molly Heremaia

\section{Paying the Bills: Scholarships \& Awards}

I thank the following for their recognition and financial support:

Victoria University of Wellington:

- Victoria Doctoral Scholarship 2012

- Katherine Pattison Award 2012

- Victoria Submission Scholarship 2016.

University of California Los Angeles:

- UCLA Research Grant 2015. 


\section{Spreading The Word: Opportunities to Present}

Thanks to all the activists, organisers and academics who offered me so many opportunities to present my work and research. Although I might have slept more, I believe my work is better for it:

- 2012: People of Colour Decolonising Your Mind Hui, Auckland: Keynote speaker

- 2012: Takatāpui Hui-a-Motu, Kaitaia: Presenter

- 2012: Te Ohāki a Hine - National Network Ending Sexual Violence Together (TOAHNNEST) National Hui: Keynote speaker

- 2012: ...I Te Pō Kerekere, Maia Gallery, Toihoukura, Gisborne: Presenter at my first solo art exhibition

- 2013: Te Ohāki a Hine - National Network Ending Sexual Violence Together (TOAHNNEST) National Hui, Wellington: Panel on Intersectionalities - Power and Sexual Violence (via TOAH-NNEST)

- 2014: NXT14: National Queer Youth Leadership, Auckland: Workshop Presenter

- 2014: Rainbow Memorial Run (opening event), Gay Games, Cleveland: Karanga and opening speaker

- 2014: VIP Function, Opening Ceremony, Gay Games, Cleveland: Keynote speaker

- 2014: Indigenous, Black and Latino LGBTIQ leaders of Chicago: Presentation (via Mona Noriega, Human Relations Commissioner, City of Chicago; and Evette Cardona, Deputy Director, Polk Foundation - founding members of Amigas Latinas)

- 2014: Fuerza Community Center, Cicero, Chicago: LGBTIQ youth leaders: Presentation (via Alicia Vega, Center Director)

- 2015: INCITE! Colour of Violence 4 Conference: Beyond The State: Inciting Transformative Possibilities, Chicago: Workshop participant (via Michelle Erai, Gender Studies, UCLA)

- 2015: DePaul University, Chicago: Guest Lecturer (via Lourdes Torres, Professor, Latin American \& Latino Studies and Ann Russo, Associate Professor, Women \& Gender Studies)

- 2015: University of Illinois Chicago: Guest Lecturer (via Professor Alicia (Phoenix) Matthews, School of Nursing) 
- 2015: Northeastern Illinois University, Chicago: Guest Lecturer (via Angela Koon, LGBTQ \& Hate Crime Specialist, State Attorney General Office and Adjunct Professor, Women \& Gender Studies)

- 2015: City of Chicago Human Relations Commission: Presenter (via Mona Noriega, Commissioner of Human Relations)

- 2015: LGBTIQ Social Inclusion Hui, Auckland: Opening speaker (via Joey Macdonald, Affinity Services and Moira Clunie, Mental Health Foundation)

- 2015: Tūramarama ki te Ora National Suicide Prevention Hui, Rotorua: Keynote speaker in association with Moira Clunie, Mental Health Foundation

- 2015: Te Waka Hourua National Research Symposium on Suicide Prevention: Keynote speaker (via Dr Kahu McClintock, Research Manager, Te Waka Hourua)

- 2015: Otago University of Wellington Medical School - health access project (Via Dr Keri Lawson - Te Aho)

- 2015: University of Auckland Medical School. Guest Lecturer (via Dr Katrina Roen)

- 2016: Ara Taiohi Rainbow Competencies Hui: Presenter (via Anya Satyanand)

- 2016: Launch of Pride Week and 30 ${ }^{\text {th }}$ Anniversary of Homosexual Law Reform (HLR), Parliament: Opening keynote speaker

- 2016: Pride Week $30^{\text {th }}$ Anniversary Picnic, Parliament: Keynote speaker

- 2016: PROUD/ILGA Oceania Regional Conference, Wellington: Keynote speaker and plenary presenter (via Mani Bruce Mitchell)

- 2016: SHIFT National Hui for Queer \& Gender Diverse Youth. Workshop (x2) presenter on Healthy Relationships and Takatāpui, Inclusion \& The Treaty. Facilitated workshop National Rainbow Strategy (via Tabby Besley, National Coordinator, InsideOUT)

- 2016: New Zealand Association of Counsellors. Presenter on 'The Treaty in Relation to Diverse Sexes, Genders \& Sexualities:' (via Ally Andersun, Lower Hutt Women's Centre)

- 2016: University of Auckland Medical School, Auckland: Guest Lecturer (via Dr Katrina Roen)

- 2016: City of Chicago Human Relations Commission: Presenter (via Mona Noriega, Commissioner of Human Relations)

- 2016: City of Chicago Human Relations Commission: Workshop participant for the communities affected by the Orlando Shooting (Latinx, Muslim and LGBTIQ) 
- 2016: Queer History Month: Workshop facilitator on Leaving a Legacy (via Tīwhanawhana)

- 2016: University of Auckland Medical School, Auckland: Guest Lecturer (via George Parker)

- 2016: GLITTFAB Conference, Palmerston North: Presenter on Takatāpui, the Treaty and Keeping Safe (via Matt Keen, MALGRA)

- 2016: Takatāpui Hui-a-Motu, Auckland: Presenter (via Kōmiti Whakahaere)

- 2016: MAI Doctoral Conference, Wellington: Presenter on my PhD thesis: Part of the Whānau: The Emergence of Takatāpui Identity - He Whāriki Takatāpui (Anne Waapu)

- 2016: ILGA World Conference, Bangkok: Co-Presenter on Using Indigenous Worldviews to Lead a National Rainbow Movement (Kevin Haunui and Kassie Hartendorp)

- 2017: Te Kawa a Māui, School of Māori Studies, Victoria University of Wellington: MAOR 408 Class. Guest Lecturer (via Dr Ocean Mercier)

- 2017: SHIFT Hui National Hui for Young People of Minority Sexualities, Sexes and Genders. Workshop presenter on Growing Up Takatāpui: Whānau Journeys (via Tabby Besley, National Coordinator, InsideOUT)

- 2017: Te Kawa a Māui, School of Māori Studies, Victoria University of Wellington: Guest Lecturer (via Terese Mcleod, Senior Administrator).

\section{Putting It Into Practice: Key Projects}

- 2013: United Nations Asia/Pacific Forum, Nepal: Represented New Zealand to draft resolution on human rights, sexual orientation and gender identity for the UN General Assembly (via Human Rights Commission)

- 2014: Ministry of Youth Development Draft Action Plan LGBTI Youth: Contributions and edit of draft Plan (via Jack Trolove, Mental Health Foundation, Auckland)

- 2014-15: RainbowYOUTH Education Programme InsideOut: Advisory group for review of existing programme and model development (via Duncan Matthews, Executive Director and Aych McArdle, Education Officer)

- 2014-15: Takatāpui: Part of the Whānau: Interviewed participants for video resource and wrote print resource as part of national suicide prevention strategy. A collaboration between Tīwhanawhana Trust and Mental Health Foundation (with Jack Trolove and Moira Clunie) 
- 2015-16: Takatāpui - A Place of Standing: Wrote autobiographical chapter (via Jordon Harris, New Zealand AIDS Foundation). Launched in November 2016 and subsequently withdrawn in January 2017 due to misattributions and inaccuracies

- 2015: Wellington Rainbow Honours: Nominated with my partner, Alofa Aiono

- 2015: SHIFT Queer and Trans Youth Hui, Wellington: Video for workshop on making groups inclusive of takatāpui (in my physical absence)

- 2015: Rainbow Youth Healthy Relationship Resource You, Me, Us Ko Au, Ko Koe, Ko Tãua, Ko Tātou: Edit of draft resource and segment entitled: Elizabeth Kerekere's Top 10 Relationship Tips (via Duncan Matthews, Executive Director, and Aych McArdle, Education Officer)

- 2015: Wiley-Blackwell Encyclopedia of Gender \& Sexuality Studies: Wrote entry on LGBTQ Activism - Mãori

- 2015: Hauora Takatāpui-Health Needs Assessment, Otago University of Wellington Medical School. Oversaw 4th year medical school students to develop project and assessment tools (via Dr Keri Lawson-Te Aho, Wellington Campus)

- 2015: In It Together, Family Violence \& Sexual Violence Sector organised by the Green Party. Project team member to compile report to Government based on sector priorities

- 2015-2016: Houhou Te Rongo Kahukura - Outing Violence: Intimate Partner and Sexual Violence Research Project: Advisory Group member. Assisted with survey development and co-facilitated 20 national community hui to contribute to report to Ministry of Social Development

- 2015-2017: Growing Up Takatāpui: Whānau Journeys: Interviewed youth and their whānau, and wrote print resource as part of national suicide prevention strategy and anti-family violence campaign. A collaboration between Tīwhanawhana Trust and RainbowYOUTH (with Toni Duder and Morgan Butler)

- 2015-17: Intersex Roundtable: Co-organiser and presenter. A collaboration between Tīwhanawhana Trust, ITANZ (Mani Bruce Mitchell) and the Human Rights Commission (Dr Jill Chrisp)

- 2016: Vodafone World of Difference Fellowships: Panel selection member (via Kate Tindall-Lum, Vodafone)

- 2016: Claiming Identity: Creating Ourselves: Curated art exhibition for Queer History Month and feature artist with Tīwhanawhana members; Jack Trolove and Peri Te Wao 
- 2016: ILGA World Conference, Bangkok: Co-organiser to bid to host the World Conference in Wellington 2018 in collaboration with ITANZ (Mani Mitchell and Tom Hamilton) and RainbowYOUTH (Duncan Matthews and Toni Duder)

- 2016-2017 It's Not OK Ministry of Social Development: Featured in the national television and social media campaign against family violence (Jac Lynch, MSD)

- 2016-2017: LGBTIQ Homelessness Project: Assistant Research Fellow, Otago University of Wellington Medical School (Dr Hera Cook)

- 2016-2017: It's Complicated: Rainbow Relationships (working title). Interviewing participants and writing print and online resource as part of national intimate partner and family violence campaign. A collaboration between Tīwhanawhana Trust and the Mental Health Foundation (Moira Clunie) in association with InsideOUT, RainbowYOUTH and the Gisborne Women's Refuge

- 2016-2017: All of Us (working title). Resource on intersections between diverse sexes, genders and sexualities and disability. Provided cultural and facilitation support (via Stace Robertson, Project Lead)

- 2017: Pōwhiri Guide Booklet. Edited protocol booklet for SHIFT Hui as part of Treaty work with InsideOUT (via Jean Sergent-Shadbolt, Tabby Besley and Ariki Brightwell).

\section{And The Hard Core...}

My Tūranga besties: Terangi Roimata Kutia-Tataurangi and Jayme Te Rauna

My trans brothers: Wai Ho, Jack Trolove and Tommy Hamilton

My takatāpui sisters: Michelle Erai in Los Angeles, Keryn Lowry in New York and their respective partners, Gwenn Vallone and Cathy Hough for work space and canine company

My Chicago whanaunga: Mona Noriega and Evette Cardona for work space, feline company and with Phoenix Matthews, Kim Hunt and Tracy Baim, intense political conversations

My former counsellor and friend: Ally Andersun and the women at the Lower Hutt Women's Centre, who helped keep my hinengaro intact so I could complete this work

My muse, taku hoa tuatahi: Leichelle Tanoa, for keeping the myth alive

My immediate whānau: Dad (the late Karauria Tarao Bison Kerekere) for your high expectations; and Mum (Erin Kerekere nee Ryan) and my siblings Desmond, Lorna and Lynn, for your unwavering support.

And finally, with whom all is possible: my life partner Alofa Aiono - since 1992 and counting. 


\section{CHAPTER 1: MAHIA TE MAHI: THE WHY, THE WHO \& THE WHAT}

\section{The Why: Putting Takatāpui on the Map}

Part of the Whānau: The Emergence of Takatāpui Identity - He Whāriki Takatāpui is the first study on takatāpui identity and well-being. Through whānau, community and scholarship support to undertake this thesis, I bring activism into the academy to highlight the work and lived experience of those Māori with diverse gender identities, sexualities and sex characteristics ${ }^{1}$ who have identified and organised as takatāpui since the mid 1980s. In 1991, Ngahuia Te Awekotuku issued her oft-quoted challenge to researchers and community activists:

My challenge is this: we should reconstruct the tradition, reinterpret the oral history of this land so skilfully manipulated by the crusading heterosexism of the missionary ethic (Te Awekotuku 1991:37).

A generation later, this study is my response. It lays down a 'Whāriki Takatāpui' - a woven mat of complex design which forms a foundation where we may sit to discuss and make decisions; and from which to step forth to make change.

Takatāpui is an ancient Māori term from the traditions of the indigenous people of Aotearoa New Zealand. It means "intimate companion of the same sex" (Williams 1871:147) ${ }^{2}$ and was separately discovered by takatāpui academics; Ngahuia Te Awekotuku and then Lee Smith; in the manuscripts of Wīremu Maihi Te Rangikāheke (c1840s). It provided context to the love triangle between Hinemoa, Tūtanekai and Tiki which had occurred some 400 years beforehand (Te Awekotuku 2005:8; Grey 1971:113). ${ }^{3}$

Te Awekotuku and Smith effectively gifted 'takatāpui' to Māori lesbian, gay, bisexual and transgender people through networks in the mid 1980s. Credence for the term was based on their reputations with Te Awekotuku in leadership roles within the art, museum and heritage sectors and Smith a renowned linguist. Since the late 1980s it has been increasingly reclaimed

\footnotetext{
${ }^{1}$ Sex characteristics refer to physical and bodily diversity. It has been identified by UN treaty monitoring bodies as the prohibited ground of unlawful discrimination against intersex people's or intersex persons' right to physical and bodily integrity, self-determination and autonomy (APF/UNDP 2016:8)

${ }^{2}$ The term 'takatāpui' was translated in the second edition of the Māori dictionary in 1852 as 'travelling companion.' The translation as 'intimate partner of the same sex' has been consistent in every dictionary since the third edition in 1871

${ }^{3}$ This narrative will be considered further in Chapter 3
} 
by Māori with diverse gender identities, sexualities and sex characteristics as both an identity and an umbrella term.

In addition to 'takatāpui,' 'whakawāhine' (like a woman) and 'tangata ira tāne' (spirit of a man) are terms which draw on traditional Māori concepts to denote those who were born with the wairua (spirituality) of a gender different to the one they were assigned at birth (Human Rights Commission 2007:13). Throughout this study, trans, gender diverse and queer are umbrella terms respectfully used to include all diverse gender identities and sexualities including but limited to; trans women, trans men and people who are trans feminine, trans masculine, nonbinary, genderfluid, genderqueer, gender non-conforming, butch, femme, asexual and pansexual. Intersex will be used as an umbrella term for people with diverse bodies and sex characteristics while acknowledging that they cut across all other diverse gender identities and sexualities. Finally, these umbrella terms include all people who reject such terminology in favour of more appropriate and culturally specific gender identities and sexualities.

In this study, I will be using the more poetic term 'Rainbow' in place of versions of the acronym 'LGBTIQA' (lesbian, gay, bisexual, trans, intersex, queer and asexual/allies) except as quoted. Its use is predicated on inclusion of all people with diverse gender identities, sexualities and sex characteristics. I recognise that the 'rainbow flag' (Moore 2001:22) is not an inclusive banner for all hence the development of new flags that celebrate the identities and highlight the struggles of trans $;{ }^{4}$ intersex $;{ }^{5}$ genderqueer and non-binary ${ }^{6}$ and other marginalised members of our communities.

\section{Telling Our Stories: Updating the Record}

As at early 2017, the existing literature on takatāpui consists of one primarily autobiographical book: Sexuality and the Stories of Indigenous People (Hutchings and Aspin 2007) ${ }^{7}$, a handful of book chapters and articles. The scarcity of information reinforced the need for this study and

\footnotetext{
${ }^{4}$ The first transgender flag was designed by Monica Helm in 1999. http://point5cc.com/the-history-ofthe-transgender-flag/ Retrieved 8 May 2016

${ }_{5}^{5}$ The first intersex flag was designed by OII (Organisation Intersex International) Australia in 2013. https://oii.org.au/22773/an-intersex-flag/ Retrieved 8 May 2016

6 The first genderqueer and non-binary flag was designed by Marilyn Roxie in 2010. http://genderqueerid.com/about-flag Retrieved 8 May 2016

${ }^{7}$ A second book 'Harris, J (2016) Takatāpui: A Place of Standing. Auckland: New Zealand AIDS Foundation' was withdrawn from circulation three months after its publication in November 2016
} 
led to the creation of two resources Takatāpui: Part of the Whānau (Kerekere 2015) and Growing Up Takatāpui: Whānau Journeys (Kerekere 2017) in the interim.

Other data on takatāpui has been extrapolated from the Māori and self-identified takatāpui respondents of Rainbow research in two main areas. The first is the (primarily sexual) health needs of gay/bisexual men and $\mathrm{MSM}^{8}$ in the context of the HIV/AIDS epidemic (Aspin 1996; Aspin et al 1998; Aspin 2000; Broughton 1996; Fenaughty et al 2006; Herewini and Sheridan 1994). The second covers a broader range of issues for lesbians and/or bisexual women such as discrimination (Rankine 2001); effects of coming out on relationships and health (Saphira and Glover 2001) and assisted human reproduction (Glover et al 2009). Lavender Islands: Portrait of the Whole Family (Henrickson et al 2007) was the first (and only to date) national strength-based multidisciplinary study of lesbian, gay and bisexual people in Aotearoa New Zealand. The resulting report Ko Wai Rātou? Managing Multiple Identities in Lesbian, Gay and Bisexual Māori found several statistically significant differences between Māori and nonMāori respondents (Henrickson 2006). The findings of this study reiterate its key findings (ibid 2006: 260-261):

- Cultural affiliation was more significant for Māori than sexual orientation and culture and spirituality played a more important role in negotiating takatāpui identities. Māori sought to balance cultural and sexual identity in a 'both/and' way that non-Māori did not, or did not need to;

- Contemporary takatāpui felt pressured to choose between being Māori and being queer; to marry and to have children;

- Both Māori men and women were more likely to have had sex or fantasised about a member of the opposite sex than their tauiwi counterparts;

- Differences for Māori women were not only statistically significant; they were 'developmentally remarkable' in that they were more likely to come out earlier and be out to everyone they knew.

While it still existed, Out There! contributed to the analysis and production of the 'nonheterosexual' report for Youth 2000 (Le Brun et al 2004) and the safe/both-sex attracted reports for Youth '07 (Rossen et al 2009) and Youth '12 (Lucassen et al 2014). Youth '07 found that $63 \%$ of young people were aware of same sex attraction by the age of 13 and $93 \%$ of them were coming out by the age of 16 . Unfortunately, they were not necessarily doing this in a safe environment. While many people think that New Zealand society is tolerant and improved by

\footnotetext{
${ }^{8}$ MSM: men who have sex with men who may not necessarily identify as gay, bisexual or takatāpui
} 
such legislation as Homosexual Law Reform and the Civil Union Act, young people coming out young felt unable to discuss their sexual orientation with their parents $(60 \%)$ and almost $40 \%$ have run away from home for fear of, or because of their parent's reaction. Specific statistics on non-heterosexual Māori find they are significantly more likely to experience bullying, unwanted sexual attention and sexual and mental health problems than both their Pākehā and heterosexual counterparts. This has culminated in negative body image, increased risk-taking behaviour, self-harm and suicide (Henrickson et al 2007, Le Brun et al 2004, Rossen et al 2009, Lucassen et al 2014). Many community groups such as Tīwhanawhana Trust have taken queer, trans and takatāpui youth under their wings and provide support where possible.

Notably, all of the studies above focused on sexuality and targeted cis-gendered ${ }^{9}$ people. The two major studies on trans people in Aotearoa New Zealand were the Transgender Inquiry (Human Rights Commission 2007) which featured takatāpui ${ }^{10}$, and the national Youth 2000 Series which produced the first report on the health and well-being of transgender high school students (Clark et al 2014). Recent work by Nikora and Te Awekotuku (2013) on death and dying has identified issues for takatāpui who are trans or gender diverse during tangihanga on marae.

The literature is consistent in that for Māori in Rainbow communities generally and takatāpui specifically, cultural identity and spirituality are as significant, if not more, than their gender identity or sexuality. A third section of literature involves theorising about Māori cultural values and practices and how that impacts on diverse Māori sexualities (Hutchings 2012, McBreen 2012).

\section{Building Our Communities: Putting Research into Practice}

While this thesis fills a major gap in the literature, my interest is more than academic.

Many Māori struggle with their cultural identity in relation to their diverse gender identities, sexualities or sex characteristics. At an individual level, my hope is that this study provides clarity and a sense of belonging for those looking for community. At a whānau level, I hope it contributes to healing, acceptance and celebration.

\footnotetext{
${ }^{9}$ Cis-gendered people are those who affirm the sex and gender identity they were assigned at birth

${ }^{10}$ The Transgender Inquiry featured Peri Te Wao who is on the Board of Tīwhanawhana Trust and a participant in this study
} 
In order to address the colonised and systemic forms of homophobia, biphobia and transphobia that impact on the health and well-being of takatāpui; activists, community workers, youth workers and health professionals must produce evidence that it occurs. This study identifies the key issues faced by takatāpui across different generations and different gender identities and sexualities. Most importantly it identifies those issues specific to takatāpui which are not shared by other Māori or by other members of Rainbow communities. By doing so, it enables organisations to access resources, funding and further research for their important and often life-saving work.

In facing to build up our communities, a number of culturally-based and creative solutions, programmes and projects must be developed by takatāpui and our allies. This study showcases Tīwhanawhana Trust as a model of a takatāpui organisation doing just that while creating influence at local, national and international levels. This study has informed my contribution into a range of projects and resources which are noted in the Acknowledgements (p12). My hope is that it will form the basis for further research and strategic change within whānau, community and government.

Fundamentally though, this is a doctoral thesis. The opportunity to develop a theoretical framework to think, reflect and write has been a revelation to me. The insight I have gained has directly impacted on my work in Māori, Rainbow and takatāpui communities.

\section{Leaving a Legacy: From Ancestors to Now}

Whakapapa is fundamental to Māori culture. Not only does it refer to lines of genealogy, it encompasses the relationships and obligations within and between generations. In acknowledging the whakapapa of takatāpui, this study recognises that the process of colonisation pathologised the sexual and gender fluidity our tūpuna enjoyed. Under pressure, successive generations deleted or toned down such references within Māori narratives (Te Awekotuku 2005:7) thus eliminating or disguising the mātauranga which existed at the time. This study aims to collate the information we have available to us. It also aims to ensure that no further mātauranga is lost and that we add to it so future takatāpui generations may benefit. Through books, resources and all manner of creative endeavours arising from this work, I hope to contribute to the elimination of homophobia, biphobia and transphobia from within whānau and the communities where takatāpui live, work and love. 


\section{The Who: Takatāpui Speak for Ourselves}

\section{A Line in the Sand: Defining Takatāpui}

The first 'official' use of the term takatāpui is attributed to Herewini and Sheridan (1994) in reference to the health needs of Māori gay men. Presumably it is termed official because it was a government document. That attribution was first made by takatāpui academic and activist Clive Aspin (Aspin et al 1998) and has been repeated fairly consistently ever since. Unsurprisingly, the first printed references to takatāpui were actually made within lesbian publishing in Mana Wāhine Māori: Selected Writings in Māori Women's Art, Culture and Politics (Te Awekotuku 1991:36) and Spiral 7: A Collection of Lesbian Art and Writing from Aotearoa/New Zealand (Kerekere 1991:64). This reflects a certain divide between the concerns of the gay/bisexual men and lesbian/bisexual women communities in Aotearoa New Zealand at the time.

The literature is generally consistent on the definition of takatāpui as a reclaimed word to signify same sex attraction for Māori "men, women and transgender people" (Aspin et al 1998:25). In her dissertation on Mana Wāhine as a theoretical framework, takatāpui academic Leonie Pihama acknowledged the increasing use of takatāpui which she defined as "Māori lesbian, gay and bisexual" (2001:12, footnote 56). When Murray (2003) questioned "Who was Takatāpui?" he gave definitions of "lesbian and gay;" "homosexual and Māori;" and advised that the term was also used by "Māori women and transgender groups" (2003:233). The first book on takatāpui shies away from giving a definition. Hutchings and Aspin note that takatāpui “encapsulates not only aspects of one's sexuality but also components of one's cultural identity" (2007:16) and refers to contributors variously as Māori who identify as "lesbian, gay, transsexual and transgender" and as "non-heterosexual" (ibid:21). Glover et al also defined takatāpui as "New Zealand indigenous non-heterosexual" (2009:295). In discussing the findings of the much vaunted but otherwise elusive 'Māori Sexuality Project,' ${ }^{11}$ Aspin and

\footnotetext{
${ }^{11}$ Aspin (2005) stated that the 'Māori Sexuality Project' and the 'Takatāpui Identity Project' had received significant research funding and would have positive impact on the sector. One of the lead investigators confirmed that the Māori Sexuality Project was written up only as an unpublished Technical Report (personal email communication 14 August 2015). Others have cited this but the 2008 report has not been available at the given URL for the course of this study. My requests for a copy of the report to consider for this study were not met.
} 
Hutchings (2010:425) state that takatāpui "has been embraced by Māori gay men, lesbians and transgender people as a culturally appropriate term to define their sexualities."

Although the inclusion of intersex people has been standard within Rainbow community definitions of takatāpui for some time, it only appears in the mainstream in 2014 on the website of Te Ara. Under the heading of Hōkakatanga - Māori Sexualities takatāpui is defined as: ${ }^{12}$

Many gay, lesbian, transgender, bisexual and intersexual [sic] Māori women and men have adopted the word takatāpui to describe themselves, which identifies them by both their sexuality and their culture.

In their work on death and dying, takatāpui academics Linda Waimarie Nikora and Ngahuia Te Awekotuku included butch, tomboy, kamp, intersex and queer in their definition of takatāpui (2013:2).

In addition to reiterating its meaning as a close or intimate companion of the same sex, subsequent hard copy and on-line Māori dictionaries also define takatāpui as "homosexual" 13 and "lesbian, gay, homosexual, gay men and women - the use of the term for a homosexual is modern." ${ }^{14}$ Based on his analysis of dictionary entries, non-Māori academic Murray ${ }^{15}$ is the only commentator who concludes that takatāpui denotes a same-sex friend only and that its meaning has been "sexualised" (2003:238).

\section{Deeper Meanings: Reclaiming Gender}

The use of qualifying gender terms for takatāpui was popularised in the 1990s. The terms 'wāhine takatāpui' (Elleray 2004:175, Hutchings et al 2011:7, Te Awekotuku 1991:59) and 'takatāpui wāhine' (Hutchings and Aspin 2007:24, Murray 2004:174) were used interchangeably to denote cis-gendered Māori lesbians and same sex attracted women (who could be bisexual). Aspin consistently used 'takatāpui tane' as the translation for cis-gendered gay and bisexual Māori men in his sexual health work (Aspin 1996, Aspin et al 1998:25). Aspin et al (1998:25: footnote 46) encapsulated the thinking at the time:

\footnotetext{
${ }^{12}$ Clive Aspin. 'Hōkakatanga - Māori sexualities' in Te Ara - the Encyclopedia of New Zealand, updated 17 July 2014 http://www.TeAra.govt.nz/en/hokakatanga-maori-sexualities.

${ }^{13}$ Ngata Dictionary: http://www.learningmedia.co.nz/ngata.

${ }^{14}$ Te Aka Dictionary: http://www.maoridictionary.co.nz

${ }^{15}$ Murray is a North American academic. who was based at Te Kawa a Māui, School of Māori Studies, Victoria University of Wellington, to undertake this research
} 
Within contemporary Māori society, takatāpui tāne applies to men, takatāpui wāhine applies to women, takatāpui whakawāhine refers to male to female transsexuals and takatāpui whakatāne refers to female to male transsexuals.

Such qualifying gender terms rarely occur within takatāpui activist circles in acknowledgement that the use of wāhine and tāne have broad implications for takatāpui. For example, an inclusive definition of 'takatāpui wāhine' would denote all female identified takatāpui who may be cisgendered, trans, trans feminine, intersex, genderqueer, genderfluid, non-binary or gender nonconforming; and who may or may not identify as lesbian, bisexual, pansexual, asexual, queer or heterosexual.

As outlined above, the definition of takatāpui has generally been reiterated as a sexual identity that is inclusive of transgender people. This study takes pains to point out that 'transgender', or the more inclusive 'trans,' is not a sexuality. It is an umbrella term for a range of gender identities and, having transitioned, many whakawāhine, tangata ira tāne and trans people may identify as female or male and as heterosexual. The binary use of 'women and men' here is also problematic in two ways. The first is in relation to intersex people who embody both female and male in remarkable ways but experience unwanted surgeries and discrimination based on their diverse sex characteristics. The second is in relation to people who are gender diverse and do not experience their gender identity as strictly female or male. All are excluded when takatāpui identity is confined to sexual orientation and binary identities.

The use of inclusive language in the definition of takatāpui is fundamental then to the development of takatāpui identity and communities. As different gender identities have emerged or been named within takatāpui and Rainbow communities, Tīwhanawhana Trust has been at the forefront of assuring their inclusion in collaboration with other community organisations such as ITANZ ${ }^{16}$ and RainbowYOUTH. ${ }^{17}$ One example is the Takatāpui, Lesbian, Gay and Bisexual Scoping Exercise for ALAC ${ }^{18}$ (Pega and MacEwan 2010:45) which provided the following definition:

Takatāpui is a traditional Māori word which means 'intimate companion of the same sex'. The term has been reclaimed for all Māori who identify as lesbian, gay, bisexual, trans, intersex, whakawāhine, fa'afafine, same sex attracted, asexual, queer and questioning.

\footnotetext{
${ }^{16}$ Intersex Trust of Aotearoa New Zealand, which was founded by pioneering intersex activist, Mani Bruce Mitchell www.ianz.org.nz

${ }^{17}$ Rainbow YOUTH was established in 1989 for queer and gender diverse youth. It is a youth led national organisation based in Auckland www.ry.org.nz.

${ }^{18}$ Alcohol Advisory Council of New Zealand
} 
This was the definition in use at the time by OUT THERE! Queer Youth Development Project; a joint project between RainbowYOUTH and New Zealand AIDS Foundation (NZAF); ${ }^{19}$ where I held the national position of Kaimahi, Takatāpui Taiohi (takatāpui youth worker) (2008-2009). Ironically NZAF does not use a similar definition. Some confusion has arisen in some places because they have produced resources within which they consistently use 'takatāpui' to refer to only gay men, Māori MSM,${ }^{20}$ and whakawāhine without positioning them within a broader and more inclusive takatāpui identity framework.

The hard-fought gains since Homosexual Law Reform in 1986 have resulted in greater levels of acceptance, and any associated privilege, for takatāpui who are cis-gendered and who also identify as lesbian, gay, bisexual or pansexual. This study emphasises that it is incumbent upon us to use that privilege to uplift all of our communities, particularly for those with diverse gender identities and sex characteristics who may or may not identify as trans or intersex - or takatāpui for that matter.

As noted earlier, this study is an opportunity for takatāpui who have claimed this identity and use it as an umbrella term which which to organise and advocate, to define takatāpui. ${ }^{21}$ Based on over 30 years of working within Māori and Rainbow communities with a focus on takatāpui and young people; and reinforced by the findings of this study; I suggest the following definition:

Takatāpui is an umbrella term that embraces all Māori with diverse gender identities, sexualities and sex characteristics including whakawāhine, tangata ira tāne, lesbian, gay, bisexual, trans, intersex and queer. Takatāpui identity is related to whakapapa, mana and inclusion. It emphasises Māori cultural and spiritual identity as equal to - or more important than - gender identity, sexuality or having diverse sex characteristics. Being takatāpui offers membership of a culturally-based national movement that honours our ancestors, respects our elders, works closely with our peers and looks after our young people (Kerekere 2015, 2016).

\footnotetext{
${ }^{19} \mathrm{NZAF}$ is fully funded by government with a range of other grants. It has a national office in Auckland and regional offices in Auckland (Burnett Centre), Wellington (Awhina Centre) and Christchurch (Te Toka Centre)

${ }^{20}$ Men who have sex with men and may or may not identify as takatāpui, gay, bisexual or pansexual

${ }^{21}$ As opposed for example to the definition of 'takatāpui' provided to An Interdisciplinary Bibliography on Language, Gender and Sexuality (Motschenbacher 2012:179) by a North American and non-Māori academic (Murray 2003, 2004).
} 


\section{Remember When: Making Oral History}

In order to provide a national overview of issues facing takatāpui in addition to their own personal experience, interviews were held with 13 takatāpui leaders. Leadership was identified by their roles and willingness to speak out within takatāpui, broader Rainbow and youth communities. The participants reflect a wide diversity of iwi, geographical location, gender identities and sexualities and, at the time of interview, they ranged in age from 19 to 64 years - three generations. In order to gain insight into the perception of whānau with takatāpui members, interviews were held with two non-takatāpui kuia (female elders) and 12 whānau members of the rangatahi (young people) interviewed in the third stage. Whānau participants ranged in age from 19 to 85 years - four generations. In total, I interviewed 27 participants in three stages over four years.

A prerequisite of this study was that all participants were willing to be named. This was largely for visibility and to model leadership. Even if their identities would not be obvious to anyone outside their whānau and communities in this study, two national resources were subsequently produced which featured their names and images (Kerekere 2015, 2017).

Each participant was given a Participant Information Sheet (attached as Appendix I). Participants were required to fill out a Consent to Participation in Research (attached as Appendix II) and an Oral History Recording Agreement Form to deposit the recordings at LAGANZ (Archive for Rainbow Communities), Alexander Turnbull Library, National Library (attached as Appendix III). I went through each form with each participant who signed prior to the interview commencing.

The first oral history interviews were held in 2012-2013 and included questions about whakapapa, childhood and youth, competency in te reo Māori, and engagement with whānau, hapū and iwi as well as Rainbow communities (attached as Appendix IV). The participants were:

- Kevin Haunui (born 1960): Ngāti Rangi, Te Ātihaunui a Papārangi, Ngāti Kahungūnu, Tūhoe, Whakatōhea, Te Whānau a Apanui

- Peri Te Wao (born 1966): Te Arawa

- Hinemoana Baker (born 1968): Kai Tahu

- Ahi Wi Hongi (born 1984): Ngā Puhi, Ngāti Maniapoto

- Morgan Cooke (born 1984): Ngāti Whātua, Ngā Puhi. 
One of the most commonly asked questions I am asked by non-Māori is "What do Māori think of takatāpui?" While the question implies that takatāpui are somehow separate from Māori, I believed the memories and knowledge of our kuia kaumātua (elders) would shed light on dealing with the homophobia, biphobia and transphobia takatāpui experience within their whānau now. In early 2013, I conducted an in-depth interview with two kuia that included questions on their perceptions of Māori sexuality and gender and their memories of takatāpui composer, Tūini Ngāwai (attached as Appendix VI). They were both resident in the rural seaside town of Tolaga Bay, Te Tairāwhiti (East Coast). Their comments have been incorporated into Chapter 4:

- Tewhanaupani (Teddi) Milner Maitai (born 1928): Ngāti Porou

- Heni Poutu (born 1945); Ngāti Porou.

The second round of interviews occurred in 2015. The Mental Health Foundation obtained funding to collaborate with Tīwhanawhana Trust to produce a resource on takatāpui identity and well-being within the kaupapa of suicide prevention (Kerekere 2015). These interviews included questions on takatāpui identity and how that could support whānau to accept their takatāpui members who were struggling with identity, depression, mental health issues and suicide ideation. I was able to re-interview Kevin, Hinemoana, Ahi and Morgan and added:

- Jennifer Edwards (born 1950): Ngāti Porou, Te Arawa.

Following this I was able to do an in-depth interview with Jennifer similar to the first round.

Finally, a third round of interviews occurred in 2016. RainbowYOUTH obtained funding to collaborate with Tīwhanawhana Trust to produce a second suicide prevention resource focused on takatāpui rangatahi (young people) (Kerekere 2017). These interviews were conducted with takatāpui rangatahi together with their parents and grandparents and included questions on how to create supportive whānau (attached as Appendix XII). Their comments have been incorporated into Chapter 6. The takatāpui rangatahi participants were:

- Ariki Brightwell (born 1989): Ngāti Porou and Tahitian

- Kassie Hartendorp (born 1989): Ngāti Raukawa ki Te Tonga.

- Emilie Rākete (born 1992): Ngāpuhi

- Morgan Butler (born 1994) and first cousin Mere-Ana Nicholson (born 1985): Ngāti Tūwharetoa, Tainui and Te Rarawa

- Nathaniel Gordon-Stables (born 1995): Ngāti Kuri 
- Cameron Kapua-Morrell (born 1996): Ngāti Porou

The whānau participants were:

- Ariki’s mother Raipoia Brightwell (born 1956): Tahitian, and father Matahi Brightwell (born 1952): Ngāti Porou

- Emilie's father, Robert Rākete (born 1966): Ngāpuhi.

- Morgan's mother Kellie Butler (born 1966); Morgan and Mere-Ana's Aunty Ellen Tupaea (born 1971); and their Nan, Nina Turanga (born 1946) - all Ngāti Tūwharetoa, Tainui and Te Rarawa

- Nathaniel's mother Angelique Gordon-Stables (born 1967): Ngāti Kuri

- Cameron's mother Natasha Morrell (born 1978); father Frank Kapua (born 1980); Nan Nan Kapua (born 1961); sister Monique Kapua-Morrell (born 1997); and cousin, Molly Heremaia (born 1996) - all Ngāti Porou.

For both resources and this study, the participants were given a grace period within which to withdraw from the project. Not only did no participant take up that offer, most re-engaged over the years of this study. The resource participants were able to comment on several drafts and edit/approve all quotes attributed to them prior to publication. For this study, participants shared highly personal information. They were able to edit/approve all quotes attributed to them. The few changes were made to protect the privacy of third parties and to preserve whānau relationships. Because this study included takatāpui who were trans and gender diverse, care was taken to ensure the correct pronoun was used when referencing participants. While most chose to use 'she/her' or 'he/him' pronouns, one participant identified their preferred use of 'they/their' as indicated in Chapters 4-7.

\section{The Nitty Gritty: Thesis \& Research Questions}

All interviews were recorded (Stage One and Three) or filmed (Stage Two), transcribed and then analysed according to the Whäriki Takatāpui framework which was outlined in Chapter 2. The specific questions designed to guide data collection and analyses were:

\section{Mana Wāhine}

- Why is whakapapa important to takatāpui?

- What can takatāpui learn from the past? 


\section{Mana Motuhake}

- Why do Māori with diverse gender identities, sexualities and sex characteristics claim takatāpui identity?

- What does 'being takatāpui' mean in relation to 'being Māori'?

Te Whare Tapa Whā

- What are the key issues that impact on takatāpui health and well-being?

- How do takatāpui address the challenges facing them?

Weaving together the responses to these questions produced the Whäriki Takatāpui which provided insight into the overarching question:

- How can takatāpui identity promote health and well-being for all Māori with diverse gender identities, sexualities and sex characteristics within whānau and society?

\section{Owning Subjectivity: Putting Myself in the Picture}

In 2009, I was asked by takatāpui elder; academic and pioneering lesbian activist, Alison Laurie; to undertake a PhD to advance takatāpui communities. As I had no plans for an academic career, the thought had not occurred to me. However, because of the esteem in which I held Alison, I agreed with no inkling of what it would entail. My experience in the sector saw the requirement for a Masters waived on condition I obtain a BA Honours (First Class) which I did through Gender \& Women's Studies, Victoria University of Wellington in 2010. On completion, I moved home to my tribal area of Tūranganui a Kiwa (Gisborne) to complete a BA Ngā Toi o Ngā Rangi Māori Visual Arts at Toihoukura. My PhD journey then resumed with Te Kawa a Māui, School of Māori Studies, Victoria University of Wellington. As someone who identifies primarily as an artist and activist, this foray into the academic world has been highly illuminating.

Because of their commitment to the kaupapa, the participants shared highly personal details about their lives, and their hopes and aspirations for takatāpui and our whānau. As an activist and leader within takatāpui and Rainbow communities, I do not separate myself from them. Therefore, I answered the same questions and shared my personal experiences alongside those of my takatāpui elders, peers and young people. This enabled me to contribute the perspective of a takatāpui leader who is cis-gendered lesbian femme; to raise issues which had not been 
raised elsewhere; and to reduce the inherent power imbalance between the researcher and the researched. My contributions in Chapters 4-7 are delineated by the use of italics.

Although I contributed to the participant subjectivities, I must remain aware of the subjectivities and inherent biases I bring to my research (Peshkin 1988). On reflection, I identified seven such subjectivities, which I hereby declare. As a descendant of Ngāti Oneone, Te Aitanga a Māhaki, Whānau a Kai, Rongowhakaata and Ngāi Tāmanuhiri who was raised to be a leader, my first subjectivity is my joy and pride in being Māori. In my zeal to embrace all Māori with diverse gender identities, sexualities and sex characteristics, I must be mindful of the ways colonisation has fractured Māori identity leaving some takatāpui without a strong sense of their Māori selves or estranged from their whānau, hapū and iwi.

As an activist of some 35 years and a self-employed consultant on Treaty of Waitangi relations for almost 15 years, my second subjectivity is my Mana Wāhine (Māori feminist) and decolonising approach to life and this thesis. I must be mindful of the different ways in which colonisation has been internalised by takatāpui who may be fearful of or resist change.

As a daughter, sister, cousin and mokopuna (grandchild/great grandchild) who experienced unequivocal whānau support when she came out as a teenager and who has openly engaged with different Rainbow communities for nearly 30 years, my third subjectivity is that I have always proudly identified as lesbian femme. I must be mindful of takatāpui who have suffered from a lack of whānau support; those who resist Rainbow terminologies; and those who abhor membership of Rainbow communities in favour of remaining within their whānau, Māori or other support systems. Notwithstanding the discrimination I have experienced as an out lesbian, I must also be mindful of how my cis-gendered privilege might obscure the systemic and other issues facing takatāpui who are whakawāhine, tangata ira tāne, trans, intersex, queer, gender diverse and non-binary.

As someone who adopted the identity when she first heard the term in the late 1980s, my fourth subjectivity is that I stand proudly as takatāpui. It is the platform on which I undertake all of my political and cultural work. I have dedicated my life to the promotion of takatāpui identity, health and well-being. I must be mindful of Māori with diverse gender identities, sexualities and sex characteristics who are new to the term or choose not to adopt it for themselves.

In 2001, I founded Tīwhanawhana Trust to provide a platform from which to uplift the mana of takatāpui through reconnecting with te reo Māori me ōna tikanga (Māori language and culture) and to advocate for takatāpui rights, health and well-being. My use of 'Rainbow' is 
based on our vision: "Tīwhanawhana ai he kahukura $i$ te rangi - a rainbow is forming in the sky (Tīwhanawhana Trust 2007:1)" which speaks to leadership, cultural values and inclusiveness of all people with diverse gender identities, sexualities and sex characteristics. Our goals are to "tell our stories, build our communities and leave a legacy (ibid)" as used in the introduction to this study. Tîwhanawhana remains the only organisation of its kind in this country. With a takatāpui Board of only five and an inclusive membership of takatāpui, their family and friends; Tīwhanawhana has created credibility and influence. Despite receiving no funding, we are currently involved in takatāpui projects in the sectors of health with a focus on trans and intersex healthcare; intersex rights, mental health; sexual health; secondary and tertiary education; youth development, suicide prevention; sexual, intimate partner and family violence; homelessness and housing; and justice in prisons and probation. As founder and Chair of Tīwhanawhana, my fifth subjectivity then is my belief that such organisations are critical in providing takatāpui leadership and building relationships across all sectors. I must be mindful that takatāpui will find many different ways of organising and such an organisation may be difficult to sustain outside of a main centre. I must also be mindful that the takatāpui community support systems we have created in Wellington and nationally do not necessarily reflect the needs of takatāpui in other parts of the country.

Since 2007 Tīwhanawhana has actively supported the queer and gender diverse youth movement of Aotearoa New Zealand. Around that time, I was appointed to several national roles in the youth sector which enabled me to advocate for Māori, takatāpui, queer and gender diverse youth. As a former youth activist, I am impressed with a generation of people coming out and transitioning when they are still young and appalled in equal measure with the high level of discrimination they experience for their courage. My sixth subjectivity then is my expectation that all older Rainbow members and organisations are responsible for nurturing our young people in their diverse glory. I must be mindful that while that is fundamental within a Māori cultural framework, some takatāpui may feel no responsibility to young people who are not Māori and non-Māori Rainbow community individuals and organisations may feel no responsibility or connection to young people at all.

Finally, Māori have been fighting against the impacts of colonisation from its beginnings and I follow in the footsteps of our tūpuna (ancestors) and kuia kaumātua (elders) to (re)claim a space for takatāpui as part of uplifting the health and well-being of all Māori. As a strategic thinker, a long-term planner and someone who gets things done, my final subjectivity is my belief that no matter how few we are, no matter how large the obstacle, and no matter how long 
it takes, our Māori culture and values will sustain us to the end. I must be mindful that many takatāpui are facing significant discrimination and dealing with trauma which impacts greatly on their ability to envision a future where all takatāpui experience optimum health and wellbeing within strong Māori and Rainbow communities.

\section{The What: My Contribution to Mātauranga}

This section summarises each thesis chapter and indicates my original contributions to the kaupapa of takatāpui identity and well-being. Some of these were summarised as Elizabeth Kerekere’s Top Takatāpui Tips (Kerekere 2015:38-39).

Chapter 1 outlines why this research was necessary and provides an accurate definition of takatāpui as it is used by those who claim takatāpui as both a personal identity and promote it as a national framework within which to organise and thrive. It highlights the particular struggles of takatāpui who are whakawāhine, tangata ira tāne, trans, intersex, queer and gender diverse within the binary society in which we live. It introduces the takatāpui leaders whose oral histories ensure authentic takatāpui voices emanate from this study and the whānau who support them. It examines the subjectivities involved in my role as both researcher and researched.

Chapter 2 introduces my Whāriki Takatāpui framework which likens a number of Māori research models to weaving of a whāriki - a mat used for every day or ceremonial purposes. The Whäriki Takatāpui framework likens Kaupapa Māori research to gathering of the tools and Kaupapa Māori theory as the harvest of the harakeke. Mana Wāhine represents preparation of the harakeke. It includes the historical legacy of colonisation on Māori expressions of gender and sexuality and I use my own customary ${ }^{22}$ Māori art practice to interpret the imagery of whakataukī (proverbs, sayings). Mana Motuhake represents the design and pattern of the weaving. It includes the use of the Multi-Dimensional Model of Māori Identity and Cultural Engagement (Houkamau and Sibley 2010) to consider subjective experiences of takatāpui identity in terms of Group Membership Evaluation, Socio-Political Awareness, Cultural Knowledge, Spirituality, Interdependence and Authenticity Beliefs. Te Whare Tapa Wha (Durie 1985) represents weaving of the whāriki; weaving takatāpui health and well-being. Whakamutunga brings everything together and ties up loose ends.

\footnotetext{
22 'Customary' Māori art encompasses contemporary art which is based on traditional Māori art forms and imagery
} 
Chapter 3 summarises what the literature tells us about the whakapapa of takatāpui within traditional Māori narratives including the use of the term takatāpui itself. I identify that takatāpui who are whakawāhine, tangata ira tāne, trans, intersex and queer embody tipua (creatures who could change gender or transform from one being to another) in remarkable ways. I contend that takatāpui were an accepted part of the whānau and did not have specific identities for the gender and sexual fluidity they enjoyed. Takatāpui was more likely a same sex version of whaiāipo (sweetheart/lover). It outlines the customary art process to examine the imagery of over 150 whakataukī to gain insight into gender and sexual fluidity in precolonial and post-arrival Māori society. I compared different translations and interpretations to find discrepancies. My most exciting contribution is that I have revealed three whakatauki which appear to confirm the presence of takatāpui behaviour.

In order to understand the historical and intersecting oppressions faced by takatāpui, I consider how the British hetero-patriarchal views of society and the imposition of the nuclear family undermined the status of Māori women in Māori culture and society. It also pathologised and made illegal a sexual and gender fluidity that had been an accepted part of traditional Māori society. I assert that the British colonial misogyny and heterosexism contributed to the historical trauma which sees many takatāpui not accepted by their whānau because of their diverse gender identities, sexualities and sex characteristics. Having said that, I posit that there may be a correlation between areas with high numbers of Māori women leaders in the past and the level of the acceptance of takatāpui in the present, particularly, for example in the Tairāwhiti. Given the impact of colonisation on the sexuality of takatāpui of all diverse gender identities, sexualities and sex characteristics, I assert that until gender and sexual issues are addressed for Māori women, it will be difficult to resolve issues for takatāpui. On that basis, I contend that Mana Wāhine is the platform for fighting discrimination against takatāpui through the restoration of balance between genders in Māori culture.

Chapter 4 introduces the six primary takatāpui leaders who took part in this study. Their earliest memories - both heart-warming and heart-breaking - provide a glimpse into the formation of their identity as Māori; including knowledge of whakapapa; the use of te reo in the home, and connection to their whānau, hapū and iwi. It follows their journey as they form awareness of their gender; and the dissonance experienced by those whose preferred gender did not conform to the gender they were assigned at birth. As their diverse sexualities emerge, it demonstrates the determination required to sustain them when not all of their whānau react with loving support. I assert that while takatāpui form their Māori identity in the complex ways of other 
Māori, their diverse gender identities and sexuality is generally formed at the same time and from a young age. Based on that, I contend that all Māori inherit their gender and sexuality from our tūpuna - it is part of our wairua.

Chapter 5 follows the participants into school where only some participants found a sanctuary of learning. It tracks their journey as they continue to pursue their Māori and diverse gender identities and sexualities within the education system and the workforce. It reveals how putting the theory of sexuality into practice (first love and heartbreak) was often the springboard for most participants to 'come out' to whānau and friends - with varied results. I identify some of the ways discrimination against takatāpui is manifested in whānau and Māori culture and society which can result in driving takatāpui away from that support base. I begin to identify the creative ways in which takatāpui have developed resilience within supportive whānau and through belonging to Rainbow communities that accepted them for who they were.

Chapter 6 traces the acceptance each takatāpui leader experienced within their whānau and in relation to other takatāpui in the whānau. It considers the complexity of whānau who would accept same-sex attracted behaviour while remaining negative toward people identifying as lesbian, gay, bisexual or trans. I argue that this phenomenon is less a result of discrimination (homophobia, biphobia, transphobia) and more of an anxiety toward visibility that is the historical legacy of whānau who protected their takatāpui members by accepting but not talking about or naming their diverse gender expressions, sexualities or relationships. I identify the survival techniques participants employed to maintain their Māori identity while being estranged from whānau; and the steps toward healing over the years. Although it has a direct impact on takatāpui, I identify that discrimination hurts all of our whānau when heterosexist stereotypes contribute to unwanted sex, unwanted pregnancies, violence and abuse. Finally, I express community concerns about the dramatic rise of suicide among takatāpui youth who could not survive long enough to develop the resilience against the discrimination they were experiencing within their whānau, schools and churches.

Chapter 7 follows the takatāpui leaders as they each encounter the term 'takatāpui' for the first time and ascertains their motivation for adopting it for themselves. It distinguishes the strength and confidence gained by participants as they personally embrace the unified identity of takatāpui and go on to join local communities and national networks. It confirms existing literature that spirituality is a primary aspect of Māori and takatāpui identity. I identify that claiming takatāpui identity is based on whakapapa, mana, identity and inclusion. For most takatāpui, 'being takatāpui' is predicated on 'being Māori'. Therefore, some struggle to claim 
takatāpui identity because they do not feel that they are 'Māori enough.' Through organisations such as Tīwhanawhana Trust, I note the importance of Māori culture to takatāpui and the ways in which those with cultural knowledge provide leadership within takatāpui communities. I posit that such organisations are critical for advocating tikanga and Treaty awareness and promoting takatāpui health and well-being which forms the basis of building an intergenerational takatāpui and Rainbow movement.

In fact, Māori have adopted homosexual, kamp, butch, femme, lesbian, gay, bisexual, trans and queer identities and been highly visible within those communities from the beginning. I contend that takatāpui have been part of defining how those identity terms and their associated communities have manifested in Aotearoa New Zealand.

Chapter 8 weaves together the many findings of this study to create a Whāriki Takatāpui. By drawing on whakapapa and tikanga, the Whāriki Takatāpui holds that takatāpui identity is fundamental to the improvement of takatāpui health and well-being. It identifies not only the discrimination experienced by takatāpui but also the creative ways in which takatāpui face the challenges before them. In conclusion, the Whāriki Takatāpui weaves a foundation for the elimination of homophobia, biphobia and transphobia and the building of resilience throughout our whānau, hapū, iwi and Māori and Rainbow communities.

\section{Maybe Next Time: What This Research is Not}

One of the major difficulties in undertaking this $\mathrm{PhD}$ was to reduce its scope. Broad as this study remains, I identify here key areas which I had naively planned to include but have set aside with regret and other areas which may appear to have been overlooked. I invite creative collaborations on any and all of the following:

To the scant literature available on gender and sexual fluidity in pre-colonial Māori society, I am proud to add my research on whakataukī. I do not explore gender non-conforming behaviour in pre-colonial Māori society such as women who were reputed to have fought beside men on certain occasions.

The definition of takatāpui provided here is as it is understood and lived by those who identify and organise as such. Apart from the commonly used terms of 'whakawāhine' and 'tangata ira 
tāne,' I do not investigate other Māori terms which have been reclaimed or created for lesbian, gay, bisexual, trans, intersex or queer; contemporary or otherwise. ${ }^{23}$

While this study acknowledges the work of takatāpui activists, academics and organisations, the following chapters do not include a comprehensive history of the achievements of whakawāhine, tangata ira tāne and Māori lesbian, gay, bisexual, trans, intersex and queer people who have worked inside or outside of Rainbow communities except where it impacts on the development of takatāpui identity and well-being. Their achievements are a source of pride for takatāpui and I encourage their stories to be told.

Talented as takatāpui are, I do not engage with their poetry, compositions, fiction or artwork, even on takatāpui topics except in regards to the work of Ngahuia Te Awekotuku $(1989,2003)$ whose pioneering work on Māori women and lesbian feminism is fundamental to an understanding of takatāpui identity.

My work emphasises takatāpui as a strengths-based Māori identity for those who chose to claim it and organise within its networks and cultural values. It does not seek to quantify how many people identify as takatāpui. It does not assess the percentage of Māori who are takatāpui or the percentage of takatāpui within the wider Rainbow communities of Aotearoa New Zealand. Although it considers the adoption of a Māori identity, this study does not compare takatāpui gender and sexuality to other Māori who are not takatāpui. It rarely compares takatāpui to our non-Māori Rainbow counterparts in Aotearoa New Zealand or elsewhere. It does not compare takatāpui to traditional Pacific identities with whom we are often and incorrectly conflated; the mahu of Hawaii and Tahiti; the vakasalewalewa of Fiji; the palopa of Papua New Guinea; the fa'afafine of Samoa and American Samoa; the akava'ine of the Cook Islands; the fakaleiti/leiti of the Kingdom of Tonga; or the fakafifine of Niue collectively known as MVP-FAFF. ${ }^{24}$

Except for a particular reference to the 'Two-Spirit' identity of North America and Canada which I consider to be the closest cultural, political and theoretical equivalent to takatāpui; this study does not compare takatāpui to traditional identities used by Indigenous or Black people

\footnotetext{
${ }^{23}$ See takatāpui Te Reo proponent, Rangitunoa Black (2007:25-34) for her discussion of traditional gender and sexuality terms, many of which were promoted on the television series Takatāpui which ran for four seasons from 2004 on the Māori Television Service. It is noted that her chapter is in te reo Māori without English translation

${ }^{24}$ MVP-FAFF was coined by Phylesha Brown-Acton in her keynote address regarding the use of traditional terms instead of Western terms such as trans women or trans feminine, Human Rights Conference, $2^{\text {nd }}$ Asia Pacific Outgames, March 2011, Wellington, Aotearoa New Zealand. A transcript of her speech is available at http://www.pridenz.com/apog_phylesha_brown_acton_keynote.html
} 
or people of colour around the world; particularly as doing so often necessitates reinforcing the work of academics who are not Indigenous, Black or of colour.

This research is grounded in Kaupapa Māori theory to consider takatāpui as a Māori identity. Most glaringly for some readers, I do not theorise about the formation of gender and sexuality or expressions of femininities and masculinities among takatāpui. I assert that those who claim takatāpui have already formed their diverse gender identities and sexualities and that takatāpui identity encompasses all fixed and fluid expressions and presentations.

On reading my first chapter outline, my supervisors pointed out that a draft National Takatāpui Strategic Plan was not a suitable conclusion for a $\mathrm{PhD}$. Therefore, I have planned that work separately and in 2016 I began development of a National Rainbow Strategy which will contain a National Takatāpui Strategy.

My greatest regret was not being able to interview more kuia kaumātua for this project, particularly those who were raised as native speakers of te reo Māori and steeped in traditional Māori culture. I look forward to opportunities to learn from their wisdom and insights into how to uplift takatāpui within our whānau and communities.

\section{He Hononga}

This introductory chapter begins to provide insight into several of the research questions within the Whāriki Takatāpui framework to do with Kaupapa Māori Theory, Mana Wāhine, Mana Motuhake and Te Whare Tapa Whā.

The appropriate use of te reo necessitates an accurate definition of takatāpui as it has evolved from those who claim this identity and from within the communities which promote its use. A narrow definition of takatāpui that excludes an analysis of gender necessarialy excludes Māori who are trans, intersex or gender diverse. Exclusive definitions only serve to alienate already marginalised takatāpui, thus perpetuating isolation, lack of support and power imbalances. An inclusive definition broadens opportunities for visibility and connection. On that basis and reinforced by the findings of this study, I advance the following definition:

Takatāpui embraces all Māori with diverse gender identities, sexualities and sex characteristics including whakawāhine, tangata ira tāne, lesbian, gay, bisexual, trans, intersex and queer. It emphasises Māori cultural and spiritual identity as equal to - or more important than - gender identity, sexuality or having diverse sex characteristics. Being takatāpui offers membership of 
a culturally-based national movement that honours our ancestors, respects our elders, works closely with our peers and looks after our young people (Kerekere 2015, 2016).

Whakapapa is important to takatāpui because it is important to being Māori and therefore to Māori identity. Having established that the term takatāpui existed centuries before, whakapapa becomes a defence against those who would discriminate today. Takatāpui may learn from the past that 'takatāpui' is an ancient term in such common usage that it first appeared in the second Māori dictionary in 1852 and was defined as 'intimate partner of the same sex' in the third edition in 1871. When separately discovered by takatāpui academics Ngahuia Te Awekotuku and Lee Smith, they gifted it to Maori in lesbian, gay and transgender communities through network and community hui. The first reference to takatāpui in print was Te Awekotuku in 1991 who has always characterised it as including all diverse gender identities and sexualities.

This study provided the voices of 14 takatāpui of diverse gender identities and sexuality, and aged 17 to 64 years of age - including my own. In order to subvert the power imbalance between the researcher and the researched, I have answered the same questions as the other participants. Every participant explains why they have claimed takatāpui identity.

The issues that impact on takatāpui health and well-being include a lack of research to advocate for the resources and funding necessary to address those issues. This study emphasised that it is incumbent upon cis-gendered takatāpui to use any privilege they may have to uplift takatāpui with diverse gender identities and sex characteristics who may or may not identify as trans or intersex - or takatāpui for that matter. 


\section{CHAPTER 2: MAHI RARANGA WHATU: THE HOW}

This study aims to create a Whäriki Takatapui; the woven mat upon which to base future research and advocacy for takatāpui. The use of weaving metaphors in Māori culture and Aotearoa New Zealand society is common and they have been applied across multiple sectors. Te Whăriki, the early childhood curriculum document for Aotearoa New Zealand was developed in the early 1990s (Nuttall 2013); He Korowai Oranga: Māori Health Strategy in the early 2000s (Ministry of Health 2002); I developed the Whatu Raranga Strategic Framework ${ }^{25}$ in 2012 for Ara Taiohi - the peak body for youth development; Te Käwhatuwhatu was developed in 2015 to advocate for Māori tikanga cultural practices in weaving classes and teaching pedagogy (Turi-Tiakitai 2015). By creating such frameworks, as weavers and researchers, we acknowledge Hineteiwaiwa, the goddess of childbirth and Te Whare Pora (the women's house of learning for weaving and the arts).

As an academic parallel to this study, I acknowledge Qwo-Li Driskill's (2010) use of Cherokee 'doubleweaving' as a metaphor for conversations between Native studies and queer studies:

To contribute to decolonial and tribally specific theories, I would like to look to Cherokee doublewoven baskets as a model for articulating the emergent potential in conversations between Native studies and queer studies. As a rhetoric scholar and a basket weaver, I am particularly interested in the rhetorical work involved in doubleweaving. For my purposes, here I would like to conceive of the conversation between queer studies and Native studies as a doubleweaving that can result in emergent critiques both within and between these disciplines... Using doubleweave as a metaphor enables me to articulate a methodological approach that draws on and intersects numerous theoretical splints - what Smith [1999:13] calls dissent lines - in order to doubleweave queer and Native concerns into a specifically Indigenous creation (2010:73-74).

For this study, Kaupapa Māori research and Kaupapa Māori theory lay the groundwork for producing a whāriki. The Whāriki Takatāpui is formed from three 'papa' (flat sections) which are held together by 'hononga' (connections/joins). The three papa - Mana Wāhine, Mana Motuhake and Te Whare Tapa Wha - each represent a stage in the weaving process. Hononga conclude each chapter and connect the papa through the research questions as outlined in the diagram below.

\footnotetext{
${ }^{25}$ Whatu Raranga Strategic Framework: http://www.arataiohi.org.nz/about-us/what-we-do/goals-andstrategies
} 


\begin{tabular}{|c|c|c|}
\hline Title \& Research Questions & Weaving Process & Kaupapa \\
\hline Kaupapa Mäori Research & Gathering the tools & Māori research models \\
\hline Kaupapa Māori Theory & Harvesting the harakeke & $\begin{array}{l}\text { Te reo Māori, tikanga and } \\
\text { mātauranga }\end{array}$ \\
\hline $\begin{array}{l}\text { - Why is whakapapa imp } \\
\text { - What can takatāpui lear }\end{array}$ & Preparing the harakeke & $\begin{array}{l}\text { Whakapapa and the impact of } \\
\text { colonisation on understandings } \\
\text { of Māori gender and sexual } \\
\text { fluidity }\end{array}$ \\
\hline $\begin{array}{l}\text { Mana Motuhake } \\
\text { - Why do Māori with div } \\
\text { and sex characteristics c } \\
\text { - What does 'being taka } \\
\text { Māori'? }\end{array}$ & $\begin{array}{l}\text { Designing patterns and colours } \\
\text { erse gender identities, sexualities } \\
\text { aim takatāpui identity? } \\
\text { âpui' mean in relation to 'being }\end{array}$ & $\begin{array}{l}\text { The subjective formation of } \\
\text { takatāpui identity }\end{array}$ \\
\hline $\begin{array}{l}\text { Te Whare Tapa Wha } \\
\text { - What are the key issues } \\
\text { and well-being? } \\
\text { - How do takatāpui addre }\end{array}$ & $\begin{array}{l}\text { Weaving the whāriki } \\
\text { that impact on takatāpui health } \\
\text { s the challenges facing them? }\end{array}$ & $\begin{array}{l}\text { Takatāpui health and well- } \\
\text { being }\end{array}$ \\
\hline $\begin{array}{l}\text { Whakamutunga } \\
\text { - How can takatāpui ident } \\
\text { for all Māori with dive } \\
\text { and sex characteristics }\end{array}$ & $\begin{array}{l}\text { Finishing off } \\
\text { ty promote health and well-being } \\
\text { rse gender identities, sexualities } \\
\text { ithin whānau and society? }\end{array}$ & Findings and conclusion \\
\hline
\end{tabular}

\section{Kaupapa Māori Research: Gathering The Tools}

As a Māori scholar researching a Māori identity on behalf of a national Māori network, Kaupapa Māori research offered me the obvious and most appropriate framework for this study:

When I think about kaupapa Māori research, I see it really simply: it's a plan; it's a programme; it's an approach; it's a way of being; it's a way of knowing; it's a way of seeing; it's a way of making meaning; it's a way of being Māori; it's a way of thinking; it's a thought process; it's a practice; it's a set of things you want to do. It is a kaupapa and that's why I think it is bigger than a methodology (Smith, L.T. 2011:10).

Kaupapa Māori research represented the tools required to weave a Whāriki Takatāpui and the most important element is the fibre plant harakeke ${ }^{26}$ itself. It is plentiful and used in a myriad

\footnotetext{
${ }^{26}$ Harakeke: phormium tenax is a fibre plant native to Aotearoa New Zealand and commonly known as flax
} 
of ways; from the putiputi (flowers) which can be woven in minutes; to the practical rourou (food basket); sturdy waikawa (vegetable carrier); delicate kete (handbag); to the painstaking korowai (cloak) which could take a year to create.

Kaupapa Māori research emcompassed a range of research models, three of which which I have adapted for this study. Its flexibility has informed the design, tools and methodology of this study as outlined in Chapter 1 .

\section{Kaupapa Māori Theory: Harvesting Language \& Culture}

In this study, Kaupapa Māori theory represented the appropriate harvest of the harakeke needed to weave the Whäriki Takatāpui:

Kaupapa Māori theory is a Māori theoretical framework that is grounded in te reo and tikanga Māori... [it] is informed by its indigenous underpinning and is defined and controlled by Māori... Kaupapa Māori theory is based upon and informed by mātauranga Māori that provides a cultural template, a philosophy that asserts that the theoretical framework being employed is culturally defined and determined (Pihama 2010:5).

Within Kaupapa Māori theory, 'Taonga Tuku Iho - The Principle of Cultural Aspiration' asserts the centrality and legitimacy of the gifts we have inherited from our tūpuna: te reo Māori, tikanga and mātauranga Māori (Māori language, culture and knowledge) (Smith, G.H. 1990). These gifts provide the cultural safety I needed to undertake this study.

Te reo Māori provides the appropriate terms and karakia (traditional incantation) associated with the harvest and the weaving processes. In this study, this is directly related to providing a contemporary definition of the term 'takatāpui' as addressed in Chapter 1. Tikanga provided structure and guided me within the protocols developed by countless generations of weavers who have gone before me. In this study, tikanga is considered in light of the negative impact of colonisation that has allowed homophobia, biphobia and transphobia to become part of Māori society. Finally, this study contributes to the mātauranga available for all Māori.

\section{Te Reo Māori: A Genderless Language?}

Every language provides insights into the society and culture from which they emerged. Because Māori were colonised by the English, te reo Māori (the Māori language) - has necessarily been impacted on by the English language. In his introduction to Part One of $N g \bar{a}$ 
Mōteatea The Songs, Apirana Ngata (1928, revised 2004) bemoans te reo Māori being reduced to "an infant walking" from European influence but states that the songs encapsulated a "high level of Māori writing." He admits to "toning down the text of the songs published in this work because our behaviour has been changed by the European' (Ngata 2004:xvii). He cites cannibalism as an example. As noted in Chapter 3 will show, entries to do with diverse sexuality were also changed over time.

Ngata (1986) stressed the importance of context in translation and interpretation because Māori had significant differences from both the language and lifestyle of the English. One example is the use of the personal pronoun 'ia' to denote 'her', 'hers', 'him', 'his' and 'it.' This genderneutral terminology was emphasised as relevant to takatāpui by the former Hauora Takatāpui (HOT) team at the New Zealand AIDS Foundation (Harris et al 2005). Te reo Māori has very few gender-specific terms overall, kuia female elder and koro male elder being notable exceptions. That no individual words existed for the terms of 'mother', 'father', 'wife', 'husband', 'daughter', 'son', 'sister', 'brother', 'aunty', 'uncle' shows that the British nuclear family was not the standard in Māori society. Instead, generic terms were used: wahine woman/wife; tane man/husband; kōtiro/hine/tamatahine girl/daughter; tama boy/son; tuahine sister (of a boy)/female cousin; tungāne brother (of a girl)/male cousin; matua parent and those of the same generation; kaumātua grandparents and those of the same or older generation.

The order of birth was considered to be much more important, as specific words did exist for the eldest child mataamua and the youngest pōtiki. The elder sisters of girls and brothers of boys were their tuakana while the younger sisters of girls and brothers of boys were their teina. Each of these positions came with specific rights and responsibilities.

Such clarifications are important to this study when assessing the translations and interpretations given for a range of traditional Māori narratives, as they are likely to reflect any gender bias of the interpreter.

\section{Tikanga: Making Judgment}

Mead (2003) introduces tikanga as a means of social control for interpersonal relationships, ways for groups to meet and interact, and to determine how individuals identify themselves:

'Tika' means 'to be right' and thus tikanga Māori focuses on the correct way of doing something. This involves moral judgements about appropriate ways of behaving and acting in everyday life (2003:5-6). 
Although tikanga also dealt with processes for correcting and compensating for bad behaviour, moral judgement is at issue here. Anne Salmond (1985:248) notes that "the meanings of tika shade from 'just' to 'customary' to 'true' and that it was a judgment of propriety as well as of accuracy of account." While colonisation imposed significant judgment against the overall sexual conduct of Māori, it also pathologised any gender or sexual fluidity that existed in traditional Māori society. In her analysis of how heteropatriarchy can be seen "creeping into interpretations of tikanga and kōrero tawhito" 27 in reference to sexuality (2012:60), Kim McBreen notes:

We need to be clear that homophobia does not come from tikanga. It comes from the colonisers. Whakapapa is about inclusion - there needs to be a really good reason to exclude or demean someone in any way. Who they sleep with is not a good reason (2012:63).

Royal (1998) suggested that Māori knowledge was created by Māori to explain their experience of the world and the world's experience of Māori: "He mea hanga te mātauranga Māori nā te tangata Māori kia marama ai ia ki tōna Ao, kia mārama rānei te Ao ki a ia" (1998:2). Most importantly for takatāpui, gender and sexual fluidity became no longer 'tika' when the mātauranga that made sense of it was suppressed or disguised. The loss of mātauranga then impacted on subsequent tikanga which, as this study shows, continues to impact on takatāpui today.

\section{Mana Wāhine: Preparing to Fight Back}

The arduous preparation of the harakeke for a whāriki is represented by Mana Wāhine and it is often the most time-consuming part of any weaving process. While preparing the 'whenu' (harakeke strands for weaving), considerably more 'para' (waste product) is produced. In this study, I liken the whenu to whakapapa (genealogy/relationships) which must be extricated from the para; a colonial history which has included the subjugation of Māori women, the suppression of gender and sexual fluidity, and the criminalisation of same-sex attraction and gender non-conformity (Hawkins 1995:93-94, Te Awekotuku 2005:7). While whakapapa has strong cultural importance, it is mediated by colonial and racist forms of homophobia, biphobia and transphobia. This section then directly responds to the research questions: 'Why is whakapapa important to takatāpui?' and 'What can takatāpui learn from the past?'

\footnotetext{
${ }^{27}$ Kōrero tawhito: pre-colonial or traditional Māori discourse
} 
Many researchers have considered the impact of colonisation on Māori women with its ongoing erosion of Mana Wāhine and the extended whānau (including Mikaere 1994; Pihama 2001; Smith, L.T. 1992, 1999). Some readers will wonder why I have used a Māori feminist framework for considering an identity as inclusive and gender diverse as takaāpui. My reasons are twofold. The first is that much of the framing and promotion of Mana Wähine has been developed by takatāpui academics and community leaders including Ngahuia Te Awekotuku (1991, 2003) and Leonie Pihama (2001). The second is that we cannot hope to provide full cultural support and advocacy for takatāpui who are trans, intersex and gender diverse if we do not restore the balance of Māori women as equal to and not subservient to men:

And no one can deny that in the last two centuries Māori women have lost, or been deprived of, economic, social, political and spiritual power; and this loss, this erosion of power - or mana - or authority, invites a feminist analysis, or feminist view, of what has happened. So Māori women are being put down for being female. Recognizing that, and wanting to work through it, is becoming a feminist. In a Māori way. There is no contradiction; for that is the message in the phrase, 'Mana Wāhine Māori' - reclaiming and celebrating what has been, and what we will become. It is not a re-action to males, and their violence against us; it is a pro-action, a determining of ourselves as Māori women, with authenticity and grace. And its ultimate aim is a rediscovery and renaming of that essential strength and harmony, that complementary relationship between genders, that may have occurred on these islands two centuries past (Te Awekotuku 1991:10).

\section{The Other Side of the Family: Colonial Impact}

Alongside any evidence of takatāpui existence must come an intersectional analysis of the impact of colonisation on Māori people and our culture. The term 'intersectionality' was coined by Black feminist Kimberlé Crenshaw (1989), to explain that the discrimination faced by Black women is not just sexism but a complex intersection of sexism and racism. Since the Combahee River Collective was formed in 1974 and made its landmark statement of 1977, Black lesbian feminists, lesbians of colour and Indigenous queers have increasingly identified the need for a deeper level of analysis: 
The development of integrated analysis and practice based upon the fact that the major systems of oppression are interlocking...We...often find it difficult to separate race from class from sex oppression because in our lives they are most often experienced simultaneously (Combahee River Collective 1986:13,16).

An intersectional analysis could be deepened to include class, age, ethnicity, gender, sexuality and ability. In this study, I use intersectionality as an interlocking framework that centres indigeneity in relation to diverse gender identities, sexualities and sex characteristics. However, I note that indigeneity is generally invisibilised in its widespread focus on race (rather than ethnicity or culture), class and sex:

Within queer studies, critiques examining the intersections of race, sexuality, and empire...have at once held promise, and then disappointed, those of us concerned with bringing Native studies and queer studies into critical conversations... Our disappointment lies in the recognition of an old story within "the new queer studies:" Native people, Native histories, and ongoing colonial projects happening on our lands are included only marginally, when included at all" (Driskill 2010:70).

In this study, Intersectionality is a means of conceptualising the interwoven forms of discrimination faced by takatāpui with a particular focus on how colonisation relates to homophobia; biphobia and transphobia in Aotearoa New Zealand. All commentators appear to concur on the impact of colonisation on Māori with diverse sexualities (see Aspin and Hutchings 2010:416, McBreen 2012, 2013; Te Awekotuku 1991; 2005) and on takatāpui overall (Kerekere 2015).

Although takatāpui share the racism experienced by other Māori, they also encounter the homophobia, biphobia and transphobia faced by other members of Rainbow communities. Intersectionality provides insight into how that manifests for takatāpui, particularly when that discrimination comes from within the whānau. In the absence of takatāpui critiques on intersectionality, I look to Two Spirit and Queer Indigenous leadership:

Indigenous Two-Spirit/GLBTQ people are asserting uniquely Native-centred and tribally specific understandings of gender and sexuality as a way to critique colonialism, queerphobia, racism, and misogyny as part of decolonial struggles...Indigenous Two-Spirit/GLBTQ people share experiences under heteropatriarchal, gender-polarized colonial regimes that attempt to control Native nations (Driskill 2010:69) ... Two-Spirit critiques see Two-Spirits as valuable participants in struggles for sovereignty and decolonization, even while they call into account the heterosexism and gender oppression taking place in Native communities (ibid 2010:81). 
One particular aspect of how that discrimination manifests is through attempts to invisibilise historical takatāpui behaviour. This point is critical because takatāpui experience a specific form of discrimination - usually from Māori - based on the assumption that gender and sexual fluidity never occurred in pre-colonial Māori society.

It is emphasised that I do not use Intersectionality to define the interlocking identities takatāpui hold because Māori and diverse gender identities, sexualities and sex characteristics are not mutually exclusive. Takatāpui is not an intersection of where Māori identity meets sexual orientation and gender identity or diverse bodies at a given point. Such a viewpoint would suggest that 'Māori' is inherently heterosexual and cis-gendered. Rather, this study asserts takatāpui are a 'subset' of their whānau, hapū and iwi; that being diverse is part of being Māori.

\section{Whakapapa: Reclaiming Our Histories}

Whakapapa is a foundation of Māori culture which is affirmed by the degree to which takatāpui construct their identity through whakapapa and 'tūpuna takatāpui' - ancestors and historical figures who had fluid genders or sexuality or who embodied both female and male. Previous studies concur on the importance of whakapapa to Māori with diverse sexualities (Aspin and Hutchings 2010:422; Henrickson 2006:259; Kerekere 2009, 2015:6; Te Awekotuku 1991:37). Generally translated as 'genealogy', whakapapa literally means to place layers. Reclaiming whakapapa often means uncovering those layers to trace back into the past. Takatāpui are by no means the first to reclaim such a metaphoric whakapapa. Māori weavers may claim ancestry from the weavers of the past or direct descent from Hineteiwaiwa herself - the goddess of childbirth and Te Whare Pora (house of learning for weaving and women's arts).

If tikanga is based on mātauranga and tikanga must adapt to address discrimination, then it is incumbent on takatāpui to find and reveal the mātauranga necessary. Other than the shared finding of the term 'takatāpui' itself around the same time as Lee Smith; the only evidence of takatāpui existence in historical Māori narratives has been found by Ngahuia Te Awekotuku in her research on mōteatea (traditional incantations, songs and chants) and whakairo (carving) (Te Awekotuku 2005:8).

To that small but treasured collection of evidence, I add my own analysis on whakataukī (proverbs/sayings). Rather than taking a linguistic approach, part of rising to Te Awekotuku's challenge to "reinterpret the oral history of this land (1991:37)" is based on my perspective as 
a customary Māori artist. ${ }^{28}$ By reviewing the imagery in over 150 whakataukī (proverbs/sayings), I hoped to gain insight into our tūpuna's thoughts about relationships, gender roles, sex and sexuality. This analysis is provided in Chapter 3.

\section{Mana Motuhake: Designing Identity in a Colonised Land}

The design and pattern of the Whāriki Takatāpui is represented by Mana Motuhake (self determination). For this is no plain or every day whāriki. This Whāriki Takatāpui is an explosion of colour and intricacy of design. This is necessary for a community who face intersectional discrimination and are often estranged from their whānau - and therefore their whakapapa and culture - because of their diverse gender identities, sexualities and sex characteristics. This design process directly responds to the research questions 'Why do Māori with diverse gender identities, sexualities and sex characteristics claim takatāpui identity?' and 'What does 'being takatāpui' mean in relation to 'being Māori'?'

\section{Standing Out: Survival Through Identity}

Some of the greatest Māori minds have long identified the importance of Māori identity for Māori survival, including Durie (1994), Karetu (1990), Pere (1988), Rangihau (1975) and Walker (1989). While these proponents emphasise the importance of connection to whānau, hapū and iwi and Māori cultural knowledge, they also remain cognisant of the enduring legacy of colonisation which has led to negative outcomes for Māori in areas of health, mental health, education, justice and employment.

Durie (1994) first suggested three 'subgroups' to categorise Māori identities. The first he named 'culturally Māori' in that they understood whakapapa (genealogy), and were familiar with te reo Māori (Māori language) and tikanga Māori (Māori culture and protocols). The second sub-group were 'bicultural;' those who identify as Māori but also operated effectively among Pākehā (white New Zealanders of primarily British descent). Durie described the third sub-group as 'marginalised' and not able to relate to Māori or Pākehā. Williams proposed three similar typologies which he termed 'traditional Māori core,' 'bicultural' and 'unconnected.' ${ }^{29}$

\footnotetext{
${ }^{28}$ Customary Māori art is contemporary work based on traditional Māori art forms and processes

${ }^{29}$ Williams, J. "The Nature of the Māori Community" Paper presented to PSSM Conference, New Zealand State Services Commission, October 2000, Wellington.
} 
He also described a large group who were socially and culturally indistinguishable from Pākehā. Tracey McIntosh (2005) proposed a framework which considered Māori identity as 'fixed, fluid and forced':

Identities, then, by their very nature, are in a state of flux yet there is a tendency to try to apply rigid labels. Whether we examine identity through a personal or collective framework, we can note that they respond to, and are shaped and informed by, the socio-political realities in which they are embedded. That some identities are more clearly marked than others signals that identity formation is a political process (2005:39).

In the 2013 Census, Statistics New Zealand reported that those claiming Māori descent or ancestry numbered 668,724 while those claiming Māori ethnicity or identity numbered 598,605 (2013:4). Of those who identified with Māori ethnicity, 110,928 were unable to name their iwi. Previous Census had consistently found that those who have a strong Māori identity have better health outcomes and better life satisfaction. Generally, it was found that life satisfaction for Māori was linked inextricably to being Māori or feeling Māori:

The more important Māori felt it was to be involved in Māori culture, the higher their levels of life satisfaction...We found no significant association between life satisfaction and the other measures of connecting with Māori culture (te reo Māori speaking proficiency and if they had ever been to their ancestral marae). This suggests that the impact on life satisfaction that comes from Māori culture is through a way of thinking rather than any specific behaviour (emphasis added - Statistics New Zealand 2013:16).

For the first time in 2015, Statistics New Zealand compiled detailed statistics on Māori subjectivities although gender and sexuality were excluded. The key findings were consistent with studies internationally and in Aotearoa New Zealand that confirmed that relationships, health and income had the strongest association with life satisfaction.

\section{In our Own Words: Takatāpui Colours \& Patterns}

In the same way as some people with Māori ancestry do not claim Māori identity, so many Māori with diverse gender identities, sexualities and sex characterstics may not claim a takatāpui identity - if in fact they are even aware it exists. And if there are many different ways to 'be' Māori, we should expect that there are many different ways to 'be' takatāpui. In this study then, takatāpui identity is considered from a subjective point of view. 
Through the use of a subjective Māori identity framework developed by Carla Houkamau and Chris Sibley (2010) Multi-Dimensional Model of Māori Identity and Cultural Engagement (MMM-ICE), I aim to weave the existing elements of this study with dimensions of identity and cultural engagement. The identity dimensions are: group membership evaluation; sociopolitical consciousness; cultural efficacy and active identity engagement; spirituality; interdependent self-concept; and authenticity beliefs (ibid 2010: 20-21).

MMM-ICE is based on Houkamau and Sibley's study of existing mechanisms for (predominantly external) measurement of Māori identity. After rigorous testing, MMM-ICE was designed as an Indigenous self-report instrument that operationalises and reliably assesses key dimensions which Māori consider (to varying degrees) to be important in their subjective experience of identification and cultural engagement as Māori (ibid 2010:8). Houkamau and Sibley go beyond knowledge of Māori cultural features and Māori cultural engagement to incorporate subjective feelings of being a group member, attitudes, group allegiances, as well as collective identification and role-related self-perceptions, political attitudes and beliefs (ibid 2010:12). While this study adapts the dimensions Houkamau and Sibley have identified, I acknowledge that MMM-ICE has far greater potential than my present application.

For the purposes of MMM-ICE, Houkamau and Sibley view as Māori those who self-identify as Māori and/or whakapapa Māori (have Māori ancestry). My definition of takatāpui embraces those with diverse gender identities, sexualities and sex characteristics who identify as Māori and/or whakapapa Māori - regardless of their knowledge of that whakapapa or of te reo Māori or tikanga Māori. For this study, the key participants meet these criteria and also specifically identify as takatāpui. Their responses to semi-structured interviews have been analysed under the six following distinct dimensions of identity and cultural engagement (paraphrased from Houkamau and Sibley 2010:20-21); group membership evaluation; socio-political consciousness; cultural efficacy and active identity engagement; spirituality; interdependent self-concept; and authenticity beliefs.

\section{Group Membership Evaluation}

This dimension considers the subjective evaluation of one's membership of the social groups 'Māori' and how central that membership is to their self-concept of 'being' Māori. In this study, I apply this analysis to membership of takatāpui social groups and the self-concept of 'being' takatāpui. This includes the perceptions of others to them being takatāpui and any discrimination they may face because of it. 


\section{Socio-Political Consciousness}

This dimension considers the perceived relevance and continued salience of the historical (socio-political) context of 'being' Māori to conceptions of the self. The relevance is reflected in the extent to which participants see those historical factors impact on them today and to what level they engage with those impacts. In this study, I apply this analysis to the socio-political context of 'being' takatāpui to conceptions of the self particularly in terms of whakapapa and the impact of colonisation.

\section{Cultural Efficacy \& Active Identity Engagement}

This dimension considers the level to which participants feel they have the personal resources to engage with other Māori in terms of te reo, knowledge of tikanga and marae protocols, the ability to recite whakapapa and engage with other Māori values and practices. In this study, I apply this same analysis to takatāpui.

\section{Spirituality}

This dimension considers engagement with, and belief in, certain Māori concepts of spirituality such as connection with whenua (land), tūpuna (ancestors), Māori traditions, and the sensation and experience of waahi tapū (sacred places) including urupa (cemeteries). In this study, I also apply this analysis to engagement with, and belief in, connection with takatāpui tūpuna.

\section{Interdependent Self-Concept}

This dimension considers how their concept of 'being' Māori is based on relationships with other Māori, rather than being defined solely as a unique and independent individual. In this study, I apply this analysis to their concept of 'being' takatāpui in relation to other Māori and to other takatāpui.

\section{Authenticity Beliefs}

This dimension considers the extent to which the participants believe that to be a 'real' or 'authentic' Māori, they must display specific features, knowledge and behaviour. This indicates the perceived rigidity or fluidity identity provides. In this study, I consider whether authenticity beliefs exist for those who identify as takatāpui and whether such beliefs create barriers to takatāpui identity or sense of belonging. 


\section{Te Whare Tapa Whā: Weaving Health \& Well-Being}

Once the harakeke is prepared and the design finalised, the weaving of the Whäriki Takatāpui is represented by Te Whare Tapa Whā. Deceptively simple, Te Whare Tapa Wha is the holistic Māori health model developed by Meihana (Mason) Durie in 1984. It has been integrated into the public health system of Aotearoa New Zealand for some decades (Ministry of Health 2002:12). As takatāpui scholar, Marewa Glover (2013) reiterates in relation to tobacco smoking:

A number of Māori models of health have been developed (reviewed in Durie 1994). Te Whare Tapa Whā however, has achieved status as a paradigm... Te Whare Tapa Whā is applied to a variety of situations to reveal a Māori perspective. It became widely accepted as the preferred Māori definition of health in the 1980s (Durie 1994) and has since achieved wide and common usage as a Māori model of health. (References contained in original) (2013:116).

Durie (1985) identifies four interlocking 'Taha' (sides/dimensions) to the 'Whare' or Wharenui (meeting house) of Māori health and well-being: Taha Wairua, Taha Hinengaro, Taha Whānau and Taha Tinana. This weaving of taha responds directly to the research questions: 'What are the key issues that impact on takatāpui health and well-being?' and 'How do takatāpui address the challenges facing them?'

\section{Taha Wairua: Spiritual Realms}

Taha Wairua refers to the spiritual dimension; the relationship with deities or higher beings, ancestors and the land; and the interconnectedness of all things. The importance of spirituality to Māori with diverse sexualities is summarised by Henrickson (2006):

Unsurprisingly, cultural affiliation is significantly stronger among Māori than for tauiwi; importantly, however, culture and spirituality play a more important role for Māori respondents as they negotiate their identities. Tauiwi appear to be more defined by their sexual identities than are Māori. Māori balance ethnic and sexual culture in a "both/and" way, something that tauiwi do not, or do not need to do (2006:261).

Previous studies have consistently noted the impact of Christian beliefs on Māori gender and sexuality as an integral (and on-going) part of colonisation (Aspin 1996:45). Despite the homophobia, biphobia and transphobia fostered by organised religion, ${ }^{30}$ takatāpui identity has

\footnotetext{
${ }^{30}$ See Hutchings and Aspin 2007 regarding the most virulent of these in contemporary times: Destiny Church
} 
been increasingly claimed. In this study, the Wairua principle guides my analysis of spirituality in relation to takatāpui:

Most Māori are aware of their gender and sexuality from a very young age - it is part of wairua: the spirit, soul or essence we were born with that exists beyond death. It is not a choice. For those who identify with the gender they were assigned at birth (cisgender) or those who show an attraction to the 'opposite sex' (heterosexual), this is welcomed as the normal course of events. Wairua can be damaged when whānau react badly to a child who identifies in ways that are unexpected (Kerekere 2015:10).

\section{Taha Hinengaro: Failing to Read Our Minds}

Taha Hinengaro refers to the pyschic dimension. Earlier literature has noted the impact of discrimination on the mental health of takatāpui as evidenced by depression, self-harm and suicidality (Hawkins 1995:94; Kerekere 2015:20) and trauma (Reynolds 2012:9).

In this study, Taha Hinengaro guided my analysis of the mental health needs of takatāpui; from kuia kaumātua recovering from historical discrimination to takatāpui rangatahi who are experiencing discrimination and trauma today. It provided insight into the particular mental distress caused by rejection from whānau who cannot accept their takatāpui members. More importantly it made sense of the psychic dissonance experienced by takatāpui who are trans, gender diverse and intersex; whose psychological sense of themselves may not align with their physical body or the gender they were assigned at birth.

\section{Taha Whänau: Maintaining the Tension}

Taha Whānau refers to the family dimension. Whānau within this health model focused on the individual relationships takatāpui had within their own whānau - their parents; immediate and extended family whose opinions and attitudes matter the most:

If all whānau members are to have equal access to good health outcomes, it is vitally important that communities include and embrace all whānau members rather than exclude them because of their sexuality (Aspin and Hutchings 2010:425).

Taha Whānau informed my analysis of takatāpui attitudes to their whānau and of whānau to their takatāpui members. Critically, it framed the impact on takatāpui when whānau support 
was withdrawn because of their diverse gender identities, sexualities or sex characteristics. As Gaye Hawkins noted in relation to takatāpui who were transsexual:

Rejection from immediate whānau members may take years to overcome. Eventually the influence of wider members of the whānau structure may persuade families to be more accepting - these members may also assist to awhi them back to their whānau (Hawkins 1995:94).

This study looks to Taha Whānau to also provide the solutions to how whānau can provide supportive environments for their takatāpui members.

\section{Taha Tinana: Embodying Identity}

Taha Tinana referred to the bodily dimension. Previous studies specific to takatāpui have focused primarily on the sexual health of Māori gay, bisexual or MSM (men who have sex with men) in the context of HIV/AIDS (Aspin 1996, Aspin et al 1998) and sexual coercion (Fenaughty et al 2006). The Great, Late Lesbian and Bisexual Women's Discrimination Survey first noted the higher rates of assaults, threats of violence and verbal abuse against Māori lesbians and bisexuals (Rankine 2001:137). This was reiterated in Lavender Islands: Portrait of the Whole Family which included 169 Māori lesbians, gays and bisexuals (Henrickson 2006:257). The lack of culturally appropriate health services was consistently noted.

Taha Tinana guides my analysis of the varying physical health needs of takatāpui across gender; sexuality; ability and age. Issues range from housing to disability support to access to culturally appropriate health services. Whereas intersex people are likely to have experienced unwanted 'gender normalising' surgery from infancy through their teenage years, trans people struggle to gain the medical interventions they require to express their preferred gender identity.

\section{Whakamutunga: Tying Up Loose Ends}

The conclusions and findings of this study that complete this Whäriki Takatāpui represent finishing off and tying up the loose ends - literally. The final whāriki provides a transformational platform created by those who identify as takatāpui for all Māori with diverse gender identities, sexualities and sex characteristics. 
Within the overall framework of Kaupapa Māori theory, I have constructed a complex design for this Whāriki Takatāpui that encompasses takatāpui health and well-being; the context of discrimination within which takatāpui exist; and the formation of takatāpui identity.

This study is not an end in and of itself. In conceiving how takatāpui identity could improve the health and well-being of all Māori with diverse gender identities, sexualities and sex characteristics, it will contribute to the transformation of whānau, hapū and iwi:

Kaupapa Māori is transformative. To think and act in terms of Kaupapa Māori while experiencing colonisation is to resist dominance. This is not something in which Māori alone are engaging. It is the experience of vast numbers of indigenous peoples across the world (Pihama 2010:6) ... The transformation or emancipatory intent of Kaupapa Māori Theory may be viewed as a decolonisation process; however, it is not solely about the theorising for transformation but it is directly related to the development of practical interventions (ibid: 2010:12).

Part of that transformation will be to eliminate the complex intersection of discrimination that takatāpui face. A daunting task perhaps but as Linda Tuhiwai Smith exhorts us, we must:

Emancipate and liberate our imaginations...We've got to be able to think about how we get through this: to be able to use our minds. To me, that is ultimately the power of Kaupapa Māori research. It has provided us a space to genuinely use our thought, or values, our theories, and our thinking skills, to think and imagine our way through - the two are equally important (2011:15).

\section{He Hononga}

Chapter 2 provided insight into several of the research questions within the Whäriki Takatāpui framework to do with Kaupapa Māori Research, Kaupapa Māori Theory, Mana Wāhine and Whakamutunga - change that leads to the transformation of Māori culture.

This study created a new Kaupapa Maori research methodology - He Whāriki Takatāpui.

This study hoped to improve the judgment required to develop tikanga in contemporary Māori society. That judgment has been greatly affected by colonisation and Christianity and continues to impact on takatāpui and their whānau today.

Intersectionality is a useful concept to understand the historical and intersecting oppressions affecting indigeneity, race, sex and gender; within which takatāpui and their whānau exist. Intersectionality is not, however, useful for considering identity. Whakapapa guided my 
analysis of the extent to which takatāpui draw strength from the evidence of takatāpui in the past to defend against discrimination from within whānau and Māori society today. 


\section{CHAPTER 3: WHAKAPAPA: LEARNING FROM THE PAST}

As noted in Chapter 2, Mana Wāhine represented the most arduous and time-consuming part of the whāriki weaving process - the preparation. It did so in recognition that such labour continued to be primarily the purview of gifted women weavers. Once the harakeke was harvested, it was allowed to rest to recover from the trauma of having been removed from the safety of its home - the Pā Harakeke. Once rested, the real preparation began. The whenu (harakeke strands used for weaving) was extricated from the 'para'; the waste product which included any part of the harakeke not required for the production of the whāriki. In this study, the whenu reinforced whakapapa (genealogy/relationships) which in turn reinforced cultural and spiritual origins and connections. The para or waste product represented the intersectional oppression takatāpui have inherited from a puritanical and colonial history which has included the subjugation of Māori women, the suppression of gender and sexual fluidity, and the criminalisation of same-sex attraction and gender non-conformity. This chapter directly responded to the research questions: 'Why is whakapapa important to takatāpui?' and 'What can takatāpui learn from the past?'

\section{Covering Up \& Toning Down: The Other Side of the Family}

Abel Tasman was the first recorded European to 'find' the isolated archipelago of the 'Unknown South-Land' in 1642. ${ }^{31}$ Tasman's legacy remained in the name the Dutch bequeathed; 'Zeelandia Nova' after one of the provinces in the Netherlands - despite not having set foot on land. When extracts of Tasman's journals were published in Europe, the “bloodthirsty” reputation of the Māori was born (Salmond 1991:82).

Captain James Cook sailed the Endeavour into Tūranganui-a-Kiwa (now Gisborne) on 6 October 1769. Salmond (1991) detailed his journey from Tahiti where he and his crew had spent three months enjoying the local food, taking part in local customs, having sexual liaisons with Tahitian women and conducting detailed research on Tahitian life. At that time, study of people came under 'Natural History' which covered plants, animals and minerals including Polynesians/Māori (1991:114-5). Salmond concluded that the Endeavour's visit to Tahiti

\footnotetext{
${ }^{31}$ See Salmond (1991:78-81) for an in-depth description of the dramatic arrival of the Zeehaen and Heemskerck on the shores of Taitapu (Golden Bay) and why the Dutch left, never having set foot on land.
} 
"profoundly influenced" the way in which the Europeans observed Māori life in that they used the Tahitian research "as a basis for considering and comparing other Polynesian people as they did not produce such detail on Māori” (1991:115). This conclusion is borne out by Cook's observation that, "The people of New Zealand were a great deal more warlike than the people of the mid-Pacific islands" (Cameron 1987:121).

Many scholars have traced the waves of settlement to this land (including McNab 1908a, 1908b,1914; Cameron 1987; Salmond 1991). The perceptions and interpretations of early recorders of Māori culture, reflected the status of women and homosexuals in their home countries, their particular version of Christianity, and their colonial intent. Cameron is adamant about the perceptions of early explorers. He commented on the gulf between understanding in terms of "possessive property-conscious Europeans" and "happy-go-lucky Polynesians" who cheerfully shared the few belongings they had (1987:119).

The difficulty here is that we can only see them [Polynesians] through other people's eyes and other people's prejudices; the romanticism of Banks and Commerson, the spiritual arrogance of the missionaries, or the sexual preoccupation of the seamen, traders and whalers (Cameron 1987:28)

Romanticising at length for example, Rickman devoted much space to the recital of a love affair between a young sailor and a Māori girl, wistfully closing his narrative with: "Love like this is only to be found in the regions of romance" (in McCormick 1940:4). Ledyard's experience also led him to observe that, "They are susceptible of the tender passions, and their women of communicating as well as receiving the most ardent love" (ibid).

Māori differed dramatically from their European visitors in a range of sexually related behaviours. Sexual language was reinforced by the use of sexual hand and hip gestures. Māori female nudity was less common than Māori male nudity but particularly apparent when bathing and at beaches (Eldred-Grigg 1984:6-14):

In Māori society, sexual language was much more explicit. The most intimate details of private life were discussed with what appears to be complete freedom, and speech seems not to have 
been modified according to whether women or children were present. The result, to Pakeha ears, was a language that was richly obscene (Eldred-Grigg 1984:6b). ${ }^{32}$

The British culture condoned sex only between men and women within monogamous marriage. Consensual sex between men was illegal; lesbian sex not being thought to exist (Ballantyne 1999; Eldred-Grigg 1984; Faderman 1985; Hyde 1970; Laurie 2001a, 2005). Eldred-Grigg (1984) noted that "the very bustle of the puritan crusade showed plainly that the moral codes of New Zealanders were not engraved on a tablet, but were the subject of controversy and conflict" (1984:2a).

That puritanical mindset did not preclude the standard colonial practice of sexualising and fetishising indigenous women. As takatāpui scholar Michelle Erai (2011) noted, colonising distant lands was based on "the assumed sexuality and amenability of Indigenous women...the potential availability of Māori women on the coasts of New Zealand:"

Sexual access to certain bodies, and particularly the less-fraught bodies of Native women, is scripted into the commercial and imperial narratives of contact, settlement and colonization. These narratives demonstrate "cartographies of desire" and "economies of flow" in colonial history making (2011:66).

Salmond concluded that "it seems clear from various journal entries that there was considerable love-making with local women, which must have resulted both in pregnancies and the transmission of venereal diseases" (1991:271). Salmond considered that two extremes existed: high-born young women and married women were modest and inaccessible - "although a very important guest might be offered an aristocratic sleeping partner as a gesture of hospitality and honour (manaaki)" (1991:175-6). Captive women were made available to visitors and "young women were at liberty to sleep with whomever they pleased." It appeared that relationships however, were not encouraged. Crew were not invited to stay ashore with any of those with whom they had sex (Salmond 1991:253).

Laurie (2005) outlined the historical context for the laws and ideas promulgated by the British in their colonisation of New Zealand when the English Laws Act 1858 criminalised buggery between men while ignoring sex between women. This was followed by systematic legislative

\footnotetext{
${ }^{32}$ Given not all settlers would have spoken te reo Māori, it is possible that the "obsence language" was attributed to the common use of 'whaka' as a causative which may have been misinterpreted as being related to the English 'fucker' it sounded like.
} 
change and prescriptive church influence over time. As settler numbers and missionary influence increased, the systematic dismantling of Māori language and culture brought with it the British legacy of misogyny and homophobia. Its impact on the expression of Māori sexuality and gender fluidity was significant. However determined the coloniser though, colonisation was an incremental, and by no means assured, process. Nor was it all a negative experience for Māori. From the Dutch to the British, the French and the Americans, Māori alternately challenged, killed, welcomed, fed, sheltered, traded, fought or had sex with, married and - in extreme and ritualistic cases - ate them. From initial contact with Pākehā, Māori sought to retain their rangatiratanga (self-determination), even as they adapted to the customs of the new arrivals.

\section{Trusting Whakapapa: Takatāpui Existence}

Gluckman (1973:121) would have us believe that neither male nor female homosexuality "as constructed in European terms" existed in pre-colonial Aotearoa, regardless of the incidence of homosexuality amongst modern Māori (1973:121 cited in Henrickson 2006:250). Arboleda and Murray (1985:131) refute contemporary Māori claims of homosexuality as a "European corruption" as indications of "contemporary stigmatization [sic]), but dubious as history." They go on to state that whilst the apparent absence of vocabulary may "imply a possible absence of homosexual role, it does not imply the absence of homosexual behaviour" (ibid).

Te Awekotuku (Starzecka 1996:32) supports the presence of same sex and both sex behaviour:

Sexuality was enjoyed in many forms. People chose partners of either sex for pleasure, and same sex love was not condemned or vilified. Continuing one's line - having children - was nevertheless a priority. High performance and erotic skill were greatly admired, and accomplished individuals, both male and female, feature prominently in the chant poems of their time, their physical attributes and relevant behaviours fondly detailed.

This viewpoint is echoed by the Royal Commission on Social Policy who were advised by many kuia and kaumātua that female and male homosexuality was common in pre-European times and that it was "in fact more readily accepted than today" (1988:167). Other Māori leaders have "grudgingly" admitted that takatāpui lifestyles existed but that they were tolerated, rather than accepted (regarding Hirini Moko Mead 2003 in Aspin 2005:4).

Having enjoyed some fluidity in the past, Māori were expected to engage with the discourse of 'homosexuality' and its inherent sexual binaries, negative connotations and punitive 
consequences, when it was introduced to Aotearoa in the 1880s. Hendrickson (2006:248) noted that the development of a 'vocabulary of homosexuality' brought with it the 'essentialist idea that a culture has a binary of two sexual identities - same sex identified and opposite sex identified.' Henrickson noted that the concept of arranging oneself within a continuum of identity between heterosexual and homosexual was developed by Kinsey, Pomeroy and Martin $(1948,1953)$ and therefore:

Constructing one's identity as gay, lesbian or bisexual may be understood as post-colonial (2006:248).

Banks tells a story (Salmond 1991:251) about a man who wanted to "attend to his creature comforts" who returned to ship most upset that the natives were "given to the Vice of Sodomy". He had paid to "make his addresses" to a suitable candidate only to discover "on examination," that it was a boy. When he complained, they sent another who also turned out to be a boy. He was laughed at when he made more complaints. Rather than accept that homosexuality might be part of Māori life, Banks was adamant that "Vice is not practised here" and thought it was more likely that "our gentleman was fairly tricked out of his cloth, which none of the young ladies chose to accept of on his terms". As Salmond says "if this was not good evidence of homosexuality, it certainly pointed to a local sense of humour” (1991:252).

The sight of naked Māori often led to sexual liaisons which Binney (1968) described as a "common problem amongst the earliest missionaries scattered throughout the Pacific." One such missionary, Reverend William Yate, took the opportunity to have sexual contact (mutual masturbation and fellatio) with an estimated 100 Māori youths during the six-year period of his mission (Binney 1975:115, French 1988). When Yate was taken to Court in 1820, one witness stated, "They [Māori men] showed no shame. They simply declared that they were unaware of any sinfulness in such practices and that Yate had not initiated them" (Court Proceedings 1820). Yate was not charged but left the colony in disgrace. As French noted:

In his own way, [Yate] was as exploitative of the Māori people as any number of missionaries, possibly doubly so. But then, at least in relation to his sexual advances, the Māoris [sic] don't seem to have complained (French 1988:15).

By the late 1880s, few people had been convicted when the English Laws Act 1858 criminalised 'buggery' in Aotearoa. However, those who chose to step outside of the accepted gender norms by cross-dressing often found themselves in Court for disorderly behaviour 
(Eldred-Grigg 1984;50-51). One example was Nikora Hune Haora who in 1929 obtained employment as a housemaid under the name of Miss June Ohara (Diamond 2007:122). After several months, Miss June was found to be a man and charged with falsely representing himself as a female. While such behaviour may have been rare, its record in the Court proceedings and extensive media coverage proves to present day takatāpui that at least one person was prepared to risk the consequences to live outside of the gender norms of their day. And if there was one, further research may uncover more.

Although we have fewer instances of female intimacy, there is no doubt that fluid sexual intimacy and gender expression was common among Māori in pre-colonial and post-contact times and has continued ever since. It was accepted without punishment and in spite of repressive English measures.

\section{Putting it in Writing: Oral Narratives in Print}

Many Māori were literate by the 1840s and Biggs (1966:447) notes that they wrote out genealogies, songs and narratives in full "just as if they were being recited or sung." However, colonisation had its impact as Apirana Ngata stated in his introduction to Part One of $N g \bar{a}$ Mōteatea: The Songs (translation by Pei Te Hurinui):

Ko te nuinga o tēnā momo waiata [waiata whaiāipo] kua ngaro; he rangi tahi ētahi, i mate tonu atu i te matenga o te hunga nāna i tito. Ko ètahi anō i mau, ā e waiatatia nei ināianei. Kei konā ngā kupu whakaaroha o te reo Māori. Ôtirā i whakararu mai anō ètahi āhua kupu, he kupu pai tonu i tō rātau nā wā, i te wā kaitangata rā, i te wā kāore anō i tū ngā tikanga Pākehā hei aruaru i èrā hanga. Nā, ko ēnā kupu kua whakangāwaritia i roto i ngā kaupapa o ngā waiata ka tāia nei (1928:xx).

Most of the songs in this group [love songs] are lost; some were of a transitory nature, and they usually died with the composers. Some have remained and are still being sung now. The most poignant expressions of the Màori language are in those songs, although unusual expressions often intruded, quite innoxious (sic) in their times; they were cannibal days, they were times before European ways had been adopted to replace such behaviour, such expressions have been toned down in the text of the songs published in this work (1928:xxvi). 
By examining how the process of colonisation has impacted on Māori attitudes to sexual and gender fluidity and diversity, it is likely that some takatāpui behaviours may have been included in the 'unusual expressions' that were 'toned down' in Māori records and therefore more difficult to identify. Takatāpui community leader Gaye Hawkins (1995) affirmed that:

The lack of reference in traditional Māori waiata, mythology and oral history to transsexualism indicates that it did not exist or was a subject that because of its normality was not referred to. Given that a wealth of literature exists on institutionalised transsexuality among the early Tahitian, Hawaiian and Samoan societies...perhaps the question needs to be asked if in recording early Māori, the Missionaries responsible may have chosen to avoid recording those issues that they deemed unchristian practices" (1995:93-94).

Aspin (2005) later reiterated that:

Evidence that exists today suggests that pre-colonial Māori society and celebrated sexuality in all its diversity. At the same time, examination of other indigenous societies provides corroborating evidence that this was the case in other communities before the onset of colonisation ....a process which continues today in a manner that suppresses and distorts the truth about indigenous expressions of sexuality from both an historical and contemporary perspective (2005:2).

Te Awekotuku had also pointed out a specific example where the word 'āitia' meaning 'sexual conduct' was replaced with 'āwhitia' meaning 'affection' in an example of both sex attraction in the lament to a fallen warrior (Te Awekotuku 2005:7)

\section{Tradional Maori Narratives: What We Know}

\section{Takatāpui: Tütanekai \& Tiki}

It is from Te Rangikāheke that the term 'takatāpui' was found (Te Awekotuku 2005:8). Wī Maihi Te Rangikāheke was probably taught to read and write in the 1830 s by missionaries (McRae 2000:4). Ironically, it is derived from the most well-known (heterosexual) love story in Māori history. Sometime in the 1300s, the beautiful and headstrong Hinemoa from Te Arawa fell in love with a visitor to her village, the handsome but unsuitable Tūtanekai. When Tūtanekai and his friend Tiki went back to stay on the small island, Mokoia, in the middle of Lake Rotorua, Hinemoa was forbidden to see him by her whānau who removed all the waka from the shore. Frustrated and rebellious, Hinemoa climbed atop the rock at Ōwhata (which still bears her name), and dove into the freezing waters. She swam into the night, guided only 
by the haunting tunes of the flute played by Tütanekai. Hinemoa finally reached the island and her union with Tūtanekai has been immortalised ever since. The main streets of Rotorua bear their names and the first New Zealand feature film in 1914 was Hinemoa, played by Hera Tawhai Rogers (NZFA 2010). As Te Awekotuku (1991) noted:

For we do have one word, takatāpui. And ironically, this word is associated with one of the most romantic, glamourized [sic], man/woman love stories of the Māori world, the legend of Hinemoa and Tūtanekai. Tūtanekai, with his flute and his favourite intimate friend, his hoa takatāpui, Tiki, and Hinemoa, the determined, valorous, superbly athletic woman - my ancestress - who took the initiative herself, swam the midnight water of the lake to reach him, and interestingly, consciously and deliberately masqueraded as a man, as a warrior, to lure him to her arms. Isn't that another, intriguing way which we, our community and tradition, have been denied?" (1991:37).

Tūtanekai may have loved Hinemoa but his heart belonged to Tiki, whom he called 'taku hoa Takatāpui' - my intimate same sex friend - and spoke about at great length (Grey 1971:113). Tūtanekai missed Tiki so much that he moaned to his adoptive father, Whakaue:

Ka mate ahau i te aroha ki tōku hoa, ki a Tiki'

I am dying for love for my friend, for my beloved, for Tiki.

Although Te Arawa has not issued a proclamation, the story of Tiki is not told in the official version of this love story. To deny that Tūtanekai and Tiki had an intimate relationship would cast aspersions on the validity of Te Rangikāheke's work which has not been in dispute otherwise. Te Awekotuku has re-imagined Hinemoa in her work $(2001,2003)$.

The following two examples were used in resource produced by the former Hauora Takatāpui Team at New Zealand AIDS Foundation (NZAF) which involved Wairaka and Tāwhaki.

\section{Whakatane/Tangata Ira Tane: Wairaka}

An example of a form of gender non-conformity also comes from the 1300s - the story of Whakatane. According to the history of the Mataatua people, the Mataatua waka (ocean voyaging canoe) arrived on the beach at (then) Kākahoroa. The men left the waka to climb a hill and observe a new land. When high tide threatened to carry off the waka, Ngāti Awa and Tūhoe believe it was Wairaka, daughter of the captain Toroa, who took it on herself to recite a 
powerful karakia (incantation) which included the phrase: “Ka whakatāne ake ahau i a au' - I will make myself like a man."

Wairaka summons the Atua (gods) to help her. With that added strength, she paddled the waka to safety, saving it from being crashed on the rocks and to this day, that town is named Whakatane; "to be like a man." A bronze statue of Wairaka stands on a rock at the Whakatane Heads to commemorate this act. Te Awekotuku has also re-imagined this story (2003).

\section{Tipua: Tongameha}

This story tells of the ancestor Tāwhaki who was on a journey when he encountered Tongameha, a tipua (spiritual force who had the ability to change form and gender). He changed his male form into a beautiful female:

Engari inaianei kua whakangāwari i tōna reo, kua whakarekareka, ka tīmata ia ki te whakatoi a Tāwhaki; 'Tāwhaki e, titiro mai. He wahine ātaahua ahau. Titiro mai ki aku kamo anō ko te moana. He tangata mate wahine koe, Tāwhaki e. Titiro mai ki aku hope e hurahura atu nei. Tāwhaki anei to kai! Āhahā, haramai kia awhitia koe e ahau (Mead 1996a:45)

Instead he lowered the volume - softened it, sweetened it - and began to tease Täwhaki: 'Tāwhaki, look this way! I am a beautiful woman. Look at my eyelashes, they are like the sea. You like women don't you Tāwhaki! Look at how my hips sway. Tāwhaki, here is what you get. Ahaha! Come here so I can embrace you!' (Mead 1996b:45).

Many travellers who had come across this sight were turned to stone by the creature. Tāwhaki however, had been warned, and was not lured to his death by Tongameha's striking beauty. The phrase 'Tāwhaki anei to kai' translates as 'Tāwhaki here is your food' which means 'here is what/get/deserve.' It is an example of 'kai' or 'food' being used in reference to attraction and sexual desire.

\section{Whakataukī: An Artistic Analysis}

This section rises to meet the challenge made by Ngahuia Te Awekotuku to "reconstruct the tradition, reinterpret the oral history of this land so skilfully manipulated by the crusading heterosexism of the missionary ethic" (1991:37). I am a devotee of whakataukī and have studied them for many years for their succinct and metaphorical insight. I decided that if evidence of takatāpui existence was inside them, it would not be obvious. Therefore my 
approach could not be obvious. I needed to find the clues I believed our tūpuna had left us but I was not a linguist. However, I was an artist so I reviewed over 150 whakataukī (proverbs/sayings) on relationships, gender roles, sex and sexuality by focusing not so much on the words but on the imagery that was used. I sketched and painted those images to connect the whakataukī together in different ways. Then I started to discern patterns and recognise where the interpretations were different.

I used one dataset from Mead and Grove (2001) who compiled a list of over 2700 pēpeha from around 325 written sources. I acknowledge the limitations of one source. However, I checked the original sources given for the whakatauki I focused on to check for any discrepancy in translation or interpretation. Some were attributed to specific tūpuna and events while many were so common that variations emerged from a range of iwi. The few which came from unknown sources or had not been translated were of particular interest to this study. Given the propensity of early writers to fudge on details of gender and sexuality, omissions and evasion have led me to uncover the first new historical evidence of takatāpui lives in decades.

I present these whakatuki as I compiled them so the reader may understand how I arrived at my conclusions. What is critical is that they show no sign of women and children being subservient to men. Women had agency and decision-making powers over her body and her life, in the context of the needs of her people. These show that men and women had specific roles that were complementary and equally valued.

\section{Born of the Gods: Gendered Attributes}

The earliest whakataukī on record are attributed to Te Rangikāheke from 1849 (Mead and Grove 2001:1849:111):

Ahau, a! He tamaiti kei taku aroaro

See me! Pregnant! A pregnant woman was valued for her contribution to the strength of the group (Mead and Grove 2001:14.21).

Ahau, a! He wahine kei taku aroaro

See me! A woman in my company' A man with a woman adds to tribal strength (ibid 2001:14.22).

This lends high credibility to the thinking that women were valued in traditional Māori society and not subservient as was the case of English women at the time of colonisation. The 
fragments considered in this section then reveal as much about traditional Māori life and customs as they do about those who recorded and edited them; predominantly Christian European men.

In traditional Māori society, the key attributes of females and males were determined by the gods. Female children belonged to Tahu, god of peace and gentleness. Male children belonged to Tūmatauenga, god of war, from whom they were thought to have inherited courage and fighting ability:

Te inati o Tahu

The portion of Tahu (Mead and Grove 2001:370.2300).

Ko ngā rākau o Tū-matauranga ō rākau

Yours are the weapons of Tumatauenga (ibid 2001:238.1451).

Consequently, in women could be found a source of peace and well-being:

He awa wai kōpua he taniwha kei roto, e mate; he awa wai kōpua wahine, taka ana te āhuru

In a river's depths lie taniwha, death, but in the depth of a woman, there is comfort (Mead and Grove 2001:68.370).

In some cases, women took a lead role in negotiating peace. In one example, Te Tiwha of Waikato and Hauraki mediated to allow Pōtatau and his war party to leave Hauraki unharmed. The outcome of the peace negotiations is compared to a door made of pounamu (greenstone); strong and permanent:

He whakahohou rongo wahine, he tatau pounamu

A peace arranged by a woman is a greenstone door (Mead and Grove 2001:137.832).

In another example the chief Manu-Kaihongi, son of Māhanga and descendant of Hotunui spared Ngāti Huarere at the pleading of his wife whose father was chief of that tribe.

\section{A Desirable Wife, A Worthy Husband: Roles \& Expectations}

The major indicators of women's agency - ability to make and act on their own decisions - are the multiple whakatauki providing advice to them for appropriate partners. Fathers advised their daughters to choose a digger of the sustainable fern root rather than a provider of delicious but seasonal food: 
Āe, engari tēnā, te tūtanga tē unuhia

Yes, that one, so that the portion will not be withdrawn (Mead and Grove 2001:11.2, see also ibid 2001:394.2464)

Te Angiangi from Ngāti Kahungunu advised his daughter, Mahinaarangi, to consider Turongo because of his skills in 'snaring birds and building houses:'

Me moe koe i a Tūrongo; hei rangatira mōu, he tangata kaha ki te mahi kai

You had better marry Türongo; let him be a husband for you, he is a man able to provide sustenance (Mead and Grove 2001:300.1863).

The right of women to choose is reinforced by the comparison of her choice to the selective, or capricious, kahawai (coastal fish): ${ }^{33}$

He wahine ki uta, he kahawai ki te moana

A woman on shore, a kahawai in the sea (Mead and Grove 2001:135.820, see also ibid 2001:78.439).

The primary role for a husband was to provide food for his family and the proof of hard work was in the hands. Hands of worthy men were sweaty (Mead and Grove 2001:308.1921) or blistered (ibid 2001:38.193, 2001:416.2606). A desirable man would be 'dexterous at dredging pipi (small bivalve) ${ }^{34}$ or mussels' while an idle man deserved to be punished by his wife:

He tāne rou kākahi ka moea, he tāne moe i roto i te whare, kurua te takataka

The husband who is dexterous at dredging pipi will be slept with, and the husband who sleeps idly around the house will have this head thumped (Mead and Grove 2001:120.718, see also ibid 2001:359.2216).

This clearly shows that not only were women choosing their own partners, they were not expected to put up with a poorly behaving one. From my analysis, the single most unattractive characteristic for either sex appeared to be laziness. In this example, a lazy man was not worth the food he ate:

\footnotetext{
${ }^{33}$ Kahawai: Arripis trutta

${ }^{34}$ Pipi: Paphies australis
} 
Ko tāne pakuroa none kai

A dilatory husband is a waste of food (Mead and Grove 2001:248.1517, see also ibid 2001:291.1799).

In another example the pōtaka (spinning top) is used to refer to someone who did not contribute to communal work (Mead and Grove 2001:267.1647).

The censure against laziness applied to both sexes. The people of Tūwharetoa suggested that a lazy woman or one who could not weave garments would experience the cold winds that swept the bare slopes of their mountain, Tongariro, as the feeling on her skin:

Mā wai e moe te wahine māngere ki te whatu pūeru. Ko Tongariro te kai ki taua kiri

Who would marry the woman who is lazy at weaving garments? Tongariro will be the nourishment of her skin (Mead and Grove 2001:291.1800).

Finding time to stop and talk during the day was considered proof of laziness so an unattractive quality in a woman. Women were expected to be nimble with their hands and feet, not their lips:

Te wahine $\mathrm{i}$ te ringaringa me te waewae kakama moea; te wahine $\mathrm{i}$ te ngutungutu whakarērea atu

Marry the woman who is nimble with her hands and feet; forsake the one who is nimble with her lips (Mead and Grove 2001:397.2483).

Wahine i te ringaringa, waewae kakama, moea; wahine i te ngutungutu, whakarērea atu A woman with nimble hands and feet, marry her; a woman who chatters, cast her out (ibid 2001:415.2603).

In other examples women's tongues are likened to a cabbage palm that constantly waves or unlike a tongue of supplejack which will crack:

He rau tī-pīnaki, he arero wahine

The leaf of a cabbage palm, the tongue of a woman (Mead and Grove 2001:115.685).

He arero kareao ka whati, engari te arero wahine kāore e whati haere tonu ana A tongue of supplejack will crack but not a woman's tongue, it goes on and on (ibid 2001:65.355).

A soft-sounding voice however, was considered an asset: 
He reo ngāwari, mehemea he pūtōrino; he wahine mārō, he reo pūkāea

A soft-sounding voice is like a flute; a hard woman, like a raucous trumpet (Mead and Grove 2001:116.689).

Sitting quietly while others chatted differentiated a woman of rank and the calmer, more efficient workers (kererū - wood pigeon $)^{35}$ from the noisy and busy others (kākā - forest parrot $)^{36}$ :

Kōrero tū ana wahine iti; kōrero noho ana wahine nui

A little woman speaks standing, while the big woman speaks seated (Mead and Grove 2001:243.1468).

Kai ana ngā kākā, noho ana ngā kererū

The kāka are eating while the wood pigeon is sitting quietly (ibid 2001:157.954).

Appearance was not considered an important asset for a relationship. One pēpēhā suggested that a plain woman is more likely to be the subject of envy and unwanted attention from other men (Mead and Grove 2001:211.1291). This is reiterated by a warning not to choose an attractive appearance over a woman with rough hands (ibid 2001:193.1181) or that a plain woman is better than a handsome man (ibid 2001:106.617). Indeed, one example warns against vanity and concern for looks. Muturangi, (literally, the last of the chieftaineses), was used as a figurative name for the last of the beautiful women (ibid 2001:268.1653). One wistful example though notes that a 'pretty face is long enjoyed:'

He pai kanōhi e kore e roa te tirohanga, he kanōhi e roa te tirohanga

While one does not look at good food for long, a pretty face is long enjoyed (Mead and Grove 2001:105.613).

In some cases, appearance could lead to some dramatic outcomes as in the case of Wairaka who was greatly attracted to a visiting warrior. She noted his sleeping place and scratched his face in the night. In the morning Wairaka informed her father, Toroa (captain of Mataatua waka) that the one with the scratches would be the man she would marry. She recanted however when it transpired that an ugly man had subsequently taken her chosen's place:

\footnotetext{
${ }^{35}$ Kererū: Hemiphaga novaeseelandiae

${ }^{36}$ Kākā: Nestor meridionalis
} 
He pō raru ai a Wairaka

The night when Wairaka was deceived (Mead and Grove 2001:109.640).

Given that Wairaka scratched a warrior's face during the night, it is likely that a sexual or intimate liaison took place. Not only was Wairaka under no obligation to the warrior in question or under censure for her behaviour, she is considered the one to have suffered an injustice. Wairaka was able to change her mind with impunity and the warrior appeared to have no choice in the matter. Being high born certainly contributed to her power in this situation.

\section{Tribal Survival: Building Alliances}

Whether to marry inside or outside the hapū or iwi was the source of some debate. In addition to strengthening the tribal base, the key benefit of staying inside the hapū or iwi was containment of any quarrels between the couple so the risk of economic loss from muru (ceremonial plunder) was eliminated:

E pai ana kia moe kōrua ko tō tuakana; kia kanga iho anō kōrua, kanga iho ki a kōrua anō

Your marriage with your cousin is desirable, if you curse each other, or if you abuse one another, it is only a family matter (Mead and Grove 2001:42.213 see also 38.195/309.1925).

Strengthening a relationship with a friendly iwi was the primary benefit for marriage between them:

He taura taonga e motu, he taura tangata e kore e motu

A gift chain may break but not a human link (ibid 2001:125.753).

Generally, a woman was expected to move to her husband's home. This represented both a loss of her contribution to her own hapū or iwi but also a loss of their support for her:

Haere atu te wahine, haere marokore

The woman goes but goes without her apron (Mead and Grove 2001:52.269, see also 2001:370.2298).

The following pēpeha are identical in structure but are translated and interpreted quite differently: 
He tane ahi tere

A husband's fire followed (Mead and Grove 2001:119.716).

He wahine ahi tere

Woman's fire moves (ibid:134.816).

This is an example where the structure is identical but the gendered interpretation quite different. The former is translated as "a husband's fire followed" while the latter is interpreted as an "argument for the value of sons." It is possible that there is gender bias from Grey (1857:29) and Williams (1908:32).

The sanction of a marriage by the hapū or iwi was symbolised by a particular type of Whāriki

- the takapau wharanui; both a physical object and a representation of tribal approval:

Kōrerotia ki runga ki te takapau wharanui

Let the discussion be on the nuptial mat (Mead and Grove 2001:243.1485).

Such a spiritual and sanctioned union was expected to create a stronger relationship:

He hono tangata, e kore e motu, kāpā he taura waka, e motu

A human bond cannot be parted, unlike the severable canoe rope (ibid:70.390).

Children born on the takapau wharanui were considered to be superior to others:

He tamaiti i aitia ki runga ki te takapau wharauni

A child conceived on the marriage bed (Mead and Grove 2001: 119.711).

Tēna tā te mea i moea ki runga i te takapau wharanui

There, that's because the child was conceived on the marriage mat (ibid 2001:379.2357).

When Tūhourangi was born to the fourth wife of Rangitihi, Papawharanui, questions were raised about his legitimacy. Rangitihi refuted this:

He pōtiki nā Papawharanui, tēnā tā te mea i moea ki runga i te takapau wharanui

A youngest child by Papawharanui, conceived on the great mat (Mead and Grove 2001:111.650).

The birth of a boy conceived in a 'trifling indiscriminate manner' was frowned upon although an equivalent term does not seem to exist for a girl: 
He tama meamea noa iho

Only a bastard son (Mead and Grove 2001:119.712).

\section{Planting \& Growing A Generation}

Successfully conceiving and raising a family was often likened to planting:

Kua tupu te pā harakeke

The flax plantation is growing (Mead and Grove 2001:275.1698).

The grief of a woman who has difficulty conceiving likened her experience to the difficulty in growing the hue while others expressed grief at the death of their sons:

Ko Wairau, ko au

It is Wairau, it is I (Mead and Grove 2001:269.1657).

Ka whati rā ia tāku māhuri tōtara

My tōtara sapling broken off (ibid 2001:198.1212).

A man without children was considered a great misfortune:

Kāhore he uri, he tangi

Without descendants there are lamentations (Mead and Grove 2001:155.941).

Me he rākau māmore au nei, tū tonu

I stand straight up like a branchless tree (ibid 2001:296.1837).

When the leader of a Ngā Puhi war party laying siege asked Ihenga chief of Kaipapa pā, Pario-tonga, how he would replace the losses they were able to sustain, Ihenga replied:

Me tupu i a wīwī, i a wāwā, tūria i te wera, piri ki te rito o te rengarenga, waiho me whakapakari ki te hua o te kawariki

Grow them like the rushes and sedges, set in warmth, thick as the shoots of the rengarenga, mature like the fruit of the kawariki (308.1916, also see 309.1922).

Overall, it appears the gender of any children was considered to be the responsibility (or fault) of the mother. Pikiao from Te Arawa complained that his wife had borne him only female offspring: 
Mā wai rā e hari taku kauae?

Who will carry my jawbone into the future? (Mead and Grove 2001:292.1804).

In an earlier record however, Pikiao dismisses his father who suggests he take a second wife after having only daughters:

Tērā, Te Takapūwhāia te tuhera

There, Te Takapūwhäia is certainly still open (Mead and Grove 2001:388.2418).

Te Takapūwhāia is a part of Lake Rotoiti and is used as a reference to his wife's future childbearing potential. The use of a water form to signify the vulva and child-bearing ability was echoed by Waitapu (III), the daughter of Ngāti Raukawa chief, Te Atainutai. She reacted against her husband, renowned warrior from Ngāti Tūwharetoa, Te Rangiita when he became angry after the birth of their fourth daughter, and refused to live with her. She dismissed him with the retort:

He aha koa? Hai te tuhera tonu te awa i Nukuhau

What of that, the river is always open at Nukuhau (Mead and Grove 2001:62.333).

Nukuhau was productive land west of the Waikato River at its exit from Lake Taupō.

The importance of a fertile woman is reinforced with a metaphor that the loss of a child is similar to a leak in a top plank compared with the loss of a woman which would be more like a split at the bottom of the waka. In a similar example, a damaged gunwale is compared to a broken keel. Because a woman can bear more children her loss is much more serious to the tribe than the loss of a child.

Mate i te tamaiti, he aurukōwhao; mate i te wahine he takerehāia

The death of a child is a small matter but the death of a woman is a calamity (Mead and Grove 2001:286.1769).

Te mate ki te tamaiti he pakaru niao, te mate ia i te wahine he pakaru takere waka

The loss of a child is only a damaged gunwale but the loss of a wife is a broken keel (ibid:377.2344).

It appears that a man taking another wife was not considered unusual, but nor was it for women. In one case Tīhore of Ngāti Mahu and Te Mārangaranga, Ngāti Awa set sail without his wife and family, she called out that there would be no children for him. He retorted that: 
Tāne rau a hine, wahine rau a tama

A woman has many husbands, a man has many wives (Mead and Grove 2001:358.2215).

When she called that he would have no more children, Tīhore replied:

Hai konā! He tamariki tonu kei te matumatu o taku ure

Good-bye, there will still be children at the tip of my penis' (Mead and Grove 2001:358.2215).

A man leaving his wife and family unsupported was considered unusual and unacceptable as seen in the case of Tūrangatao who abandoned his family to the mercy of enemies. As he fled, he also called out to his wife:

He tamariki kei te matamata o te ure

There are children at the end of my penis (Mead and Grove 2001:92.533. See also ibid 2001:221.1348).

If taking more wives or husbands was considered acceptable, being deserted was a source of humiliation. A deserted woman was likely to neglect her appearance so her garments were said to be stripped of feathers or decoration:

He kaka tīhorea he tohu nō te wahine mahue

A garment stripped of its covering is the sign of a deserted woman (Mead and Grove 2001:82.463).

An older woman who feels discarded by her husband may compare herself to the mooring rope mentioned above:

He kaha anō ka motumotu

Like a worn out mooring rope (Mead and Grove 2001:78.436).

Other women despairing that their husbands have left them for younger women may compare themselves to an old fishing net or the sea foam to their grey hair:

Ka ruha te kupenga, ka pae kei te akau

When the old net is worn out, it is cast upon the beach (Mead and Grove 2001:184.1122).

Kua pae nei hoki te kōputunga ngaru ki te one

Masses of sea foam have been cast up to lie on the sand (ibid 2001:273.1684). 
Leadership and influence was more to do with whakapapa and marriage than gender. The extended whānau in the Waiapu of Ngāti Porou were well known for their 'chiefly women':

Waiapu kōkā huhua

Waiapu of many mothers (Mead and Grove 2001:415.2605)

As noted earlier the ability to sit quietly while other women chatted was a sign of rank:

Kōrero tū ana wahine iti; kōrero noho ana wahine nui

A little woman speaks standing, while the big woman speaks seated (Mead and Grove 2001:243.1486)

One of the most enduring, and misinterpreted, pēpeha states that men die because of women and land:

He wahine, he oneone, i ngaro ai te tangata

For women, for land, men die - the two most likely causes of conflict (Mead and Grove 2001:134.817)

He wahine, he whenua, ka ngaro te tangata

Women and land cause the death of men (ibid 2001:134.818)

Ko ngā take whawhai, he whenua, he wahine

The causes of warfare are land and women (ibid 2001:238.1452)

Mā te whenua mā te wahine ka mate te tangata

Men die for land and for women (ibid 2001:288.1779)

One of several variations of this pēpeha, all with the same gist, ends with the phrase 'e ea ai te pakanga,' 'result in war.' Translated and interpreted in varying degrees of disapproval, women are identified as the cause of quarrels, warfare and death. Kāretu (1995) however, clarifies that it was for the 'acquisition' of these two important assets that most warfare took place.

Perhaps the second most misinterpreted pēpēhā concerns 'te whare o aitua' (Mead and Grove 2001:399.2497). Hinenuitepō was the guardian of souls in the spirit world so this saying expresses the inevitability of death: 
He ai atu tā te tangata, he huna mai tā Hine-nui-te-Pō

Man begets; Hine-nui-te-Pō destroys (Mead and Grove 2001:65.349)

Because Māui was killed trying to gain immortality by climbing between the legs of Hinenuitepō, 'te whare o aituā' is translated as the 'house of death or misfortune' while 'te whare o te ora' is the house of life. This kōrero is attributed to Rangi in response to Tane and other gods who were searching for the female element which they eventually found in the earth (203.1236). It is used to justify the viewpoint that women's bodies, specifically the vulva and womb, are places of misfortune and inferiority Karetū (1995) however states that:

...one need not exercise the mind too much to realise that this is an allegorical reference to the act of copulation for the male at the beginning of the act is strong and virile in his tumescence but after orgasm is limp and lifeless. While the reference is to the 'house of death' my own interpretation is that this exhibits a healthy respect for that part of the female and therefore, in my opinion, a healthy respect for the act of copulation itself.

\section{Spicing It Up: Sexual Metaphors \& the Language of Lust}

Māori often used the word 'moea' (to sleep) instead of unambiguous 'aitia' (Mead and Grove 2001:15.29/359.2216) to refer to sex. This was related to the custom where being intentionally found in bed together signified a relationship. This occurred even when the match was frowned upon - as was the case of Hinemoa and Tutanekai when their union was formalised once their legs were found entwined at the end of the bed. When being found in shared quarters may not have been appropriate; other imaginative solutions were found. As in the case of Wairaka (109.640) mentioned earlier. She scratched the face of a man in the night which left marks for the morning. That they had sex seems a likely reason for a sleeping warrior not to be adverse to such attentions.

The use of water imagery to refer to female sexuality has been covered in poetic fashion earlier in this chapter. References to male sex organs were more succinct:

Ure toa

Warrior penis - applied to a brave warrior (Mead and Grove 2001:414.2598)

Ure pūkaka

Direct penis - this is the term for agnatic or male line of descent (ibid:414.2597)

Arā tāne, ure pūkaka 
The ways of men, impatient men, men will be men (ibid:19.59)

Ka tū te ure he toa, ka hinga ka mate

If the penis stands erect, victory; if it falls limp, defeat; the outcome of ceremonial copulation determined the outcome of pending battle (ibid:191.1166)

Ko noho, ko ure; ko mahi, ko kai

The lazy penis stays at home while the woman goes out to gather kai (ibid:239.1461)

Waikato kuku raho

Waikato, squasher of penises - used by Waikato to intimidate potential enemies (ibid:420.2635) An interesting use of 'ure' is given here:

He ure, he ure, te kai mō te tangata haere

A penis, a penis, food for the wayfarer (Mead and Grove 2001:132.802)

This pēpēhā is explained as an interpretation by Pakanui of the nightly trumpet notes that sounded from the Wahineiti pā at Waikawa on the eastern shore of the Bay of Plenty. Thereby insulted, Pakanui, great-grandson of Poroumātā, twice attacked the pā without success. He then asked his cousin Tūwhakairiora for help. That warrior responded, defeating the Wahineiti subtribe at the battle of Te Roro-hukatai. (132.802). However, this may bear some further investigation given the use of food imagery in relation to sex which was indicated in the Tāwhaki and Tongameha story.

Some ancestors were well known for their sexual prowess; one of the most virile being Kahungunu. Apparently, he had only to look at a woman for her to fall in love so his eyebrows became synonymous with his sexual magnetism:

Ngā tukemata o Kahungunu

The eyebrows of Kahungunu (Mead and Grove 2001:334.2078).

In a related example, the famous eyebrow represents his attraction to the beautiful women of the Hawke's Bay, hence his many descendants (Mead and Grove 2001:262.1611). It was not his eyebrows though that evoked female interest. After settling at Whangarā (about $20 \mathrm{~km}$ north of Gisborne), word went around about the size of his 'sexual equipment'. When Ruaheretai of Tūranga (Gisborne) heard the story, she uttered these words: 
Nā te mea rā e āki ki runga ki tai i Maihirangi; ka taka mai ia ki te awa i Tātāpouri, pokopoko noa tōna hanga nā

That was because it was grounding on the beach at Maihirangi; if he comes around the river of Tātāpouri, his thing will be completely consumed (ibid:316.1964).

When Kahungunu heard about this he went to Türanga and married her. Later, he journeyed south to Whareongaonga where he married Hinepūaiari. When the local women asked her how she was faring, she replied:

Kāore hoki tērā te hanga o tāku tāne, kāore e rūpeke mai ana, takoto noa mai te nuinga i waho The remarkable thing is that the treasure of my husband could not be admitted inside and the major part is obliged to remain outside (Mead and Grove 2001:316.1964)

When this remark reached Rongomaiwahine, she scoffed:

Nā te mea anō rā he kōpua pāpaku, mehemea e taka mai ana ia ki te kōpua hōhonu a Rapa e tuhera atu nei, pokopoko ana ia ki roto

It is because it is a shallow pool; should it have fallen into a deep pool of Rapa now opening towards him, it would have been lost out of sight (Mead and Grove 2001:316.1964)

Rapa was Rongomaiwahine's father. Although these stories are told to prove the virility of Kahungunu, the reality is he roamed the country in response to the sexual boasts of the women - very much led by his ure.

\section{A Familiar Boast}

Particular tribal areas used sexual references to describe their best features:

Tāmaki-makau-rau

Tāmaki of many lovers (Mead and Grove 2001:357.2207)

Tāmaki was a place which 'commanded people's affections because of its fertility and physical location'. Likewise, Wairoa is described as a 'much desired place' and its attractions 'led to so much warfare that it was likened to a young maiden with many suitors':

Wairoa makau rau

Wairoa of a hundred lovers (ibid:421.2639)

My people of Tūranga appear to display no such modesty. 
Tūranga-makau-rau

Gisborne of many lovers (Mead and Grove 2001:411.2580, also see ibid:267.1646)

Best (1903:56) refered to 'Tūranga of the numberless husbands' - explaining that the married women of the Tairawhiti were 'somewhat loose in their morals.' Kōhere (1951:46) defended their virtue, saying that 'he and many other husbands are grateful to Gisborne for fine and faithful wives.' In an effort to downplay the sexual pride inherent here, Mead and Grove (2001:267.1646) gave Te Kani Te Ua the final word which is that Gisborne and its men are noted for their fertility.

When asked about the food in Tūranga, Taharākau famously replied to his host Tapuae:

He ahi kōuka i te ao, he ai wahine i te pō

Roasting kōuka during the day; making love to a woman at night (Mead and Grove 2001:64.347, also see ibid:14.26 for gender neutral version 'he ai i te pō')

The kōuka is the favoured nut-like kernel in each leaf cluster of the tî tree (cabbage palm). Another food/sexual comparison example includes a berry which are not worth being woken for:

Kia whakaoho koe i tāku moe, ko te whatuturei a Rua

If you rouse me from sleep, let it be for the treasure of Rua (Mead and Grove 2001:220.1344)

A sense of humour accompanies most references to sex:

He rongo tāhae ka whakamākia, he rongo aitanga, ka menemene Moetanga, Waiora ka kata

News of theft is cause for shame; news of sexual conquest makes Marriage smile and Procreation laugh (Mead and Grove 2001:117.702).

This set of pēpeha use fire imagery to describe sexual activity:

Ko te kaunoti kei te wahine, engari te hika kei te tāne tērā

The receiving piece is with the woman but the fire-causing piece is with the man - about cooperation for the welfare of the family and tribe (Mead and Grove 2001:253.1552)

The source for this peppeha is listed as unknown but it is listed under 'sex organs' in the index even though it avoids any such reference in the text. The following example is closely related and listed under 'qualities attributed to women' in the index: 
Kei te wahine te kaunohi, kei te tāne te hika

The woman is the stationery piece while the man is the active one (ibid:206.1259).

This entry is explained as the proper way of generating fire by friction. The stationery piece (kaunohi or kauahi) is steadied by the woman while the man rubs the other piece (hika or kāureure) against it (Best 1924:202). Again, any explicit reference to sexual activity is avoided.

This example at least admits to being a 'euphemism for or an illusion to sexuality activity':

Kōrero ahiahi, tūmata ngaingai

Talk in the evening is lighting fires and planting (Mead and Grove 2001:243.1483, Williams 1908:15)

The same phrasing is used to infer that the daytime accomplishments of a person do not always measure up to their night-time boasts:

He kōrero ahiahi nā Tiketike-i-rangi

An evening tale by Sky-High (or Blow Hard) (Brougham 1975:8; Kōhere 1951:34; ibid:86.497; Williams 1908:28)

Although 'kōrero ahiahi' is explained in all other cases as a reference to sexual activity, in the following example it states that 'the origin of this metaphor for 'idle tales' is unknown:'

Ngā kōrero ahiahi a Hinewhā

The evening stories of Hinewhā (Mead and Grove 2001:324.2011)

It goes on to state that 'the context usually suggests the more private talk that women exchange when by themselves.' Based on the consistent use of imagery, this final whakatauki is a specific reference to intimacy and sex between two or more women. My conviction on this matter has been reinforced as I have been unable to find any other reference to Hinewhā since. Also the known references in this final fire section are all linked back to the Tairāwhiti from whence I hail. It seems I was meant to find it.

\section{He Hononga}

Chapter 3 provided insight into the research questions within the Whäriki Takatāpui framework to do with Mana Wāhine.

As Māori we claim our identity through whakapapa over countless generations of ancestors. Whakapapa places us within a whānau, hapū and iwi which in turn connects us to marae and 
specific tribal areas on Papatūānuku, our earth mother. Because of this, whakapapa is central to takatāpui identity and spiritual connection to tūpuna takatāpui. It is clear that fluid sexual intimacy and gender expression existed among Māori in pre-colonial and post-contact times and has continued ever since. It was accepted without punishment and in spite of repressive English measures. There is not yet evidence that Māori had diverse gender identities or that takatāpui played specific roles in pre-colonial times; notwithstanding any roles which have developed over the past 150 years.

The process of colonisation is on-going so the inherent racism, sexism, homophobia, transphobia and biphobia of its structures continues. Through whakapapa however, takatāpui may access the historical resilience developed by our tūpuna takatāpui who were accepted for their fluid gender and sexuality in order to face discrimination; to show leadership, to survive and thrive. Until we further dismantle the tools of colonisation, we must rebalance the status of women and men within Māori culture. Therefore, Mana wahine is the key to eliminating homophobia and transphobia in whānau and Māori society.

My artistic analysis of 150 whakatauki gave insight into the status of women in traditional Māori society, relationships, gender, sex and sexuality. It confirmed that women were equal to men with complementary roles that worked for the collective good of their whānau, hapu and iwi. Women leaders were a result of whakapapa and training. As men were valued as warriors, so women were valued for their role in brokering peace. Women had control over their own bodies and sexuality so could chose to stay with or leave a partner. Women could censure a partner who was not pulling their weight. Both women and men had multiple partners.

This study has identified the first new evidence of historical takatāpui existence in some decades. The whakataukī Ngā korero ahiahi o Hinewhā is from my tribal home in the Tairāwhiti and refers to sexual activity between two or more women. 


\section{CHAPTER 4: SURVIVING CHILDHOOD: GROWING UP DIFFERENT}

This chapter introduces the oral histories of the primary participants of this study; Jennifer Edwards, Kevin Haunui, Peri Te Wao, Hinemoana Baker, Ahi Wi Hongi and Morgan Cooke. These participants were selected because they represent many of the identities encompassed by the term 'takatāpui' and the leadership they have shown within takatāpui and Rainbow communities. They descend from iwi throughout the country and their ages ranged from 29 to 64 at the time of interview, representing three generations of takatāpui. As a member of the takatāpui community who embodies another expression of being takatāpui, I have woven in my own narrative - as shown in italics. By doing so, I also hope to redress the power imbalance between myself as a researcher and the participants of my research who have publicly shared such intimate details about their lives. I hereby issue a content warning because of some of the harrowing experiences shared on these and following pages.

This small sample of in-depth oral histories about growing up Māori with diverse gender identities and sexualities begin to answer the research questions: What are the key issues that impact on takatāpui health and well-being? and How do takatāpui address the challenges facing them?

\section{Takatāpui Participants}

Jennifer Edwards was born in Waipiro Bay, Tairāwhiti, in 1949. She is Ngāti Porou on her mother's side and Te Arawa on her father's. Although she had two sisters and three brothers, Jennifer was raised by her grandmother, effectively as an only child. She was assigned male at born but has only ever identified as female and a woman, and now as takatāpui. She uses she/her pronouns.

Kevin Haunui was born in Rotoiti in 1960. On his mother's side, he is Ngāti Tūwharetoa, Ngāti Hau and Ngāti Rangi, and on his father's, he is Ngāti Kahungunu, Tūhoe and Te Whānau a Apanui. He is the eldest child and has three sisters. He identifies as male, takatāpui and gay and uses he/him pronouns.

Peri Te Wao was born in Tauranga in 1963 and raised in Maketu. Both birth and whāngai parents were of Te Arawa. Peri lived briefly with his grandmother after his mother died when he was three years old. He was then raised by his father's brother who had no children. Although Peri was born the middle child between two sisters, he was effectively an only child. 
Peri identifies as male, takatāpui and a trans man. He uses he/him pronouns and is married to Karen Te Wao.

Hinemoana Baker was born in Christchurch in 1968. On her father's side, she is Ngāi Tahu, Ngāti Raukawa, Te Ātiawa and Ngāti Toarangatira and her mother is Pākehā. Hinemoana is the youngest child with one sister ten years older than her and another elder sister on her father's side whom she met as an adult. Hinemoana identifies as female, takatāpui, bisexual and queer. She uses she/her pronouns.

Ahi Wi Hongi was born in Meremere in 1984 and is Ngā Puhi and Ngāti Maniapoto. Ahi is a middle child and has four elder and two younger sisters and a younger brother. Ahi's eldest sister was raised by their grandmother, and when Ahi was six years old, the second eldest sister was sent to live with an aunt and uncle. Their remaining two elder sisters also left home by the time Ahi was 11, effectively making Ahi the eldest. Ahi identifies as queer, takatāpui and a trans man and uses they/their pronouns.

Morgan Te Awhi Komene Cooke was born in Auckland in 1984. On her mother's side, she is Ngāti Whatua and Ngā Puhi and her father is Pākehā. She has one younger brother. Morgan identifies as female, takatāpui and pansexual. She uses she/her pronouns.

I was born in Gisborne in 1965. I am Te Aitanga a Māhaki, Ngāti Oneone, Whānau a Kai, Rongowhakaata and Ngāi Tāmanuhiri on my father's side and my mother is Pākehā Irish. I am the eldest of one brother and two sisters. I identify as cis-gendered female, takatapui and lesbian femme. I use she/her pronouns.

The identification of gender identities and pronouns for all participants acknowledges the privilege of those takatāpui whose gender identity matches the sex they were assigned at birth (cis-gendered). All participants in this study were referenced with their chosen pronouns.

\section{Disconnecting \& Reconnecting to 'Home'}

That fewer than half of the participants were born and grew up with their own hapu or iwi is not surprising given the urban drift of Māori to the cities from the 1950s and 1960s. The impact of urban migration on Māori culture and identity has been covered extensively elsewhere. For more information, see for example Grace et al (2001), Nikora, L.W. (2007), Szaszy et al (1993) and Walker (1992). Coney (1993) noted that: 
Many young Māori men and women attracted to their own sex welcomed the opportunity to escape scrutiny in country areas by moving to the cities. The young women involved formed the basis of the pre-women's movement lesbian communities. An older generation of Māori women involved in same sex relationships remained in their local areas. There has been some speculation about some prominent Māori women who sometimes wore men's clothing. Stories by NTA about her aunties and other older women reflect the lives of many tribally based women of the 1950s (1993:171).

Only the eldest participant, Jennifer, grew up as a native speaker in the wholly rural context of Waipiro Bay before she joined that drift herself and moved to Wellington as a teenager. As the participants get younger, the disconnection from their tribal origins becomes more and more apparent, until the youngest participant, Morgan, who grew up with her whānau, hapū and iwi in the wholly urban context of central Auckland.

Jennifer was raised amongst native speakers and Māori was her first language. However, the English language was being increasingly promulgated throughout rural areas and Jennifer herself was attracted to the opportunity:

I do enjoy my Māoritanga... when I was at school, Māori language was just coming back in but I'd lost interest. I could understand it because my mother and grandmother used to talk to me all the time but she wanted me to learn English too and I became really good at it. I was exquisite at English. Even in High School...it was one of my favourite subjects (T6A 2014:18).

However, only Jennifer had the option to choose. All other participants reflected the national trend of English becoming the only language in Māori homes; reinforced by a number of different legal and educational strategies. These included passing of the Native Schools Act in 1867 which emphasised the use of English as the language of instruction; propaganda that retaining te reo Māori would inhibit children from learning English; and the systematic use of violence against children and young people speaking te reo Māori at school. Spolsky (2005:67) refers to this as 'language management' where an individual or authority seeks to "modify the language practices or language ideology of others."

Although Kevin's father was brought up to "kōrero Māori i roto i te whare i ngā wā katoa" (T1A 2012:5), his mother was encouraged to speak English and that was the language of the home. Kevin's mother was unaware that her husband was even a native speaker until several years into their marriage. Kevin realised that his "most intense Māori learnings" came from his father's side (T1B 2012:1) whereas generations of boarding school was the colonial framework in operation: 
Not only did my mother go to Hukarere ${ }^{37}$, her grandmother went to Hukarere ... My mother was born in 1939 so I understand her grandmother went to Hukarere at the turn of the century... so there was an element around education from the area that they were from, where they were, that was encouraged. So, to me there is the connection between that and English being the language of the home (T1A 2012:5).

Whereas Peri may originally have begun life as a native speaker himself, English was the language of his whāngai home:

I don't remember but what I was told as I was growing up that when I was young and my mother had died, I went to live with my grandmother for a short time. My grandmother only spoke Māori and for some reason I understood her but when I went to live in Rotorua with my whāngai parents they didn’t speak Māori at all (T2 00.04.05).

Peri was not to learn until later in life that his whāngai mother was strapped at school for speaking te reo Māori.

When Benton (1991) documented the state of Māori language loss during a study of 6470 Māori families in 1973-1979, he surmised that by the late 1960s only $8 \%$ of children could understand te reo Māori. For further information on the role of Native Schools and particularly, Māori girl's boarding schools see Higgins et al (2014) and Jenkins and Morris Matthews (1995, 1998).

Growing up in traditional Māori environments, being Māori was a given for both Jennifer; growing up with her grandmother in the Tairāwhiti; and Peri who lived on Tūtanekai Marae in Rotorua. In contrast to those who were brought up in more Pākehā or urban environments, Māori identity was not something Peri even thought about:

I didn't have the stimulus to think about [being Māori] or the conversations about it ... living up at the marae, going to tangi, going to see Nanny at Te Puke, it was just life in general. I didn't categorise it as such (T2 00.05.15).

Morgan was predominantly brought up around her Māori side in Auckland with occasional visits to her Pākehā grandmother in Dunedin but became aware of how disconnected other members of her whānau were:

\footnotetext{
${ }^{37}$ Hukarere Girls' College was established in 1875 as Hukarere Native School for Girls. It provides "guidance and support in both Māori and [Anglican] Christian environments, encouraging participation in a range of academic, cultural and sporting activities" www.hukarere.ac.nz. Retrieved 3 March 2015. For further information see Jenkins and Morris Matthews (1995)
} 
But [I was] really brought up Māori. It was very obvious early on that I was a very Māori individual and one of the few in our extended family. So I've kind of latched onto that, but haven't really moved forward as much as I'd like... in my sort of personal circles, family and friends there's no one, and that's where I was like, no that's wrong (T3A 00.02.56).

Morgan also felt a responsibility to increase her knowledge and learn to speak te reo Māori:

There's no one in my age group ... not really, that is Māori, that's learning the language so I want to change that (T5 00.03.17).

All of those participants who grew up away from whānau, hapū and iwi - 'away from home' identified the issue of not just the dislocation but that 'disconnection' in establishing and maintaining their Māori identity. Their responses indicate a decision-making progress regarding the level to which they went on to re-establish that connection with whānau, hapū and iwi; learn more about Māori culture and learn to speak te reo Māori - if that was even available as an option. Fishman et al (1985:45) called this phenomenon 'translinguificiation' where New Zealand Māori were cited as a successful case of maintaining ethnic identity despite the reported loss of language.

Kevin's parents were teachers and so they periodically moved to different areas depending on where they were posted. So although Kevin grew up with two Māori parents and a strong Māori identity, he was always aware of being 'Iwi a waho' on his father's side:

There's a background of iwi displacement, whānau disconnection, and the need for families to engage in areas where they weren't necessarily from, so those ties in those areas actually needed to be established (T1A 2012:6).

Hinemoana's father was one of 18 children and the eldest of the five full brothers who were placed in an orphanage when their Māori mother died - despite her whānau being willing to whāngai them. And although he lost contact with his taha Māori, Hinemoana's father did all he could to instil her with a Māori identity: 
I just always knew that I was [Māori]. I didn’t necessarily know our Iwi or anything. Dad knew we were from Ngāti Raukawa but because his Mum had died when he was such a young age, he was only nine and his Pākehā father had put him and his brothers into an orphanage ...I don't know if they were the only Māori kids in the orphanage but there were certainly no Māori language spoken and no cultural things happening there, as you can imagine - just a lot of physical abuse and sexual abuse and really bad cruelty. Quite legendary. ... So, he grew up, he didn't speak the reo and he didn't have much contact with his Iwi or his hapū or marae (T5A 00.11.01).

Despite Hinemoana's father being forcibly disconnected from his whānau, he remembered the location of his marae in Ohau and they would often stop outside on their travels:

He didn't really grow up with a strong sense of his own place, his tūrangawaewae or anything. But he did know where his Mum was buried in a particular place, in an urupā, ...and he knew where that marae and urupā was. ...We would stop there and he would say, "This is where your grandmother was buried but I don't know where" (T5A 00.13.06).

Ironically, the Māori connection Hinemoana's family maintained was through the Pākehā side of the family. Hinemoana's Aunty Kath was her father's half-sister through his Pākehā father and she married a Puketapu - 'Uncle Tut' - from Taranaki. She and her sister Peace, another half-sister, were much older than Hinemoana's father and they became like mothers after the orphanage. After Aunty Kath married Uncle Tut, he became somewhat of a surrogate father to Hinemoana's father. So almost everything her and her father learned about being Māori, they learned from Uncle Tut, "so he became a koro for me even though he was my Dad's halfsister's husband" (T5A 00.15.29).

Hinemoana's Uncle Tut was a farmer and sheep dog trainer and the farm was a huge attraction; despite the puppy fleabites and the odd tussle with an electric fence:

It was awesome you know and all my cousins would visit and we'd all be at the farm at the same time and we'd run around like crazy wild things. Yeah, it was my best holiday times. The best times of my childhood were spent on that farm in the freezing Taranaki winters ... That was my main connection with being Māori - on that side of the family (T5A 00.16.26).

Of all the participants, Ahi had the least connection with their iwi, hapū or whānau origins. Having been moved to the mountains of the West Coast as a toddler, Ahi did not develop a strong Māori identity from their two Māori parents: 
My parents joined a church when I was eight so things changed a lot then, but before then their friends were, like, other alcoholics. So everyone we were around were like on the piss all the time and quite a few of their friends were Māori but I didn't know lots of people so I didn't ever think about being Māori (T4 00.05.24) ... We didn't really talk about it and we didn't speak te reo and we never talked about whakapapa. We didn't really have anything to do with it. Both my parents had no contact at all with their families (T4A 00.07.30).

Ahi enrolled in an extramural te reo Māori course during their pregnancy when they were 19 years old, but this was interrupted by parenting their new baby. When Ahi moved from Nelson to Whanganui with their child at the age of 21, recognition of their identity as Māori coincided with their politicisation:

That's when I really realised that I was Māori, in a sense, because like half the population there is Māori and I had always been in really, really Pākehā places and, because it's so racist there, it's really noticeable... People are always saying, "Oh that's so Māori" when they mean something is broken or stupid. And I was really like shocked and saying "What are you saying, what do you mean?" ... Even the nice people I knew were really racist and they didn't know it (T4A 00.42.13).

By the time their child was four years old, Ahi was increasingly aware of the double standards implicit in racism against Māori:

But I was really, really identifying as being Māori and I had started noticing things like the Pakeha single mothers that I knew would say, "let's get some beers and go and drink in the park with our kids. Let's have some beers in the park." And I was like, I would never do that, no way and they'd be like, "what?" and I'd say, "well, I think it's because yous [sic] are Pākehā, people aren't going to look at you and go, "bad parents getting drunk in the daytime with your children but people would look at me and think that" So just realising heaps of that stuff (T4A 01.03.13).

Several participants raised the issue of how Christianity had affected them over their lives and in relation to perceptions of them as takatāpui. This is discussed further in Chapter 6. Both Kevin and Morgan specifically talked about Christianity and spirituality as part of being Māori. Kevin's mother was a member of the Anglican Church: 
We weren't particularly religious, I went to Sunday school, but it was only because it was something to do on Sunday. That was in Te Whaiti but other than that it wasn't our practice to go to church. But we would go, for example Christmas time, with my mother's family. They would go to church, so we would go to church (T1A 2012:6).

In dramatic contrast, Kevin's father was from the Ringatū faith:

The marae where he was, and when he was brought up, they used to have kāuta around the meeting house, so each of the whānau of the hapū used to all have their own kāuta and cook food and then everyone will bring out the food and eat. So his circumstances and his style of upbringing was very different from my mother's side, so there were some quite striking differences... down at the marae, church was part of it but we didn't know the distinction, it was just part of the whole thing (T1A 2012:6).

Morgan's mother was lapsed Ratana and her father was Presbyterian. Apart from three months in a Presbyterian Sunday School where she lost her lisp, Morgan had no recollection of organised religion playing a significant part of her childhood:

Spirituality wasn't really discussed. We're not the most Māori of Māoris really. It's just something I feel. ... Just something within, more so when I'm on our land or especially at our urupā. It's beautiful there and overwhelming but in a blissful way, it's amazing (T3A 00.15.39).

Despite the importance of spirituality in her life, Morgan did not attribute that to her immediate whānau:

I'm extremely spiritual and I put that down to me being me 'cause it's not a thing in my immediate family at all. None of my immediate family are spiritual and in my extended family, there's no one who is overly spiritual. Or it's not something we talk about. It's something I've always known or sensed when a spirit is around or something is going on. Part of who I am (T3 00.13.50).

Morgan did, however, associate her spirituality with her elders and her marae:

The only spirituality moments I can recall is listening to my elders like my Aunty who passed away New Years Eve just gone. Listening to her was always quite captivating and it was just talking about stuff, everyday stuff, with the family members catching up on old goss and that sort of thing but it was just the words. I don't know the way she spoke was just, always touched me and that's why I've struggled so much with her passing this year ... because that isn't there anymore. And it's almost like, with her not being there, that spiritual connection has almost been lost (T3 00.14.49). 
My father was the first grandchild and was given as whangai to his grandparents at his birth in Gisborne in 1940. His mother, my Nana Betty, was not allowed to marry Dad's father because she already had an arranged marriage. She married him and had nine more children. Dad's father also married and had six more children. Dad became the baby brother to his mother and five Uncles and Aunties so in total Dad had 21 brothers and sisters; none of them to the same two parents.

Dad would recount stories of his mother, my Nana Betty, being beaten at school in the 1930s for speaking te reo Māori. Dad often spoke of Nana coming home bleeding as if he had watched it himself which indicated the significant impact it made on him. So, although my father was raised in a Māori speaking house and therefore it was his first language, he focussed on being good at English once he started school. That being said, as an artist, carver and storyteller, he was familiar with all the terms and whakapapa related to the Marae and whakairo, kōwhaiwhai and tukutuku.

In his early 20s, Dad moved to Wellington to find work and a Pākehā wife. As he would say, "you marry a Pākehā, you marry a woman. You marry a Māori, you marry her whole family." My parents moved back to Gisborne to have their children and Dad insisted we be given Pākehā names to protect us from the abuse and mispronunciation he received with his first name 'Karauria Tarao.' One enterprising teacher changed his name to 'Claude' which he was known by for his entire school life. When I was five years old, my parents moved to Dunedinnearly as far from home Dad could get.

My memories of Dunedin are vivid because of the extreme contrast we experienced. Firstly, it got cold. Freezing cold. And suddenly we went from Mum being the only Päkehā on the marae to Dad being one of the few Māori in town. Instead of normal we went to being 'darkies' sometimes used affectionately - and 'horis' - which most definitely was not. Us kids had to go out in groups to avoid being beaten up by Pākehā children and sometimes threatened by adults. We were in many fights until neighbouring children learned that they best leave us alone. The racism we experienced as children though was magnified for our father. Few businesses would employ Māori and landlords preferred not rent to them so it took a long time for us to finally settle in Dunedin.

As the eldest, Dad taught me Māori pronunciation, whakapapa and every Māori art-related term he knew. It was my job to teach the others when they were ready to learn. Dad taught me about Māori gods and being in touch with our whânau who had passed away. Dreams 
were taken very seriously especially after my Nana Betty passed away when I was 10 years old. Even though he had left home, he brought me up with the expectation to become well educated and take that experience and knowledge home for the good of the whānau.

Every year I counted down till the Christmas holidays so we could go home. We stayed at Poho o Rawiri Marae where we could run riot with all of our cousins. Over time we lost our accents and our skin became fairer from a lack of sun. By the time we were teenagers, our cousins started calling us the 'South Island' or 'Pākehā' cousins. The power of my father and my close relationships with my Nana Betty and my great grandmother ensured that my sense of myself as Māori was ingrained, regardless of where we lived or what colour I was.

\section{From the Mouths of Babes: First Awareness}

This section considers how the takatāpui participants became aware of their gender and sexuality; the age of first awareness and on-going development, any dissonance related to it. A common term used in LGBTIQ communities in relation to this process is 'coming out'. De Monteflores and Schultz described it thus:

Coming out is the developmental process through which gay people recognize their sexual preferences and choose to integrate this knowledge into their personal and social lives. A number of experiences are critical in this process: the awareness of same-sex attractions, first homosexual experience, coming out in the gay world, labeling oneself as gay or homosexual, coming out to friends, family, and co-workers, and coming out publicly (1978:59).

The participants' rare use of the term 'coming out' was less in reference to the sexualityspecific development process and more to specific events; making a clear decision about their gender or sexuality or the moment of disclosing to their parents. The significant difference between this traditional framework where parents and family are usually informed after considerable identity development, is that takatāpui are more likely to inform their whānau (and most people they know) at much earlier stages of awareness.

In that regard, the participants here reflect the experience of the 169 Māori participants $(8.3 \%$ of the sample), of Lavender Island: Portrait of the Whole Family (Henrickson 2006: 258,261); the first strengths-based multidisciplinary study of lesbian, gay and bisexual (LGB) people in Aotearoa New Zealand. Although trans people who identified as LGB were able to participate, the study is necessarily limited by its focus on sexual orientation. However, its finding that "Māori and other cultural minority groups must manage multiple, and sometimes competing, 
cultural presses, the negotiation of which shapes individual identity" (ibid 2006:262) is certainly applicable to the shaping of takatāpui identity.

All of the participants had awareness of their gender from their earliest memories as toddlers. Half of the participants - Kevin, Hinemoana and Morgan - are cis-gendered; their gender identity matching the sex they were assigned at birth. Jennifer, Peri and Ahi were the converse of this. Pathologised as a mental illness; 'Gender Identity Disorder (GID)' implies that it is a person's identity rather than their body - and associated discrimination - which needs to be fixed:

By its title and diagnostic criteria, the diagnosis contradicts treatment goals that correct the body. These shortcomings could be addressed by replacing GID with a new diagnosis unambiguously defined by chronic distress rather than social nonconformity. This would both reduce the harm of unnecessary stigma and help to support the medical necessity of sex reassignment procedures for those who require them (Winters 2006:72-73).

Jennifer appears to have lived a charmed life within the protection of the strong women leaders her area has long been known for (Mahuika 1972). Recognising her unique status, Jennifer's grandmother claimed her as her own and raised her as the girl they both knew her to be:

[My grandmother] was able to tell whether my mother was going to have a boy or a girl - or anybody, actually - any other woman in our iwi. And when it came to me she doubted me ... "What's this about?"... I think I was about five years old and I knew that I was totally different from everybody else (T6A 2014:1).

Although she knew she was different, Jennifer never had a concept of herself as male:

I never have that thought, "why am I like this?" I am like it. But I think it was instilled in me by my grandmother (T6A 2014:17) ... [If] they say were you born male, I said no, I was born female. Always been a female, you know. I said the equipment might be wrong but, you know.... my grandmother knew it and my godmother knew it, you know, so I know what I am (T6A 2014:8).

Both Peri and Ahi reported the stigma they faced to live as male and the effort required to change their bodies to match that identity. As a child though, Peri experienced no confusion on the matter of his gender: 
I can't put an age but pretty much first recollections when you're thinking about "I'm a boy" you know from down here [signifies low height], from the word go really and it was for me. It was a definite. It wasn't "I think..." or "What's this? What's that?" It was "I'm a boy," but it didn't quite flow that way did it? (T2 00.13.02).

Ahi's early awareness of their gender and attraction for girls was tempered by the knowledge that neither would be acceptable:

I don't remember ever thinking about that [lesbian, bisexual or gay]. Like I knew that I liked women when I was like three years old or something and I knew that I wasn't allowed to so I knew that that was not a positive thing. And I also used to think that I was a boy and Mum would always be, "don't be stupid you're a girl," and I never really thought into that. I knew that I would probably get into lots of trouble if Mum found me looking at pictures of girls (T4 00.14.33).

\section{Naming Attraction}

Jennifer enjoyed the indulgence of her grandmother, godmother and aunties for her early preferences:

There was always those times, you know, when we were alone that I can just put a dress on... she knew it wasn't just, you know, for kicks... it was just because I wanted to... you know, all the time. And my aunties were the same, you know. One of my aunties had like a stiff petticoat and I used to use it as a wedding gown, you know, and I wasn't allowed to take it outside. And I had a... this old horse, I couldn't ride horses ....and I stuck flowers in its bridle and on the saddle, you know, sitting side saddle in my petticoat ... and my godmother going past and "who's that over there?" "Who do you think it is? Bring that petticoat back inside." And of course one time I had it on my head, and my aunty was looking out the window, and we were just below the kitchen window... and I said "now because I'm the bride you have to lift up my veil and kiss me" and my aunty goes "kiss you?!!" And my cousin's going, "no," and I was

going, "yes, grooms always kiss the bride." And it was just silly things like that. And, of course they all knew, you know, and it was just......totally accepted (T6A 2014:13).

The dressing up was not limited to their home, although others in the whānau may not have known what to make of her:

When I was seven years old I had a masquerade ball, she [grandmother] dressed me as a Kewpie doll ... and I cried because I had to partner a horse and I didn't want to. And I wanted to partner the prince, but he was already... he had his partners. ...and I could see them all looking at me 
and going "oh, that kid, that kid." You know, that's just all they used to say about me, "that kid" (T6A 2104:2).

Kevin knew his sexual orientation from the beginning but considered it safer to hide it:

I've always known that I was same-sex attracted right from probably when I was about three or four years old, and then of course, after that, it's all a matter of playing a game depending on how well you want to live, or live in the community that you're around (T1C 2012:1) ...I had more intense experiences with male company from the time I was five or six (T1A 2012:7).

Although Hinemoana could not recall where she first heard the word bisexual, it was in her vocabulary growing up:

.. and I felt completely positive about it but I don't know how that happened. ...I knew from the time I was really young that that's what I was and it was all good. I didn't feel in any way negative about it or ashamed. I knew other people would so I kept it quiet for quite a long time (T5A 00.40.53).

Although Ahi preferred the term 'fluid,' they initially accepted being called 'bisexual' because "it didn't really worry me very much what other people thought that I was." By the time they were in their early 20s, Ahi realised that there were "more people than boys and girls" and bisexual was therefore no longer a useful term (T4A 00.16.30). As Ahi stated, "I was attracted to whoever, regardless of what their stuff was" (T4B 2014:3). Ahi began identifying as queer although they could not recall where they had learned that word. The increased awareness of trans came about in their mid 20s, around 2008-09:

I knew that trans women existed, I didn't know that trans guys existed but I didn't think about them.. and so I didn't think "I'm interested in trans women" or "I'm interested in cis-women," I was just like defaultedly [sic] dating cis-women and I knew that I wasn't interested in guys but I knew that I could be interested in guys and so I didn't think that I was a lesbian (T4A 01.00.04).

Morgan was 14 when she first consciously thought about 'liking girls' and spent the next three years trying not to think too much about it again:

When I was 14 I had had a thought and it was about [her openly bisexual friend] but it was like "no way in hell, that is so wrong, there's no way a girl can like a girl, that's just impossible." So for three years I was just off and on, it would pop into my head. ...I knew I definitely liked guys but there was this other element inside me that was very confusing and hard to understand at the time because within me and my upbringing, that was not an option (T3A 00.24.04). 


\section{In the Whare - Home Sweet Home}

Both Jennifer and Kevin spoke fondly of their childhoods. Jennifer had powerful memories of living with her grandmother, her godmother and her aunties who protected her from the world:

I was actually raised by my grandmother, who was an amazing lady, taught weaving, did whāriki, and while she did that, she used to have me under her skirts and I'd be listening to all the gossip and occasionally run up to Auntie's place and tell them all the news before she could... when they used to come and visit she used to roll her eyes to let everybody know I was under her skirt, not to say too much. I had a wonderful upbringing... She was a sort of rangatira; where everyone used to go for medicines... so she was well-respected (T6A 2014:1) ... Where I grew up in Waipiro Bay, it's a beautiful place (ibid 2014:10).

Kevin also grew up in a loving family and he recalls his mother saying "that comes from my side" because his father was "brought up quite hard" (T1B 2014:1). Kevin did not elaborate on the nature of his father's 'hard' life but did not think that it affected him adversely at all.

Unfortunately, such a happy beginning in life could not be said for the rest of the participants who experienced upbringings characterised by violence, sexual abuse, neglect and alcoholism. This resulted in the use of alcohol and drugs, unwanted sex and rape, depression and suicidality. Peri lived on Tùtanekai Marae until he left home at the age of 17. Although he enjoyed the fishing and gathering food when he went home to Te Puke, the "weekend ritual" revolved around alcohol, as his home life did during the week:

I grew up a lot with myself, being an only child, being exposed to a lot of alcohol environments. I think I would have spent most of my young childhood, right up to about ten, maybe older, sitting in the back of the Holden outside the local pub in Te Puke waiting and waiting for someone to take me home (T2 00.13.42).

Within the busy marae environment, Peri inhabited an intensely lonely world in his whāngai family as they rarely spoke to each other. His mother was violent and abusive towards him, making him feel like an unloved accessory which was routinely placed in unsafe situations:

Again, in the boozy party environment, so I've been exposed to being turfed out to be looked after by other people who would take advantage of us kids and I've been a victim of child molestation, and that sort of stuff with people who were entrusted with our care. And they didn't do that at all, they abused us (T2 00.15.12).

Peri recognised that he was quite naive but "old enough to know that's not my home, I have to make my own home" (T2 00.24.52). When Peri's grandmother on his whāngai mother's side 
realised something was wrong, she took him to live with her. Life improved somewhat and despite limited communication and the age gap, Peri felt safe with his grandmother. He trusted her and learned how to cook, garden and to be humble from her. However, it was still a lonely and simple life:

So, I didn't have a stimulating, educational home life. In fact, I thought I was quite dumb, I didn't know much, about much. And I learnt a lot from TV, even my first indication about effeminate men was from the Grace Brothers "Are You Being Served?" Not a lot of learning going on, a lot of watching, even on the marae, just one of the kids, nothing special, just stayed in there and hung in (T2 00.16.48).

Hinemoana believed that her father suffered from severe depression because of his own abusive childhood, which in turn affected her own. The impact of her father's experience on her was profound:

So, my early childhood memories are dominated by memories of my Dad's violence and his anger. He was violent towards my mother and my sister and me but in different ways. I think my sister copped a lot of it because she was quite mouthy and would try to protect Mum and she often got the brunt of Dad's anger physically and she ended up being kicked out of home when she was only $15 .$. So even when I wasn't being hit by Dad I felt like I was about to be, pretty much most of my young life. I was really scared of him (T5A 00.06.11).

Since neither her mother nor her sister could protect Hinemoana from her father, it was through a Pākehā friend that she began to start protecting herself:

He [friend's father] was one of the most amazing people I'd ever met. He was so quietly funny and loving and I had never witnessed a father-daughter relationship like that in my life and so once I started to get to know her and see the way she interacted with her Dad, that's when I realised that actually not everybody's father was like this ... and I guess I stopped blaming myself and my mother subconsciously and started to turn my anger towards him for his behaviour (T5A 00.09.54).

Hinemoana's mother wanted to leave her father but was not confident she would win the custody battle if it went to Court. As soon as Hinemoana turned 14 years old - the age when a child could choose which parent to live with - she chose her mother and two weeks later they both moved to Nelson. However, Hinemoana was sad to leave Whakatane and the few happy memories she had of her father: 
I really liked Whakatane, I really loved living there. I don't have any bad memories about the town; I just have some pretty unhappy memories about the house I grew up in. But also you know I remember loving being by the beach and loving going out on the boat with Dad sometimes and my Mum is a really cool singer and she used to teach me songs and I remember singing with her (T5A 00.08.12).

Ahi has vivid memories of their lifestyle in the mountains of the West Coast as they were growing up:

When I was little my parents were just drunk all the time and did drugs all the time and ... so I spent lots of time with my siblings, and we were really, really poor. That's probably the defining thing about when I was young (T4A 00.00.56).

Ahi's parents were both fashion designers specialising in leather clothes. Her father made patches for both the Mongrel Mob and Black Power so gang members were frequent visitors to their home. Ahi recalled hanging out with their children and although the widespread fear of her father prevented any gang violence, home was not a safe environment:

I was scared of Dad. I was more scared of Mum because she would be the one who sends you to Dad to get a hiding... I guess when they would all be partying, kids would go off to the bedroom or whatever and they would sort of put us away ... or we would sit outside the pub in the car. And so I didn’t feel scared for us but I often felt scared for Mum (T4A 00.06.50)

Ahi's parents separated when they were about 11 years old and they were mostly raised by their mother, both in the family home and in a series of rental homes in seaside communities nearby. Since their father was the main authority figure, their mother had limited ability to set boundaries and Ahi became increasingly independent.

Born and raised in Auckland, Morgan characterised her upbringing as 'traditional.' She was shocked to discover that her parents had been activists, including during the Springbok Tour of 1981, and that she had grown up with the children of their activist friends:

Mum was very Māori and Dad's a red head with blue eyes so it was very juxtaposed all the time, and maybe all the more reason for what they did at the time. They blew up a landmark, they got in trouble for it - big time - it was along the same lines. And I only learnt that in the last few years, growing up Dad was very kind of mono[tonous]. When I found out that I was like "really?" (T3A 00.17.04).

Morgan was not exposed to that history or those politics but because her mother was quite an outgoing person and her father was an intellectual, she grew up around a diverse network of people. However, her relationship with her mother was fraught: 
I think the ways she dealt with things was to hit and to beat, which you know ... in her age group that was the way it worked and that was how she was brought up and all her friends etc. So I can understand but that's how our dynamic was, so I moved out as soon as I could. And then I missed my family too much so came back six months later to just have dinners and touch base and stuff and we've been really good ever since (T3A 00.38.24).

At the age of 16, Morgan was dismayed to discover that one of her older aunties had tried for five years to whāngai her but her mother had consistently refused. When the relationship with her mother was difficult, Morgan's Aunty Josie would say, "If I'd had you, things would be so different," to which her mother would respond, "She'd probably be hapū [pregnant], without a job, living on Boot Hill” (T3A 00.04.27).

My memories of Gisborne come in flashes of grapes and fruit trees in the back yard; sunny beaches; the marae; the ride on truck at school; and my Nana Betty loving me. I also remember someone coming into my room and waking me when everyone else was asleep. Although the 'official line' is that Dad did not want us growing up around gangs, my older cousins and I consider it more likely that he found out what Uncle had been doing. Dad may have left the incest and sexual abuse behind but he brought his violence with him and we grew up in absolute fear. Obedience failed to save me because he would hit us in order of age; being the eldest meant I was responsible for my sibling's misbehaviour.

Mealtimes were particularly fraught as Dad was a great cook and Mum was not. As the 'woman' though, Mum was expected to cook and food would be thrown if it did not meet his standard. We were forced to eat the food even if Dad would not. The days Dad cooked were such a relief and he made the Māori bread and fried bread. I still had a sense of loving my father as much as I hated him. I would walk to his work after (primary) school and we would talk and laugh. Then I would walk him to the pub and go home. He returned drunk most nights and often woke us with his shouting. Sometimes he would bring us outside so we could watch him beat up our mother. Many times, she told the story of seeing us in a line with our mouths wide open screaming and crying but she could hear nothing. We all had recurring nightmares into our teenage years.

Our parents had regular parties and Dad would put down a hangi with a tiny one just for us kids, which made us feel so special. I recall $R \& B$ music, hotpants, arguments, and sex in our bedrooms. Us kids would huddle together as the night progressed, our ears tuned to the sound of Dad's voice. In the morning, I consumed the leftover alcohol and they would wake to find 
me drunk. I must have been 9-10 years old. Why that would happen more than once remains a mystery to me but it was just one more element of our dysfunctional whānau.

Apart from going home to Gisborne, the highlights of my childhood were watching Dad carve or draw. He would make up characters and one time he made me a little book about them. I still have it. Another time he came home (not drunk) with a set of expensive drawing pads and paints for each of us and we spent the weekend together making art. If Dad brought people home we watched him be funny and tell stories - he was a gifted storyteller. Each brief respite from fear was enough to make the rest of our lives bearable.

By the time I was 12, my mother had enough support from her family to leave Dad. As she said "my bones don't heal as well as they used to." We were 12, 11, 10 and nine years old. With limited authority to control us and forced to work, Mum had to leave us to our own devices most of the time. She was however adamant that she not be blamed for us missing out on our "Māori side," so we joined a kapa haka group and become involved in the new urban marae, Araiteuru, being built in Dunedin. We learned tikanga and kapa haka from pākeke, kuia and koroua from iwi throughout the country.

Dad stalked us for years, each time finding us and breaking down the doors of the not-so-safe houses we lived in. Still, every Saturday I would visit my father and we started to develop a different relationship as he never hit me again. Often, he would take me to the Otago Museum and we would study the wharenui, Mataatua, and the taonga on display.

Although I thought that being Māori meant growing up in violence and alcoholism, I never thought that being Māori meant being violent or an alcoholic. To survive, I chose to focus on the positives of our cultural values, Atua, whakapapa and art.

The alarming level of violence experienced by the participants is reflected throughout the large body of research on violence in New Zealand. In its 2007 literature review on the topic, Amokura Family Violence Prevention Consortium concluded that:

As a whole, the statistics suggest that Māori are over-represented as both victims/survivors and perpetrators of violence within families (Erai et al 2007:11).

The Ministry of Social Development (MSD) reiterated that finding in its comprehensive study on family violence:

There is fair consensus that Māori are substantially over-represented as both victims and perpetrators of violence in families/whānau (2007:55). 
MSD also found that Māori levels of domestic violence were significantly higher in urban than rural areas (ibid:56).

As the violence and abuse occurred within Māori homes, it had a lasting effect on the mental health of the children within them. In their study on recovery from mental health issues, Lapsley et al (2002) identified three major themes as childhood contributors to later mental health issues; abuse, loss and abandonment and feeling different. Physical, emotional and/or sexual abuse within family, at school and by outsiders was mentioned in close to half of their 40 narratives on recovery from disabling mental health problems (ibid 2002:17).

Although Lapsley et al (2002) found no difference between the experiences of Māori and nonMāori, childhood trauma has a specific impact on Māori construction of identity. Hand et al (2002) found that:

The significance of whānau, hapū and iwi for Māori victims of family violence is complex and wide-ranging. On the one hand, whānau can be a site of intergenerational abuse of children and adults, and abuse in turn can result in alienation from whānau and poverty and transience for women and children who are victimised. On the other hand, whānau, hapū and iwi can represent a source of identity, belonging and values. Whānau can also be a primary source of support, intervention and protection for victims, even if responses are not always appropriate (cited in Ministry of Social Development 2007:56).

This chapter has illustrated that even such a small sample of takatāpui can represent complex variations of the construction of Māori identity in postcolonial Aotearoa New Zealand. Factors include whether they remained within their own whānau, hapū and iwi boundaries as children; the disconnection subsequent to being raised 'away from home;' access to Māori language and culture; and loss of whānau support or intervention. The upbringing of parents played a major role in the home environment where affection and nurture is offset by violence, neglect, abuse and the harmful use of drugs and alcohol. While school could be a haven from an abusive home and the road to higher education, it could also be the mechanism for learning to meet low expectations and experiencing failure.

\section{He Hononga}

Chapter 4 provided insight into research questions within the Whäriki Takatāpui framework to do with Mana Wāhine, Mana Motuhake and Te Whare Tapa Whā. 
Takatāpui share childhood experiences of growing up Māori with their siblings and other Māori, constructing identity for themselves that makes sense of it all. Where the construction of Māori identity differs for takatāpui is that they are constructing their gender identity and sexuality at the same time. Takatāpui generally identified their gender and sexual orientation at a young age. For many, their self-acceptance and lack of shame occurs regardless of the level of knowledge, support or affirmation available. The level of secrecy though is directly related to the perceived level of discrimination around them - something even children can identify.

Regardless of their upbringing, almost all participants gained that certainty of identity without knowledge of the terms; 'lesbian, gay, bisexual and trans' (let alone takatāpui) or exposure to positive role models. Even as children and young people they strove to avoid negative stereotypes and found ways to be themselves.

Participants confirmed the importance of whakapapa for a sense of belonging. Colonisation contributed to the urban drift of the 1950-60s and the steady disconnection of Māori away from their homes and cultural bases. Almost all participants identified a wish to improve their level of te reo Māori. Some discussed the role of spirituality in their lives and how that contributed to their sense of being Māori.

Participants shared insights into key issues that impact on takatāpui health and well-being and how they addressed the challenges facing them.

Whakawahine and trans participants noted their awareness of gender difference (from the one they were assigned at birth) from a very young age. Their ability to live as their preferred gender relied on whānau recognition and acceptance which was not always forthcoming. Almost all participants were aware from a young age that discrimination against people with diverse sexualities existed which affected their decision to come out (or not) when they first became aware themselves. This led me to realise they were modern day version of tipua spiritual creatures who could change gender and form.

Participants mirrored common Māori experiences of growing up variously with violence, sexual abuse, neglect and alcoholism. This often resulted in the harmful use of alcohol and drugs, unwanted sex and rape, depression and suicidality as they grew up. This did not however, stop any of the affected participants from claiming their diverse gender identities or sexualities.

The connection of growing up with parents and elders who kept them safe was critical to wellbeing and instilling a sense of Māori identity. The relationship and trust developed between 
participants and their parents, immediate family and wider whānau growing up had a strong bearing on the reactions when takatāpui disclosed their diverse gender identities, sexualities and sex characteristics. Where dysfunction, strained relationships and abuse already existed, anything which threatened the 'normality' of home life could be traumatic. Participants reported better relationships with their parents' as they grew older which would be of benefit if disclosure was delayed until that point. However, most takatāpui did not delay that disclosure even if they expected a negative response. 


\section{CHAPTER 5: SCHOOL, WORK \& CLAIMING IDENTITIES}

This chapter continues the oral histories of our participants as they grow older; go to school, start work and start to identify in their diverse genders, sexualities and loves. Here it continues to answer the research questions: What are the key issues that impact on takatāpui health and well-being? and How do takatāpui address the challenges facing them?

\section{Making It or Faking It: Negotiating the Classroom}

School is often the first encounter Māori children have with the world outside their own home. Their attitude toward it and their potential success within it are influenced by their parents' own attitude to education; the reception they receive from teachers and other pupils; and their ability to meet its requirements.

Kevin was raised by two teachers in a home which valued education; Peri and Hinemoana saw school as a place of refuge away from home while Jennifer, Ahi and Morgan wanted to leave school as soon as possible. Most participants related how their school experiences informed their identity as Māori.

Both Kevin's parents graduated as teachers from Ardmore College in 1959, the year before Kevin was born. His primary schooling consisted of him attending a range of schools where his parents were stationed. From first living in Rotoiti, Kevin was taught at Rotokawa, Te Whaiti Primary or Native School, Murupara Primay School and Tāwhiuau Primary School. Kevin spent his secondary school years boarding at St. Stephens School in Auckland from 1973-1977. St Stephen's, or 'Tīpene' as it was known, was a Māori environment that Kevin loved:

I think St. Stephens introduced me to become more aware of pan-Māori, just different Iwi, different tribes, different natural groupings that the boys seemed to go to, so the Mataatua ones would start to come together, all the Coast ones would come together, all the North Auckland ones would come together ... it also started to build up a very extensive network of Māori throughout the country, some quite strong networks which still exist today (T1A 2012:2). 
Kevin achieved his School Certificate and University Entrance. ${ }^{38}$ By his Bursary year ${ }^{39}$ he was less interested in his studies and his highlight was representing the school in a world tour to Wales, England, Holland and Los Angeles with sports and kapa haka.

Kevin started at the University of Waikato in 1978 but struggled with his first experience of a Pākehā environment:

It was all both a Pandora's box of new learning and not quite understanding what was going on, wanting to do all sorts of things and not necessarily being focused on any one thing (T1A 2012:3)

He soon left and his parents sent him to live with whānau in Wellington. He worked at the Post Office and then spent 15 years in the banking industry. At the Wilson \& Horton Group, Kevin's role involved highlighting business and other opportunities. He suggested they build a stronger relationship with Māori by supporting the Traditional Māori Performing Arts Festival ${ }^{40}$ while following local groups in their community newspapers around the country. In due course the Group became a sponsor of the Festival:

Because we were there involved in a type of sponsorship capacity, I was also there right from the pōwhiri to the poropororakī but what it did was reconnect me and highlight that my taha Māori side was really lacking ... it was then that I realised that I wanted to strengthen my ties more and get to know more about my taha Māori ...in a way that it was a part of my everyday life as opposed to a weekend or an event (T1A 2012:9).

With that commitment to himself, Kevin re-engaged with tertiary education. He matriculated from the Wellington College of Education in 2000 while he began several years at Te Wānanga o Raukawa increasing his fluency in te reo Māori.

Peri attended Rotokawa School and Mokoia Intermediate, which was a welcome reprieve from home:

I think things improved from there, with going to school. They tried to make an effort to make me look the best and I did, I think I did look really good. About school, I loved school. It was like a retreat for me actually and I slowly learned to communicate because I didn't [before] and to interact with other kids apart from the ones at the marae (T2 00.20.16).

\footnotetext{
${ }^{38}$ Equivalent to Years 11 and 12 qualification

${ }^{39}$ Equivalent to Year 13 qualification

${ }^{40}$ Now Te Matatini National Kapa Haka Festival http://www.tematatini.co.nz/
} 
Given her father's history, Hinemoana thought it was "quite ironic" (T5A 00.05.39) that she was sent to St Joseph's Catholic School. She recalled her black gym frock and being taught more by lay teachers than nuns:

But they [lay teachers] were quite a progressive bunch of women actually in general, they were quite a good influence on me, I think. The fact that they used to hit us wasn't so great... but enough that were very loving and wise and fun and very smart to kind of balance that experience out for me (T5A 00.03.40).

Around the time she moved away from her father and friends, Hinemoana experienced quite pronounced mental health issues, which were disregarded seemingly because of her continuing achievements:

I'd had depression in my early life, when I was about 14; a very serious depression and no one really helped me at that time. All they did was tell me to pull myself together... I tried to kill myself at that point when I was 14 but it didn't work and people just tried to ignore it away and because my school marks didn't suffer I wasn't really offered the same kind of support maybe I would have if my school marks had been failing (T5A 00.33.39)

Hinemoana went on to attend secondary at the low decile Trident High School. Five minutes walk away, she enjoyed school but encountered prejudice from other Māori:

As I got older I went to Trident High School, I started to understand that I didn't kind of fit in. I tried to join the kapa haka group and I was kind of vibed out by these other girls and I eventually worked out that it was because I was fair. So, they didn’t think I was Māori or Māori enough and that was a bit puzzling because I had always felt really accepted and totally just like all of my other cousins (T5A 00.17.24).

The impact of that invisibilising prejudice was accumulative. Hinemoana completed high school and attended Canterbury University in Christchurch. Although she remained interested in and respectful of things Māori, she did not identify as Māori as strongly as she had before. Jennifer thought "going to school was a breeze" (T6A 2014:2) but at the age of 15 she took the opportunity to live with her mother in Wellington. On her arrival, Jennifer discovered her mother had her school uniform ready. Jennifer was quite adamant that she was not going to school any longer, she was going to work which she eventually did (T6A 2014:3).

Because of the whānau's remote location, Ahi was home schooled until the age of 12. Enrolling at the local primary school was both a dramatic and frustrating change: 
Correspondence school sent us our school work but we sort of just did it with each other. So, Mum and Dad didn't [help]. I don't know what they did all the time when I was a kid, but my sisters would help, everyone would sort of help each other. It was cool because you can do things to your level so I was five years ahead in Art and English but behind in Maths. But I could do all of my work in four hours then go and play. When I got to primary school we spent all day and didn't learn anything, we kept lining up and ...I was really like, you're trying to keep us stupid? I didn't do well at school (T4 00.02.54).

Ahi considered that the main reason they did not fit in was because of class:

But I didn't fit in because I could do stuff the other kids couldn't and I understood how things worked and the other kids didn't and I thought they were really immature. But lots of things they didn't know how to do, like fix a hole in your socks, make the gravy or cook dinner and I used to go, "yous are fucking stupid" but I didn't realise that that was a class thing. They had parents who did that stuff for them. If they wanted gravy they made it out of a packet (T4 00.18.10) ...I didn't wear the proper shoes, 'cause I didn't have shoes. I was always late because I had to push the car to get to school, you know all that kind of stuff (T4 00.19.48).

It is possible that class and race were connected in that instance, although Ahi did not specifically identify being Māori as one of the reasons for experiencing prejudice or teasing. With the negative environment they were experiencing, Ahi began smoking marijuana and became increasingly disinterested in school, despite having high marks in their subjects.

Morgan's primary memories were of her high school years because her choice of Auckland Girls Grammar was probably one the most regretted decisions of her life:

...That school was very devoid of creativity or creative outlets aside from drawing and painting etc, and that's where I would have excelled, I feel. So, I probably should have went to Western Springs or something like that, where they do support or encourage the artistic side a bit more, whereas AGG's was more academic or sport, and I didn't really fit into either (T3A 00.06.25).

Despite not enjoying her school years, Morgan placed a high value on education:

I left school with only computing which was a surprise because school was not the funnest of places for me. Yet I stayed, I don't know why. ...I did try to do study [later on] because I knew education was key in order to improve one's situation and better yourself (T3A 00.11.10).

Although finding the right area of study was a challenge, it did confirm where Morgan's interests lay: 
Audio engineering - definitely not my thing. It's very mathematical and science based, which I didn't know music was. So that was an interesting challenge. I did learn that I love and prefer live recording or live music or live audio engineering. Haven't gone back to that yet but that's definitely something that I would want to do. I keep in touch with my muso mates. That's a bit of me that's missing at the moment - I need to change that (T3A 00.11.35).

School was a place of refuge for some and a source of frustration for others. Some participants continued to explore their gender and sexual identities on the playground and in the class. Even though she was taught by her grandmother to act in a certain way at school or outside the home, it did not affect Jennifer's sense of self:

But when I had to go to school then things started to change, but ... when you get home it's your home... being a kid I sort of had to change and be part of the iwi (T6A 2014:12).

Jennifer still held memories of an idyllic school life:

...everybody treated me as a girl, you know. Even at school I was the same... sports days... my friends and I used to sit around - and I only had girlfriends - and we'd be comparing legs. You know, and I had the best legs. And then sitting there in their rompers, and I'm sitting with my shorts rolled right up, you know. But, you know, it was all part of life too. I wouldn't go swimming unless I had a top on (T6A 2014:3).

By Form One ${ }^{41}$, Kevin was playing rugby but he would also play netball with the girls, which was highly unusual at the time. Being called a "sissy and being effeminate" (T1A 2012:7) was a regular cause for frustration:

I've always strived my hardest but not always succeeded, probably never succeeded ... because I didn't want to be classified like that. But I also thought of it as pigeon-holing me into how people thought I should be or what group I thought I belong to (T1A 2012:7)

Kevin had never heard the words 'lesbian' or 'gay' growing up. He came across the word 'gay' at school but neither his effeminate nature nor his sexual exploits with fellow students were attributed to it:

It wasn't part of the language that I ever heard. ...We didn't talk about things so that was probably a starter ...We just took things for granted or that was normal or perhaps not too ... enquiring within our own minds... It became more part of the Pākehā world as far as I was concerned than it was in terms of the upbringing that I had (T1A 2012:11).

\footnotetext{
${ }^{41}$ Equivalent to Year 7 in Middle School or Intermediate
} 
Although the 'sissy' label continued at secondary school, Kevin developed strategies to explore his sexual interests without being bullied. It seemed to him that the all-male environment created a need to mirror a 'normal looking world:'

So, they start to ascribe female characteristics to certain members of the community... I wasn't the only one in that category. There would've been others and they were definitely not necessarily effeminate or sissy in my view. But having said that, there were definitely men who displayed effeminate characteristics or what we describe as effeminate characteristics. But I guess the thing is that I knew how to, and I learnt how to, moderate my behaviour and to take care of my needs in a way which generally speaking I was able to protect myself through not only secondary school but also after (T1A 2012:8).

Despite the less than supportive school environment, the adolescent Ahi was not deterred:

Maybe 12 [years old] I read like Cleo or Dolly magazine or something and it was talking about bisexual people and I was like, ooh, that's like me. I'm like that. I like different people so maybe I'm like this thing. I knew that gay people existed, I knew that lesbians existed, but I never really thought about lesbian or gay and then I came out to my friends (T4 00.15.15). ...I think I came out as fluid and they [my friends] were like, "what's that?" and I said "I read about it in this magazine, it's like bisexual and these were like boys and girls" and they were like, "okay as long as you don't come on to us" and I was like, "whatever" (T4 00.15.51).

After only two years in formal education, Ahi left school at about 14 years old partly because of the on-going discrimination and mis-conceptions about their sexuality:

I guess eventually I left school because of homophobia. ... People teased me and said I was a lesbian but I didn't care, I was always like "fuck you, whatever." It didn't bother me but then this girl told people we kind of hooked up and then I was blamed for turning her into a lesbian (T4 00.20.09).

Like Peri and Hinemoana, I left the issues of home for school where, regardless of open racism, I could relax and excel - much to the oft-expressed surprise of the nuns who taught me. Both Mum and Dad valued education and my Catholic mother convinced Dad that they provided the best education so Dad acquiesced, but not enough to allow us to attend church. As Hinemoana noted, teachers were still allowed to physically discipline children and I was hit on the head with a bible on several occasions. It was here that I learned that we were poor and that we fitted - or were assumed to fit - many racist stereotypes about Māori children and families.

After giving more than one morning talk about what Dad had done to Mum or us the night before, I was told to stop talking about it because it was upsetting the other children. Although 
the nuns and teachers subsequently talked to Mum - who denied it - no one offered help or support. I gained a reputation amongst the teachers and pupils as a liar so I regaled them with outrageous tales about my rich father and the wonderful life we had, which met with significantly greater intervention. By the end of primary school I had stopped expressing anything personal or communicating altogether; at which point they labelled me as 'reserved' and 'painfully shy.'

From about the age of 15-16, some students at school were making snide remarks about me being lesbian because I was a 'Māori radical', a feminist and had no boyfriend. I did not associate my feelings for girls with the Pākehā lesbians I met through my activism so it was not until I met Māori activists who were out lesbians that I adopted it for myself. I fell in love with my best friend at 16 and I (foolishly) thought we would live happily ever after. Apart from my father, I told all of the significant people in my life soon afterward. At 17 in 1983, I was not allowed to take a female partner to the $7^{\text {th }}$ Form Ball so I took my brother instead.

Because we moved often to escape our father, my sisters and I attended several primary schools which all contributed to the only Catholic high school in Dunedin; Moreau College. This meant I arrived there with existing networks of friends and acquaintances which made the heightened level of racism much easier to bear. Moreau was academically streamed and I was in the top stream. By the time my sisters arrived two and three years after me, I was the only Māori in the senior school and of approximately 500 students, we were three of the five obvious and self-identified Māori; the other two being our adopted cousins.

The school reinforced my role as leader of the 'Māoris' [sic] by bringing me in any time an incident was reported - which Māori had shoplifted at the local chemist, which Māori had painted graffiti at the back of the school and which Māori were smoking in the bushes (in that case, usually my sisters and their friends). With a complete lack of respect for authority and a political grounding of feminism, racism and the Treaty of Waitangi, I argued with teachers, the principal and deputy principal on a regular basis. I learned Latin, French, German and could read in Ancient Greek. Every year I asked to learn te reo Māori and was told that there would never be a job that required it - better to learn Japanese. I saw the principal so often that by my final year we would casually chat in her office over a cup of tea. She told me that I was an unusual Màori who would "go a long way" and could be "a leader for [my] people." Because my marks were high they could not expel me but school retaliated in other ways. I never received any academic awards despite report cards putting me in the top of most of my 
subjects. Nor was I accredited University Entrance as was expected for all those in the top of the top stream. In $7^{\text {th }}$ Form I was voted House Captain by the students but excluded from the School Council where the Head Girl and Deputy, (other) House Captains, Deputies and Prefects made decisions on House and student matters.

During my senior school years, I attended the newly introduced Te Ataarangi classes to learn to speak te reo Māori. After spending 1984 in full-time political activism, I attended Dunedin Teachers Training College and Otago University; paid for by my teaching Te Ataarangi at Otago Polytechnic. I transferred for my final year to Palmerston North Teacher's College and Massey University to be closer to home (Gisborne). In 1988, I returned to Gisborne to teach at the Intermediate school across the road from my great grandmother.

All participants showed indications of their gender and sexual orientation as children and adolescents, with Morgan being the eldest to realise at 14 years and to convince herself at the age of 17. This is considerably younger than the findings of Lavender Island where the mean age of 'first felt different' was 11.7 years for female Māori and 10.2 years for male Māori. The mean age for 'came out to self' was 20 years for females and 17.8 years for males (Henrickson 2006:266).

Apart from Morgan, none of the participants felt shame or guilt even as some knew to keep it hidden in the meantime. They did this in the face of whānau and systemic homophobia and transphobia and self-imposed fears. Regardless of their upbringing, almost all participants gained that certainty without knowledge of the terms; 'lesbian, gay, bisexual and trans' (let alone takatāpui) or exposure to positive role models. Even as children they strove to avoid negative stereotypes and found ways to 'be themselves'.

\section{Heading Out To The World}

Although both Ahi and Morgan left school early, the lives they pursued from that point were dramatically different. At 14, Ahi was drinking alcohol and partying with people in their 20s. Ahi would sleep under the bridge or at a friend's house. Recognising the need to gain some income, Ahi approached an existing foster parent who attended the same parties. Ahi moved in and became their full-time babysitter. The parties, alcohol and drugs created a very unsafe environment: 
I was raped a lot of times when I was a teenager but I didn't know at the time, I thought it was this particular, 'down a dark alley with a stranger' thing, and so I didn't ever think that's what it was. But then one time I was 14, I was like this is actually like rape and it's not cool and I told my foster mum and she was like, "oh, what a jerk and blah blah blah." But then she invited him to my $15^{\text {th }}$ birthday party and I wasn't that happy about it and then everything kind of fell apart a bit (T4 00.23.03).

This reflects a culture within which rape and sexual abuse was so commonplace that no accountability was expected from the men perpetuating it and the young people experiencing it had limited capacity to discuss it or provide support for each other.

It was mostly like I was drunk and passed out and someone had sex with me. I never called it rape. I was upset about it. But also, when I did tell my friends, "this boy raped me," and they'd be like, “oh that sucks" but it wasn't a big deal. And of course, it wasn't a big deal because it was happening to everyone...it was all so normal. It wasn't the sort of thing I could talk to my mum about (T4 00.24.27).

Ahi recalled that during that period, the only person who seemed to care about their well-being was a woman who lived next door to one of the party houses. This woman wore a swandri every day and would offer Ahi a cup of tea, a safe place to sleep and even offered to pay for them to go to college. On reflection, Ahi realised that the neighbour was lesbian as were the only other women who tried to intervene on their behalf.

Being cis-gendered and femme, I had the dubious privilege of 'passing'42 so I routinely corrected people who assumed I was heterosexual or flatly refused to believe I was lesbian because "I didn't look like one." Men have offered me sex to "turn me straight" since I was 16 years old. Up until that point, all the discrimination I had faced was because I was Māori. However, at age 19, when I started going out with lesbians who were butch or perceived to be masculine, I was accused of trying to mimic a heterosexual relationship. Ironically this was from both within and without the Rainbow communities I was around. I was supposedly 'the woman' and my partner 'the man' and therefore I may as well have relationships with men; which basically came back to the same point - I was not anybody's stereotype of a lesbian. ${ }^{43}$ Fortunately, with the strength instilled in me by my father I dismissed all of that and continued to be myself.

\footnotetext{
${ }^{42}$ Passing - in this case, appearing to be heterosexual ie: not fitting any stereotype of lesbian

${ }^{43}$ This experience is reiterated by other takatāpui who are femme; Marewa Glover (2007:59) and MereAna Nicholson (in Kerekere 2017:19)
} 
As my father had beaten into me, I was indeed responsible for us children to the extent that when I was raped several times as a teenager, I dismissed it as too upsetting for my mother to bear. The responsibility took a toll. I never took drugs or smoked but I drank heavily as a teenager; predominantly with the other half-caste Màori who ironically almost all had violent alcoholic Māori fathers and Pākehā mothers. By the time I was nearly 18 years old, I realised I needed to get back in control. I gave up drinking on that birthday and have been sober ever since.

After briefly living with their elder sister when they were 15 years old, Ahi moved in with their boyfriend who was 27 years old - an age gap which was apparently common in Westport at the time. They lived in abandoned sheds in Nelson until they found a squat which they eventually bought. Later Ahi started a course at polytechnic but their home life was not conducive to study and nor was it a safe place to bring friends home. Ahi admitted they were depressed a lot as a teenager and went to polytechnic to make friends and be around other people.

Ahi stayed in that highly abusive relationship until they were about 18 years old. At 19 Ahi became pregnant and had their child at 20 years old. Ahi found their child increasingly difficult to manage but it took until baby was four years old before being diagnosed as autistic.

Morgan put her emotion into music, a passion she inherited from her father who was a roadie:

I have a turn table, and a mixer which I play around with, I've got five or six crates of records, so yeah music's a big thing. Boxes of CDs, I've got electric and base guitar so yeah. And Dad and I jam every Sunday, so that's like our catch up and our music, it gets better (T3A 00.07.45).

From music, Morgan developed her passion into movement:

I'm not as skilled with the dance stuff but I can sort of envision things, and music inspires movement so with relaying that with Jay, who was my partner, 'cause she has a degree in dance. We can sort of communicate and suss out what's going on in my head and she can sort of put it into action (T3A 00.06.58).

Writing was another outlet for her creativity and emotions:

I just pretty much just put pen to paper and see what happens, sometimes I write a story, sometimes it's a song, sometimes it's a poem or a little note to a friend or something (T3A 00.07.30). 
Hinemoana began working with two friends, Katerina Kawana, who was takatāpui, and Ramona Tiatia to produce 50 radio programmes for students on Māori and Pacific musicians. They formed Mana Wāhine Productions and produced a show called Mana Tagata: ${ }^{44}$

It was really satisfying to say at the end of every show, "Mana Tagata produced by Mana Wāhine." They would broadcast around the country on student radio and as far as I know they were the first radio programmes specifically about Māori and PI musicians together and also to be broadcast on a national network (T5A00.32.12).

With a double major at university, writing plays, making radio shows and working four-five jobs to supplement her student allowance, Hinemoana began to burn out. By the time she graduated she was exhausted and began to fall into depression. Moving to live with her sister in Tauranga did not work out well, so Hinemoana moved to Auckland where she spent the next few years working seriously on her music. In 2002, she moved back to Wellington to do her MA at Victoria University.

Hinemoana's primary role in the community is as a teacher and writer. Like many other takatāpui, she works to support Māori in the wider community; in her case with telephone counselling at Quitline Me Mutu. Her health has had a significant impact on Hinemoana's ability to be more active in the community:

I don't do gigs. I don't necessarily go to queer gigs or panel discussions or festivals or anything like that but that's not because I feel excluded. It's actually because I feel tired most of the time or busy (T5B 00.06.44).

Hinemoana limits her appearances at festivals to those with a takatāpui or queer kaupapa, particularly queer youth:

I would say that my early 20 s right up to my late 20 s I was an extremely active activist in lots of areas but then as my mental health has started breaking down I have withdrawn a lot from that. I kind of do things very selectively and I try not to put myself in the fray so much (T5B 00.11.17).

In addition to feeling very strongly about queer youth and takatāpui and queer/trans youth suicide, Hinemoana saw that decolonisation was one of the most significant issues facing takatāpui, building on where we have come to so far:

\footnotetext{
${ }^{44}$ Note this is the Pacific spelling of the word, as opposed to Māori which would be Tangata (people)
} 
I still think there is a lot to do in terms of decolonising ourselves. ... I'd still love our people to be at the vanguard of decolonisation and anti-racism. I feel like we're in such a unique position to recognise so many different kinds of intersectionalities (T5B 00.08.15).

A large body of research exists on the poor achievement of Māori in mainstream primary, secondary and tertiary education and the range of government, institutional, community strategies designed to reverse that trend. Māori have been consistently active in that space with the creation of initiatives to increase Māori participation up to the highest level of academic achievement. One such initiative, Fire That Kindles Hearts: Ten Māori Scholars (Katene 2015), features the thoughts of 10 Māori professors, including Ngahuia Te Awekotuku. However, they are at the tip of a bottom-heavy pyramid. Bishop et al (2003) summarise the general statistics in their study on Māori in Years 9 and 10:

Māori students' educational achievement and formal qualification levels are lower than those of most others in the population, they are suspended from school at three times the rate of nonMāori and they leave school earlier than other students. In turn, these factors contribute to high unemployment or employment in low paid work and an over-representation in the negative indices of the wider community beyond school (2003:189).

Their study reiterated the findings of several earlier studies, in that deficit theorising by teachers is the "major impediment to Māori students' educational achievements" (Bishop 2003:190). The environment of low teacher expectation subsumes all other influences, including whānau circumstances and systemic/structural issues, and leads to a self-fulfilling prophecy of low Māori achievement and failure (ibid 2003:190).

The establishment of Te Ataarangi in 1979, Te Wānanga o Raukawa in 1981, Kōhanga Reo in 1982, and Kura Kaupapa Māori in 1985 have led the regeneration of te reo Māori amongst Māori children and adults. Depending on age and location, some of the participants were able to access these options and a few went on to become more fluent speakers themselves.

School challenged the normality of home life and brought into clear focus their sense of Māori as being 'Other.' For the older participants, this happened later in life but for the younger it began at primary school. The impact of violence and abuse in the home on children is profound and the evidence of depression and suicidality is not surprising. 


\section{Cracking It To Live As A Woman}

Jennifer was the only participant who talked specifically about her employment being a mechanism for expressing her gender identity. From the sanctuary of home in Te Tairāwhiti to moving in with her Wellington-based mother, Jennifer came face to face with transphobia:

When I first came here they used to go queen this and queen that, you know, while I was walking past, you know. And I was going gosh, look at those old people out there calling me queen... And then my cousin heard me and she goes "that's not the queen they're talking about," and I'm going "what do you mean?" She said "they're... you're weird, you know." And I'd go "oh, for goodness sake, you know, how come that didn't click before." It was only because back home it was just there, you know (T6A 2014:3).

Soon after arrival Jennifer became close to another takatāpui who had grown up as male, and they would sneak into clubs as women. Within a few months, they decided to make it official:

Then my mother started finding wigs I think, but she knew and, you know, they never said anything ... it became very serious, you know, that we were determined that we were going to be women, fulltime, you know. So, we moved into town, got us a flat, and it was really hard leading a double life, you know, try to keep a job and going out at night just to make that extra money because we needed to build our wardrobes and things like that, you know, and... didn't make much money in those days. And of course, that's when we had to work the streets and start cracking it... It started off we were a bit shy, but then after a while we became quite experienced, you know. And in those days, it was called trick sex... they never used to know... then the new girls wanted to be sexually active with the men. The men started noticing the difference, you know. Not in the sex, but... in the girls themselves (T6A 2014:4-5).

Although Jennifer speaks almost fondly of being a sex worker, at the time and for many years afterward, sex work was one of the few employment options for trans girls and women (Nadal et al 2014:169). Māori women were disproportionately represented as sex workers although working indoors was considerably safer than working the streets (Plumridge and Abel 2001:79, NZPC 2013:3). In their respective books, takatāpui and whakawāhine icons; Carmen Rupe (1988) and Georgina Beyer (1999) both discuss their pragmatic approach to sex work.

At 16, Jennifer and her friend realised they needed more secure employment so they pretended to be 18 and became strippers at Club Exotic. Jennifer gradually adopted the title of queen but never 'drag queen' 45 because "I never have been, you know. I've always worked as a woman

\footnotetext{
45 'Queen' is generally used for whakawāhine and trans women who perform as women whereas 'drag queen' is generally used for gay men who perform as exaggerated versions of women
} 
(T6A 2014:8). After about a year they were invited to help start a new club in Christchurch. Jennifer went alone:

...because in those days they didn't know what a queen was, and I was the only queen that went down ... just the way I used to talk and carry on, you know. And they said this is quite good, you know, people are enjoying this queen. So, they brought three others down, and then they had this competition where the public had to guess 'which were the queens?' (T6A 2014:5).

After 25 years in show business, Jennifer performed her last show at the age of 40. She was flown over to Kangaroo Island on a private plane for the Miss South Australia show:

We were told by our agent “don't take your g-strings off because the police commissioner's going to be there." And we... we were wasted, weren't we, and off came the g-strings. By that time, I was working with drags as well ... we were called Between the Sexes. Yeah. And there was the time we lost our hula record, they wanted something Polynesian... so we had to hula to Nutbush City Limits. Can you imagine that?!” (T6A 2014:7).

Long before sex work was decriminalised in New Zealand in 2003, Jennifer managed to avoid many of the pitfalls associated with sex work; violence, sexually transmitted diseases and depression (Plumridge and Abel 2001:82) Instead she viewed sex work and stripping as a means of controlling her own life:

I'm glad when I became good enough to work for myself and, you know, get jobs and things like that, that I was able to be myself. But ... I've never lost the glamour of being a stripper, yeah, daytime, night-time, you know. I said as soon as I walk out that door it changes, you know. But even at home I would just laze around... always got to be a bit of glitter somewhere (T6A 2014:9).

Both Jennifer and Peri referred to the systemic homophobia and transphobia they experienced. Jennifer experienced the police harassment familiar to trans women and Māori sex workers while Peri faced the wrath of the New Zealand Army.

For Jennifer, it was a huge shock suddenly finding herself part of a marginalised group:

Oh, and it wasn't until I came to the city that I saw the great change, eh. Oh, the abuse and... and from authorities. Yeah, that was the worst, you know. You thought there'd be a bit of understanding there, but it wasn't (T6A 2014:13).

Jennifer's experience mirrored that of many Māori trans women and other workers who were routinely harassed by Police (NZPC 2013:3): 
Of course, in those days as well the police just didn't like us... oh, they used to treat us dreadful. But we knew we had to, you know, stand up and just face them... And the abuse we had to take from them was really quite scary really. But I was a typical Libran, you know, I used to avoid arguments as much as I could. I used to go, "oh no, just do as they say" (T6A 2014:6).

On one occasion, a police officer from Wellington recognised Jennifer at a swimming pool in Christchurch and made a complaint. Her argument that she worked with "the most beautiful girls in New Zealand" so why would she be looking at his wife did not wash with the Judge and Jennifer was charged with disorderly behaviour (T6A 2014:6). In particular, Jennifer remembers the blatant disregard the police had for takatāpui lives:

... about 12 of our friends were killed and they were never investigated. Oh, they just... you know, just queens, just prostitutes, you know. One was found in a bottom of a pit, and the only way they knew that she was a queen, though they found her breast implants... This takatāpui had been going with a policeman for all these years, and we knew it was her. And she was a beautiful stunning girl (T6A 2014:10) ... one of our... Dana and I's best friend, she was tall, elegant, a model, and she... was takatāpui, she was murdered after the Melbourne Cup ...And then there was another one. That was in the 60 s, about ' 66 , he was murdered in a fire, there's been no closure on that... oh there's so many of them, you know, and... you can only have your tangi, you know, because you know they're not going to do anything about it (T6A 2014:11).

Jennifer confirmed though that she had seen a change over the years:

Definitely the police are more respectful towards us, you know, and they involve us in, you know, their enquiries rather than tell us, you know, or boss us... which sort of turns us off straightaway .... But, no, I do respect the police a bit more now, but I'm still wary, you know, yes, I'm still wary. I don't think I'll ever lose that (T6A 2104:11).

\section{Denying Lesbian, Claiming Trans}

Encouraged by an Uncle who was in the Army, Peri signed up and waited until he was old enough to leave home. Peri loved being in the Army but after five years, his last posting in Wellington, 1986 turned sour. Although Homosexual Law Reform came into law that year, homosexuality remained an "unnatural offence" 46 in the Armed forces until the New Zealand

\footnotetext{
${ }^{46}$ A phrase commonly used by armed forces internationally and previously contained within the New Zealand Defence Force Manual of Armed Forces Law
} 
Human Rights Act of 1993 which prevented discrimination on the grounds of ethnicity, gender or sexual orientation.

Peri worked in the confidential area of signals and communication and false accusations of a sexual nature were made against him. Peri was made to stand in the common room while his belongings were searched. He was then interrogated at Head Quarters by 10-12 ranked personnel from the Navy, Air Force and Military:

They said "You're a lesbian" and I went "No, I'm not" and they said, "You're a lesbian" and they did everything they could to try and break me but I knew what I was (T2 00.28.02).

In this case, Peri was assumed to be a 'butch' (perceived as masculine) lesbian when, actually, he was a heterosexual man. No charges were ever laid and no apology given. Ironically, Peri was offered a promotion just as he left the Army which he declined, not because of the false accusations, but for the complete lack of support he received from his immediate superiors and those who knew him.

His dreams of 20 years of Army service dashed, Peri floundered. He stayed in Wellington in a number of clerical jobs which he did not enjoy but sport was something that kept him sane. Then Peri began meeting women in the community:

...played sports and I did go have relationships with women, 'cause I love women and it happened to be that it was in the lesbian community and they supported me and they were my friends and they were okay with me. I was never right into the community but I was always there. Like the extra rep at the sports team, the helper, never the shining star, 'cause that's not me by nature... That's why I always say to this day, I will never not support the lesbian community if I can or any part of that community because they were there for me. And that's how I became a resident in Wellington - it was right (T2 00.33.01).

Notwithstanding his networks in the lesbian community, his relationships with women were not altogether fulfilling:

I didn't really know anything about relationships and love. I was never taught that. So, it was trials and tribulations galore. The relationships I had were the relationships with people who wanted to have relationships with me but I actually wasn't sure who me was (T2 00.40.29).

By the early 1990s and still living under his birth name, Peri knew it was his gender which remained most at issue:

If I was too proud or too conscious of what other people thought about me I would never ask for help but you know what? It was the biggest and most important thing in my life; actually, 
realising I'm at the rock bottom of my life. I've spent most of my life being frustrated and always feeling empty and feeling a great urgency to do something but not knowing what the heck it was. Aligning myself with communities here in Wellington, such as ones that would visit, people that would visit the Evergreen ${ }^{47}$... looking at different communities and trying to wonder where I fit (T2 00.39.26).

Feeling suicidal, Peri went to his GP, Dr Kathy James, and laid his life before her, not knowing how she might react. He said to her, "I feel I'm in the wrong body. I don't feel I'm this person; I'm someone else" (T2 00.43.05). Dr James was immediately supportive and suggested Peri admit himself to Ward 27 [psychiatric ward, Wellington Hospital] while she arranged for him to join the gender reassignment programme. While the short-lived experience at Ward 27 was awful, Peri began taking testosterone and eventually underwent the first of several surgeries.

Even though their parents struggled at the beginning, Ahi felt so normal thinking of them self as not quite female or male, they did not even consider transition until much later:

I never thought I shouldn't be like this, ever, and I think also that's ... why it was quite late in the piece that I was like "oh, oh, I'm actually trans." Because actually it was just always normal ... I never felt like "oh I need to change anything" until I was like quite older then... when I realised that's how it was ... maybe because it was easy for me to be that, then it was easy for me to find other people who were just being that (T4B 2014:3).

Being gender-diverse, Ahi was aware of confounding many stereotypes:

I'm definitely not a girl but... I like pink hair and I like high heels... but anyway, so, you know, I think I'm kind of flamboyant so I don't really do subtle (T4B 2014:5).

Despite the challenges around embodying their gender and sexuality, Ahi found that process simpler than reclaiming their whakapapa:

...it has been a much easier journey than being Māori, and I guess maybe part of that is actually because racism is a huge, huge enormous thing... I mean there was like structural disadvantage with all of those, and there's discrimination and stigma, you know, on being trans and on being non-straight, and... you know, and on being Māori, so... from lots of angles (T4B 2014:3).

\footnotetext{
${ }^{47}$ The Evergreen Coffee House was run by Carmen Rupe until 1980 and Chrissy Witoko took over from 1984. Chrissy had previously owned the Sunset and the Nutcracker.
} 


\section{Crushes, Love \& Relationships}

For some participants, falling in love and relationships helped confirm their sexual orientation or helped to develop their identity further by introduction into the broader LGBTIQ communities. For both Kevin and I, breaking up from our first love precipitated 'coming out' to our parents. Jennifer preferred to keep her independence:

Oh, I'm totally relaxed about myself, you know. I can live the life I want to live. People ask, you know, how come I haven't got a partner. I said I tell you now I'm a selfish person, I like my time, my time's my own, you know, and... really, I've never wanted anybody around, you know, I like to do things when I want to do them, I didn't want to have to explain to anybody, ...I've only had about three or four relationships and I was always the dominant person, you know. This is what I'm doing and this is how it's going to be done, and that was it... I had a relationship with a guy in Sydney, he was a self-made millionaire. Him and I we were really good ... company for each other ... And he realised quite quickly that him having a lot of money didn't mean a thing to me... (T6A 2014:15). But he was wonderful, gave me a Stag sports car for my birthday and I couldn't drive. I said it's ok, my girlfriend, my flatmate can drive (T6A 2014:16)

Because he had not yet come out, Kevin was susceptible to whānau pressure. When he left St Stephen's, Kevin knew that he was expected to get married:

I sort of made up the excuse, "I'm not getting married until I'm 35" so that gave me 15 more years or so to play with ... So, I wasn't an out, proud gay homosexual at all. I was in the closet for many years until, again, my early 30s seem to be a point in my life where I had recognised in myself that I wanted to be real. And not that everything else was just false before that. But I still had to manage it in a way that was acceptable to me, to go through the whole process (T1A 2012:8).

Apart from getting cold feet in a brief relationship with a woman, Kevin did not look for or encourage anything serious. When he began a relationship around 1996, they soon began living together and purchased a home. Kevin's partner was actively involved in the gay community which gave Kevin a platform to develop his own politics and community work:

I was also pretty much in awe of his integrity and honesty around being a gay male, right from when he was actually at secondary school, when he came out to his parents and he had actually lived his life along that path ever since. So, I learnt a heck of a lot through observing, talking with him, learning about different things that he had been involved with (T1A 2012:9). 
His relationship and community involvement made Kevin aware of the predominantly Pākehā environment in which he found himself:

Questioning around some of the ways of thinking that they had and where it came from and I guess sometimes disputing that and knowing also that there was a different way of thinking as far as the taha Māori side (T1A 2012:9).

Peri met his future wife, Karen, when he offered to answer enquiries about female to male transition at the Prostitutes' Collective where she worked. By the mid-1990s, Peri was part way through his transition and had already had some surgeries. Karen refused to believe he was born female so it was not an auspicious meeting. However, Peri later began helping her put together a regular community newsletter and eventually he asked her out. Total opposites, the relationship was not smooth but they developed a strong companionship:

I guess what we realised is that if we really did compromise and talk more and communicate, if the balance is there, it's good. And it is, it is there. It took a few things. We were given a baby ... and that was taken away from us and we were both vulnerable, for the same thing, at the same time. And when you scrape away all the other stuff ... we were raw and that's when we saw, shit we're right, we're right together. From there we started building up. It's been a really strong relationship since then. Because we realised at the most needed time, we're there for each other (T2 00.51.34).

When she was about 12, Hinemoana had her first crush on a girl; a good friend who lived over the road in a similar domestic situation to her. They would "hang out at each other's houses when things got tough" (T5A 00.09.14). As she grew older, her initial feelings were reiterated:

I kind of knew that I was bisexual. I put that much together by the time I'd reached that age [21] mainly because I had already had sexual experiences with young women during my high school years, one particularly intense one with a best friend in Nelson. It ended up being quite destructive and yucky but I knew that I was just as attracted to her as I was to boys. It wasn't an issue for me, I never felt like it had to be one or the other (T5A 00.19.47).

Her interest in theatre led Hinemoana to write two plays which were produced by Taki Rua Theatre in their first two Te Reo Māori seasons in 1994 and 1995. She acknowledged the editing done by Piripi Walker and Keri Kaa of her "terrible first year Māori” (T5A 00.23.41). Her next relationship with a very creative man who identified as bisexual was part of her selfdiscovery: 
That relationship was really about me coming out more as a creative person and getting more confidence along those lines" (T5A 00.30.05).

While in Zimbabwe, Hinemoana also met and fell in love with her "first real out lesbian," a Jewish writer:

I guess it was the beginning of coming out in lots of ways, coming out as queer and coming out as a writer and definitely learning a lot politically (T5A 00.24.10).

Where others might identify as bisexual and then later identity as lesbian, gay or queer, Hinemoana did not:

Sometimes bisexuality is a beginning identity for people but it's never been a beginning identity for me even though now I've been, in terms of years of my life, way more in relationships with women than men, I still identify as bisexual or takatāpui. I don't, I just don't feel that exclusivity. ...I just never felt that (T5A 00.41.46).

Ahi became aware of political anarchists whilst living in Whanganui and the one book Ahi had read on feminism precipitated challenges to their boyfriend at the time which eventually ended the relationship. Through networks in the queer music scene and friends involved in $128,{ }^{48}$ Ahi was exposed to more political thinking, including feminism. They discovered that the theory of political lesbianism was not always conducive to the practicalities of an actual relationship. From one particular lover, Ahi learned about the intricacies of being 'femme:'

She was always talking feminist theory... was super high femme and I remember her saying things like "it's so annoying how everyone assumes you're straight because you're femme" and I'd think I never thought about those things. So, from now on I'm just going to assume everyone's gay, or everyone's queer, probably. Maybe I'm wrong sometimes but everyone's queer. She was all about how you don't have to have hairy legs to be a lesbian; how you can wear makeup and be a lesbian - none of those things invalidate you being a lesbian. I'm quite glad I hung out from her and heard all those things (T4A 00.55.05).

Ahi became aware of more lesbians who identified as femme or butch but had not considered applying the term to them self, although that particular femme lover was adamant:

She used to always say to me "you're a butch" and I'd say "I don't even know what that is." "You wear these clothes and you fix things." This, this, this. Well maybe, maybe I am (T4A $1.00 .04)$.

${ }^{48} 128$ is an anarchist/activist centre located at 128 Abel Tasman Street, Wellington 
It was not until her bisexual friend was due to leave town that Morgan suddenly realised that her lukewarm farewell did not reflect her true feelings. Unfortunately, she was thrown into confusion about what that meant for her sexual identity:

I think I like her. $F^{* * *}$, why do I like her now? She's leaving. Like I was going through all that sort of stuff and again still constantly thinking, ok she's a girl, I'm a girl, this doesn't happen, I need to be with a guy. This is so wrong, but it feels so good when we hung out, like what is that? (T3A 00.27.42).

With prompting from her best friend, Morgan overcame her own negative talk and fear of rejection:

So I ran after her, she was still outside, pulled her over, "I need to tell you something" ...and the words left me ...so I managed to stutter out, "I like you in like that way." Goofy as, I still feel like so shame that it came out like that ... and she gave me a massive hug and whispered in my ear, "like if you said it earlier I would've asked you out," and I was like "awwwww devastation" but such relief at the same time because I actually confirmed to myself that I actually liked a girl (T3A 00.27.53).

At 17 and a half years old, Morgan had finally professed her feelings to a girl but it was unexpected and she was still struggling with a sense of self-disappointment:

These feelings, and my body was reacting crazily to these thoughts about women and about friends it was, yeah it just seemed very wrong to me (T3A 00.32.15).

Having one of the only gay men associated with her whānau commit suicide because of homophobia may have had more of an influence on Morgan's ambivalence about her own sexuality than she realised:

He actually killed himself because his family disowned him because he was gay and he was absolutely beautiful, he was a beautiful guy. I remember he stayed up with us for a good while when I was about 12. I think him dying and learning that when I was 15-16, that he killed himself and how, which was quite severe ... he killed himself because of something he couldn't change. He was who he was, he wasn't going to deny that but his family just couldn't handle it and [he] thought his best option was to kill himself (T3A 00.36.15).

Morgan acknowledged that she internalised suicide as an option for not being able to deal with whānau:

At that time, I was wondering what I was feeling, not trying to think about it too much because it's such a bad, bad thing. But the fact that someone so close that I knew had decided to take his own life that almost instantly put that in my head as an option and that became a bit of a 
problem a few years after that. Once I really realise yes, I do. I do like girls a lot. Unfortunately, it is still a bad thing at the time, still thought of as a bad thing but this is who I am and how do I work it out, so that was definitely a few hard years (T3A 00.37.10).

Sometimes the key relationships in our lives were not positive. Children who experienced or witness violence in their home often become involved in abusive or violent relationships later on in their lives. Ahi had been in abusive relationships with men, Hinemoana alluded to one relationship that ended up being "quite destructive and yucky" while Morgan reported that she "had one quite abusive relationship which did put me off women for quite a while, tried to be straight but that's not part of who I am" (T3A 00.09.54).

As a teenager and into my early 20s, I used every opportunity to find and network with other takatāpui. I hitch hiked to Wellington and Auckland to attend Women's Dances hoping to meet 'wāhine mō ngā wāhine. ${ }^{49}$ So of necessity my first relationships were long distance. Toll calls were exorbitant so we wrote letters - no cell phones or email back then. At 19 years old I began a relationship with a Màori lesbian who beat and raped me. She increasingly controlled my life but I was raised to recognise love from within violence and I stayed for two years. I left and returned several times. The morning I woke to a knife at my throat I made one last decision and with whānau support, I left. I came out of that feeling both empowered and suicidal so began intensive counselling. I moved homes and changed phone numbers several times because she stalked me for the next five years, repeating my father's own abusive and stalking behaviour. Members of my whānau wanted to beat her up because, for them, abuse was abuse regardless of gender or sexuality. The lesbian community however, struggled and many wanted to protect and help her. On two separate occasions, she was provided with my contact details with offers of mediation so she could "apologise in person" and we could "work things out." Such well-intentioned 'interventions' minimised the issue while the stalking and random violence resumed.

All participants showed indications of their gender and sexual orientation as children. This is even younger than the findings of Lavender Islands where the mean age of 'first felt different' was 11.7 years for female Māori and 10.2 years for male Māori. The mean age for 'came out

\footnotetext{
${ }^{49}$ Wāhine mō ngā Wāhine o Te Moananui ā Kiwa was a network of Māori and Pacific Island lesbians in the 1990s. See Pihama (2001:12) Tïhei Mauri Ora Honouring our Voices: Mana Wāhine as a Kaupapa Māori Theoretical Framework. Thesis submitted in fulfilment of degree of Doctor of Philosophy, Education, University of Auckland
} 
to self' was 20 years for females and 17.8 years for males (Henrickson 2006:266). The particpants appear to truncate these statistics so although, for example, Morgan was the eldest to 'feel different' at 14 years of agebut came out to self at 17

As noted in Chapter 4, those participants who grew up in violent, abusive or alcoholic environments also indicated a range of self-destructive behaviours, depression and suicidality as they grew older. Some became involved in negative and violent relationships. Several of the participants noted feeling depression and suicidality but for most, that had occurred many years before. Unfortunately, the rangatahi involved in this study reiterated that circumstances have not changed significantly over the years as they negotiate coming out and transitioning today. This will be addressed further in Chapter 6.

Rankine (2001) in her study of lesbian and bisexual women found that "Māori women reported higher rates of assault, threats of violence and verbal abuse." In the 1990s, takatāpui scholar, Marewa Glover, was introduced to the Duluth Abuse Intervention Power and Control Model ${ }^{50}$ which explained how men institutionalise their dominance in relationships. Marewa attempted to apply the model to violence in same sex relationships (Glover 1993) but struggled with it in an Aotearoa New Zealand context:

Race, ethnicity and nationhood as sources of power and racism as a form of abuse were not included in the Power and Control Model. New Zealand, as a nation, enjoys a high standard of living, which reflects our high position in the hierarchy of nations (which is based on race). But within Aotearoa, power is further divided and distributed according to a set hierarchy, for instance, ethnicity (Pākehā, including all Anglo/white tauiwi, come first), gender, age, physical and mental able-bodiness (Glover 2007:61-62).

Community meetings were held but efforts floundered soon afterward. It remained a fraught issue within the takatāpui and Rainbow communities, when it was raised at all (Erai 2007:7). It was not until 2015 that the topic was formally addressed with the formation of Hohou Te Rongo Kahukura: Outing Violence project. I was a member of the Advisory Group and I cowrote the survey and co-facilitated the 20 consultation meetings which were held nationally. The research findings echoed Glover's concerns:

Rainbow communities themselves have low recognition of partner violence and sexual violence as the majority of awareness raising has targeted relationships between men and women. Dynamics of homophobia, biphobia, transphobia and gender policing underpin intimate partner

\footnotetext{
${ }^{50}$ Commonly referred to as either the 'Duluth Model' or the 'Power and Control Wheel'
} 
violence and sexual violence in Rainbow communities and must be understood as the cultural scaffolding which enables such violence, as well as making help-seeking difficult and complex. For Māori, Pacifica, Asian or other non-Pākehā people who experience racism both inside and outside Rainbow communities, understanding and responding to gendered violence must include recognising the structural, interpersonal and internalised violence of racism (Dickson 2016:8).

One third of Māori respondents reported racial abuse from at least one partner, compared to one in five overall. Just under half used alcohol or drugs more than usual to cope with impacts of partner violence, or felt concerned for their safety (Dickson 2016:22).

\section{He Hononga}

Chapter 5 provided insight into research questions within the Whāriki Takatāpui framework to do with Mana Motuhake and Te Whare Tapa Whā.

This study reiterated pervious research that Māori are more likely to identify their diverse gender identity and sexualities - and come out or transition - at a younger age than non-Māori. For most participants, school was the place they became 'Other;' a Māori going into a predominantly non-Māori space; not being perceived as 'Māori enough' because of skin colour; or as someone starting to explore their diverse gender or sexuality. This was a period of coming to terms with multiple identities.

Discrimination against takatāpui has been normalised in the context of colonisation so claiming takatāpui identity can be seen as a means of decolonising diverse gender identities, sexualities and sex characteristics. Most participants rarely experienced shame or guilt in who they were even as some knew to keep it hidden in the meantime. They did this in the face of whānau and systemic homophobia, transphobia and biphobia. and self-imposed fears. Regardless of their upbringing, almost all participants gained that certainty without knowledge of the terms; 'lesbian, gay, bisexual and trans' (let alone takatāpui) or exposure to positive role models. Even as children they strove to avoid negative stereotypes and found ways to 'be themselves'.

For those who grew up in traditional Māori environments, the terms 'lesbian, gay, bisexual, trans and queer' were considered Pākehā (white Western culture) even though takatāpui who claimed them were engaging in the same (sexual/emotional) behaviour as whānau who did not identify with those terms. There is more of a process then, in accepting those terms and joining 
those communities. For Māori living in urban areas or who are estranged from their culture, those umbrella and identity terms may feel more familiar.

From a young age, most participants experienced some form of depression and suicidality. Considering that this occurred decades ago for some, it is alarming to find that the present generation of young people continue to share that experience. The impact of discrimination on mental health and overall well-being is significant, particularly when takatāpui are feeling pressured by whānau to maintain cis-gendered heterosexuality; to marry and have children. Several takatāpui have experienced intimate partner and sexual violence in their lives and the quality of relationships can be fraught within marginalised communities.

However, takatāpui are not without agency. They have met these challenges; not so much with individual self-care; but through their own creativity and connecting with community. This included music, writing, poetry, composition, making magazines, theatre, radio shows and sports. 


\section{CHAPTER 6: UN/CONDITIONAL LOVE: YOU CAN'T PICK YOUR WHĀNAU}

This chapter considers the reaction the participants received from their whānau when they began to express and disclose their diverse genders and sexualities. While some reactions were positive, many were not. To supplement those stories this chapter contains two other sections. One which is historical, on celebrated composer Tūini Ngāwai, and the other which is highly topical, of takatāpui rangatahi and their whānau. Collectively they answer the research questions: Why is whakapapa important to takatāpui? What can takatāpui learn from the past? What are the key issues that impact on takatāpui health and well-being? and How do takatāpui address the challenges facing them?

\section{Reflecting on Whānau}

The extended whānau is the basic building block of Māori culture. It connects us to our hapu (sub-tribe), iwi (tribe), marae (tribal meeting house) and whenua (land), wairua (spirituality) and tūpuna (ancestors). It is at the core of our identity as Māori. Never having or losing that connection to whānau can shake that core. Whānau survival is ensured through the care of children and young people. This is why the word for child is 'tamariki' which stems from 'tama+ariki' meaning 'little chief.' In my years of working and speaking on this kaupapa, the most common question received is "What do Māori think about takatāpui?" This loaded question implies that takatāpui are somehow separate from Māori rather than being Māori; and that all Māori share a homogenous and definitive opinion on the matter. Even in this small research sample, participants represented a broad range of the reaction and support received from those whānau most important to them; positive (Jennifer, Kevin and Hinemoana), mixed (Morgan) and quite negative (Peri and Ahi).

Jennifer believed that her grandmother kept Jennifer to herself in order to protect her and ensure that she was prepared for a life that was "going to be totally different to theirs" (T6A 2014:2). One major decision caused friction when Jennifer received a share of the land rights and money denied her sisters. They later came to understand that it was allocated because she would "never have a family" and the shares would provide something for her to fall back on (T6A 2014:2).

...oh, it's been amazing to find that... you know, all that land up there and those trees and, you know, and my grandmother and my fathers had left that to me, you know, and I'm going oh, 
I'll be happy later on, you know. But it's been... it's been good for me, you know, helped me get through life (T6A 2014:2).

Jennifer consistently acknowledged her grandmother for her continuing 'luck' in life:

I suppose I was able to get under the radar, you know. You know, and I've always worked amongst it, you know, worked amongst ordinary people, you know. And, no, there'd been nothing untoward towards me, you know. And that's why I always say I was lucky, you know. I think my grandmother sort of had prepared me for it, she says... just some things that happened to me and then she'll come into my mind, you know ... you're still there, you know, taking care (T6A 2014:12).

Jennifer blamed Christianity for warping Māori perceptions of takatāpui within other whānau: ...to me it's Christianity, you know, they brought in “can't do this, can't do that," you know. Oh I tried to understand it but I couldn't. And she... my grandmother always said “just carry on with your life" (T6A 2014:2).

Kevin delayed telling his whānau until his early 30s when the breakup of his first relationship with a man necessitated him finally telling his parents:

I wasn't out to my folks at that time until he left and then, until our relationship broke up and I had no one else to go to, so I had to tell Mum and Dad. So, it was quite the funniest... I had to declare to them that I was gay and then I had to declare to them that I was distressed but I'm also really distressed because of my relationship. And so that was the start of that (T1A 2012:8).

After a loving reaction from his parents, "heaven knows why I needed to think otherwise" (T1A 2012:8), Kevin told his whole family, none of whom were surprised. They decided not to tell the children but rather for them to know Uncle Kevin just as himself, and with any partner he might bring home.

Hinemoana was accepted by most of her whānau, most importantly her Aunty Kath, whom she and her partner at the time, Tyree, lived with and nursed for two years after a stroke:

Aunty Kath was totally accepting of Tyree and my relationship with her. And so were all the rest of my family. ...but other members of my family, my Māori family, haven't been as accepting. Most of them - 99.9 percent - totally no issue but one Aunty in particular was particularly vicious and that's still why I don't go back to my marae at Ohau because she's still there ...I just don't want to deal with being abused by her in a public forum which is sad and it's terrible but it's just the choice I've made (T5A 00.43.31). 
Hinemoana's elder sister was in a relationship with a woman for a long time when Hinemoana was living with her although she was unsure of how her sister identified. When they finally met a third sister their father had 'fathered' when he was 16-17 years old, they discovered that she was gay too. It became a family joke:

I said to Dad, "It's definitely your genes (laugh); that's what you get for wishing for boys." But he's been really cool about it, totally accepting. He's just not phased about it at all. In fact, he's so un-phased other people come to him with their troubles about having gay children... it's not like he's out there advocating every day but he's completely unashamed of me and just talks naturally about me and my partner (T5B 00.00.52).

In Morgan's case, she received both negative and positive reactions from her whānau. She found out many years afterward that her mother already had suspicions:

What happened was, I was 16, hanging out with a mate and her step-father works with Mum. Now my friend at the time, my mate was openly bisexual and I was aware of that but she was my mate and I didn't care and we were just chilling out in her room writing poetry which is what we did. I think we were just hanging out for a few weeks too much and he mentioned to Mum that we were hanging out heaps so I must be gay...The hardest thing was not knowing because we didn't talk about it. I got a hiding when I got home, didn't know why and that was it (T3A 00.22.11).

Her mother told Morgan to stop seeing that friend, which Morgan quietly defied. The following year when she realised she was actually bisexual, Morgan went to the head of the whānau; her favourite Aunty:

It was my Aunty Mary [who passed away] that I was really worried about. Talked to her and my Nana and they were like "you are who you are, you haven't changed, we love you girl" and it was just like "oh thank goodness" because my parents, my mum especially, did not take it at all well (T3A 00.21.48).

It was not until Morgan had left home and was in her mid-20s that she was able to sit down and talk things out with her mother:

But that's because of the dynamic between my mother and I not being good. I think the ways she dealt with things was to hit and to beat, which you know was in her age group. That was the way it worked and that was how she was brought up and all her friends etc. ...so I moved out as soon as I could and then missed my family too much so came back six months later to just have dinners and touch base and stuff and we've been really good ever since (T3A 00.35.43). 
Morgan recalled how difficult it was to broach the subject and the effort it required:

That dynamic was quite hard, so I had to have a lot of mana and strength to be able to talk to her about that. ...She was really upset, really upset and we had a really touching moment as two people talking - two people who love each other unconditionally talking. So that was really cool and ... we're kind of moving forward as a new sort of relationship (T3A 00.35.56).

Despite that resolution, Morgan believed that her mother would always struggle with the fact that she could love women. Ahi experienced several different strategies deployed by their mother in response to her child having both a boyfriend and a girlfriend; the first being avoidance:

So, there was always like there were the overt things like, you know ... like going home one time and I said to my mother... I think it was on my Facebook or something, she was looking, and I said "oh, this is my boyfriend," and she was like "oh, he looks like Jesus" because he had a beard, but she was like "oh, oh he looks nice," you know, and da-da-da, and I was like "yeah, oh, yeah, yeah, yeah, and this is my girlfriend," and she was like... well no comment. (T4B 2014:4).

When her son advised her that Ahi had 'come out,' Ahi's mother opted for denial:

She asked me and I said "yeah," and she says "oh, because you're into girls as your friends," and I said "no, like I'm into girls the same way that I am into boys," and she was like "yeah, because you have boys who are your friends" ... so there's lots of the kind of denial stuff and like it took a long time for them to be like "oh, ok, this is a reality" (T4B 2014:4).

Subtler though were the messages that not only should Ahi appear to be 'normal' - ie cisgendered, monogamous and heterosexual - they should want to be normal:

...then there's lots of subtle ways that families do... can make people feel... not even necessarily like they shouldn't or they can't be trans or be queer or be gay or whatever it is that they are, but definitely not feel like this is normal and I think that probably like even when families, you know, have the expectation that everyone grows up and marries, you know, a husband or wife, or... you know, there's all the little ways that families expect people to fit into gender roles, or fit into certain kinds of relationships that tells people that anything else is not normal, and that you should want to be normal (T4B 2014:4-5).

Ironically, it was other areas of support from their parents that gave Ahi the strength to never be ashamed of who they were:

I think maybe part of that actually is because my parents were quite radicals [sic]... they were quite against the system sort of thing, and ... I think a lot of the stuff that I got from them which 
is really awesome and stuff is the idea that... you know, that like fuck the world, if the world is going to be shitty to you they can get fucked (T4B 2014:6-7).

Ahi's parents may not have thought their values would be applied to their child being trans but it created a resilience that has enabled Ahi to withstand homophobia and transphobia in other areas of their life:

So, one of the great things that I think I got from my parents being radical was them... they didn't agree with all the laws, they didn't agree with the ways that the laws were enforced, they didn't agree with the prison system, you know... in a lot of ways they had quite cool values, and were really used to being thought of as freaks even though, you know, they were straight as far as I know ... I mean straight in the heterosexual sense but definitely not in the conservative sense. So, you know, so they had really strong feelings that even if the world, or even if society disagrees with the way that you do your life; if you're not doing anything that's hurting people then you should be allowed to do it. And if you're not allowed to do it, do it anyway (T4B 2014:7).

My mother found out when my distraught 16 years old self called her in the middle of the night because my fairy tale romance had dramatically fallen apart - without ever really getting started. Mum later became part of PFLAG South ${ }^{51}$ and wrote about my 'coming out' story in the Methodist Church newsletter! Me being so femme, Mum was surprised but she gave me only love and support. Her worries about having no grandchildren were allayed by the others supplying her with ten mokopuna. In her work with PFLAG South, Mum has counselled other parents and grandparents not to apply such pressure and that being LGBTIQ does not necessarily mean a lack of descendants.

My siblings were wonderful. My sister Lorna rolled her eyes and said; "Oh that's just typical isn't it? You're already a radical and now this." My father had made homophobic comments in the past and even though he had not hit us since we left him when I was 12, we all thought this might do it. But Dad used to say "stick to your story," which meant he respected people who stood by their viewpoint regardless of others' opinions. I was 18 before I was ready to take the hiding - to 'stick to my story.' I told him that I was lesbian but since I was his eldest, I expected his support whether he liked it or not. He stared at me and said, "Fine. Now turn the TV back on." And that was it - no discussion, no questions, no violence. Dad accepted whoever I brought home and he loved my wife Alofa Aiono. Dad backed me up and where some

${ }^{51}$ PFLAG - Parents and Friends of Lesbians and Gays. PFLAG South is based in Dunedin 
of my whannau felt like they had to leave Gisborne or New Zealand to be themselves; no one ever hassled me. Sadly, Dad passed away in 2005, just before Alofa and I had our Civil Union.

\section{Same Stuff: Different Name}

Participants who grew up in traditional, more rural, Māori environments reported markedly different attitudes towards, and perceptions of, takatāpui to those who grew up in more urban environments. The terminology of 'lesbian, gay and bisexual' was not familiar to rural Māori and therefore considered a 'Pākehā' thing whereas urban Māori were more likely to accept Māori within its definition - even though the same sex/both sex attraction and behaviour was the same in both cases.

Within Jennifer's traditional home, the standing of her grandmother meant that she was protected and allowed to grow up naturally, regardless of whether anyone else had an issue with that or not.

Kevin's awareness of same sex attraction was reinforced through his primary school years and an understanding that it was not common within his family or community but it did occur. Kevin was aware of butch Māori women or effeminate Māori men in the Murupara and Te Whaiti communities he grew up in but to him they were a "normal part of the whānau" (T1A 2012:11). Despite this, Kevin hid his own feelings and behaviour and he is unclear why his child self made that decision.

Kevin's Great Aunt lived for many years with her "flatmate come partner come close friend" (T1A 2012:3). He briefly lived with them when he first moved to Wellington. They were in their early 50s when Kevin was a teenager:

I don't know why, but we never used to think of any sexual connotations. It was always Aunty and [her friend]. They were a normal part of our family ... I never ever really thought of saying, of questioning you know ... or this doesn't seem right or anything like that, it just never occurred to me... In the community, they were the clearest expression, when I reflect, of two who lived together and who were really close, close friends but I don't know if they were lesbian ...that's how we might see it right now but we never actually questioned that (T1A 2012:10).

This appears to be a coy reading of a couple, who may or may not have shared a bed. Others who were more sex positive might have been prepared to attribute sex and sexuality where Kevin was not. 
Kevin had one cousin on his father's side who transitioned from male to female. The same age, they grew up together in Murupara and when Kevin's cousin moved to Wellington she began living as a woman:

It was interesting to make the observation around how the family re-engaged with [her], and wrapped around her and she remained an essential part of the whānau. So, we all just transitioned ... the model of particularly my Aunty and Uncle and how they accepted things, became the model for the whānau (T1A 2012:10).

This is a similar example to Jennifer and my own experience where the head of our respective whānau set the tone of behaviour for the others.

Despite having grown up in an exclusively Māori environment, Kevin had not heard any traditional Māori narratives about same sex/both sex relationships or gender change. Kevin attributed part of that to being a 'whānau a waho.' Not growing up in his own tribal context meant that he did not learn many of his iwi narratives until he returned as an adult. He also considered his age was a key factor as he only moved into a Pākehā environment when he was older:

I'm not too sure whether it was ever an opportunity as youth to actually hear those stories ... Maybe if we were adults, maybe adults might be asking [about] those stories but I never heard them, or might have been a wānanga to do that, as kids we were never really at wānanga. We were at reunions and we might hear about things there, but then the reunions were always about whakapapa (T1 2012:10).

Peri was aware of same sex couples in his whānau but he was not aware of any issues:

I didn't see them as having a difference in that way. They were different but I didn't actually place it with the words we use now, being gay or lesbian. They were just 'like that' and that was okay (T2 00.06.05).

Peri's favourite Uncle was in a relationship for many years with a man; "What became obvious as I grew up is that his immediate family were totally supportive of him, understood him" (T2 00.09.20). Because of the family support, there was no discrimination against him. Confusing for a child though, Peri was aware of what was said about his Uncle in his absence:

I found the whānau to be a little bit two faced. They'd be nice as pie in front of them. No problem to be supportive in that way but when they're away, no problem to run them down as well. "They're stupid," "that's weird". Because I was a kid and I wasn't allowed to be part of any conversations. I was seen and not heard (T2 00.06.33). 
When his partner died, Peri's Uncle made a complete life change that Peri later came to realise was based on companionship and deep friendship:

What got even worse is that after his partner died, he actually went with someone of the opposite sex... and they actually got married. Now the family came around with that, they all thought "that's bizarre, that's not normal" but eventually though because they loved him they accepted it (T2 00.10.36).

Although Peri was estranged from his whāngai parents, his close relationship with his takatāpui Uncle continued throughout his life.

[Uncle] loved me so much that he came to my wedding but my immediate family didn't. So that says a lot (T2 00.11.31).

My great grandmother, Barbara Kerekere nee Grant, was born in Te Puke in 1903. When I hitch-hiked home to tell her at 16 that I was lesbian, the term meant nothing to her. I explained that I loved a girl and we wanted to live together as a couple. This she had no problems with. She told me stories of her aunties who lived together as couples when she was growing up. She said it was not unusual, especially as you got older and as long as you had your childrenwhich she still expected me to do. When I asked whether there was a name for it, she said no "they're just part of the family, part of the whannau." Given her aunties must have been born in the late 1800s, this has always given me the confidence to stand up against anyone who claims we did not exist in the past. Interestingly, she was Christian but the only church-related comment she made was to ensure that I "stay faithful" just as she had stayed faithful to my great grandfather. Later I realised that my great grandparents were contemporaries of Tüini Ngāwai and they were all involved with establishing the first kapa haka competition in Gisborne in $1952 .^{52}$

\section{OK For Friends But Not My Kids}

The parents of younger participants Peri, Ahi and Morgan had lesbian and gay whānau and friends, and at least in Ahi's case, trans friends. Surprisingly, this did not influence them to react more positively to the gender identity or sexual orientation of their own children.

\footnotetext{
${ }^{52}$ Ngāpo Wehi recorded the attendance of my great grandparents, Kahungunu and Barbara Kerekere, and Tūini Ngāwai, at the first meeting (Haami 2013:63).
} 
From the age of 13, Peri worked in forestry every school holiday. It was hard, physical work; "Yes, I was still a girl but it was right up my alley, I loved it" (T2 00.22.13). Peri was working with members of his whānau; many of them other young cousins. It was there that he first met gay, lesbian and trans people and he "loved" them. His mother had issues with this though:

She had no problem with everybody else but with me, she'd lash out. I couldn't even put a foot right. ...I was very tomboyish. It was really cute. I got my first real kick out of...a trans that started in the forestry with us and thought I was a really handsome young man. That got back to the old lady and she beat the crap out of me (T2 00.22.46).

Ahi's mother made leather clothes for strippers when they lived in Auckland so she enjoyed the outrageous fashion and company of drag queens, most of whom would have been trans women or gay men. This however did not eliminate her homophobia:

My parents were quite homophobic so when I was little and because we lived in such a small place... it's a really small homophobic town... so there was no one out and gay. I had one teacher who was out and gay but he was famously gay and everyone talked about him - all really negative... Mum would make homophobic remarks, I never heard anything positive (T4 00.11.34).

Morgan could not recall either positive nor negative messages from her parents and so attributed it to being raised 'traditionally':

So, there was [sic] gay people around all of the time and our whānau there's gay, queer people as well ...I remember loving them because they would actually sit down and sort of just talk to you, but yeah it was never mentioned that gays were wrong or that or if you like a girl that's wrong but again we didn't sit down and talk about that stuff either. ...And I think it was really just my upbringing, that fact that ... most of our family and friends were, you know, male and female parents and then the kids (T3A 00.30.12).

\section{The Mother of Kapa Haka in Men's Clothes: Tūini Ngāwai}

In Tahuri, Te Awekotuku (1989) uses fiction to provide insight into how same sex attraction and relationships were accepted in rural Māori whānau; giving voice to the often silent lives lived by Māori women who we might now identify as takatāpui. In one particular story, Tahuri is intrigued by Mirimiri's Aunty who wears a big-belted overcoat, lace up shoes and a man's hat but performs in piupiu and taniko bodice with the other women. When Tahuri asks if the Aunty is 'like that', she is told that they cannot talk about it outside of the family (1989:77-80, 
$85,90)$. Notwithstanding her disclaimer regarding unintended resemblance to anyone living or gone, Te Awekotuku appears to be remarking on the same woman 16 years later when she vividly recalls the image from her childhood of a woman wearing a man's hat, lace-up shoes, and a heavy belted trench coat who appears later that evening on stage in a piupiu and a taniko bodice (2005:9). Still without giving a name, Te Awekotuku finishes her speech with a waiata written by the mystery woman: Putiputi kānehana e. Without doubt then, the identity of that fictionalised character is Tuīni Ngāwai, hailed as a genius, and composer of over 300 waiata. Born in 1910 with high expectations of fulfilling a prophecy of leadership, Ngāwai was considered the mother of modern day kapa haka; an artform she invented with Apirana Ngata and subsequently taught throughout the Tairāwhiti (Pēwhairangi 1985, Takurua 2000). Ngāwai was variously described as generous, fussy, meticulous, stern, exacting, authoritarian and knowledgeable; a woman who was "loved, respected and feared" (Takurua 2000:9).

Tūini attended the local Native School during World War I. Māori was banned from schools but Tūini kept her Māori language and became fluent in English. Before her father passed away when she was 10, Te Ra Haangu expressed his disappointment that Tūini had not yet fulfilled the prophecy. When Tüini was 13 years old however, she composed a waiata which her mother put to music. By the time Te Ipo Harata passed away the following year, she was convinced that the prophecy would come true. Little is recorded about Tüini's life growing up or who raised her after she became an orphan.

Tūini sometimes composed her own music (as in Karangatia Ra and E Nga Rangatahi) but she usually based them on popular songs so they could be learned quickly for specific occasions. Tūini never learned to read music and worked by ear; teaching herself the mouth organ and ukulele followed by Jews harp, koauau, saxophone, piano, drums, violin and others.

As World War II began, Tūini established the first kapa haka group, Te Hokowhitu a Tū, to assist Ngata in his recruiting efforts for the 28th New Zealand (Māori) Battalion. Tūini wrote Arohaina Mai in a few minutes to farewell to C Company boys at Tokomaru Bay and E Te Hokowhitu a Tu on their return. Arohaina Mai was considered by her and others as her masterpiece. It caused Ngata to hail her as a composer of genius and the song became the Māori Battalion's unofficial anthem. In 1943, Ngata arranged for Tūini to teach Māori culture to every school with Māori students from Te Karaka in Gisborne to Cape Runaway. At the 1943 hui to celebrate the award of the Victoria Cross to Te Moananui-a-Kiwa Ngarimu, Tüini had all the 
schools perform en masse the song Karangatia Rā, a famous action song composed by Ngata for the return of Māori soldiers after the World War I (Pēwhairangi 1985, Takurua 2000).

From 1946, Tūini became involved with the Kotahitanga movement, which sought to restore Māori pride and identity through cultural revival. She was also involved with efforts to achieve greater recognition for the Treaty of Waitangi. As always, Tüini voiced her deepest feelings through the words of songs such as Te Kotahitanga Ra E.

Also in 1946, Tüini took on the leadership of sheep shearing gangs. She learned to shear and went on to win the Women's Section of the Golden Shears competition - at the age of 51. Many of her songs commemorating Māori shearing gangs are still sung on the East Coast. In addition to the gender non-conforming employment, Tūini was known to only wear men's clothes unless performing - as depicted in several images in Pēwhairangi (1985). Ngāwai never married and had no children of her own, although she raised many whāngai. Her relationships with women were known to her whānau but kept hidden from the public. This is evidenced by the silence on this matter in her first biography, which was written in te reo Māori by her niece and protégé, the equally celebrated Ngoingoi Pēwhairangi (1985), and the second in English which was based on it (Takurua 2000). Of the many lyrics contained in Pēwhairangi (1985), those written specifically to a woman are not always indicated as such in the translation provided.

Regardless, Tuīni’s primary relationship was with Pēwhairangi:

All of Ngoi's peers intertwined their stories of Ngoi with Tūini to the extent that the two became synonymous in some respects. It is apparent that Ngoi was mentored by her aunt, and although they had distinctive personalities, there is definitely a strong connection between these two women (Ka'ai 2008:9).

At the beginning of 1965 Tüini fell ill with cancer, and she died at Tokomaru Bay on 12 August. Tūini was buried at Ngaiopapa, Tokomaru Bay, where her headstone reads:

A woman of dignity and true faith

A genius, author and composer.

Other writers have considered at length the issues surrounding contemporary lesbian researchers seeking to claim historical public figures as lesbian, even if they were married to men and well before the term 'lesbian' became widespread in the 1970s (Faderman 1985, Laurie 2001). With regard to the retelling of the Hinemoa story, Te Awekotuku cautions against 
imposing a construct such as lesbian upon her that is as "ill-fitting and inappropriate as [Sir George] Grey’s colonizing [sic] romanticism” (Te Awekotuku 2001:3).

Ngāwai never publicly identified herself or wrote her own story. In fact, she did not even write down any of her own songs (Takurua 2000). In a Māori environment where Tūini was supported in her diverse gender expression and sexuality, identity may have been superfluous. Be that as it may, it appears whānau were aware of the homophobia elsewhere and protected her from exposure by keeping silent.

\section{Expecting The Worst, Hoping For the Best: Whānau}

The third stage of interviews was arranged in collabration with RainbowYOUTH ${ }^{53}$ for this part of this study and to produce the print resource Growing Up Takatāpui: Whānau Journeys (Kerekere 2017). Designed for takatāpui rangatahi (youth) and their whānau, it followed my print and film resource: Takatäpui: Part of the Whānau (2015) which promoted the urgent need for whānau acceptance and celebration of their takatāpui members in the fight against suicide. As noted in Chapter 1, all participants approved the use of their quotes for this study and the resource. The takatāpui rangatahi participants were:

- Ariki Brightwell (born 1989): Ngāti Porou and Tahitian

- Kassie Hartendorp (born 1989): Ngāti Raukawa ki Te Tonga.

- Emilie Rākete (born 1992): Ngāpuhi

- Morgan Butler (born 1994) and first cousin Mere-Ana Nicholson (born 1985): Ngāti Tūwharetoa, Tainui and Te Rarawa

- Nathaniel Gordon-Stables (born 1995): Ngāti Kuri

- Cameron Kapua-Morrell (born 1996): Ngāti Porou

The whānau participants were:

- Ariki’s mother Raipoia Brightwell (born 1956): Tahitian, and father Matahi Brightwell (born 1952): Ngāti Porou

- Emilie's father, Robert Rākete (born 1966): Ngāpuhi.

\footnotetext{
${ }^{53}$ RainbowYOUTH is based in Auckland and provides support for queer and gender diverse young people https://www.ry.org.nz/
} 
- Morgan's mother Kellie Butler (born 1966); Morgan and Mere-Ana's Aunty Ellen Tupaea (born 1971); and their Nan, Nina Turanga (born 1946) - all Ngāti Tūwharetoa, Tainui and Te Rarawa

- Nathaniel's mother Angelique Gordon-Stables (born 1967): Ngāti Kuri

- Cameron's mother Natasha Morrell (born 1978); father Frank Kapua (born 1980); Nan Nan Kapua (born 1961); sister Monique Kapua-Morrell (born 1997); and cousin, Molly Heremaia (born 1996) - all Ngāti Porou.

Colonial settler society made corporal punishment and child abuse commonplace. Children and young people were to be "seen and not heard" so they began to lose their voice within the whānau along with their mothers. Ideas of gender became constricted with so-called subservient Māori women and warrior Māori men. However, whānau survival is ensured through the care of children and young people. This is why the word for child is 'tamariki' which stems from 'tama+ariki' meaning 'little chief.'

Always remember that your tamariki are the most important thing in the world. Never forget that, no matter what - Raipoia (Mum) (2017:8)

Whakapapa is important because when gender and sexual fluidity in the past is hidden, it has a negative impact on the present. Knowledge of whakapapa creates strength and conviction - if takatāpui were accepted by our tūpuna, so they should be accepted today:

Of course, there were gay people back in the day. If it was possible for us then, it should be possible for us to accept it more now - Cameron (2017:11).

I think the Māori prejudice against this kind of behaviour [being takatāpui] comes from that they see it as unnatural. We're forgetting to see it as a natural phenomenon" - Matahi (Dad) (2017:12).

While the whānau may still be a strong way of connecting to Māori culture, parts of that society may no longer accept takatāpui behaviour. Often this means that whānau do not accept their takatāpui members:

My cousin was beaten, belted. He was always cooking, cleaning. I remember my older cousin saying, 'get outside and clean the hangi pit.' Yet they didn't mind eating his beautiful kai. He could only hold his own for so long. Sadly, my cousin died in his thirties. And I truly believe it was through...dying inside. He was not nourished and he was not nurtured - Ellen (Aunty) $(2017: 12)$ 
All of the cultural messages of trans women are real bad so it's difficult to learn anything good about trans women or the idea that you can be a trans woman and not just be a weird joke Emilie (2017:13).

All of the rangatahi spoke with pride of their Māori identity and where they came from:

I'm proud of my cultural heritage and my language and everything about being Māori... I just love that we have that connection to Papatūānuku [earth mother] and Ranginui [sky father]. It's just amazing - Cameron (2017:8)

However, disconnection from whānau because of discrimination often leads to disconnection from Māori culture - and therefore from Māori and takatāpui identity.

Not feeling Māori enough because of whatever reason, it's actually a tool of the coloniser for me to feel that way and to think that way. And it benefits the coloniser - Kassie (2017:13).

The term takatāpui is not a Maori translation of an English term, it has its own integrity and meaning which people should know and embrace when they claim it:

It's important to not just call yourself takatāpui. To be takatāpui is to understand that queerness is not just a Pākehā thing - Emilie (2017:9).

By claiming takatāpui identity, takatāpui rangatahi recognised that their diverse sexes, genders and sexualities were part of what makes them Māori.

Takatāpui means that first and foremost, I'm Māori. Then I'm everything else but together I am everything I am. I am queer, I am Māori and I am tangata ira tane [a trans man]. And I have this entire community backing me up whenever I use that identity - Nathaniel (2017:27).

The diversity of Māori who hold this identity is I think really beautiful. For me, it's a great word, because I don't have to be specific about how I identify - Morgan (2017:27).

Nothing has really felt right until takatāpui, because to me takatāpui is about whakapapa. It is about connection to a huge history and trajectory of whānau and of amazing people and communities who have always existed. That feels like it really links me into that history as well and into that whakapapa" - Kassie (2017:29).

Instead of the strength of whānau support, takatāpui rangatahi can be isolated or made invisible. They can be the butt of jokes or even kicked out of home. This can lead to drug and alcohol addictions, unwanted pregnancies, depression, self-harm and suicide. When whānau members started seeing changes in their takatāpui rangatahi but they felt disconnected and did not know what to do about it. 
There was this cloud that followed her, and Mum and I just wanted to make that cloud go away... We knew something was happening and we were worried because you love your babies and you don't want them to be unhappy. You just want to fix it. But we didn't know what it was - Robert (Dad) (2017:14).

As a parent, you notice when your child is not fully there. You learn to listen and you hear more what is not said. This huge burden he had on his shoulders. I didn't want him to fall into darkness... depression... suicide - Angelique (Mum) (2017:14).

Takatāpui rangatahi meanwhile reported feeling anxious, confused and reluctant to disclose how they were feeling to their whānau. They also did not know what to do about it.

It'd be in those driving moments where Mum'd be like, "So... how's everything going? Everything's good?" I'm like, “yeah nah, it's all good. Everything's sweet. And so to answer those questions, I found quite hard. Because... I didn't know myself' - Nathaniel (2017:15).

One thing that really frustrated me was I remember my mum saying to me when I did come out to her, 'I always knew you were gay'. And I looked at her and I said, 'well why didn't you tell me? Why are you making me go through this?' - Mere-Ana (2017:15).

It was a horrifying journey. I didn't know what I was doing but I thought I needed to talk to someone... I needed help. I didn't want to exist anymore - it was that bad - Ariki (2017:15).

It often took some time for takatāpui rangatahi to raise the courage to tell their whānau about their diverse gender or sexuality for fear of whānau rejection. Common feelings included guilt, embarrassment, isolation, fear, depression, anger and hopelessness:

She would turn to me at random times and say 'please don't be a lesbian, I want grandchildren,' which made me feel guilty about disappointing her and her plans for me - Morgan (2017:17). Some nights I would just go to sleep and think about all the things that my siblings could do that I couldn't because of my sexuality. Such as bring a boyfriend home, you know, greet the whānau... just normal Māori stuff - Cameron (2017:16).

I got to a point where I felt like a volcano... I didn't know what was going on, but I just felt unhappy and I felt depressed, angry and upset. Very angry. Not knowing who I was in terms of my own identity, I would spend a lot of time playing video games - 'cause that was my way to escape - Ariki (2017:17).

I showed [Mum] all my self-harm scars which are not visible and I just said, 'I'm just letting you know that this is what it did to me on the inside. I'm not blaming anyone but when you are so flippant about my sexuality and my story and my feelings and where I've come from... This is not a casual thing. This has actually been a really, really hard thing for me to go through' Kassie (2017:17). 
Whānau reported that finding out their children had a diverse sexuality or wanted to transition from the gender they were assigned at birth, was generally unexpected. Some whānau struggled - even if they wanted to be supportive. Common feelings included shock, embarassment, denial, a justified fear for their safety, feelings of conflict, and a particular grief when rangatahi wanted to transition.

I was in shock - I just thought she'd make some guy a beautiful wife. But my love for her was always gonna beat that one - Nina (Nan) (2017:18).

I never thought it was a gender thing because she never really displayed any clear signs - and that's why it was a 'hit by a train' kind of thing - Raipoia (Mum) (2017:18).

I was a patched gang member when he first came out, my first comment was 'no comment.' I was still trying to deal with it. I was a little embarrassed because my peers are all staunch men. And I felt like I was hiding my son's secret - Frank (Dad) (2017:19).

I didn't react really well and I'll tell you that I didn't. It was my fear of what I'd seen when I was growing up. That was my biggest fear. Oh my god, how can I protect her? How can I keep her safe? - Kellie (Mum) (2017:20).

Some felt conflicted because of either their cultural or Christian beliefs:

The warrior culture that I come from says, 'No way! No way!' And I have to balance that emotion that comes up constantly inside me - Matahi (Dad) (2017:21).

I went around to some friends who were in the church...I cried and I said 'I don't know what to do' because I was conflicted about the Bible - Kellie (Mum) (2017:21).

Grief was a significant issue for whānau whose child wanted to transition:

People just don't know how to deal with their own personal grief. And sometimes you say things... really horrible things. And then when you look back at them later on... they were just things that you never should have said but that's how you felt at the time - Angelique (Mum) (2017:21).

That's the grieving that parents go through. And the behaviour ... comes from that feeling. Most of the time people don't really know what to do because you feel like your child has gone, but your child is still there - Raipoia (Mum) (2017:21).

Building good whānau communication included patience, self-awareness, trust, acceptance, love and - eventually - pride. 
Patience is the number one key thing that this process has taught me...Know that it takes time and understanding to get to the point where it's okay... It does get better. But it gets better by you trying - Nathaniel (2017:22).

When your child comes out as transgender, that's not a journey you prepare for and some people struggle with that. Sometimes you have to cut your family some slack because it takes a while to get your head around it - Robert (Dad) (2017:22).

Whānau members advocated for Māori values as guidance:

Where do we get these principles from to judge? We say in our culture 'manaakitanga' [generosity], 'whanaungatanga' [connectedness], 'awhinatanga' [help]. 'Aroha' [love]. Isn't that the strongest emotion in our culture? Why don't we practice that? ... I shouldn't behave like I'm Maori if I reject someone that I brought to earth. That's totally wrong - Matahi (Dad) (2017:23-24).

If your moko [grandchild] comes out and says that she's different or he's different, you love that moko. You love them anyway. Don't judge them - Nina (Nan) (2017:23).

Eventually, all of the whānau have come to a place of pride:

We saw the spark in our baby from him coming out. [Cam] was very closed down, stayed locked up in the room. There was just something missing. And then when he come out, oh it's made him the beautiful baby he is today. I'm so proud of him and of who he has become Natasha (Mum) (2017:25).

I'm very proud of [Nathaniel]. Because the fact is that he's taken on such a huge, big challenge. And I think his biggest challenge was really to get that across to me - Angelique (Mum) (2017:25).

For takatāpui rangatahi and their whānau, calling on tūpuna and tūpuna takatāpui helped on the journey:

My Māoriness is about whakapapa and even if I can't see it really clearly and I don't have faces necessarily to put to those people, I can feel them $100 \%$ and they guide me. They lead me and they support me all of the time - Kassie (2017:28).

I always remember who I am. I always go back to that. And at times of hardship I think about my family. I think about my ancestors and remember where I came from. That gives me strength - Ariki (2017:29). 
[Mum] died about 35 years ago. And I kinda thought... what would she do in this situation? She was an awesome and loving person. And she told me, 'this is what you need to do.' And I did it - Angelique (Mum) (2017:28).

Daily I ask my ancestors 'what would you do?' And the answer always comes back inside of me, 'you never turn your back on one of your own.' So I have to uphold the principles of my ancestors. I'm a hypocrite if I don't - Matahi (Dad) (2017:28).

Gender identity and expression, sexual identity and being true to oneself are integral to being takatāpui. It is a part of our wairua. When that is trampled on through discrimination and rejection, the distance between takatāpui rangatahi and their whānau increases. Spiritual reconnection is a whānau responsibility:

You understand but the emotional and wairua reconnection takes a while - Raipoia (Mum) (2017:29).

Discrimination, isolation and fear of rejection from whānau takes a toll on the mental health of takatāpui rangatahi. It affects their confidence and their ability to be in the world, as well as their outlook on the future. As noted earlier, it can lead to high rates of depression, self harm and suicide. Being Māori means being born into whānau, hapū and iwi. Creating a sense of 'belonging' however relies on building connections and relationships. It is the whānau's responsibility to ensure that takatāpui rangatahi know their inclusion is never in doubt.

Being Māori means... you always belong somewhere no matter what. No matter where you are or what you do. Everything you do in your life, you will always belong - Nan Kapua (Nan) (2017:30).

True acceptance of takatāpui rangatahi was more than just accepting them as an individual member of the whānau. It extended to the partners they brought home, the friends they found and the Rainbow organisations and activism they became involved with:

We don't want more suicides because of non-acceptance. That's just not something that should be accepted in our society. Every child has the right to be accepted and loved for who and what they are - Kellie (Mum) (2017:31).

The care of 'tinana' (physical body) has particular implications for takatāpui rangatahi who may be born into whānau who do not support them or who suffer routine discrimination in other parts of their life. Whānau is the first and most important place of protection all rangatahi have. In wider society, takatāpui rangatahi are likely to face violence and abuse in their lives 
because of their diverse gender identities, sexualities or sex characteristics. They need to know their whānau have got their back.

If you know your whānau backs you, that no matter if anything else happens, that your family are going to be there - such a huge protective factor. Such a huge difference to how your life is going to go" - Kassie (2017:32).

[The gang members] didn't accept gays in general but they accepted [Cam] was gay. They never rubbished him, they never spoke down to him. They all just treated him how they treated him prior to that. But they stopped using homophobic words around me... 'Cause I'd get upset... There would be consequences - Frank (Dad) (2017:32).

There's been no hiding in our family. We roll as one unit and if you don't like it - ka kite anō [good-bye]! - Ellen (Aunty) (2017:33).

Being in charge of one's own body took on specific meaning for those takatāpui rangatahi with diverse bodies and gender identities who often had negative experiences with health services: If you care about Māoritanga [Māori way of life] and you care about Te Ao Māori [the Māori world] and all of our taonga [treasures], then part of that is making sure that takatāpui are safe and nourished and have space to live and grow - Emilie (2017:33).

Whānau is key to the survival of takatāpui rangatahi. Whānau support contributed to building up their confidence and resilience. Support from immediate whānau and especially kuia kaumātua (elders) helped them to stand in their own mana - to be strong in who they were and to face whatever challenges came their way:

You just wish that you could give a child enough confidence that when they walk out that door, their shoulders go back, their head goes up and they own it. And it's their ownership that they take. Their mana - Kellie (Mum) (2017:34).

I feel like my job as a parent and my role in life is to be able to allow my children to live their truth. Whatever that's to be - Robert (Dad) (2017:34).

Having broken the ice to tell immediate whānau, takatāpui rangatahi needed allies to contact the extended whānau and everybody else who matters:

[My family] gave me the courage and the strength to be who I am. And to pursue who I believe I am and go out there in the world and not worry what people say [or] care about what people think - Ariki (2017:35). 
I was with Cam every step of the way when he told each and every one of our family members - Monique (Sister) (2017:35).

Now that everyone in my life has been told pretty much...my life has been a lot less stressful. A lot less to manage - Emilie (2017:35).

When asked to give final advice to other whānau, our participants responded:

I learned from the $23^{\text {rd }}$ Psalm [The Lord is my Shepherd] that you had two choices to make in life. You could take the easy road or you could take the high road and face the challenges of life and overcome them. I think we've done that as a whānau - Nina (Nan) (2017:36).

My advice is to take a big, big breath in. You need to ask yourself some very important questions. 'Do I still want to have this connection?' And if I do, we need to find steps to move forward. And if I don't, we need to ask more questions as to why - Angelique (Mum) (2017:36). One Sabbath we were learning the lesson of 'if you have not sinned, cast the first stone.' And I guess my whakaaro [thinking] had to go back to that. Who are you to throw stones, whether it be your moko, your daughter or anyone - without looking at yourself first? - Ellen (Aunty) (2017:36).

Finally, whānau suggested that 'aroha' (love) be the guide:

Children are the most important thing. They are our biggest gift. It wouldn't have mattered what [Morgan] came out as. You know, because it was the love that I felt for her. For parents out there that don't have family that have come out before, it's safer now than it was back then. And don't hide behind your fear... Bottom line is, they're our gift. We need to embrace them and love them regardless of what they are - Kellie (Mum) (2017:37).

The journey is different for everybody but I hope that we all end up in the place of acceptance and love because if you do that, it's better for everybody, including your own heart - Robert (Dad) (2017:37).

Love conquers all I think. If you genuinely love someone, nothing should matter. My love for [Cameron] conquered everything that I was facing. It's unconditional and that's what got me through it - Frank (Dad) (2017:37).

Whānau confirmed that patience and research would pay off:

We never walked away or got really angry 'cause that would not have helped. It never entered our mind. It was more like 'how can we adjust?' - Raipoia (Mum) (2017:38).

It's going to be okay, it's really going to okay because what you'll have is a happy person. Trust in that" - Robert (Dad) (2017):38). 
My Mum went out of her way to research and understand exactly who I was and even though that took time, it's gotten to the point where it's amazing - Nathaniel (2017:39).

\section{He Hononga}

Chapter 6 provided insight into research questions within the Whäriki Takatäpui framework to do with Kaupapa Māori Theory, Mana Wāhine, Mana Motuhake and Te Whare Tapa Whā.

The term takatāpui is not a Maori translation of an English term. It has its own integrity and meaning which people may learn and embrace when they claim it.

By claiming takatāpui identity, takatāpui recognised that their diverse gender identities, sexualities and sex characteristics were part of what made them Māori. Knowledge of whakapapa created strength and conviction - if takatāpui were accepted by our tūpuna, so they should be accepted today. Knowing who they were as Māori was critical for them knowing who they were as takatāpui.

Tūini Ngāwai is an example of a public historical figure whose whānau and community supported her diverse gender expression and sexuality. I believe their decision to keep silent over her relationships with women was to afford her protection against the homophobia and transphobia which was known to exist outside of their Māori world. Further, this is an example of an historical protection for takatāpui in many Māori communities such as my great, great aunts who lived as couples in the late 1880s. Today when whānau are scared or angry with takatāpui being visible, I consider this is not necessarily evidence of homophobia, biphobia and transphobia, but rather the vestiges of an historical anxiety - a memory from our tūpuna that silence was protection. We cannot know how Tūini identified herself but over 50 years after her death, takatāpui can proudly claim her as one of our most prominent tūpuna takatāpui.

Without traditional Māori values guiding acceptance of gender and sexual fluidity, whānau could take on the worst of colonial and Western culture: shame, silence and religious persecution. While the whānau may still be the easiest way of connecting to Māori culture, that culture may no longer accept takatāpui behaviour. Disconnection from whānau because of discrimination often leads to disconnection from Māori culture - and therefore from Māori and takatāpui identity.

Discrimination from within whānau can take specialised Māori forms. For example, takatāpui may be accepted and supported within their whānau but the whānau do not support them identifying as lesbian, gay, bisexual, trans, intersex or queer because those are considered to 
be 'Pākehā' or 'Western' things. This is related to the historical anxiety of naming and visibility mentioned above. Claiming takatāpui identity and whakapapa enabled takatāpui to reframe the conversation to one based on Māori language and culture.

Discrimination, isolation and fear of rejection from whānau took a toll on the mental health of takatāpui rangatahi. It affected their confidence and their ability to be in the world, as well as their outlook on the future, which in turn led to high rates of depression, self harm and suicide. Being Māori meant being born into whānau, hapū and iwi. A sense of 'belonging' however, relied on building connections and relationships. It was the whānau's responsibility to ensure that takatāpui rangatahi knew their inclusion was never in doubt. True acceptance of takatāpui rangatahi was more than just accepting them as individual members of the whānau. It extended to the partners they brought home, the friends they found and the Rainbow organisations and activism they became involved with.

When whānau members saw changes in their takatāpui rangatahi, they felt disconnected and could not communicate with them. It often took time for takatāpui rangatahi to raise the courage to tell their whānau about their diverse gender or sexuality for fear of whānau rejection. Common feelings included guilt, embarrassment, isolation, fear, depression, anger and hopelessness. In turn, when takatāpui rangatahi disclosed their diverse sexuality or wish to transition from the gender they were assigned at birth, some whānau struggled - even if they wanted to be supportive. Common feelings included shock, embarassment, denial, a justified fear for their safety, feelings of conflict, and a particular grief when rangatahi wanted to transition.

By claiming Māori values, these whānau participants embarked on a journey of love, acceptance and celebration of their takatāpui rangatahi - and in some cases - saved their lives. Building good whānau communication included patience, self-awareness, trust, acceptance, love and - eventually - pride.

For takatāpui rangatahi and their whānau, calling on tūpuna and tūpuna takatāpui helped on their journey. Gender identity and expression, sexual identity and being true to oneself were considered integral to being takatāpui. It is a part of our wairua. When that is trampled on through discrimination and rejection, the distance between takatāpui rangatahi and their whānau increases. Spiritual reconnection is a whānau responsibility.

The care of tinana has particular implications for takatāpui rangatahi who may be born into whānau who do not support them or who suffer routine discrimination in other parts of their 
life. Whānau is the first and most important place of protection all rangatahi have. In wider society, takatāpui rangatahi are likely to face violence and abuse in their lives because of their diverse gender identities, sexualities or sex characteristics. They need to know their whānau have got their back. Being in charge of one's own body also took on specific meaning for those takatāpui rangatahi with diverse bodies and gender identities who often had negative experiences with health services.

Whānau is key to the survival of takatāpui rangatahi. Whānau support contributed to building their confidence and resilience. Support from immediate whānau and especially kuia kaumātua (elders) helped them to stand in their own mana - to be strong in who they were and to face whatever challenges came their way. One member of the whānau who is hostile could have a disproportionate impact on takatāpui if nobody challenged their behaviour. Conversely, one strong ally who stood up to everyone helped build resilience that prepared takatāpui for the future. Part of that role often involved contacting the extended whānau. Moving forward together involved acknowledging it was a journey, letting aroha guide them, not giving up and seeking more information.

Remarkably, having other takatāpui in the whānau or parents having friends who are takatāpui or Rainbow did not necessarily correlate with parents reacting well to their child disclosing diverse gender identities or sexualities. Each case was different and whānau needed support to go through that journey with their takatāpui members. 


\section{CHAPTER 7: HONOA TE PITO MATE KI TE PITO ORA: RECLAIMING TAKATĀPUI}

This chapter continues tracing the journey of each participant as they first encounter and then adopt takatāpui as an identity for themselves. Told in order of encounter, my own story begins in the late 1980s within the Māori Women's Movement and Māori lesbian networks. Hinemoana's story begins in the 1990s at Victoria University of Wellington. As founder and Chair of Tîwhanawhana Trust, my story begins to intertwine with those of Kevin, Peri and Jennifer, in the early 2000s. Ahi's story evolves from within the Wellington anarchist/activist scene in the late 2000s and Morgan's as a youth activist in Auckland in the early 2010s. This chapter responds to the questions: Why is whakapapa important to takatāpui? Why do Māori with diverse gender identities, sexualities and sex characteristics claim takatāpui identity? What does 'being takatāpui' mean in relation to 'being Māori'? What are the key issues that impact on takatāpui health and well-being? and How do takatāpui address the challenges facing them?

\section{You Always Remember the First Time...}

During the mid-late 1980s, I first heard of takatāpui through two different networks; Māori and Pacific lesbian networks and Māori educational/academic networks. I heard from Ngahuia Te Awekotuku at hui including Ngā Wāhine mō Ngā Wāhine o Te Moananui a Kiwa ${ }^{54}$ and from Lee Smith who was teaching Te Reo Mãori at Kuratini (Wellington Polytechnic). During that period, I also met Rex Perenara who ran Te Roopu Tautoko and spearheaded the third network; the predominantly Māori gay men and whakawähine who were spearheading the fight against HIV/AIDS. Being an artist, the use of a traditional term to describe a contemporary identity appealed to me. ${ }^{55}$ I claimed it immediately. I would use lesbian/femme in Pākehā settings and increasingly takatāpui in Māori settings.

Through the influence of academics Ngahuia Te Awekotuku and Lee Smith, the term takatāpui began to circulate within academic circles. Hinemoana first heard the term 'takatāpui' at Māori Studies at Victoria University of Wellington in the early 1990s:

\footnotetext{
${ }^{54}$ National network of Maori and Pacific Island lesbians as described by Pihama (2001:12).

55 This seemed to mirror the use of 'customary' to define contemporary Māori art which is based on traditional Māori art forms.
} 
It was a term that was used then and I used it kind of interchangeably with bisexual and just as proudly. You know there was some debate because a lot of lesbian dances, they were advertised as takatāpui dances, takatāpui wāhine dances and I used to get quite cross. I thought they can't steal that word, it belongs to me as well (T5B 00.03.32) ...It felt very important to me for the term not be hijacked by concepts to me that weren't indigenous to it (T5B 00.05.12).

Kevin first heard about takatāpui in 2000:

I had joined up with a group that eventually became known as Tīwhanawhana and takatāpui was a word that I heard more and more and learnt about more and more (T1C 2014:3) ...I don't think takatāpui occurred to me... it wasn't until slightly later through Tīwhanawhana and then the involvement with the connection to the NZ Aids Foundation, that takatāpui came into my lexicon of thinking (T1B 2012:6).

Peri also became aware of the term takatāpui in the early 2000s through Tīwhanawhana and its work in the community leading up to and after the Gay Games, Sydney 2002.

Ahi first heard of takatāpui from a friend who was attending the Takatāpui Hui-a-Motu, Wellington 2009. Their friend translated takatāpui as "kind of like queer" and although that friend referred to Ahi as takatāpui, Ahi had reservations about whether to adopt that term themselves:

I guess like a lot of Māori people who grow up in a really Pākehā setting, like a kind of cultural incompetence ... I felt Māori but I thought that if I was in a Māori setting, people would expect me to know things that I wouldn't know and I'd be really embarrassed. I didn't care if I didn't know things in front of a Pākehā but I didn't want to embarrass myself in front of Māori people (T4A 01.09.40).

Ahi continued working within the predominantly Pākehā anarchist scene before joining the Black Rainbow group in 2010 which was comprised of five Māori and two Pākehā activists who were cis-gendered, trans and gender queer. ${ }^{56}$ As Ahi noted:

I've never been in a lot of spaces that were predominantly Māori spaces, so hanging out with, in the Black Rainbow group; that kind of helped me work out lots of stuff like this feeling of "I don't know my place in the Māori world." You know realising everyone in the group felt like that... Everyone had their insecure feelings about it and I was like "oh right, this is just colonisation - this is just what it is to be Māori." Like you know one of the women in the group

\footnotetext{
${ }^{56}$ Black Rainbow was formed in 2010 by Rachael Fabish and members of the anarchist/activist movement as the subject of her doctoral thesis (Fabish 2014) to examine how Māori and Pākehā work together across difference and how Pākehā could work better with Māori.
} 
said at some point, "to be Māori is to be colonised" and I was like "yeah right." So, all of these things that have stopped me from engaging with my Māori identity; ... that's colonisation and that's bullshit and that's not for me. That's not something that I need stopping me from being who I am (T4A 01.16.57).

It was some time before Ahi developed a greater understanding of takatāpui by attending the international Trans Hui held in conjunction with the Wellington OutGames 2011. Arranged by Peri and Karen Te Wao and others, it was attended by many people identifying proudly as takatāpui:

I was just kind of figuring out my gender stuff and to hear lots of people talking there and I had lots of good conversations there. So, I was like "Actually I'm takatāpui. Cool, I'm takatāpui" and I can say that and it's not stupid. I mean I don't feel stupid. I don't feel like I'm saying something that I might not be. I understand what that is (T4A 01.18.36).

On reflection, Ahi realised that their involvement with the Black Rainbow group had primed them for being ready to adopt a takatāpui identity:

...the [Black] Rainbow group made me think that it was really important to... like I kind of feel I want to say 'being out' about being Māori. That's kind of funny because how can you not be out about being Māori? You can't take off the colour of your skin. But like that group made me feel like it's really important to be really proud of being Māori and it's really important to put that out in the world. ... And so then probably when I went to that trans hui, it was like right, it's also important you know to claim that "I'm takatāpui" and be out about that (T4A 01.19.02).

Jennifer also heard the word through Tīwhanawhana:

I think it was somebody from Tīwhanawhana that had said takatāpui, and I said "excuse me, what's takatāpui here", and then they'd tell me ... I was quite fascinated with the word. But I think it sort of explains us exactly (T6A 00.09.53)

Morgan first heard the term takatāpui through gaining the Takatāpui role on the youth-led board of Rainbow Youth in 2012. Morgan had been volunteering for two years within the education programme of Rainbow Youth, which entailed telling her 'coming out story' to students at Auckland Girls High School. Morgan did not frequent the Rainbow Youth drop-in centre and was not able to attend the Board election itself so the Education Co-ordinator spoke on her behalf and confirmed success via a txt message. When Morgan realised she had been appointed to a specific takatāpui position, she searched Google for answers: 
The Tūtanekai and Tiki story was one of the first things that came up. Also, Wikipedia ${ }^{57}$ had a description. The Tūtanekai and Tiki story was actually quite, I thought that was quite cool. When I read that I was just like wow! It also made me understand why my extended whānau were all so welcoming when I did talk to them about it (T3A 00.21.20).

For many it was their takatāpui identity that spurred them into political action as Hinemoana recounted:

In terms of my relationships and takatāpuitanga, when I was doing Women's Studies I would identify pretty militantly as bisexual because I felt that it was an identity that was so invisibilised, kind of silenced ... I don't know that anyone particularly meant to be bi-phobic but it just happened. In a syllabus on Gay, Lesbian \& Bisexual Studies, there was half an hour in one lecture on bisexuality (T5A 00.35.24).

Although Hinemoana acknowledges that she was probably "unbearably PC" and "really irritating to the lecturers" (T5A 00.38.35) of both departments, she felt targeted by one particular lecturer and the matter ended up at the Disciplinary Committee. Although he was not dismissed, Hinemoana noted that takatāpui academic, Ngahuia Te Awekotuku, was appointed to a professorship in his stead. Ngahuia subsequently taught a paper on Ngā Huinga Takatāpui. With so few people studying in both Women's Studies and Māori departments and little written material available, Hinemoana sometimes felt lost:

My saving grace was Ngahuia Te Awekotuku's book Mana Wāhine ${ }^{58}$ which pretty much literally fell apart because I read it so much and amazing women like Moana Maniapoto who was singing a lot at that time and still is. Kathy Irwin and Irihapeti Ramsden and all these women I read about and learned about, yeah it was a pretty amazing and stimulating time (T5A 00.28.20).

Her experiences in Women's Studies at Victoria led Hinemoana to become more involved with local politics and she joined the Wellington Bisexual Women's Group:

I was part of that time where those politics were very alive between lesbians and bisexual women about, you know whether bisexual women were okay to come to lesbian dances. That whole identity politics thing was very volatile (T5A 00.36.21).

\footnotetext{
${ }^{57}$ The Wikipedia entry on takatāpui was based on the work of takatāpui academics Ngahuia Te Awekotuku and Clive Aspin

${ }^{58}$ Te Awekotuku, N. (1991) Mana Wāhine Māori: Selected Writings in Māori Art, Culture \& Politics. Auckland: New Women's Press
} 
Because of that volatility, bisexual women began to organise their own dances to be more inclusive:

That was good, it was fun. It was also sometimes difficult because we would get called names by women who came to the dances but we didn't really care; we just wanted to make a safe space. I was really proud of my involvement at those times and in those events (T5A 00.36.59).

As with Hinemoana, most participants were already active members of Rainbow communities prior to hearing the term takatāpui. Peri was actively involved in the wider Wellington community. He worked and fundraised for a number of years with the Soup Kitchen run by the Mother Aubert Home of Compassion, where he became a Board member. Some roles crossed over several communities such as the Wellington City Council [LBGT] Advisory Committee where Peri helped train the Council's Walkwise staff on looking after RAINBOW people on the streets, many of whom were takatāpui. He was also involved in projects looking after animals and planting trees; "weave in and out of the community, that's what I like to do - not just stick to one" (T2 00.36.41).

As his transition progressed, Peri received increasing requests for advice for females transitioning to male (FTM). He had been meeting with a group of trans men, who spoke at length about setting up an organisation to address this. After two years Peri wondered, "how many other people out there need someone to talk to? I'll just do it" (T2 00.53.34). He founded FTM $^{59}$ Aotearoa in 2004 and fondly recalls the privilege he felt at being part of helping someone make a decision.

Several years later, Ahi was also looking for community when they came out as trans. Ahi realised that although they personally knew many trans people, they were unsure of whether the trans men knew the trans women. Joining existing online groups did not meet Ahi's political needs:

...people were saying all this misogynist, really racist, really fatphobic like "isn't fat feminising?"...If you tried to say anything they'd [reply] “just because we're trans doesn't mean we're political" (T4A 01.22.54).

To address a perceived lack of trans connectedness, and inspired by a need to create "a space where we can talk about things that are important" (T4A 01.24.40), Ahi began creating opportunities for people to meet, in person and online. From there Ahi went on to help organise

\footnotetext{
${ }^{59}$ See www.tapatoru.org.nz for more info on FTM Aotearoa New Zealand
} 
the People of Colour Decolonising Our Minds Hui, Auckland 2012, where we met as I was the keynote speaker.

\section{Breathing Life into Definition: Takatāpui Meanings}

All participants understood takatāpui to be a contemporary adaption of a traditional word that had been translated as 'intimate friend of the same sex' and were familiar with the Tütanekai and Tiki narrative from which it arose. Most participants were aware that it had been unearthed through the separate research of takatāpui scholars Ngahuia Te Awekotuku and Lee Smith; both of whom had spoken at Takatāpui Hui ā Motu during the 1990s and 2000s.

Inclusion was the most important aspect for the takatāpui participants. On one hand, it privileged their Māori identity regardless of their knowledge or experience of whakapapa, te reo Māori or tikanga; their level of connection with their whānau, marae, hapū or iwi; or the colour of their skin. It invited takatāpui to reconnect with Māori culture, values and worldviews:

Takatāpui to me, as I understand it now ....whatever the meaning may have been - to me it just identifies within my time, my community ... that I am same-sex attracted. I am takatāpui but definitely Māori, and so my values and the framework through the world views and so forth that I sort of look at things, come from that background of being brought up in what, to me, is a Māori environment (T1C 2014:3).

On the other hand, takatāpui also included all diverse gender identities and expressions and sexualities, thus providing an umbrella term similar to the inclusive use of 'Rainbow' ${ }^{60}$ which denoted membership of community without necessarily having to provide details of identity. It also ensured longevity of language as takatāpui would not require revision in the likely event that new identities demanded representation as had occurred with the acronym LGBTIQ having grown from the original 'G.'. As Hinemoana confirmed:

\footnotetext{
${ }^{60}$ Use of the word Rainbow to denote all diverse sexualities and gender identities is derived from the Rainbow Flag, originally designed by Gilbert Baker in San Francisco 1978 at the behest of Harvey Milk. The original eight colours represented sexuality (hot pink), life (red), healing (orange), sun (yellow), nature (green), art (turquoise), harmony (indigo) and spirit (violet). The flag was simplified to its current six colours; firstly, as a result of printing issues during mass production (removal of pink) and then at the 1979 Gay Freedom Day Parade in response to the assassination of Milk (replacing indigo and violet with purple)
} 
I really love that aspect of it, that it's an inclusive term. It makes you deal with people. You can't just put a fence up and say this is my territory, that's your territory and these are the reasons why we're different and these are the reasons why I don't like you (TB5 00.04.05).

Peri considered that organisations such as Tīwhanawhana exemplified inclusion by providing a space for takatāpui to explore their Māori identity free from discrimination, homophobia or transphobia:

Tīwhanawhana, I absolutely love, because it's really about me as a Māori. It's the only place I can be me as a Māori (T2 00.37.43).

Overall takatāpui was an identity that pulled all the different parts of cultural, gender and sexuality together without "selling out one for the other" (Kerekere 2007:37). As Peri noted, it was a place to be free:

That's what I love about being under a takatāpui umbrella, I feel it's so inclusive and widely inclusive, and it's about addressing the people and not the condition ...'Cause I belong to the trans community ... "it's a gender dysphoric condition" blah blah blah but takatāpui, it's everybody, you know, everybody. It feels much, much more, freer (T2 01.07.25).

Whakapapa is fundamental to Māori identity and Hinemoana was grateful for a term which recognised those genealogical and spiritual connections:

Takatāpui means to me, you know the word itself meaning intimate friend of the same gender. That's the meaning I take from the dictionary but the thing I love about it is that it's not an exclusive term, it's an inclusive term. So, I guess for me it's as close as you'd get to the word queer in English but ...it's got such a rich whakapapa, cultural whakapapa from Te Arawa (T5B 00.02.17).

More than just an inclusive term, Hinemoana saw takatāpui as indicative of the inclusive nature of te reo Māori:

And that's what the Māori language to me is so good at, is forcing that kind of communal discussion. There's not the facility in Māori to be quite so brutally disconnected as you can in English. ... but what I like about English is the ability to be so nuanced and so specific about what's different between you and another person, between that colour and this colour. The thing that I love about Māori is it's really difficult to do that (T5B 00.04.24).

Kevin also referred to the nuances of takatāpui to denote both inclusion and differentiation:

I love the fact that it so inclusive, that we can be all collective as one but also, I value where we are different within that collective term that resonates with me (T1B 2012:9) ...It seemed to 
speak to me about my situation as a same-sex attracted gay but at the end of the day Māori person. So politically I think takatāpui meant that I was able just to distinguish who I am, or the type of person I am, so to speak, within a Māori society and therefore also how I might be able to relate that, and the difference within the LGBTI community that I was becoming more and more involved with (T1C 2014:3).

Ahi noticed the intergenerational nature of takatāpui when they attended their first Takatāpui Hui-a-Motu, in stark contrast to the predominantly Pākehā activist/anarchist scene in which they were involved:

There's such an age range. There were like old, old, old people and a 15 year old. It made me think "oh right this is what's missing" (T4A 01.32.44).

\section{Taking Takatāpui to the World: Tīwhanawhana Trust}

Tīwhanawhana has played a key role in the emergence of takatāpui identity, particularly in the Wellington and throughout the national queer and gender diverse youth movement. Its development is an integral part of many takatāpui stories.

The idea to found the group which became Tiwhanawhana Trust crystalised when my partner Alofa and I attended the Gay Games in Amsterdam, 1998. During the Opening Ceremony, Alofa suggested I organise Team Wellington so we could bring all our friends to the next one. The Sydney 2002 Gay Games would be a mere four hour flight away so we began promotion immediately upon our return. By 2000 Team Wellington ${ }^{61}$ was re-formed and I became CoChair. My commitment was to engage Māori and Pacific Island Rainbow people as sport/cultural co-ordinators, participants and supporters. Nearly 50 takatāpui and low income lesbians and gender diverse people took part in the weekly fundraiser I ran for three and a half years to support their participation.

My goals in founding Tīwhanawhana were to provide a safe and fun space for takatappi to live our culture in a way that would honour our diversity; to address issues for trans, intersex and gender non-conforming takatāpui within the strict gendered roles of Māori protocols and performance; and to address racism by improving the use of tikanga within Rainbow communities. Finally, to support the Wellington and New Zealand delegations attending the Gay Games, Sydney 2002 and beyond.

\footnotetext{
${ }^{61}$ Team Wellington organised the Wellington delegation to attend the Amsterdam and earlier Gay Games
} 
The tikanga (protocols) put in place at the first Tīwhanawhana practice remains in place 16 years later. Fortunately, my political and cultural interests coincided with those of Tì Kouka (Māori women's art collective) whose members Dale Ferris and Rapai Te Hau ${ }^{62}$ became our first tutors; and Kevin Haunui, who shared his expertise in karakia, tikanga and composing waiata from the outset:

... the juncture of Tīwhanawhana, was also the juncture of when I had started to develop my reo and also understand my whakapapa and hapu history a lot more as a result of going to Te Wānanga o Raukawa. So, you know, saying that I wanted to get back into my taha Māori... (T1B 2012:5)

From its inception, Tīwhanawhana sought to model the inclusivity embedded in the phrase which contained its name. 'Tīwhanawhana ai he kahukura $i$ te rangi - a rainbow is forming in the sky.' This translated as providing a foundation of takatāpui leadership with practices open to all Rainbow people and their friends and whānau. As we drew closer to the Gay Games, practices of 50-60 people became common with participants ranging from elders to children. This formed the basis for future Rainbow community outreach, as Kevin noted:

...what resonated for me around Tīwhanawhana was that there was the Gay Games which were going to be held and so I thought and I fully supported and encouraged, strong, Māori identity developed for, and be expressed at the Gay Games....But I think, again all starting to confirm my [Māori] identity, and .... not so much provide leadership, but also be able to advocate once I started to get more connected within the LGBTI community and about being takatāpui; about advocating for... our taha Māori being valued in our community (T1B 2102:8).

After living and breathing Team Wellington for four years, it was a proud moment when the multi-cultural members of Tiwwhanawhana led the Wellington delegation into the Opening Stadium Sydney Stadium, 2002 - in black and performing the haka pōwhiri. ${ }^{63}$ Immediately prior to this, Tiwhanawhana had been performing while the Gay Games participants queued outside and some of the Australian organisers advised us that we were not permitted to perform the haka ${ }^{64}$ during the Opening Ceremony inside Sydney Stadium. In unsurprising defiance, Tiwhanawhana founding member Heta Timu led the male-identified members to haka in front

\footnotetext{
${ }^{62}$ Dale Ferris and Rapai Te Hau who also performed as comedy duo 'Te Coasties' at the time

${ }^{63}$ Haka pōwhiri is part of a traditional Māori welcoming ceremony (Karetu 1993)

${ }^{64}$ The Australians were referring to a particular haka 'Ka Mate' performed by New Zealand teams at the beginning of most international sports events/matches - made famous by the New Zealand rugby team; the All Blacks
} 
of the dignitaries. Perhaps resigned to the inevitable, the Australian organisers subsequently invited Tiwhanawhana to perform at another Gay Games event and we have been performing ever since.

Flushed with success after Sydney 2002, Tīwhanawhana considered its role subsequent to the Gay Games:

So Tīwhanawhana was fantastic at the Gay Games and where to from there? So, I guess, it has been really quite useful for us that we do have a vision and we do have a goal. But there is always a kaupapa, which helps us along, which brings expression to that. So, for example knowing that there was a hui coming up and that we would need to prepare for it and what are we going to do with that, or helped us always having a goal in mind (T1B 2012:9).

Tīwhanawhana extended its reach through the community networks it had established prior to the Gay Games and eventually became an indigenous cultural presence at every Rainbow event in the Wellington region. More importantly than pure performance, Tīwhanawhana modelled the use of tikanga and provided support at those events until others felt comfortable to apply that tikanga by themselves.

\section{The Good, the Bad \& the Ugly: 2004}

The year 2004 began auspiciously with the launch of Māori Television on 28 March with a line-up that included the programme Takatāpui with takatāpui presenters; Tania Simon, Ramon Te Wake and Tane Mete. It was the first free-to-air indigenous queer programme in the world and its successful magazine-style format went on to run for four seasons. Takatāpui was produced by Front of the Box (FOTB) Productions, led by takatāpui business woman Claudette Hauiti with primarily takatāpui staff including director Maawhi Torrance. Although FOTB is no longer in operation, the show's rich source of personal experience and takatāpui activity has been preserved in the archives of Television New Zealand. See Paul Diamond (2007:126) for an overview of the series. Speaking in terms of power and relating, Marewa Glover (2007) saw Takatāpui as a powerful vehicle:

We have whakapapa that ties us to each other. We are whānau. Some of us share, or aspire to share, and continue values from a Māori world view, for instance, manaakitanga, aroha and pono. We have a tikanga Māori we can live by that makes relationships and the quality of relating central. As takatāpui, we can help forge new ways of relating. We can help shift the balance of power to the diverse. It is enough to live differently and model a different way for 
our children. The personal is still political. As evidenced by Māori Television's Takatāpui programme, we are developing a whānau supportive of tino rangatatiratanga and of individuals who are not sexual as defined by Anglo, Judeo-Christian, Freudian, Jungian, Ellision, lesbianfeminist or American sexologists and psychiatrists and who are not defined by sex (2007:6869).

Many takatāpui who were Christian, and many who were not, were outraged when our very existence was called into question by a Māori Church leader (Hutchings \& Aspin 2007). Appearing on the front page of the national newspaper was the banner: 'A World Without Gays.' In opposition to the stated decision of the Anglican General Synod, Archbishop of Aotearoa and Polynesia, Te Whakahuihui Vercoe, announced that:

Homosexuality was not a part of traditional Māori society and that many people within the Māori community looked forward to the day when this would be the case again (NZ Herald, 5 June 2004).

Having recovered from that, takatāpui throughout the country were appalled to watch the fundamental Destiny Church-led march onto Parliament grounds on 23 August 2004 in protest against the proposed Civil Union legislation. Under the banners of 'Family Values' and 'Enough is Enough,' this predominantly Māori march intimated that takatāpui were not part of the whānau - and should not be. While Rainbow people and our allies were contained on the other side of the security fence, takatāpui MP Georgina Beyer ${ }^{65}$ descended Parliament steps and fearlessly challenged Destiny Church leader and self-appointed bishop, Brian Tamaki, and the hundreds of raging protestors spread out behind him. Interestingly, Tamaki's ambitions included a seat of his own in Parliament and the Destiny New Zealand Party ${ }^{66}$ ran a campaign which promised the repeal of the Homosexual Law Reform Act 1986. His parishioners may have followed Tamaki on that march but their failure to cast votes for him saw his political hopes disappear.

Having experienced warm acceptance from within her own whānau, Hinemoana was horrified by the Destiny Church-led march:

I was one of the many people on the anti-Destiny Church march when it happened in Wellington and that was a really poignant, pivotal point for me because I'll never forget watching all of

\footnotetext{
${ }^{65}$ Georgina Beyer made history as the first transsexual Mayor in the world (1995) and the first MP (1999)

${ }^{66}$ The Destiny New Zealand Party operated from 2003-2007. Tamaki effectively rebranded to form its replacement, the Family Party, in 2007. After receiving only $0.35 \%$ of the total vote at the General Election in 2008, the Family Party was deregistered in 2010.
} 
those men, mainly Māori men, lined up outside Parliament, dressed in black and doing haka in hatred against the takatāpui communities. It was a really heart-breaking moment for me; and one that is still being healed (T5B 00.09.44).

Sexuality \& the Stories of Indigenous People (Hutchings and Aspin 2007) was the first nonfiction book devoted to takatāpui. It arose partly as a positive and visibility-raising response to the Destiny Church-led march, 2004 and several of the 17 book contributors remarked on the march's negative impact on them personally and on Māori society generally:

Social discourse should reflect aroha and attempt to draw people into ideas, values and ways of being. It should be about inclusion. That is what horrified me most about the Destiny Church marches in Auckland and Wellington. When we have marched as Māori homosexuals, our intention has been to secure our own freedom, not denigrate other people. What I saw and experienced during the march in Wellington ws evil, open hatred of other people. It was not the names they called us that offended me or their pontificating about what constitutes normal. I was shocked by their arrogance and bad manners... During the months following, Destiny effectively gave licence for bigots to express their hatred of us (Blank 2007:108).

Paul Diamond (2007) drew attention to the unusual tikanga aspects of the march:

I suspect I'm not the only takatāpui person who found the Destiny rally at Parliament on 23 August 2004 a chilling experience. While haka, karanga and whaikōreo were prominent, traditional trappings of Christianity, like karakia [incantations/prayers] and hīmene [hymns] were nowhere to be seen or heard. It's the first time I can remember Māori tikanga being used to deny a group that includes Māori (2007:129-130).

The march was a topic of much discussion for Tīwhanawhana and it prompted Kevin to compose the waiata Takatapui Noa Ahau; a subtle yet powerful response to the violence of the march itself:

Takatāpui Noa Ahau composed and translated by Kevin Haunui

Tirohia mai au, he mōrehu tangata i puta mai i Rangiātea

He toka tū moana; he pou whakaaraara

He ururoa mārohirohi; he tīrairaka tauwhetawheta

He pari tū kārangaranga; he puna roimata hōhonu rawa

He manu tīoriori; he pare raukawakawa mōteatea

Ka uru mai, ka uru mai, ka uru mai 
Ka uru mai he aniwaniwa tūramarama

Kaua e whakarērea, he takatāpui noa ahau

He kōtuku rerenga tahi

He whetū e rere runga $i$ te rangi

Ka uru mai, ka uru mai, ka uru mai

Ka uru mai he aniwaniwa tūramarama

Kaua e whakarērea, he takatāpui noa ahau

Tirohia mai au, he mōrehu tangata i puta mai i Rangiātea

Look at me, a survivor from Rangiātea

A rock buffeted by the sea; a sentry, alert and guarded

A shark, stubborn and relentless; a fantail challenging your path

An echoing cliff; a deep spring of tears

A speaker strong and clear like a bird

A singer of memories from a wreath of kawakawa

It comes, it appears - an illuminating rainbow

Don't overlook me just because I am takatāpui ${ }^{67}$

Don't leave me behind, I am only takatāpui

Like a treasured moment, to see the white heron or a flying star

It comes, it appears - an illuminating rainbow

Don't overlook me just because I am takatāpui

Don't leave me behind, I am only takatāpui

Look at me, a survivor from Rangiātea

${ }^{67}$ Kevin Haunui had originally translated 'takatāpui' as 'gay' for brevity but this has been changed to retain takatāpui in recognition of the more complex interpretation required. 
As Kevin explains what he sought to capture in composition of this waiata:

The essence of trying to bring together those characteristics combined with saying gay or takatāpui, was to try and instil and confirm for takatāpui who they are and the values that make up who they are and the parts that they play in Māori society or any society really. So ...these are the values that we have, and that's not isolated in takatāpui, or that takatāpui are isolated from it. We're in it, we're part of that as well... Again, trying to give value to who I am, and who I see my peers are as takatāpui (T1B 2012:12).

The use of the word 'noa' and its translation as 'only' has been a source of consternation at conferences $^{68}$ where I have discussed this waiata; as it appears to audience members to undermine and belittle takatāpui identity. The Te Aka Māori online dictionary gives the following definition for noa:

1. (particle) only, just, merely, quite, until, at random, idly, fruitlessly, in vain, as soon as - a particle following immediately after the word it relates to. Denotes an absence of limitations or conditions (my emphasis). Often occurs in combination with other particles, e.g. noa iho.

My interpretation is that 'noa' expresses both an expression of humility and of bewilderment that Māori and sometimes our own whānau would treat us poorly because of our gender identity and sexuality orientation. In acknowledging the limitations of the English translation, Kevin wryly noted that "people can be so literal" (T1B 2012:12).

Because of their significant funding, the takatapui staff of the New Zealand AIDS Foundation have organised several of the Takatāpui Hui $\bar{a}$ Motu, with an associated focus on the sexual health of gay men and MSM (men who have sex with men). Subsequent to attending the Takatāpui Hui ā Motu at Waipapa Marae, Auckland University in 2004, Tīwhanawhana hosted the next at Hongoeka Marae, Porirua on 3-5 November 2006. We approached the Hui with a broader perspective of the health and well-being of takatapui with the use of story-telling, art, music and movement.

Impressed with his work in the trans community and after his brilliant keynote at that Hui $\bar{a}$ Motu, Peri Te Wao was invited to join the new Board when we decided to register Tiwhanawhana as a legal entity. Kevin and Peri participated in the first strategic planning session I facilitated in Martinborough in December 2006, to develop the Moemoea (vision),

\footnotetext{
${ }^{68}$ Asia Pacific OutGames Human Rights Conference, Melbourne 2008 and Fifth International Language and Gender Association Conference (ILAGA5), Wellington 2009
} 
Kaupapa (mission) and Mahi/Arataki (objectives) for Tïwhanawhana Trust (attached as Appendix VIII).

For Kevin, Tīwhanawhana provided a vehicle to advocate for takatāpui and relationship building within Rainbow communities:

So clearly for me is the importance is around being inclusive, but politically, Tîwhanawhana has real value in opening those doors, so that we can be very inclusive for the rest of the waka, whoever wants to join the waka. It does open the doors in that way (T1B 2012:10).

Peri emphasised the importance of Tīwhanawhana within the Wellington and national LGBTIQ communities, particularly for promoting the inclusive framework that is takatāpui:

Tīwhanawhana, like me, is like a small precious gem. Very small - like an iti pounamu - but very precious. And it's precious because we can, we have, and we can still become very important parts of different parts of our community, not just the one (T2 01.07.25).

In particular, Peri noted Tīwhanawhana Trust's unique role in insisting on the correct use of tikanga Māori throughout LGBTIQ communities:

As support and providing that safety, bringing in the world that never gets addressed, like the spiritual world. Bringing that in; because out there - it's not spiritual. It's just so plastic and surface-like but we can actually get deeper and I think that's what a lot of people love (T2 $01.08 .44)$

As Kevin concurred:

Tīwhanawhana is a great vehicle for takatāpui. It's for takatāpui. It's about takatāpui, and it's very inclusive of takatāpui. It aims to ... keep us connected to our taha Māori (T1B 2012:10).

Through its involvement in the World OutGames in Montreal 2006, Tīwhanawhana was invited to take part in the Opening Ceremony and Human Rights Conference at the first Asia Pacific OutGames, Melbourne 2008. While I continued the relationship with the Federation of Gay Games, Kevin went on to represent Tīwhanawhana on GLISA for the Asia Pacific OutGames: The OutGames is one of those things where I have represented Tīwhanawhana and the ideals, the visions of Tīwhanawhana being established within the OutGames and also the other aspect of that is trying to be inclusive for others who are not normally associated with Tīwhanawhana (T1B 2012:10). 
In 2008, Tīwhanawhana was invited to perform at the Opening Ceremony of the Asia Pacific OutGames in Melbourne. Seven members including Kevin Haunui, Peri and me took to the stage in front of over 2000 excited Rainbow people from around the world. In deference to Peri, the men had agreed not to remove their shirts but in the heat of the moment, Kevin pulled his off and Peri was faced with a major decision:

I was absolutely terrified - mainly because I was fat. I was fat and I had not worked out. And it's like, oh my god, I have to go out there with no top on and I hadn't had the flashest surgery. I was actually a guinea pig but for me, it was the best surgery ever. But if you kind of like put me out and stood in front of several thousand people, it's like oh shit, you know. But that's the beauty I say about Tīwhanawhana and in general, under the umbrella of takatāpui, you feel supported. ... "Breathe Peri breathe - look out, don't look in." ... It was a challenging time and I think I took the right road (T2 00.59.18).

In a courageous move, Peri removed his top and became the first takatāpui trans man to represent Aotearoa New Zealand in kapa haka on an international stage.

Tïwhanawhana ran a workshop at KAHA '07 National Queer \& Trans Youth Hui on making queer and gender diverse youth groups welcoming to takatāpui. In my role as Kaimahi, Takatāpui Taiohi for OUT There! National Queer Youth Project, I ran KAHA '09 with staggering community support from over 30 different Rainbow individuals and organisations. Ever since then, Tiwhanawhana has supported the national queer and gender diverse youth movement in Aotearoa at every national, and many regional, events.

Peri and Karen developed FTM Aotearoa into Tapa Toru around 2010. Based on an inclusive takatāpui framework and targeted to trans everywhere, their bi-monthly e-newsletter has over 5000 subscribers from around the world. ${ }^{69}$ Their annual calendars since 2011 feature takatāpui who are trans and community supporters. They include whakataukī and affirmations. For the future Peri plans to take it to another level; "as I say to everyone - not sure how it's going to happen but something will, if we just put it out there" (T2 00.56.30).

Part of their strategic thinking included them both training in the health field. In 2012, Peri completed his third-year training to be a registered nurse and Karen was taking psychology

${ }^{69}$ Tatou ceased to be produced in early 2017 
papers. Peri hoped Karen would take on therapeutic training with a more holistic focus, "what we'd like to do is set up some sort of a community for trans but maybe not just for trans, just for our people" (T2 00.57.17).

\section{Stepping Up Representation: Wellington 2011}

The $2^{\text {nd }}$ Asia Pacific OutGames was hosted in Wellington, March 2011. It comprised of multiple sporting and cultural activities and a Human Rights Conference where I featured as the opening keynote speaker. Kevin's leadership role ensured that tikanga and kaupapa Māori were integrated into the planning process for Wellington 2011 from the beginning:

You have to be in the right places to be able to ensure that your kaupapa, in fact our kaupapa of Tīwhanwhana comes along, so we're in place to be able to influence - to ensure at the highest level of those organisations we were represented, which of course is what happened (T1B 01.25.01).

At every level of decision-making from the planning, website and Bid Document to selection of speakers and event management; Tīwhanwhana facilitated access for takatāpui. As Kevin noted:

We kept up the banner for our local community and they are aware of Tīwhanawhana as it became involved in the OutGames in Wellington and its involvement of just in some feeding some very clear messages around being involved right from the beginning in terms of protocols, and also the types of visibility that the organisation should be showing, whether it was orally, or electronically, there was Māori expression.... I mean the bid document itself featured Tîwhanawhana right at the beginning and so it sent very strong messages through, and I guess the key thing that I, like most relationships, because we are in a relationship with our community, is making sure that we keep strong, and that was about our kaupapa (T1B 2012:7).

The OutGames opened with a parade from Civic Square to a pōwhiri ${ }^{70}$ at the national museum and art gallery; Te Papa Tongarewa - in place of the Opening Night dance party usually held at such events. Tīwhanawhana oversaw all aspects of tikanga throughout the week-long event, in consultation with local iwi, Te Atiawa.

Peri, his wife Karen and others arranged an international Trans Hui as part of Wellington 2011, which Ahi attended as noted earlier, thus reinforcing the importance of takatāpui being

\footnotetext{
${ }^{70}$ Pōwhiri: Traditional Māori welcome
} 
involved in wider community events as a means of connecting with Rainbow Māori working in other communities.

In addition to the many volunteers and visitors involved, 1350 participants registered for Wellington 2011 from 29 countries ranging in age from 17 to 76 years. It was the second largest community event in Wellington that year bringing in an estimated \$1.3-\$1.7million to the local economy. At the Wellington City Council's 2011 Wellington Airport Regional Community Awards, the organising group, Wellington 2011 Inc, won the Sport \& Leisure category and was then awarded the Supreme Award by Mayor Celia Wade-Brown.

Although Tīwhanawhana was a small organisation, Peri noted that its networks were extensive, as was its influence. Having received positive feedback about Tīwhanawhana's international work confirmed to Peri the role models takatāpui could be for Rainbow people elsewhere:

I got the feeling from the Asia Pacific OutGames that we've got something unique. We're actually a strong people and people got a feel for that coming to New Zealand because when you listen to their stories, they're so downtrodden and minimalist and we're not. We may feel we are but we're not really. People will listen to us and we will put up a fight (T2 01.09.19).

Operating within a parallel sphere of activism in Wellington, Ahi was engaged in issues of power and privilege between the predominant cis-gendered lesbian, gay and bisexual communities and the trans/queer communities:

...it seems like there's this real divide. You know in the gay scene world, ${ }^{71}$ gay cis[gendered] guys dominate the scene and then in the more politicised queer world, cis[gendered] women run the scene. It seems a lot of trans guys used to be butch cis women or they are coming from the kind of lesbian scene and so they can still be part of those things but trans women are probably coming from a really different, and probably not even coming from the gay scene world they're coming from the straight world (T4A 01.31.52).

Ahi became increasingly aware that online and other discussions among trans men groups deteriorating into arguments around divisive language and privilege:

People would come along and say "but I'm trans and I get harassed". I would think oh fuck, you're setting it up as though there are white people who are trans and there are like all people of colour; it's that oppositional thing again. There are lots of trans people of colour... So, lots

\footnotetext{
${ }^{71}$ Referring to gay, lesbian and bisexual political and social communities which are often seen by queer, trans and more gender diverse communities to have become more mainstream or exclusionary of others 
of fights. You know what, "I'm over this Internet stuff, I'm just going to do real life stuff" (T4A 01.29.39).

Bringing together other trans people who were interested in boxing or self-defense courses but felt excluded from gendered training, Ahi started a social queer trans fight club. The classes are run by takatāpui self-defense proponent Sue Lytollis. $^{72}$

As part of the Pākehā dominated anarchist/activists sector, Ahi's activism included actions for October $15^{\text {th }}$ Solidarity ${ }^{73}$ and being part of a collective whose plan to run an animal sanctuary competed with the environmental concerns of local Māori. Pākehā attempts to address their racism, White-centricism or actualise support for tino rangatiratanga [indigenous selfdetermination] often put Ahi in an awkward position. At one hui in 2012, Ahi hoped to see changes in the way that trans and cis-gendered Rainbow people worked together. As one of four people of colour amidst about 25 participants, Ahi's frustration was exacerbated by a failure by the participants to hold a White-centricism session that had originally been mooted:

It's interesting that everyone's initial reaction was like, "yeah, we're against racism but they're like what we really want to talk about is something else"... They were like "I think that that's really important that we should talk about that but let's save it for another time" (laughs) and I said, "oh yeah Pākehā people always say that" and there was this like awkward moment in the room (laughs) but I was cracking up laughing (T4A 01.34.36).

The differences between their other experiences and the Takatāpui Hui-a-Motu Ahi had just attended was glaringly obvious:

It's funny because when I was at the Takatāpui Hui, I was like, it's not like that here. We're all takatāpui, we're all here together and it's all sweet ...Also being at that Hui Takatāpui 2013, that day we rode horses and went down to the beach - that never happens in the Pākehā dominated world, it's like, "we're here together. We're doing this thing together" (T4A $01.32 .44)$.

\footnotetext{
${ }^{72}$ Sue is renowned for developing self defence classes for women and girls in the 1980s which are still being taught in New Zealand schools. Sue was awarded a Queen's Service Medal (QSM) in 1996 for her services to women. She specialises in Judo and Kendo and has won medals in several Gay Games and OutGames

${ }^{73}$ Solidarity work on Condition 8 after several activists were arrested and some subsequently imprisoned
} 


\section{Putting Up A Fight \& Staring Down Challenges}

Kevin attributes his resilience partly to growing up in a loving whānau and partly to growing up in a 'whānau' or 'iwi ā waho:'

It occurs within the individual, within the whānau and that there's always that within the hapū. ... essentially it's that ability to make your own decisions, whether as an individual or as a collective or whatever. So that sort of sustained me in terms of my connection to ... recognising myself as takatāpui and then also recognising that those elements of my taha Māori were very much a natural part of that and ... irrespective of what others might think who are Māori - that was my rangatiratanga (T1B 2012:4).

This was particularly important when faced with Māori who were not supportive ...for me what's vitally important within our communities is being proud of who we are and where we come from and things like that, so that's where my, and again gives me the kaha, sometimes to [express] that in audiences which are Māori (T1B 2012:11).

Proud of being different, Peri is not one to conform. "If anybody tells me I can't do this, I'll be nice to them but if you really looked into my eyes, I'm saying, "who are you, telling me what to do?"' (T2 01.04.00). Peri attributed his survival to the techniques he had honed over the years:

The skill behind that is probably for me not to challenge the moment but to stand back and just give them the look: "I've heard what you're saying but I have my own take on it, thank you very much, good bye" and go do my own thing (T2 01.04.33).

Peri gave his own wedding to Karen as an example. The law did not allow them to marry as a trans couple at the time. But for them, it was not about the law, it was about love. Karen had received devastating news about a health condition which meant she could die at any moment. When Peri asked her for the one thing she most wanted, Karen requested a white wedding with all her friends and family:

And I said "then that's what you're going to have." And no law, no person sitting in a flash building at Parliament is going to tell me otherwise ... So I guess for me when we talk about issues for takatāpui, there's ways around it... I'm Māori, I'm not into big and flashy. I wouldn't have minded if we got married at the beach with a barbeque. The fact is we did what we wanted to do (T2 01.05.33). 
His refusal to see anything as insurmountable is also based on his solid confidence in being Māori and our ability to endure, survive and thrive:

I think takatāpui are very lucky in comparison to what's happening around the world and I think we need to be reminded of that every day and build from it and not go backwards. I don't think we are. In the small community that I work with, and live with, amongst takatāpui, I love what we've got. I know it could be bigger and better but that's okay, you know, better than nothing. I come from a pōhara family so better than nothing is cool. I'm not out for the grandest and biggest, I'm just out for something and I'll take what I can get. So issues for takatāpui, nah, I think, I think issues are not so much excuses but just little obstacles that, if we work together we can find a way to get over it. We don't need anyone else's approval. We're from here. This is our home. We're the boss (T2 01.06.15).

Peri's consideration of the key issues facing takatāpui is based on him having overcome the challenges of his past to become a national leader within the takatāpui and trans communities:

I think the key issues facing takatāpui are the boundaries that are placed on us but there's boundaries placed everywhere... I think the only limits to takatāpui are takatāpui (T2 01.03.22).

While Peri may consider himself a background person, he continues to do what needs to be done and in that, provides leadership for all takatāpui:

You have to think like that to get through. It's not just about me. It's about my whānau. It's about my community. It's about everybody really, who can affiliate to what you see (T2 01.02.18).

\section{He Hononga}

Chapter 7 provided insight into research questions within the Whäriki Takatāpui framework to do with Kaupapa Mãori Theory, Mana Wāhine, Mana Motuhake and Te Whare Tapa Whā.

Once discovered, the term takatāpui was disseminated through three main networks; Māori and Pacific lesbians/queer women political organising; Māori gay men/whakawāhine fighting HIV/AIDS; and educational/academic networks. Its definition has evolved to reflect takatāpui activism and the depth of intersectional analysis within Rainbow communities.

Whakapapa was an important way of understanding relationships that connect takatāpui with each other, regardless of whether they claim a takatāpui identity or not. Because the forces of colonisation which affect Māori identity also affect takatāpui identity; claiming takatāpui was an act of decolonisation. 
Takatāpui was a Māori identity that was still emerging into the mainstream. Māori with diverse gender identities, sexualities and sex characteristics generally became exposed to it through Rainbow networks and the work of organisations such as Tīwhanawhana Trust. Some Māori felt they could not claim it because they were not 'Māori enough' which suggests that the level of comfort with 'being Māori' directly correlates with the level of comfort with 'being takatāpui.'

The major attraction of takatāpui was that it was inclusive of all Māori with diverse gender identities, sexualities and sex characteristics; regardless of skin colour or knowledge of Māori language and culture; and even regardless of claiming takatāpui identity. Identifying as takatāpui meant becoming part of something bigger that unified communities. Similar in scope to the umbrella term of 'Rainbow,' participants reiterated the importance of takatāpui defining and evolving the understanding of the term.

The emphasis on whakapapa reinforced a spiritual descent from tūpuna takatāpui. Adherence to the core Māori values of whānau and whanaungatanga (relationships and interconnectedness) had developed an intergenerational takatāpui movement characterised by respect for elders and responsibility for young people.

Tīwhanawhana Trust was founded to "build our community, tell our stories, and leave a legacy" (2007:1). It is an example of how takatāpui can live their Māori identity in an environment that honours their diverse gender identities, sexualities and sex characteristics. It provided Māori language and performance to reconnect takatāpui to their culture; encouraged and supported Rainbow communities to incorporate Māori language and protocols into their activism; and promoted takatāpui leadership and representation at local, national and international levels.

The takatāpui leaders in this study operated from strength-based positions that expect influence, access to decision-making, achievement and success. Considerations of colonial and intersectional oppression are then framed from a place of agency with a focus on collaboration and respectful, tikanga-based dialogue. In the face of discrimination from whānau and wider society, takatāpui creatively fought back by creating spaces, organising protests, writing books, making television programmes and always having something to look forward to. 


\section{CHAPTER 8: WHAKAMUTUNGA: HE WHĀRIKI TAKATĀPUI}

Part of the Whānau: The Emergence of Takatāpui Identity - He Whāriki Takatāpui is the first study on takatāpui identity and well-being. It lays down a Whāriki Takatāpui; a woven mat of vibrant colour and intricate design to form a foundation. It creates a place where takatāpui may sit to discuss and make decisions; and from which to step forth to fight and make change.

\section{Gathering The Tools - Kaupapa Māori Research}

This study adds a new Kaupapa Maori research methodology - He Whāriki Takatāpui as outlined in the diagram below.

\begin{tabular}{|c|c|c|}
\hline Title \& Research Questions & Weaving Process & Kaupapa \\
\hline Kaupapa Māori Research & Gathering the tools & Māori research models \\
\hline Kaupapa Māori Theory & Harvesting the harakeke & $\begin{array}{l}\text { Te reo Māori, tikanga and } \\
\text { mātauranga }\end{array}$ \\
\hline Mana Wāhine & Preparing the harakeke & \multirow{2}{*}{$\begin{array}{l}\text { Whakapapa and the impact } \\
\text { of colonisation on } \\
\text { understandings of Māori } \\
\text { sexual and gender fluidity }\end{array}$} \\
\hline \multicolumn{2}{|c|}{$\begin{array}{l}\text { - Why is whakapapa important to takatāpui? } \\
\text { - What can takatāpui learn from the past? }\end{array}$} & \\
\hline Mana Motuhake & $\begin{array}{l}\text { Designing the patterns and } \\
\text { colours }\end{array}$ & \multirow[t]{2}{*}{$\begin{array}{l}\text { The subjective formation of } \\
\text { takatāpui identity }\end{array}$} \\
\hline \multicolumn{2}{|c|}{$\begin{array}{l}\text { - Why do Māori with diverse gender identities, } \\
\text { sexualities and sex characteristics claim takatāpui } \\
\text { identity? } \\
\text { - What does 'being takatāpui' mean in relation to } \\
\text { 'being Māori'? }\end{array}$} & \\
\hline Te Whare Tapa Whā & Weaving the whāriki & \multirow{2}{*}{$\begin{array}{l}\text { Takatāpui health and well- } \\
\text { being }\end{array}$} \\
\hline \multicolumn{2}{|c|}{$\begin{array}{l}\text { - What are the key issues that impact on takatāpui } \\
\text { health and well-being? } \\
\text { - How do takatāpui address the challenges facing } \\
\text { them? }\end{array}$} & \\
\hline Whakamutunga & Finishing off & \multirow[t]{2}{*}{ Findings and conclusion } \\
\hline \multicolumn{2}{|c|}{$\begin{array}{l}\text { - How can takatāpui identity promote health and well- } \\
\text { being for all Māori with diverse gender identities, } \\
\text { sexualities and sex characteristics within whānau and } \\
\text { society? }\end{array}$} & \\
\hline
\end{tabular}




\section{Harvesting the Harakeke - Kaupapa Māori Theory}

The appropriate use of te reo necessitates an accurate definition of takatāpui that recognises its integrity while acknowledging those who claim takatāpui identity and the communities which promote its use. A definition that excludes a gender analysis necessarily excludes Māori who are trans, intersex or gender diverse. An inclusive definition breaks down power imbalance and broadens opportunities for support, visibility and connection. On that basis and reinforced by the findings of this study, I advance the following definition:

Takatāpui is an umbrella term that embraces all Māori with diverse gender identities, sexualities and sex characteristics including whakawāhine, tangata ira tāne, lesbian, gay, bisexual, trans, intersex and queer. Takatāpui identity is related to whakapapa, mana and inclusion. It emphasises Māori cultural and spiritual identity as equal to - or more important than - gender identity, sexuality or having diverse sex characteristics. Being takatāpui offers membership of a culturally-based national movement that honours our ancestors, respects our elders, works closely with our peers and looks after our young people (Kerekere 2015, 2016).

\section{Preparing the Harakeke - Mana Wāhine}

'Takatāpui' was an ancient term in such common usage that it appeared in the Second Māori Dictionary (1852) and was defined as 'intimate partner of the same sex' in the Third Edition (1871). When separately discovered by takatāpui academics Ngahuia Te Awekotuku and Lee Smith, they gifted it to Māori through lesbian, gay, transgender and academic networks from the early 1980s. The first hui were held by takatāpui who were lesbian/bisexual/queer (1981) and who were gay/MSM/whakawāhine (1986). The first reference to takatāpui in print was from Te Awekotuku (1991) who has consistently characterised it as including all diverse gender identities and sexualities.

Whakapapa is important to takatāpui because it is fundamental to being Māori and therefore to Māori identity. It is a legacy Māori inherit regardless of skin colour, ability to speak te reo Māori, familiarity with culture or number of marae visits. Whakapapa places takatāpui within a whānau, hapū and iwi which in turn connects us to marae and specific tribal areas on Papatūānuku, our earth mother. Takatāpui often search for our predecessors as we strive to see ourselves reflected in the past - for commemoration, validation and pride. Whakapapa is central to takatāpui identity and spiritual connection to tūpuna takatāpui. 
Intersectionality was a useful concept for understanding the historical and intersecting oppressions (affecting indigeneity, race, sex, gender) within which takatāpui and their whānau exist. Intersectionality was not, however, useful for considering identity. Whakapapa guides my analysis of the extent to which takatāpui draw strength from the evidence of takatāpui in the past to defend against discrimination from within whānau and Māori society today. In order to address that discrimination, the balancing of gender within Māori society through Mana Wāhine was essential.

My artistic analysis of 150 whakatauki gave insight into the status of women in traditional Māori society, relationships, gender, sex and sexuality. It confirmed that women were equal to men with complementary roles that worked for the collective good of their whānau, hapu and iwi. Women leaders were a result of whakapapa and training. As men were valued as warriors, so women were valued for their role in brokering peace. Women had control over their own bodies and sexuality so could chose to stay with, leave or censure a partner. Both women and men had multiple partners. This study identified the first new evidence of historical takatāpui existence in some decades. The whakataukī Ngā korero ahiahi o Hinewha is from my tribal home in the Tairāwhiti and refers to sexual activity between two or more women.

\section{Mana Motuhake}

This study shared the voices of 14 takatāpui of diverse gender identities and sexualities, aged 19 to 64 years of age (three generations) at the time of interview - including my own. Supplementing those were voices of 13 whānau members, aged 19 to 84 years of age (four generations). The construction of Māori identity differed for takatāpui in that they were constructing their gender identity and sexuality at the same time. These are interwoven and may not be easily or usefully separated.

By claiming takatāpui identity, takatāpui recognised that their diverse gender identities, sexualities and sex characteristics were part of what made them Māori. This study found that gender and sexuality were part of our wairua on the basis that Māori are more likely to identify their diverse gender identity and sexualities - and come out or transition - at a younger age than non-Māori despite whānau and systemic discrimination; self-imposed fears; knowledge of terms related to sexuality or gender; or exposure to positive role models. Knowledge of whakapapa created strength and conviction - if takatāpui were accepted by our tūpuna, so they 
should be accepted today. Knowing who they were as Māori was critical for them knowing who they were as takatāpui.

Without traditional Māori values guiding acceptance of gender and sexual fluidity, whānau could take on the worst of colonial and Western culture: shame, silence and religious persecution. Disconnection from whānau because of discrimination could lead to disconnection from Māori culture - and therefore from Māori and takatāpui identity. Discrimination from within whānau was the most difficult for takatāpui to face. Takatāpui may be accepted and supported within their whānau but identities such as 'lesbian, gay, bisexual, trans, intersex or queer' were seen as 'Pākehā' or 'Western.' With homophobia, transphobia and biphobia normalised in the context of colonisation, claiming takatāpui identity could be seen as a means of decolonisation. It enabled takatāpui to reframe their identity from negative or marginalised to one based on whakapapa, te reo and tikanga, inclusion, intergenerational values and belonging. Part of belonging was connection to Rainbow communities. Orgnisations such as Tīwhanawhana Trust were critical in providing safe spaces, cultural support and political advocacy and leadership.

\section{Te Whare Tapa Whā}

Takatāpui share negative health outcomes with other Māori and with other members of Rainbow communities who share their diverse gender identities, sexualities or sex characteristics. A lack of research limits the resources and funding necessary to identify and address those issues specific to takatāpui. This study emphasised that it is incumbent upon cisgendered takatāpui to use any available privilege to uplift takatāpui with diverse gender identities and sex characteristics who may or may not identify as trans or intersex - or even takatāpui.

\section{Taha Wairua}

Whakawāhine, tangata ira tāne and trans participants noted their awareness of gender difference (from the one they were assigned at birth) from a very young age. That led me to realise they were modern day version of tipua - spiritual creatures who could change gender and form. Takatāpui ability to live as their preferred gender relied on whānau recognition and acceptance which was not always forthcoming. Almost all participants were aware from a young age that discrimination against people with diverse sexualities existed which affected their decision to come out (or not) when they first became aware themselves. Being able to call 
on tūpuna and tūpuna takatāpui helped takatāpui rangatahi and their whānau on their journey together. Gender identity and expression, sexual identity and being true to oneself were considered integral to being takatāpui. When that wairua was trampled on through discrimination and rejection, the distance between takatāpui rangatahi and their whānau increased. Spiritual reconnection was a whānau, not rangatahi, responsibility.

\section{Taha Tinana}

Takatāpui shared the common Māori experience of growing up variously with violence, sexual abuse, neglect and alcoholism. Their whānau may not support their diverse gender identities, sexualities or sex characteristics or takatāpui may suffer discrimination, bullying and violence in other parts of their life. That increased the likelihood of the harmful use of alcohol and drugs, unwanted sex and rape, intimate partner and sexual violence. Whānau was the first and most important place of protection all rangatahi had. They needed to know their whānau had their back. Being in charge of one's own body took on specific meaning for those takatāpui rangatahi with diverse bodies and gender identities who often had negative experiences with health services.

\section{Taha Hinengaro}

Discrimination, isolation and fear of rejection from whānau took a toll on the mental health of takatāpui rangatahi. It affected their confidence and their ability to be in the world, as well as their outlook on the future, which in turn led to high rates of depression, self harm and suicide. Being Māori meant being born into whānau, hapū and iwi. A sense of 'belonging' however, relied on building connections and relationships. It was the whānau's responsibility to ensure that takatāpui rangatahi knew their inclusion was never in doubt. True acceptance of takatāpui rangatahi was more than just accepting them as individual members of the whānau. It extended to the partners they brought home, the friends they found and the Rainbow organisations and activism they became involved with. Almost all takatāpui participants experienced some form of depression and suicidality. Considering that some happened decades ago, it was alarming to find that the present generation of young people continued to share that experience. The impact of discrimination on mental health and overall well-being is significant, particularly when takatāpui are feeling pressured by whānau to maintain cis-gendered heterosexuality; to marry and have children.

\section{Taha Whānau}


Tūini Ngāwai was an example of a public historical figure whose whānau and community supported her diverse gender expression and sexuality. Their decision to keep silent over her relationships with women afforded Tūini protection against the homophobia and transphobia which was known to exist outside of their Māori world. Further, this was an example of an historical protection for takatāpui that occurred in many Māori communities. When whānau were scared or angry with takatāpui being visible, this was not necessarily evidence of homophobia, biphobia and transphobia, but rather the vestiges of an historical anxiety - a memory from our tūpuna that silence was protection. We cannot know how Tūini identified herself but over 50 years after her death, takatāpui may proudly claim her as one of our most prominent tūpuna takatāpui.

Having whānau who kept them safe was critical to well-being and instilling a sense of Māori identity. The relationship and trust developed between participants and their parents, immediate family and wider whānau growing up had a strong bearing on the reactions when takatāpui disclosed their diverse gender identities, sexualities and sex characteristics. Where dysfunction, strained relationships and abuse already existed, anything which threatened the 'normality' of home life could be traumatic. Participants reported better relationships with their parents' as they grew older which would be of benefit if disclosure was delayed until that point. However, most takatāpui did not delay that disclosure even if they expected a negative response.

When whānau members saw disturbing changes in their takatāpui rangatahi, they felt disconnected and unable to communicate. It often took time for takatāpui rangatahi to raise the courage to tell their whānau about their diverse gender or sexuality for fear of whānau rejection. They experienced guilt, embarrassment, isolation, fear, depression, anger and hopelessness. In turn, when takatāpui rangatahi disclosed their diverse sexuality or wish to transition from the gender they were assigned at birth, some whānau often experienced shock, embarassment, denial, a justified fear for their safety, feelings of conflict, and a particular grief when rangatahi wanted to transition. By claiming Māori values, whānau embarked on journeys of love, acceptance and celebration of their takatāpui rangatahi - and in some cases - saved their lives. Key to building good whānau communication included patience, self-awareness, trust, acceptance, love and - eventually - pride.

Whānau is key to the survival of takatāpui rangatahi. Whānau support contributed to building their confidence and resilience. Support from immediate whānau and especially kuia kaumātua (elders) helped them to stand in their own mana - to be strong in who they were and to face whatever challenges came their way. One member of the whānau who is hostile could have a 
disproportionate impact on takatāpui if nobody challenged their behaviour. Conversely, one strong ally who stood up to everyone helped build resilience that prepared takatāpui for the future. Remarkably, having other takatāpui in the whānau or parents having friends who are takatāpui or Rainbow did not necessarily correlate with parents reactimg well to their child disclosing diverse gender identities or sexualities. Each case was different and whānau needed support to go through that journey with their takatāpui members.

\section{Whakamutunga}

At the beginning of this study, I identified many areas which it did not cover. Having completed it and based on the current state of our Rainbow communities, I have identified four priorities moving forward. The first is development of a National Rainbow Strategy which will contain a National Takatāpui Strategy, for which planning is well underway. Second is continuing my work on whakataukī. Third is a living bibliography of takatāpui past and present which details their achievements and contribution to our whānau and communities. Fourth will be intergenerational collaborations with indigenous activist scholars and artists in the Pacific and the Americas. Throughout my work, I strive to "honour our ancestors, respect our elders, work closely with our peers and look after our young people" (Kerekere 2015, 2017) within our whānau and across all our diverse communities.

This Whäriki Takatāpui was intended to be the woven mat that lies inside Te Whare Tapa Whā of takatāpui health and well-being. It has been woven based on ancient traditions with contemporary colours and patterns. Providing a place to sit, talk and move to fight, the Whäriki Takatāpui brings life back to a once vibrant meeting house which has become dusty and run down. As the meeting house is rebuilt, so it will contribute to the transformation of Māori culture - a place where takatāpui are valued and discrimination is unacceptable. Takatāpui will continue to act with agency and speak to power. We will meet challenges with creativity and intergenerational connection. With our whānau and allies we will adorn this Whare Tapa Whā in a manner befitting its significance; the gardens will be planted and the people resilient and healthy. 


\section{BIBLIOGRAPHY}

Alice, L. and Star, L. (2004) Queer in Aotearoa New Zealand. Palmerston North: Dunmore Press Ltd.

APF/UNDP (2016) Promoting and Protecting Human Rights in Relation to Sexual Orientation, Gender Identity and Sex Characteristics: A Manual for National Human Rights Institutions. Sydney: Asia Pacific Forum of National Human Rights Institutions and Bangkok: United Nations Development Programme

Arboleda, G. and S. Murray (1985) The Dangers of Lexical Inference with Special Reference to Māori Homosexuality in Journal of Homosexuality. Vol 12 (1):129-134.

Aspin, C. (1996) "Gay Community Development in New Zealand in the 1970s and Implications for the Health of Gay Māori Men in the 1990s" in Social Policy Journal of New Zealand Te Puna Whakaaro. December. (7):42-51. and A. Reid, H. Worth, P. Saxton, T. Hughes, E. Robinson, R. Segedin (1998) Male Call: Waea Mai Tāne Mā. Report Three: Māori Men Who Have Sex with Men/Tāne Māori Moea Tāne. Auckland: New Zealand AIDS Foundation. (2000) Trans-Tasman Migration and Mãori in the Time of AIDS. A thesis submitted in fulfilment of the requirements of the degree of Doctor of Philosophy. Wellington: Wellington School of Medicine, University of Otago. (2005) "The Place of Takatāpui Identity with Māori Society: Reinterpreting Māori Sexuality within a Contemporary Context." Paper presented at Competing Diversities: Traditional Sexualities and Modern Western Sexual Identity Constructions Conference, 1-5 June 2005, Mexico City.

and Hutchings, J. (2006) "Māori Sexuality" in Mulholland, M. (ed) (2006) State of the Māori Nation: Twenty-First Century Issues in Aotearoa. Auckland: Reed Publishing. 227-235.

and Hutchings, J. (2007) "Reclaiming the Past to Inform The Future: Contemporary Views of Māori Sexuality” in Culture, Health \& Sexuality - An International Journal for Research, Intervention and Care. Vol 9 (4):415-427.

(2011) "Exploring Takatāpui Identity within The Māori Community: Implications for Health and Well-Being" in Driskill, Q-L. and C. Finley, B.J. Gilley, and S.L. Morgensen, (eds) Queer Indigenous Studies - Critical Interventions in Theory, Politics and Literature. Tucson: The University of Arizona Press. 113-122. 
Ballantyne, A.J. (1999) "The Reform of the Heathen Body - CMS Missionaries, Māori and Sexuality" in Reilly, M. and J. Thomson (eds) When the Waves Rolled In Upon Us Essays in Nineteenth Century Māori History. Dunedin: University of Otago Press.

Beaglehole, J.C. (ed) (1962) The Endeavour Journal of Joseph Banks. Sydney: Angus \& Robertson.

(ed) (1968) The Journals of Captain James Cook on His Voyages of Discovery: Vol I. The Voyage of the Endeavour 1768-1771. Cambridge: University Press, for the Hakluyt Society.

Belich, J. (1996) Making Peoples - A History of the New Zealanders from Polynesian Settlement to the End of the Nineteenth Century. Auckland: Penguin Group.

Benton, R.A. (1991) 'The Māori Language: Dying or Reviving' in Alumni-in-Residence Working Papers Series. Hawaii: Honolulu East-West Center.

Beyer, G. (1999) Change for the Better: The Story of Georgina Beyer as told to Cathy Casey. Auckland: Random Press.

Best, E. (1903) "Māori Marriage Customs, Tūhoe Tribe" in Transactions of the New Zealand Institute. 36:14-67 (1924) The Māori. Vol II. Wellington: Tombs.

Biggs, B. (1960) Māori Marriage. Wellington: Polynesian Society Inc. 12-14. (1966) "Māori Myths and Traditions" in McLintock, A.H. (ed) Encyclopaedia ofNew Zealand (Volume II). Wellington: Government Print. 447-454.

Binney, J.M.C (1968) The Legacy of Guilt: A Life of Thomas Kendall. Christchurch: Oxford University Press. 93,99,100,169. (1975) "Whatever Happened To Poor Mr Yate? An Exercise in Voyeurism" in New Zealand Journal of History. Vol 9:113. (1987) "Māori Oral Narratives, Pākehā Written Texts: Two Forms of Telling History" in New Zealand Journal of History. Vol 21 (1):16-28.

Bishop, R. and M. Berryman, S. Tiakiwai, C. Richardon (2003) Te Kōtahitanga: The Experiences of Year 9 and 10 Māori Students in Mainstream Classrooms - A Report to the Ministry of Education. Wellington: Ministry of Education.

Black, R. (2007) "Mana Takatāpui” in Hutchings, J. and C. Aspin (eds) (2007) Sexuality and the Stories of Indigenous People. Wellington: Huia Publishers. 25-34.

Blank, A. (2007) "Name-Calling" in in Hutchings, J. and C. Aspin (eds) (2007) Sexuality and the Stories of Indigenous People. Wellington: Huia Publishers. 104-109.

Bowman, R. (1983) “Beyond the Pink Triangle: The New Zealand Public's Attitude Towards 
Homosexuality" in Hill, M. (ed) (1983) Shades of Deviance: A New Zealand Collection. Palmerston North: Dunmore Press.

Brickell, C. (2008) Mates \& Lovers: A History of Gay New Zealand. Auckland: Random House.

Brougham, A.E. and A.W. Reed (1975) Māori Proverbs. Reprint. Wellington: Reed.

Broughton, J. (1996) "He Taru Tawhiti: Māori People and HIV/AIDS" in Davis, P. (ed) Intimate Details and Vital Statistics: AIDS, Sexuality and the Social Order in New Zealand. Auckland: Auckland University Press.

Brown, A (1994) "Ngahuia Te Awekotuku" in Mana Wāhine: Women Who Show the Way. Auckland: Reed Publishing.

Cameron, I. (1987) Lost Paradise - The Exploration of the Pacific. London: Century Hutchinson Ltd.

Carmen (1988) Carmen: My Life as told to Paul Martin. Auckland: Benton Ross Publishers.

Chatterjee, P. (2001) A Time for Tea: Women, Labor, and Post/Colonial Politics on an Indian Plantation. Durham: Duke University Press.

Clark, T. C. and M.F.G Lucassen, P. Bullen, S. J. Denny, T. M. Fleming, E.M. Robinson, F. V. Rossen (2014) “The Health and Well-Being of Transgender High School Students: Results from the New Zealand Adolescent Health Survey (Youth '12)” in Journal of Adolescent Health. Vol 55: 93-99.

Combahee River Collective (1986) The Combahee River Collective Statement: Black Feminist Organizing in the Seventies and Eighties. New York: Kitchen Table: Women of Colour Press

Coney, S. (1998) Stroppy Sheilas and Gutsy Girls: New Zealand Women of Dash and Daring. Auckland: Tandem Press.

(ed) (1993) Standing in the Sunshine: A History of New Zealand Women Since They

Won The Vote. Auckland: Viking Press.

Court Proceedings (1920) Hocken Library MS 66/149.

Crenshaw, K. (1989) "Demarginalizing the Intersection of Race and Sex: A Black Feminist Critique of Antidiscrimination Doctrine, Feminist Theory and Antiracist Politics" in University of Chicago Legal Forum. Chicago: University of Chicago.

Curnow, J. (2010) “Te Rangikāheke, Wiremu Maihi - Biography” in Dictionary of New Zealand Biography. Te Ara - the Encyclopedia of New Zealand http://www.TeAra.govt.nz/en/biographies/1t66/1. 
Dann, C. (1985) Up From Under: Women and Liberation in New Zealand 1970-1985. Wellington: Allen \& Unwin NZ Ltd in association with Port Nicholson Press.

Darwin, C. and R. FitzRoy, P. King (1839) Journal of Researches into the Natural History and Geology of the Countries Visited During the Voyage of H.M.S. Beagle. Vol I-III. London: Henry Colburn Publishers.

De Monteflores, C. and S.J. Schultz (1978) "Coming Out: Similarities and Differences for Lesbians and Gay Men” in Journal of Social Issues. The Society for the Psychological Study of Social Issues. Summer. Vol 34 (3):59-72.

Diamond, P. (2007) "Representation of Takatāpui - Then and Now" in Hutchings, J. and C. Aspin (eds) (2007) Sexuality and the Stories of Indigenous People. Wellington: Huia Publishers. 122-132.

Dickson, S. (2016) Hohou Te Rongo Kahukura: Outing Violence - Building Rainbow Communities Free of Partner and Sexual Violence. Wellington: Hohou Te Rongo Kahukura: Outing Violence

Driskill, Q-L. (2010) "Doubleweaving Two-Spirit Critiques: Building Alliances between Native and Queer Studies" in GLQ: A Journal of Lesbian and Gay Studies. Vol 16 (12):69-92. and C. Finlay, B.J. Gilley, S.L. Morgensen (eds) (2011) Queer Indigenous Studies Critical Interventions in Theory, Politics and Literature. Tucson: The University of Arizona Press.

Du Plessis, R. (ed) (1992) Feminist Voices: Women's Studies Texts in Aotearoa/New Zealand. Oxford: Oxford University Press. (2004) “Queer, Queerer, Queerist? Feminisms, Heterosexualities and Queer Theory” in Alice, L. and Star, L. (2004) Queer in Aotearoa New Zealand. Palmerston North: Dunmore Press Ltd.

Dunsford, C. and S. Hawthorne (eds) (1990) The Exploding Frangipani: Lesbian Writing from Australia and New Zealand. Auckland: New Women's Press.

Durie, M.H. (1985) “A Māori Perspective of Health” in Social Science \& Medicine. Vol 20 (5):483-486.

(1994) Whaiora: Māori Health Development. London: Oxford University Press.

Eldred-Grigg, S. (1984) Pleasures of the Flesh: Sex \& Drugs in Colonial New Zealand 18401915. Wellington: Reed Publishing.

Elleray, M. (1999) "Weaving the Wāhine Takatāpui: Mirimiri and Tahuri” in Alice, L. and L. Starr (eds) (2004) Queer in New Zealand. Palmerston North: Dunmore Press. 175-186. 
First published in SPAN: Journal of South Pacific Association for Commonwealth Literature and Language Studies. (1999): 48-49.

Erai, M. and W. Pitama, E. Allen (2007) Literature Review \& Annotated Bibliography. Auckland: Amokura Family Violence Prevention Consortium. (2011) “A Queer Caste - Mixing Race and Sexuality in Colonial New Zealand” in Driskill, Q-L. and C. Finlay, B.J Gilley, S.L. Morgensen (eds) (2011) Queer Indigenous Studies - Critical Interventions in Theory, Politics and Literature. Tucson: The University of Arizona Press.

Fabish, R. (2014) Black Rainbow: Stories of Māori and Pākehā Working Across Difference. A thesis submitted to Victoria University of Wellington in fulfilment of the requirements for the degree of Doctor of Philosophy in Social Anthropology. Victoria University of Wellington.

Faderman, L. (1985) Surpassing the Love of Men - Romantic Friendship and Love between Women from the Renaissance to the Present. London: The Women's Press.

Fenaughty, J. and V. Braun, N. Gavey, C. Aspin, P. Reynolds, J. Schmidt (2006) Sexual Coercion among Gay Men, Bisexual Men and Takatāpui Tāne in Aotearoa/New Zealand. Auckland: The Department of Psychology, University of Auckland.

Finley, C. (2011) "Decolonizing the Queer Native Body (and Recovering the Native BullDyke) - Bringing “Sexy Back” and Out of Native Studies' Closet” in Driskill, Q-L. and C. Finlay, B.J Gilley, S.L. Morgensen (eds) (2011) Queer Indigenous Studies - Critical Interventions in Theory, Politics and Literature. Tucson: The University of Arizona Press.

Fishman, J.A. (1985) "Bilingualism and Biculturalism as Individual and Societal Phenomena" in Fishman, J.A. and M. Gertner, E.G. Lowy, W.G. Milan (1985) The Rise and Fall of the Ethnic Revival: Perspectives on Language and Ethnicity. Berlin: Walter de Gruyter \& Co.

French, R. (1988) "Tìtoitoi with the Natives" in Outrage. (57):13-15.

Foucalt, M. (1978) The History of Sexuality Volume 1. Translated from the French by Robert Hurley. London: Penguin Books.

Glover, M.P. (1993) "Power and Control in Lesbian Relationships" in Broadsheet. Autumn/Ngāhuru. Vol 197:36-37. (2007) "Eroticising Equality, Coming to Power" in Hutchings, J. and C. Aspin (eds) (2007) Sexuality and the Stories of Indigenous People. Wellington: Huia Publishers. 58-69. 
and A. McKree, L. Dyall (2009) “Assisted Human Reproduction: Issues for Takatāpui (New Zealand Indigenous Non-Heterosexuals)" in Journal of GLBT Family Studies Vol. 5 (4):295-311.

(2013) “Analyzing Smoking Using Te Whare Tapa Whā” in Banwell, C. and

S. Ulijaszek, J. Dixon (eds) When Culture Impacts Health: Global Lessons for Effective Health Research. Cambridge: Academic Press. 115-128.

Gluckman, L.K. (1973) "Transcultural Consideration of Homosexuality with Special Reference to the New Zealand Māori” in Australia New Zealand Journal of Psychiatry. June 1974. Vol. 8 (2):121-125.

Grace, P. and I. Ramsden, J. Dennis (2001) The Silent Migration: Ngāti Pōneke Young Māori Club 1937-1948. Wellington: Huia Publishers.

Grey, G. (1853) Ko Ngā Moteatea me Ngā Hakairara o Ngā Māori. Wellington: Robert Stokes. (1857) Proverbial and Popular Sayings. London: Trubner.

(1914) Ngā Mahi a Ngā Tūpuna Wellington: A.H \& A.W. Reed (NZ) Ltd. 106-113. (1971) Ngā Mahi a Ngā Tūpuna. Fourth Edition. Wellington: Reed. First published 1854.

Gudgeon, W.E. (1895) Mãori Tribes on the East Coast of New Zealandart II in Journal of the Polynesian Society Vol 3 (1):17-32.

Haami, B. (2013) Ka Mau Te Wehi: Taking Haka to the World - Bub and Nen's Story as told to Bradford Haami. Auckland: Ngapō and Pimia Wehi Whānau Trust.

Hand, J. and V. Elizabeth, H. Rauwhero, S. Selby, M. Burton, L. Falanitule, B Martin (2002) Free from Abuse: What Women Say and What Can be Done. Auckland: Public Health Promotion.

Harris, J. and T.H. Herewini, G. Rua'ine (2005) Ko Ia - He or She. Auckland: New Zealand AIDS Foundation.

Hawkins, G. (1995) “A Discussion Paper on Transsexualism from a Māori Perspective” in Te Kawa a Maui (1998) Te Huinga Takatāpui Course Reader. Wellington: Victoria University of Wellington. 92-96.

Henrickson, M. (2006) "Kō Wai Rātou: Managing Multiple Identities in Lesbian, Gay and Bisexual New Zealand Māori” in New Zealand Sociology. Vol 21 (2):247-269. and S. Neville, C. Jordan, S. Donaghey (2007) "Lavender Islands: The New Zealand Study" in Journal of Homosexuality. Vol 53 (4):223-248.

Herewini, T. and R.H. Sheridan (1994) A Report on the Health Needs of Màori Gay Men. Wellington: Public Health Commission. 
Higgins, R. and P. Rewi, V. Olsen-Reeder (2014) The Value of the Māori Language: Te Hua o Te Reo Māori. Wellington: Huia Publishers.

Houkamau, C.A. and C.G. Sibley (2010) “The Multi-Dimensional Model of Māori Identity and Cultural Engagement" in New Zealand Journal of Psychology. Vol 39 (1):8-25.

Human Rights Commission (2007) To Be Who I Am - Ka Noho Au ki Toku Anō Ao: Report of the Inquiry into discrimination Experienced by Transgender People He Pūrongo mō Te Uiuitanga mō Aukatitanga o Pāngia ana e Ngā Tangata Whakawhitiira. Auckland: Human Rights Commission.

Hutchings, J. and Aspin, C. (eds) (2007) Sexuality and the Stories of Indigenous People. Wellington: Huia Publishers. and H. Potter, K. Taupo (eds) (2011) Kei Tua o Te Pae Hui Proceedings - The Challenges of Kaupapa Māori Research in the 21st Century. Wellington: NZCER Press.

(2012) "The Hetero-Patriarchy and the Corruption of Tikanga" in Mikaere, A. and J. Hutchings (2013) Kei Tua o Te Pae Hui Proceedings Te Wānanga o Raukawa, Ōtaki, 4-5 September 2012. Wellington: NZCER Press and Otaki: Te Wānanga o Raukawa. 31-35.

Hyde, H.M. (1970) The Other Love - An Historical and Contemporary Survey of Homosexuality in Britain. Suffolk: William Heinemann Ltd.

Irwin, K. (1994) "Maori Research Methods and Practices" in Sites 28. Autumn. 22-29.

Jenkins, K. and K. Morris Matthews (1995) Hukarere and the Politics of Māori Girls' Schooling. Palmerston North: Dunmore Press. and Morris Matthews, K. (1998) "Knowing their Place: The Political Socialisation of Māori Women in New Zealand through Schooling Policy and Practice, 1867-1969” in Women's History Review. Vol. 7 (1).

Johnston, P. and L. Pihama (1995). "What Counts as Difference and What Differences Count: Gender, Race and the Politics of Difference" in Irwin K. and I. Ramsden (eds) Toi Wāhine: The Worlds of Māori Women. Auckland: Penguin Books.

Ka'ai, T.M. (2008) Ngoingoi Pewhairangi: A Remarkable Life. Wellington: Huia Publishers. 9-13.

Karetu, T. (1990) “The Clue to Identity” in New Zealand Geographic. January-March (5): 112117. (1993) Haka! The Dance of a Noble People. Wellington: Reed. 
(1995) Te Tau o te Reo Māori: The Influence of the Mãori Language. Paper presented at the Hui Whai Maramatanga Whai Oranga. Hui on Reproductive Health and HIV/AIDS, Auckland.

Katene, S. (2015) Fire That Kindles Hearts: Ten Māori Scholars. Wellington: Steele Roberts Kerekere, E. (1991) "Preparing the Art World for Māori Dykes" in McPherson, H. and J. King, M. Evans, P. Gerrish Nunn (eds) (1992) Spiral 7: A Collection of Lesbian Art and Writing from Aotearoa/New Zealand. Wellington: Spiral 7 in association with Daphne Brasell Associates Press. Based on a presentation given on 27 January 1991, Dowse Art Museum, Hutt City, New Zealand.

(2007) "Takatāpui: When Worlds Collide" in Hutchings, J. and C. Aspin (eds) (2007) Sexuality and the Stories of Indigenous People. Wellington: Huia Publishers. (2009) KAHA 09: National Hui for Takatāpui, Queer \& Trans Youth. Report 2009. Wellington: OUT THERE! Queer Youth Project. (2009) "Honoa Te Pito Ora ki Te Pito Mate: Takatāpui Past and Present” in Te Kāhui Kura Māori. Vol 0 (2).

(2015) Takatāpui: Part of the Whānau. Auckland: Tīwhanawhana Trust and Mental Health Foundation.

(2016) "LGBT Activism Among Māori” in The Wiley Blackwell Encyclopedia of Gender and Sexuality Studies 1-5. Published online 21 April 2016. http://onlinelibrary.wiley.com/doi/10.1002/9781118663219.wbegss666/full. (2017) Growing Up Takatāpui: Whānau Journeys. Auckland: Tīwhanawhana Trust and RainbowYOUTH.

Kinsey, A.C. and W.B. Pomeroy, C.E. Martin (1948) Sexual Behavior in the Human Male. Philadelphia: W. B. Saunders.

Kinsey, A.C. and W.B. Pomeroy, C.E. Martin and P.H. Gebhard (1953) Sexual Behavior in the Human Female. Philadelphia: W. B. Saunders and Bloomington: Indiana University Press.

Kirkman, A. and P. Maloney (eds) (2005) Sexuality Down Under: Social and Historical Perspectives. Dunedin: Otago University Press.

Kōhere, T.M. (1951) He Kōnae Aronui. Wellington: Reed.

LAGANZ (2009) Lesbian \& Gay Archives of New Zealand Constitution. Wellington: LAGANZ Board. 
Lapsley, H. And L.W. Nikora, R. Black (2002) “Kia Mauri Tau!” Narratives of Recovery from Disabling Mental Health Problems - Report of the University of Waikato Mental Health Narratives Project. Wellington: Mental Health Commission.

Laurie, A.J. (ed) (1992) Oral History Interview with Bub Hetet. Wellington: Oral History Centre, Alexander Turnbull Library. (2001a) "Frances Mary Hodgkins: Journeys into the Hearts of Women" in Laurie, A.J. (ed) Lesbian Studies in Aotearoa/New Zealand. New York: Harrington Park Press. 2747.

(ed) (2001b) Lesbian Studies in Aotearoa/New Zealand. New York: Harrington Park Press.

(2003) Lady-Husbands and Kamp Ladies: Pre-1970 Lesbian Life in Aotearoa/New

Zealand. A thesis submitted in fulfilment of the requirements of the degree of Masters of Education. Victoria University of Wellington.

(2005) “'Filthiness' Became a Theory: An Overview of Homosexual and Lesbian Organising from Nineteenth Century Europe to Seventies New Zealand” in Laurie, A.J. and Evans, L. (eds) (2005) Outlines: Lesbian and Gay Histories of Aotearoa. Wellington: Lesbian and Gay Archives of New Zealand. 10-18.

Le Brun, C. and E. Robinson, H. Warren, P.D. Watson (2004) Non-Heterosexual Youth - A Profile of Their Health and Well-being: Data from Youth 2000. Auckland: University of Auckland.

Lucassen, M.F.G. and T.C. Clark, E. Moselen, E.M. Robinson, The Adolescent Health Research Group (2014) Youth '12 The Health and Wellbeing of Secondary School Students in New Zealand: Results for Young People Atraatced to the Same Sex or Both Sexes. Auckland: University of Auckland.

McBreen, K. (2012) “It's About Whānau - Oppression, Sexuality and Mana” in Mikaere, A. and J. Hutchings (2013) Kei Tua o Te Pae Hui Proceedings Te Wānanga o Raukawa, Ōtaki, 4-5 September 2012. Wellington and Otaki: New Zealand Council for Educational Research and Te Wānanga o Raukawa. 55-64.

(2013) Ahunga Tikanga and Sexual Diversity https://www.researchgate.net/publication/235664484_AHUNGA_TIKANGA_AND_ SEXUAL_DIVERSITY. Otaki: Te Wānanga o Raukawa.

McCormick, E.H. (1940) Letters and Art in New Zealand. Wellington: Department of Internal Affairs. 
McIntosh, T. (2005) "Māori Identities: Fixed, Fluid, Forced" in New Zealand Identities: Departures and Destinations. 38-51.

McNab, R. (ed) (1908a) Historical Records of New Zealand Vol I. Wellington: Government Print. (ed) (1908b) Historical Records of New Zealand Vol II. Wellington: Government Print. (1914) From Tasman To Marsden: A History of Northern New Zealand from 1642 to 1818. Dunedin: J. Wilkie \& Company.

McPherson, H. and J. King, M. Evans, P.G. Nunn (eds) (1992) Spiral 7: A Collection of Lesbian Art and Writing from Aotearoa/New Zealand. Wellington: Spiral 7 in association with Daphne Brasell Associates Press.

McRae, J. (2000) "Māori Oral Tradition Meets The Book" in Griffith, P. and P. Hughes and A. Loney (eds) (2000) A Book in the Hand: Essays on the History of the Book in New Zealand. Auckland: Auckland University Press. 1-16.

Mahuika, A.T. (1972) Ngā Wāhine Kai-Hautu o Ngati Porou: The Female Leaders of Ngati Porou. A thesis submitted in partial fulfilment of the requirements for a Masters Degree. http://hdl.handle.net/2123/1877

Mead, H. M. (1996a) Tāwhaki Nui-a-Hema - Āna Mahi Whakahirahira. Auckland: Reed Publishing. (1996b) Tāwhaki - The Deeds of a Demigod. Auckland: Reed Publishing. and N. Grove (eds) (2001) Ngā Pēpeha a Ngā Tīpuna. Wellington: Victoria University Press (2003) Tikanga Māori: Living Māori Values. Wellington: Huia Publishers.

Mikaere, A. (1994) "Māori Women: Caught in the Contradictions of a Colonised Reality" in Waikato Law Review. Vol 2.

Milne, M. (2005) Maori Perspectives on Kaupapa Māori and Psychology: A Discussion Document. Wellington: Commissioned by the New Zealand Psychologists Board.

Ministry of Health (2002) He Korowai Oranga: Māori Health Strategy. Wellington: Ministry of Health.

Ministry of Social Development (2007) The Scale and Nature of Family Violence in New Zealand: A Review and Evaluation of Knowledge. Crime and Justice Research Centre, Victoria University of Wellington. Wellington: Ministry of Social Development.

Moore, C. (2001) Sunshine and Rainbows: The Development of Gay and Lesbian Culture in Queensland. Brisbane: University of Queensland Press. 
Motschenbacher, H. (2012) An Interdisciplinary Bibliography on Language, Gender and Sexuality (2000-2011). Amsterdam: John Benjamins Publishing Company.

Murray, D.A.B. (2003) "Who Is Takatāpui? Māori Language, Sexuality and Identity in Aotearoa/New Zealand" in Anthropologica. Vol 45. (2):233-44.

(2004) “Takatāpui, Gay or Just HO-MO-SEXUAL Darling? Māori Language, Sexual Terminology and Identity in Aotearoa/New Zealand" in Leap, W. and T. Boellstorff (eds) (2004) Speaking in Queer Tongues: Globalization and Gay Language. Urbana and Chicago: University of Illinois Press. 163-180.

Nadal, K.L. and K.C. Davidoff, W. Fujii-Doe (2014) "Transgender Women and the Sex Work Industry: Roots in Systemic, Institutional, and Interpersonal Discrimination” in Journal of Trauma \& Dissociation. Vol 15 (2):169-183.

New Zealand Film Archive (2010) Close Ups on New Zealand Film History: Hinemoa. http://www.filmarchive.org.nz/tracking-shots/close-ups/hinemoa.html.

NZPC (2013) What Impact has the Decriminalisation of Sex Work in New Zealand had on Māori? Wellington: New Zealand Prostitutes Collective.

Ngata, A.T. (1928) Ngā Mōteatea: He Maramara Rere no Ngā Waka Maha (Part 1) Wellington: Polynesian Society/A.H. Reed \& A.W. Reed (NZ) Ltd. (ed) and P.T.H. Jones (translation) (2004) Ngā Mōteatea: The Songs Part One. Revised Edition. Auckland: Auckland University Press.

Ngata, A.T. and P. Buck, M.P.K. Sorrenson (ed) (1986) Nā To Hoa Aroha From Your Dear Friend: The Correspondence between Sir Apirana Ngata and Sir Peter Buck 1925 50. Auckland: Auckland University Press.

Nikora, L.W. (2007) Māori Social Identities in New Zealand and Hawai’i. A thesis submitted in partial fulfilment of the requirements for the Degree of Doctor of Philosophy. Hamilton: University of Waikato. http://hdl.handle.net/10289/2574 and N. Te Awekotuku (2013) Moehewa: Death, Lifestyle and Sexuality in the Māori World. Paper presented to the $10^{\text {th }}$ Global Conference: Making Sense of Dying and Death. 7-9 November 2013.

Nuttall, J. (ed) (2013) Weaving Te Whāriki - Aotearoa New Zealand's Early Childhood Curriculum Document in Theory and Practice. 2nd Edition. Wellington: NZCER Press.

Olliver, I. and C. Hingley, J. Spencer (1987) Extracts from journals relating to the Visit to New Zealand in May-July 1772 of the French Ships Mascarin and Marquis de Castries under the command of M. J. Marion du Fresne. Wellington: Alexander Turnbull Library Endowment Fund with Indosuez NZ Ltd. 
Out There Queer Youth Project (2005) Safety in our Schools Ko Te Haumaru i o Tatou Kura - An Action Kit for Aotearoa New Zealand Schools to address Sexual Orientation Prejudice. Wellington: Out There Queer Youth Project.

Papakura, Mākereti (1938) The Old-Time Māori. London: Victor Gollancz.

Parkinson, P. (1989) Sexual Law Reform: The New Zealand Experience from Wolfenden to the Crimes Bill 1989. An Essay to Accompany an Exhibition at the ATL July-August 1989. Wellington: LAGANZ. (2005) “'A Most Depraved Young Man’: Henry Miles Pilley, the New Zealand Missionary" in Laurie, A.J. and L. Evans (eds) (2005) Outlines: Lesbian and Gay Histories of Aotearoa. Wellington: Lesbian and Gay Archives of New Zealand. 19-23. Parkinson, S. (1972) A Journal of a Voyage to the South Seas in His Majesty's Ship, The Endeavour. Facsimile Edition. Adelaide: Libraries Board of South Australia.

Pega, F and MacEwan, I. (2010) Takatāpui, Lesbian, Gay and Bisexual Scoping Exercise: Report to the Alcohol Advisory Council of New Zealand. Wellington: ALAC.

Pere, R. (1988) “Te Wheke: Whaia Te Maramatanga me Te Aroha” in Middleton, S. (ed) (1988) Women and Education in Aotearoa. Sydney: Allen \& Unwin. 6-19.

Peshkin, A. (1988) "In Search of Subjectivity - One's Own” in Educational Researcher. Vol 17 (7):17-21.

Pewhairangi, N. (1985) Tūini: Her Life and Her Songs. Tokomaru Bay: Te Hokowhitu a Tū.

Pihama, L. (1993) Tungia Te Ururoa, Kia Tupu Whakaritorito Te Tupu o Te Harakeke: A Critical Analysis of Parents as First Teachers. A thesis submitted in fulfilment of the requirements of the degree of Masters of Education. Auckland: University of Auckland. (1998). Reconstructing meanings of family: Lesbian/gay whánau and families in Aotearoa. The Family in Aotearoa New Zealand, 179-207. (2001) Tihei Mauiora Ora: Honouring our Voices, Mana Wāhine as a Kaupapa Māori Theoretical Framework. A thesis submitted in fulfilment of the requirements of the degree of Doctor of Philosophy. University of Auckland.

(2010) "Kaupapa Māori Theory: Transforming Theory in Aotearoa” in He Pūkenga Kōrero A Journal of Māori Studies. Raumati (Summer). Vol 9 (2):5-14. and P. Reynolds, C. Smith, J. Reid, L.T. Smith, Linda, R. Te Nana (2014) “Positioning Historical Trauma Theory within Aotearoa New Zealand" AlterNative: An International Journal of Indigenous Peoples. Vol. 10 (3). 
Pitama, S. and P. Robertson, F. Cram, F. Gillies, T. Huriana, W. Dallas-Katoa (2007) "Meihana Model: A Clinical Assessment Framework" in New Zealand Journal of Psychology. Vol 36 (3):118-135.

Plumridge, L. and G. Abel (2001) “A 'Segmented' Sex Industry in New Zealand: Sexual and Personal Safety of Female Sex Workers" in Australian and New Zealand Journal of Public Health. Vol 25 (1):78-83.

Pohatu, T.W. (2005) “Āta: Growing Respectful Relationships” in Journal of Social Work Values and Ethics. Spring. Vol 2 (1).

Rangihau, J. (1975) "Being Māori” in King, M (ed) (1975) Te Ao Hurihuri: The World Moves On. Wellington: Hicks Smith \& Sons. 221-223.

Rankine, J. (2001) “The Great, Late Lesbian and Bisexual Women's Discrimination Survey" in Journal of Lesbian Studies. Vol 5 (1-2):133-142.

Reynolds, P. (2012) “Trauma and Māori LGBTQ (Takatāpui) in New Zealand” in Traumatic Stress Points. International Society for Traumatic Stress Studies. Vol 26 (4):9-10.

Rossen, F.V. and M.F.G. Lucassen, S. Denny, E. Robinson (2009) YOUTH'07: The Health \& Well-Being of Same/Both-Sex Attracted Youth in New Zealand. Wellington: OUT THERE! Queer Youth Development Project.

Royal Commission on Social Policy (1988) "Women and Social Policy Part 1 - Māori Women" in The April Report. Vol 2 (2.2.38) Wellington: The Royal Commission.

Royal, T.A.C. (1998) “Te Ao Marama - A Research Paradigm” in He Pukenga Körero. Koanga (Spring), Volume 4 (1).1-8.

Said, E.W (1978) Orientalism. London: Routledge and Kegan Paul.

Salmond, A. (1985) "Māori Epitemologies" in Overing, J. (ed) (1985) Reason and Morality. London: Routledge. 240-263. (1991) Two Worlds - First Meetings between Māori and Europeans 1642-1772. Auckland: Penguin Books.

Saphira, M. and M. Glover (2001) "The Effects of Coming Out on Relationships and Health" in Laurie, A.J. (ed) Lesbian Studies in Aotearoa/New Zealand. New York: Harrington Park Press, The Haworth Pres Inc.

Selby, R. and A.J. Laurie (eds) (2005) Mãori Oral History. Wellington: NOHANZ.

Smith, A. (2011) "Queer Theory and Native Studies: The Heteronormativity of Settler Colonialism" in Driskill, Q-L. and C. Finlay, B.J. Gilley, S.L. Morgensen (eds) (2011) Queer Indigenous Studies - Critical Interventions in Theory, Politics and Literature. Tucson: The University of Arizona Press. 
Smith, G.H. (1990) “Research Issues Related to Māori Education.” Paper presented to NZARE Special Interest Conference, Massey University. Reprinted (1992) The Issue of Research and Māori. Research Unit for Māori Education, The University of Auckland (1997) The Development of Kaupapa Māori Theory and Praxis. A thesis submitted in fulfilment of the requirements of the degree of Doctor of Philosophy. Auckland: School of Education, University of Auckland.

Smith, L.T. (1992) "Māori Women: Discourse, Projects and Mana Wāhine" in Middleton, S and Jones, A (eds) (1992) Women and Education in Aotearoa 2. Wellington: Bridget Williams Books. (1999) Decolonizing Methodologies: Research and Indigenous Peoples. London: Zed Books Ltd and and Dunedin: Otago University Press. (2011) “Opening Keynote: Story-ing The Development of Kaupapa Māori - A Review of Sorts" in Hutchings, J. and H. Potter, K. Taupo (eds) (2011) Kei Tua o Te Pae Conference Proceedings - The Challenges of Kaupapa Māori Research in the $21^{\text {st }}$ Century. Wellington: New Zealand Council of Educational Research. 10-15.

Spolsky, B. (2005) "Māori Lost and Regained” in Bell, A. and R. Harlow and D. Starks (eds) (2005) Languages of New Zealand. Wellington: Victoria University Press.

Statistics New Zealand (2013) 2013 Quick Stats About Māori: 2013 Census. Wellington: Statistics New Zealand. (2015) Ngā Tohu o Te Ora: The Determinants of Life Satisfaction for Māori 2013. Wellington: Statistics New Zealand.

Szaszy, M. and A. Rogers, M. Simpson (eds) (1993) Te Timatanga Tatau Tatau; Early Stories from Founding Members of the Māori Women's Welfare League - Te Rōpū Wāhine Maori Toko I Te Ora. Wellington: Bridget Williams Books

Takurua, A.K. (2000) "Ngāwai, Tūini Moetu Haangu 1910 - 1965" in Dictionary of New Zealand Biography (2000) Volume Five (1941-1960). Wellington: Ministry for Culture and Heritage.

Te Awekotuku, N. (1989) Tahuri. Auckland: New Women's Press. (1991) Mana Wāhine Māori: Selected Writings in Māori Women's Art, Culture and Politics. Auckland: New Women's Press. (1992) "So Easy to Please/Auntie Marleen" in McPherson, H. and J. King, M. Evans, P. Gerrish Nunn (eds) (1992) Spiral 7: A Collection of Lesbian Art and Writing from Aotearoa/New Zealand. Wellington: Spiral 7 in association with Daphne Brasell Associates Press. 
and S. Tamihana, J. Glamuzina and A. Laurie. (1993) "Better Out Than In" in Else, A. (ed) (1993) Women Together: A History of Women's Organisations in New Zealand Nga Ropu Wahine o Te Motu. Wellington: Historical Branch, Department of Internal Affairs and Daphne Brassell Associates. 545-569. (1996) "Māori: People and Culture" in Starzecka, D. C. (ed) (1996) Māori Art and Culture. Auckland: David Bateman Ltd in association with London: British Museum Press.

(2001) "Hinemoa: Retelling a Famous Romance" in Laurie, A. (ed) (2001) Lesbian Studies in Aotearoa/New Zealand. New York: Harrington Park Press. 1-11. (2003) Ruahine: Mythic Women. Wellington: Huia Publishers. (2005) "He Reka Anō: Same Sex Lust and Loving in the Ancient Māori World" in Laurie, A.J. and Evans, L. (eds) (2005) Outlines: Lesbian and Gay Histories of Aotearoa. Wellington: Lesbian and Gay Archives of New Zealand. 6-9.

Te Rangikāheke, W.M. Hine-Moa. GNZ MMS 51 in Special Collections, Auckland Public Library.

Te Ua, H. (2005) "Reflections on Being Gay and Māori” in Laurie, A.J. and Evans, L. (eds)

Outlines: Lesbian and Gay Histories of Aotearoa. Wellington: Lesbian and Gay Archives of New Zealand. 1-5.

Tīwhanawhana Trust (2007) Tīwhanawhana Trust Deed. Wellington: Tīwhanawhana Trust.

Turi-Tiakitai, J. R (2015) Tū Te Turuturu Nō Hineteiwaiwa - Maintaining Cultural Integrity in the Teaching of Māori Weaving. Thesis submitted in fulfilment of a Master of Arts. Hamilton: University of Waikato.

Walker, R. (1989) “Māori Identity” in Novitz, D. and W.E. Willmott, B. Willmott (eds) (1989) Culture and Identity: In New Zealand. Wellington: Manaaki Whenua Press. 35-52. (1990) Ka Whawhai Tonū Mātou: Struggle Without End. Auckland: Penguin Books.

Weeks, J. (1977) Coming Out: Homosexual Politics in Britain from the $19^{\text {th }}$ Century to the Present. London: Quartet.

White, J. (1889) The Ancient History of the Māori. London: Sampson Low.

Williams, W.H. (1971) A Dictionary of the Māori Language. Seventh Edition. First Edition 1844. Second Edition 1852. Third Edition 1871. Fourth Edition 1892. Fifth Edition 1917. Sixth Edition 1957. Wellington: Government Print. (1908) He Whakataukī, He Titotito, He Pēpeha. Gisborne: Te Rau Kahikatea. Winters, K. (2006) “Gender Dissonance: Diagnostic Reform of Gender Identity Disorder for 
Adults" in Journal of Psychology \& Human Sexuality. Vol 17 (3-4):71-89.

Worth, H., Paris, A, and L. Allen (eds) (2002) The Life of Brian: Masculinities, Sexualities and Health in New Zealand. Dunedin: University of Otago Press.

Wybrow, V. (1999) "Edward Shortland - First Anthropologist of the Māori” in Reilly, M. and J. Thomson (eds) When the Waves Rolled In Upon Us - Essays in Nineteenth Century Mãori History. Dunedin: University of Otago Press. 


\section{APPENDICES}

\section{Appendix I: Participant Information Sheet}

\section{Researcher: Elizabeth Kerekere, Te Kawa a Māui \\ Te Aitanga a Māhaki, Whānau a Kai, Ngāti Oneone}

Tēnā koe! Thank you for considering being part of this unique research project. It is aimed at recording the development of takatāpui as an identity and its acceptance within Māori society. Takatāpui is a traditional term which means 'intimate friend of the same sex'. It has been increasingly adopted by Māori who identify as lesbian, gay, bisexual, trans, intersex, asexual, queer, genderqueer or questioning. Although diverse sexual and gender expression existed in traditional Māori society, colonisation had a huge impact on its visibility. As the expression was moved from sight, so the occurrence began to move from memory. So much so, that many Māori refuse to believe it ever happened. By reclaiming the word, takatāpui are reclaiming the right to be seen. Seen, accepted and supported.

Since the 1900s, Māori who lived differently from the gender expectations of colonial society have suffered from prejudice. Takatāpui youth today are most at risk as they join the global phenomena of young people 'coming out' when they are young. With less support and fewer resources than adults, they face unprecedented levels of homophobic and transphobic bullying $^{74}$ - in homes, schools and churches. My hope is that this research will contribute toward reducing both homophobia and transphobia in Māori and New Zealand society.

To ensure the voice of present day Māori is heard alongside the traditional stories of our tūpuna, a series of interviews and a rangatahi focus group will be conducted. All the interviews will be audio recorded, and if you agree, video recorded. While most of the information collected will be summarised, some quotations and images may be attributed to you by name. Interview notes and video/audio recordings will be kept safely during the research and then deposited at LAGANZ after project completion. You are able to have a copy of all video/audio recordings. Should you wish to withdraw from the project, you may do so without question by contacting the researcher within two weeks of this interview which is

This research will contribute to my $\mathrm{PhD}$ at Victoria University. Ethics approval has been granted which requires your written permission for this process prior to the interview taking place. In addition to my $\mathrm{PhD}$ thesis, I also intend to publicise the research through a book, conference presentations, academic articles, educational resources and film or documentary.

I have been actively involved with the takatāpui community for over 20 years. I am Chair of Tīwhanawhana Trust which I founded in 2000 to provide support, advocacy and a cultural base for takatāpui in Wellington and nationally. As part of that role I sit on the Board of LAGANZ (Lesbian \& Gay Archives of NZ) and actively support the queer/trans youth movement in Aotearoa.

\section{If you would like further information, please contact:}

Primary Supervisor: Dr Rawinia Higgins, Te Kawa a Māui rawinia.higgins@ vuw.ac.nz

Researcher: Elizabeth Kerekere, Te Kawa a Māui aionokerekere@xtra.co.nz 0274048277

\footnotetext{
${ }^{74}$ Irrational fear, prejudice and violence toward people perceived to be homosexual or whose gender expression differs from the gender assigned at birth
} 


\section{Appendix II: Consent to Participation in Research}

I have been provided with sufficient information about this project. I consent to information, opinions or audio recordings that I have given during this research being attributed to me by name in any reports, thesis, conferences presentations, books, or resources based on this research.

I understand that I will be given the opportunity to check, make corrections to, and/or withdraw any quotations or discussions attributed to me.

I understand that the original audio recordings made of me will be held at LAGANZ (National Archive for Rainbow Communities) and I can determine access to them.

I understand that I can withdraw from this project if I contact the researcher within two weeks of this interview which is

I consent to the use and reproduction of images of me created during this research for multimedia resources, publications or conference presentations. $\quad \square$ Yes $\quad \square$ No

I would like a copy of the raw video/audio recordings of my interview given to me at the conclusion of the interview/s. $\square$ Yes $\quad \square$ No

I would like to receive a copy of any publication or conference paper specifically based on this research. $\quad \square$ Yes - to email below $\quad \square$ Yes - to address below $\square$ No

Print Name:

Signed:

Date:

Email:

Phone(s):

Mailing address:

If you have any questions about the project or would like further information, please contact: Researcher: Elizabeth Kerekere, Te Kawa a Māui aionokerekere@xtra.co.nz 0274048277 


\section{Appendix III: Oral History Recording Agreement Form}

PROJECT NAME:

FULL NAME OF PERSON INTERVIEWED:

DATE OF INTERVIEW:

COMMISSIONING ORGANISATION/PERSON:

INTERVIEWER:

COPYRIGHT HOLDER:

1. PLACEMENT: I, the person interviewed, agree that the recording of my interview and accompanying material, prepared for archival purposes, will be held at

2. ACCESS: I agree that the recording of my interview and accompanying material may be made available for research, at the above location or at a location approved by the commissioning organisation/person, subject to any restrictions in Section 4.

3. PUBLICATION: I agree that the recording of my interview and accompanying material, may be quoted or shown in full or in part in published work, broadcast, or used in public performances, subject to any restrictions in Section 4.

\section{RESTRICTED RECORDINGS AND ACCOMPANYING MATERIAL:}

I require that there be no access to

I require that there be no publication of (cross where

appropriate)

this recording and accompanying material without my prior written permission

NOTES:

REVIEW/RELEASE DATE:

5. PRIVACY ACT: I understand that this Agreement Form does not affect my rights and responsibilities under the Privacy Act 1993.

\section{COMMENTS:}

PERSON INTERVIEWED:

Date:

INTERVIEWER:

Date:

FOR COMMISSIONING ORGANISATION:

Date:

NOTE: This Agreement Form may be amended only by the person interviewed, or by the commissioning organisation/person with the authority of the person interviewed. Any amendment must be registered with the commissioning organisation/person.

This Agreement Form is approved by the National Oral History Association of New Zealand 
Kevin Haunui (T1A-B)

Peri Te Wao (T2)

Morgan Komene Clark (T3A)

Ahi Wi Hongi (T4A)

Hinemoana Baker (T5A)

Jennifer Edwards (T6B)

\section{INDIVIDUAL}

\section{Biographical Details}

- Name (at birth and current)

- Gender (at birth and current)

- Address

- Contact details

- Date and place of birth

- Iwi, hapū, whānau and marae

- Other cultural identities

- Birth name, dob, dod and occupation of Mother, Father, other caregiver, siblings, children, whāngai

- Partner/spouse and date of marriage/civil union

\section{Background}

- Education

- Employment

- Community work

- Politics

- Religion/spirituality

- Health

- Places lived

\section{Growing Up}

- Beyond the Tūtanekai narrative, what do you remember about same-sex or gender change in the traditional Māori narratives you grew up with?

- What Māori terms do you recall were used to describe them? Non- Māori?

- Are you aware of any particular roles these people may have played?

- What do you remember hearing about lesbians or gays growing up?

- What about boys who lived as girls or girls who lived as boys? 
- How did that make you feel about such people?

- When you were young, did you have anyone in your whānau who did not fit gender/sexual stereotypes? Any who identified as lesbian, gay, transgender?

- How did the whānau treat them or talk about them?

- How did you feel about them?

- What does the term takatāpui mean to you?

- When did you first hear of it?

- How is it the same or different from lesbian and gay?

- What do you think Māori (rural, urban, kaumātua, youth) generally think about lesbians and gays? About takatāpui?

- How many takatāpui do you know in your whānau, hapū, iwi?

- What roles do they play within the whānau, hapū, iwi?

\section{Your Identity (prompts if not already covered)}

- When did you first become aware of your own sexuality or gender?

- Who did you tell and how did they react then?

- How do people react now?

- What, if anything, has changed over time?

\section{And in Conclusion...}

- Thank you for taking the time to answer my questions today, is there anything else you would like to add? 


\section{Appendix V: Takatāpui Interview Guidelines - Suicide Prevention (2015)}

Kevin Haunui (T1C)

Morgan Komene Clark, Auckland (T3B)

Ahi Wi Hongi (T4B)

Hinemoana Baker (T5B)

Jennifer Edwards (T6A)

- Firstly, please tell us about where you grew up

- What is your connection to your whānau? Marae?

- How do you feel about being Māori?

- What is it about being Māori that brings you joy?

- What do you remember hearing about lesbian, gay or bisexual people when you were growing up?

- What about trans, queer or fluid people?

- How did that make you feel about such people?

- When you were young, did you have anyone in your whānau who did not fit gender/sexual stereotypes? Any who identified as LGBTIQ?

- How did the whānau treat them or talk about them?

- How do you identify yourself in terms of gender and sexuality?

- When did you know?

- When did you come out to whānau and how did they react? Prompt: elders etc

- What was the best thing that happened within your whānau?

- What was the worst?

- Where do you get support to heal from that?

- When did you first hear the term takatāpui?

- What does being takatāpui mean to you?

- What is the best thing about being takatāpui?

- What do you think whānau could do to create a positive environment for young people exploring their sexuality or gender?

- What would you say to a young person who is struggling within their whānau?

\section{And in Conclusion...}

- Thank you for taking the time to answer my questions today, is there anything else you would like to add? 


\section{Appendix VI: Whānau Interview Guidelines (2013)}

Tewhanaupani (Teddi) Milner Maitai (W1)

Heni Poutu (W2)

\section{Biographical Details}

- Name (at birth and current)

- Gender (at birth and current)

- Address

- Contact details

- Date and place of birth

- Iwi, hapū, whānau and marae

- Other cultural identities

- Birth name, dob, dod and occupation of Mother, Father, other caregiver, siblings, children, whāngai

- Partner/spouse and date of marriage/civil union

\section{Background}

- Education

- Employment

- Community work

- Politics

- Religion/spirituality

- Health

- Places lived

\section{Growing Up}

- Are you aware of the Tūtanekai and Tiki narrative?

- What do you remember about other same-sex or gender change in the traditional Māori narratives you grew up with?

- What Māori terms do you recall were used to describe them? Non- Māori?

- Are you aware of any particular roles these people may have played?

- What do you remember hearing about lesbians or gays growing up?

- What about boys who lived as girls or girls who lived as boys?

- How did that make you feel about such people?

- When you were young, did you have anyone in your whānau who did not fit gender/sexual stereotypes? Any who identified as lesbian, gay, transgender?

- How did the whānau treat them or talk about them?

- How did you feel about them? 
- What does the term takatāpui mean to you?

- When did you first hear of it?

- How is it the same or different from lesbian and gay?

- What do you think Māori (rural, urban, kaumātua, youth) generally think about lesbians and gays? About takatāpui?

- How many takatāpui do you know in your whānau, hapū, iwi?

- What roles do they play within the whānau, hapū, iwi?

\section{Discrimination:}

- Many takatāpui suffer discrimination which is called homophobia for same or both-sex attracted people and transphobia for trans people. Are you aware of this happening in your whānau or community?

- In what ways do your whānau embrace takatāpui? How do you?

- Would they describe you as being an inclusive person?

\section{And in Conclusion...}

- Thank you for taking the time to answer my questions today, is there anything else you would like to add? 


\section{Appendix VII: Rangatahi \& Whānau Interview Guidelines (2016)}

\section{Rangatahi}

Morgan Butler and Mere-Ana Nicolson

Emilie Rākete

[Taupuru]Ariki Brightwell

Nataniel Gordon-Stables

Cameron Kapua-Morrell

Kassie Hartendorp

\author{
Whānau \\ Kellie Butler, Ellen Turanga, Nan Nina Tupaea \\ Robert Rākete \\ Matahi and Raipoia Brightwell \\ Anglique Gordon-Stables \\ Frank Kapua, Natasha Morrell, Nan Kapua, \\ Monique Kapua-Morrell, Molly Heremaia
}

\section{Form To Fill Out}

- Name (at birth and current) - confirm for publication

- Gender (at birth and current)/preferred pronouns

- Address

- Contact details

- Date and place of birth

- Iwi, hapū, whānau and marae - confirm for publication

- Other cultural identities

- Birth name, dob and dod parents/caregivers, siblings, children, whāngai

\section{Rangatahi Patae}

- Firstly, please tell us about where you grew up

- What is your connection to your whānau? Marae?

- How do you feel about being Māori?

- What is it about being Maori that brings you joy?

- What do you remember hearing about lesbian, gay or bisexual people when you were growing up?

- What about trans, queer or fluid people?

- How did that make you feel about such people?

- When you were young, did you have anyone in your whānau who did not fit gender/sexual stereotypes? Any who identified as LGBTIQ?

- How did the whānau treat them or talk about them?

- How do you identify yourself in terms of gender and sexuality?

- When did you know?

- When did you come out to whānau and how did they react? Prompt: elders etc

- What was the best thing that happened within your whānau?

- What was the worst?

- Where do you get support to heal from that?

- When did you first hear the term takatāpui?

- What does being takatāpui mean to you? 
- What is the best thing about being takatāpui?

- What do you think whānau could do to create a positive environment for young people exploring their sexuality or gender?

- What would you say to a young person who is struggling within their whānau?

\section{Whānau Patae}

- What do you remember hearing about lesbian, gay or bisexual people when you were growing up?

- What about trans, queer or fluid people?

- How did that make you feel about such people?

- When you were young, did you have anyone in your whānau who did not fit gender/sexual stereotypes? Any who identified as lesbian, gay, transgender?

- How did the whānau treat them or talk about them?

- How did you feel about them?

- What does the term takatāpui mean to you? Provide definition if required

- How did you find out * was takatāpui?

- How did you feel about that then?

- How has that changed over time?

- What is special about *?

- Many takatāpui suffer discrimination which is called homophobia for same or both-sex attracted people and transphobia for trans people. Are you aware of this happening in your whānau or community?

- What do you think whānau could do to create a positive environment for rangatahi exploring their sexuality or gender?

- What would you say to a rangatahi who is struggling within their whānau?

- What would you say to the parents/aunties/uncles of that rangatahi?

- What would you say to the grandparents of that rangatahi?

- Thank you for taking the time to answer our questions today, is there anything else you would like to add? 


\section{Appendix VIII: Tīwhanawhana Trust}

Moemoea - Vision: Tīwhanawhana ai he kahukura i te rangi - A rainbow is forming in the sky. This signifies Tīwhanawhana's goal to provide leadership and inclusiveness for takatāpui and within Rainbow communities in Wellington, Aotearoa and around the world.

Kaupapa - Mission: To tell our stories, build our community and leave a legacy.

\section{Mahi/Arataki - Objectives:}

- Advocate for the health, well-being and societal acceptance of Takatāpui within the wider LGBTFIQ $^{75}$ communities, Māori society, Aotearoa New Zealand society and internationally including and not limited by:

○ Providing opportunities for Takatāpui to participate in performance, sport, art, activities and hui in Aotearoa and internationally

- Promoting a positive portrayal of the lives and achievements of Takatāpui

○ Creating a repository for Takatāpui collections.

- Promote and develop the cultural dimensions of Takatāpui within the wider LGBTFIQ communities, Māori society, Aotearoa New Zealand society and internationally by:

○ Providing tikanga, te reo, kaupapa Māori and kapa haka support and training

○ Hosting an annual Hui-a-Motu for Takatāpui and whānau

- Sending Takatāpui representation to indigenous and other international cultural and sporting events

- Have input into policy development and services delivered by government agencies and NGOs on matters of relevance to Takatāpui by:

○ Researching of and consulting with Takatāpui

○ Developing strong relationships with government and key NGOs.

\footnotetext{
${ }^{75}$ LGBTFIQ includes recognition of traditional Pacific sexual and gender identities through the inclusion of ' $F$ ' for fa'afafine (Samoa) which was common at the time of registration as a legal entity. Tiwwhanawhana acknowledges that MVPFAFF better acknowledges the range of Pacific identities separately from the LGBTIQ acronym. Also, since then we have used 'Rainbow communities' instead of 'LGBTFIQ.'
} 